\title{
Nutritional and genetic determinants of cognitive ageing : a neuroepidemiological approach
}

Citation for published version (APA):

Schiepers, O. J. G. (2011). Nutritional and genetic determinants of cognitive ageing : a neuroepidemiological approach. [Doctoral Thesis, Maastricht University]. NeuroPsych Publishers. https://doi.org/10.26481/dis.20111221os

Document status and date:

Published: 01/01/2011

DOI:

10.26481/dis.20111221os

Document Version:

Publisher's PDF, also known as Version of record

\section{Please check the document version of this publication:}

- A submitted manuscript is the version of the article upon submission and before peer-review. There can be important differences between the submitted version and the official published version of record.

People interested in the research are advised to contact the author for the final version of the publication, or visit the DOI to the publisher's website.

- The final author version and the galley proof are versions of the publication after peer review.

- The final published version features the final layout of the paper including the volume, issue and page numbers.

Link to publication

\footnotetext{
General rights rights.

- You may freely distribute the URL identifying the publication in the public portal. please follow below link for the End User Agreement:

www.umlib.nl/taverne-license

Take down policy

If you believe that this document breaches copyright please contact us at:

repository@maastrichtuniversity.nl

providing details and we will investigate your claim.
}

Copyright and moral rights for the publications made accessible in the public portal are retained by the authors and/or other copyright owners and it is a condition of accessing publications that users recognise and abide by the legal requirements associated with these

- Users may download and print one copy of any publication from the public portal for the purpose of private study or research.

- You may not further distribute the material or use it for any profit-making activity or commercial gain

If the publication is distributed under the terms of Article $25 \mathrm{fa}$ of the Dutch Copyright Act, indicated by the "Taverne" license above, 


\section{Nutritional and Genetic Determinants of Cognitive Ageing}

A Neuroepidemiological Approach 
(C) Copyright O.J.G. Schiepers, Maastricht 2011

Cover Hersenspinsels (collier, 2007), Aniek Schiepers www.aniekschiepers.nl

Print Datawyse | Universitaire Pers Maastricht

Publisher Neuropsych Publishers

ISBN $\quad 9789075579543$ 


\title{
Nutritional and Genetic Determinants of Cognitive Ageing
}

\author{
A Neuroepidemiological Approach
}

\author{
PROEFSCHRIFT \\ Ter verkrijging van de graad van doctor aan de Universiteit Maastricht, \\ op gezag van de Rector Magnificus, Prof. mr. G.P.M.F. Mols, \\ volgens het besluit van het College van Decanen, \\ in het openbaar te verdedigen \\ op woensdag 21 december 2011 om 16:00 uur
}

door

Olga Jacoba Gertruda Schiepers

Geboren op 11 maart 1979 te Maastricht 


\section{Promotor}

Prof. dr. J. Jolles (Vrije Universiteit Amsterdam)

\section{Copromotores}

Dr. M.P.J. van Boxtel

Dr. R.H.M. de Groot (Open Universiteit)

\section{Beoordelingscommissie}

Prof. dr. F.R.J. Verhey (voorzitter)

Prof. dr. J.F.C. Glatz

Prof. dr. ir. C.P.G.M. de Groot (Universiteit Wageningen)

Prof. dr. L. Krabbendam (Vrije Universiteit Amsterdam)

Prof. dr. I. Myin-Germeys

The research described in this thesis was performed at the Department of Psychiatry and Neuropsychology, School for Mental Health and Neuroscience (MHeNS), Maastricht University, Maastricht, the Netherlands; and the Centre for Cognitive Ageing and Cognitive Epidemiology, University of Edinburgh, Edinburgh, United Kingdom.

Financial support for the publication of this thesis was kindly provided by Alzheimer Nederland (Bunnik), Efamol Ltd., Lundbeck B.V., Novartis Pharma B.V., and Nutricia Advanced Medical Nutrition. 
Chapter 1 Introduction

Part I

Chapter 2 Plasma phospholipid fatty acid status and depressive symptoms: association only present in the clinical range

Chapter 3 Fish consumption, not fatty acid status, is related to quality of life in a healthy population

Chapter 4 Consuming functional foods enriched with plant sterol or stanol esters for 85 weeks does not affect neurocognitive functioning or mood in statin-treated hypercholesterolaemic individuals

Chapter 5 Serum iron parameters, HFE 282C $\rightarrow$ Y genotype, and cognitive performance in older adults: results from the FACIT study

\section{Part II}

Chapter 6 Genetic variation in folate metabolism is not associated with cognitive functioning or mood in healthy adults

Chapter 7 MTHFR polymorphisms and cognitive ageing in the ninth decade: the Lothian Birth Cohort 1921

Chapter 8 DNA methylation and cognitive performance in healthy older adults

Chapter 9 APOE E4 status predicts age-related cognitive decline in the ninth decade: longitudinal follow-up of the Lothian Birth Cohort 1921

Chapter 10 Concluding remarks

Summary

Samenvatting

Appendix Author reply to comment on Chapter 5

Dankwoord

Curriculum vitae 

CHAPTER 1

Introduction 


\section{Cognitive decline, depressed mood, and quality of life in the ageing population}

Cognitive functioning gradually declines with advancing age, even in otherwise healthy individuals. Ageing may affect multiple domains of cognitive performance, including memory, executive functioning, attention, and speed of information processing (Birren \& Schaie, 2006; Salthouse, 1996). It has been found that the course and rate of cognitive deterioration show a large amount of individual variability (Wilson et al., 2002). Although cognitive decline in older individuals is often age-congruent, thereby representing one of the characteristics of normal ageing (Schönknecht et al., 2005), it might also progress toward pathological degrees of cognitive impairment, such as dementia (Boyle et al., 2006; Comijs et al., 2004).

Next to cognitive decline, ageing may also be accompanied by changes in mood state. In the general population, up to $16.5 \%$ of persons aged 55 years or older suffers from depressed mood (Beekman et al., 1995; Geiselmann et al., 2001). By causing considerable functional impairment, subclinical depressive symptoms are associated with extensive societal and economic costs (Cuijpers et al., 2004; Cuijpers et al., 2007; Rapaport \& Judd, 1998). In addition, depressive symptoms are often accompanied by cognitive deficits, such as attentional dysfunction and impairment of working memory (Marazziti et al., 2010). Moreover, it has been found that subclinical depressive symptomatology significantly increases the risk of developing major depression (Cuijpers et al., 2004; Horwath et al., 1994), which aggravates the health-care burden.

By affecting both physical and mental functioning in daily living, cognitive decline and depressed mood may have a significant impact on quality of life in older persons (Comijs et al., 2005; Da Silva Lima \& De Almeida Fleck, 2007; Goldney et al., 2004). As life expectancy increases, societies are facing a steadily rising proportion of older individuals. Projections have indicated that by 2050 , one in every three persons living in the more developed countries is likely to be 60 years or older (United Nations, 2002). Because of these demographic changes, the utilisation of health-care services by older people suffering from cognitive impairment or poor mental well-being is extending rapidly (Mathers \& Loncar, 2006). From a public health perspective, it is of increasing importance to establish which factors may underlie individual differences in the rate of cognitive deterioration and the development of depressive symptoms. Therefore, in the last decades, identifying the biological determinants of age-related cognitive decline and mental well-being has become a research topic of growing interest. 


\section{Biological determinants of age-related cognitive decline and depressed mood}

Two broad categories of biological factors that may underlie individual variation in cognitive performance and mood can be discerned. First, a person's genetic makeup may determine part of the variance associated with these behavioural parameters, i.e. particular genes might increase individual susceptibility to cognitive deterioration or depressed mood (Levinson, 2006; Payton, 2009). Second, environmental factors, such as lifestyle or dietary habits, may also be partly responsible for individual differences in cognitive functioning and mood state. For example, nutritional deficiencies, which are relatively common in older persons due to poor dietary intake or chronic illnesses, have been found to compromise neurocognitive functioning (Rogers, 2001).

Aside from the independent effects of genetic and environmental factors on cognitive performance and mental health, it should be noted that both types of variables might also interact or show additive effects in influencing cognitive and behavioural phenotypes. For instance, genetic make-up may modify individual vulnerability to certain environmental factors, e.g. the impact of psychological stress on cognitive performance may be more pronounced in individuals with a genetic predisposition to Alzheimer's disease (Lee et al., 2008).

A particularly noteworthy type of interaction between genetic and environmental factors is the biological mechanism of epigenetics, which entails the reversible and dynamic regulation of gene expression occurring independently of DNA sequence (Reichenberg et al., 2009). Without altering the genetic code itself, epigenetic mechanisms allow the organism to adapt to the environment by influencing gene activation. Among the environmental parameters known to affect epigenetic mechanisms, dietary factors have been suggested to play an important role (Levi \& Sanderson, 2004).

\section{Aims and approach of the present thesis}

The aims of this thesis are to identify possible associations between nutritional and genetic factors on the one hand, and age-related cognitive decline or depressed mood on the other in community-dwelling older individuals. A number of studies in the present thesis also address the putative interaction between genetic and nutritional variables in relation to cognitive performance and mood state. Since its main objective is to examine the relationship between biological factors and behavioural outcome measures on the association-level, i.e. from an epidemiological perspective, this thesis primarily consists of observational studies. One experimental study 
is included, evaluating the long-term effects of a nutritional intervention on neurocognitive functioning.

Most of the association studies performed had a prospective design; not only did we aim for investigating the putative biological determinants of cognitive functioning or depressed mood at any given moment in time, we were also particularly interested in studying these relationships in a longitudinal perspective. Indeed, only prospective studies allow for examining causal associations, and enable the assessment of behavioural changes over time. However, as longitudinal research tends to be very expensive and time-consuming, it was not feasible to design and carry out one or more prospective studies for the purpose of the present thesis. Thus, the possible associations between genetic and nutritional factors one the one hand and cognitive performance or mental well-being on the other were investigated in a number of pre-existing datasets, which are outlined below.

\section{Datasets used in the present thesis}

For the purpose of the present thesis, we selected four datasets that matched our research goals. Data from two large prospective studies, the Maastricht Aging Study (MAAS) and the Lothian Birth Cohort 1921 (LBC1921), were used to test several hypotheses addressing the potential nutritional and genetic determinants of cognitive ageing and depressed mood.

MAAS is a 12-year longitudinal study into the determinants and consequences of cognitive ageing (Jolles et al., 1995; Van Boxtel et al., 1998). Participants were randomly drawn from a register of family practices (Metsemakers et al., 1992). The MAAS study population consists of 1,823 individuals, aged 24 to 81 years at baseline, and comprises four demographically identical panels, each stratified for age, sex, and general ability level. From 1993 onwards, cognitive functioning, mental well-being, lifestyle characteristics, and health-related variables were assessed every 3 years for participants aged 50 years or older, and every 6 years for participants aged below 50 years. Because of the extensive follow-up period, its broad age range, and the comprehensive set of neurocognitive and health-related data available, the MAAS study is very well equipped for examining the influence of biological variables on the level of cognitive functioning and mood state in general, and individual trajectories of age-related cognitive decline in particular.

The LBC1921 consists of 550 surviving participants of the Scottish Mental Survey 1932, which tested cognitive ability in almost all children born in 1921 and attending school in Scotland, United Kingdom, in June 1932 (Scottish Council for Research in Education, 1933). Participants living in Edinburgh and the surrounding areas were recruited for medical and cognitive retesting via general practitioner's patient lists and advertisements in the media (Deary et al., 2009; Deary et al., 2004). 
Data on cognitive functioning, medical history, lifestyle factors, as well as genetic information were collected at 4-year intervals, i.e. at mean ages of 79, 83, and 87 years. As this cohort provides data about cognitive ability in early life as well as in old age, it offers the unique opportunity to study lifetime cognitive change. In addition, multiple follow-up measurements at specific ages in later life enable the assessment of possible biological determinants of individual differences in the course and rate of cognitive decline, while compensating for any heterogeneous effects of these parameters on cognitive performance at different ages.

In addition, for various other studies described in the present thesis, data from a large clinical trial, the Folic Acid and Carotid Intima-Media Thickness (FACIT) study, were used. Participants were recruited from blood bank registries as well as from municipal registries. The study population consisted of 818 men and women, aged 50 to 70 years at baseline. This randomised, double-blind, placebo-controlled trial was originally designed to investigate the effects of 3-year supplementation with folic acid on the risk of cardiovascular disease as measured by carotid intima-media thickness (Durga et al., 2005; Durga et al., 2007). The FACIT study constitutes an extensive dataset, comprising a vast number of variables, including blood concentrations of various nutrients and inflammatory markers, genetic and epigenetic factors, as well as lifestyle and health-related variables, most of which were measured longitudinally. Cognitive functioning was assessed at baseline and after 3 years by means of the comprehensive cognitive test battery used in the MAAS study. Although originally designed as an intervention study, the large number of participants, in combination with detailed, longitudinal information on cognitive as well as biological variables, makes the FACIT study perfectly suited for investigating hypotheses into the determinants of cognitive ageing.

Finally, for the single experimental study included in this thesis, we used data from a randomised, double-blind, placebo-controlled dietary intervention trial (De Jong et al., 2008). This trial was originally conducted to assess the effects of 85week supplementation with plant sterol or stanol ester-enriched functional foods on markers of endothelial dysfunction and arterial stiffness. The study sample consisted of 54 hypercholesterolaemic individuals, aged 43 to 69 years at baseline. Cognitive performance and mood state were measured at baseline and at the end of the intervention period. In the present thesis, these data were used to examine the effects of long-term consumption of plant sterols and stanols on neurocognitive functioning.

\section{Thesis outline}

The present thesis, consisting of eight studies, is divided in two parts. The first part (chapters 2 to 5 ) mainly focuses on nutritional determinants of cognitive perform- 
ance and depressed mood in older individuals. The second part (chapters 6 to 9) primarily concerns the involvement of genetic factors in cognitive ageing. It is worth noting that both parts include studies investigating the possible interaction between nutritional and genetic determinants of neurocognitive functioning.

Chapters 2 and 3 address the cross-sectional associations between long-chain polyunsaturated fatty acids (LCPUFA) and fish consumption on the one hand and depressive symptoms or quality of life on the other in healthy community-dwelling individuals. Fatty acids, including the LCPUFA, comprise a class of nutrients that are important for normal brain functioning (Bourre, 2004; Yehuda et al., 1999). As the human body itself is not capable of synthesising these essential nutrients, they need to be supplied through the diet. The major source of LCPUFA is fatty fish, such as salmon and mackerel. Both infrequent fish consumption as well as low blood concentrations of fatty acids have been implicated in depressive disorders and poor mental well-being (Edwards et al., 1998; Hibbeln, 1998; Tanskanen et al., 2001). The present studies investigated whether LCPUFA and fish consumption might also play a role in subclinical degrees of depressed mood (chapter 2 ) or quality of life (chapter 3). Both studies were performed using MAAS data.

In chapter 4, the effects of long-term supplementation with plant sterols and stanols on cognitive performance and mood are presented. Plant sterols and stanols, which are primarily found in vegetables, fruits, and cereals, are known for their cholesterol-lowering properties (Heinemann et al., 1991; Miettinen et al., 1995). Because of their health benefits, these compounds may be incorporated into food products, such as margarines. Although the use of foods enriched with plant sterols and stanols, e.g. as an adjunctive cholesterol-lowering treatment in hypercholesterolaemic patients, has no adverse effects on physical health (Plat \& Mensink, 2005), the putative impact of long-term use of plant sterols and stanols on cognitive functioning and mood has not been investigated before. For this experimental study, we used data from a randomised, double-blind, placebo-controlled dietary intervention trial.

Chapter 5 addresses the relationship between serum iron parameters and cognitive performance in healthy older individuals. Iron homeostasis is crucial for normal brain functioning (Beard \& Connor, 2003; Hidalgo \& Núñez, 2007), and both iron deficiency and excess body iron have been reported to affect cognitive performance (Sandstead, 2000; Youdim, 2008). Most research into the cognitive effects of disturbed iron homeostasis has been conducted in children and young adults, although older individuals in particular may be susceptible to disturbances in iron homeostasis, due to poor nutritional habits, chronic diseases, or age-related changes in body iron status (Killip et al., 2007; Koziol et al., 2001; Marshall et al., 2001). Apart from serum iron parameters, the present study assessed genetically determined variation in body iron status in relation to cognitive functioning. Using data 
from the FACIT trial, both cross-sectional and longitudinal associations were investigated.

The relationship between genetic variability in folate metabolism and neurocognitive functioning is presented in chapters 6 and 7. Low blood concentrations of $B$ vitamins, such as folate or vitamin $B_{12}$, have been associated with deficits in cognitive functioning, as well as depressed mood (Duthie et al., 2002; Tiemeier et al., 2002; Tucker et al., 2005). In these studies, we examined the cross-sectional and longitudinal associations between the polymorphic variants of three genes encoding different enzymes involved in folate-homocysteine metabolism on the one hand and cognitive performance or mood state on the other. For the study described in chapter 6, we used MAAS as well as FACIT data. In addition, data from the LBC1921 were used for the study presented in chapter 7.

Chapter 8 deals with the epigenetic mechanism of DNA methylation. The extent to which cytosine residues in the promoter region of a given gene are methylated, influences the expression of this gene (Jones \& Takai, 2001). In humans, dysregulation of DNA methylation has been associated with neurodevelopmental disorders, such as Fragile $X$ syndrome and Prader-Willi syndrome (Tsankova et al., 2007). In addition, animal research has indicated that DNA methylation may be involved in the regulation of non-pathological cognitive performance (Levenson \& Sweatt, 2005; Miller \& Sweatt, 2007). Using data from the FACIT study, we examined whether DNA methylation status might also play a role in individual variability in cognitive performance in healthy older adults.

In chapter 9, we assessed the role of the gene encoding the lipid transport protein apolipoprotein $\mathrm{E}(A P O E)$ in age-related cognitive decline. Possession of the $A P O E$ E4 allele is a well-established risk factor for Alzheimer's disease (Corder et al., 1993). By using 8-year longitudinal data from the LBC1921, we were able to investigate the associations between APOE genotype and individual differences in the rate of cognitive decline in non-demented older individuals.

Chapter 10 reflects on the studies presented in this thesis by evaluating the main findings from a broader perspective, thereby discussing methodological considerations, practical implications, and directions for future research. 


\section{References}

Beard, J. L., \& Connor, J. R. (2003). Iron status and neural functioning. Annu Rev Nutr, 23, 41-58.

Beekman, A. T., Deeg, D. J., Van Tilburg, T., Smit, J. H., Hooijer, C., \& Van Tilburg, W. (1995). Major and minor depression in later life: a study of prevalence and risk factors. J Affect Disord, 36(1-2), 65-75.

Birren, J. E., \& Schaie, K. W. (Eds.). (2006). Handbook of the Psychology of Aging (6th ed.). San Diego, CA: Elsevier Academic Press.

Bourre, J. M. (2004). Roles of unsaturated fatty acids (especially omega-3 fatty acids) in the brain at various ages and during ageing. J Nutr Health Aging, 8(3), 163-174.

Boyle, P. A., Wilson, R. S., Aggarwal, N. T., Tang, Y., \& Bennett, D. A. (2006). Mild cognitive impairment: risk of Alzheimer disease and rate of cognitive decline. Neurology, 67(3), 441-445.

Comijs, H. C., Dik, M. G., Aartsen, M. J., Deeg, D. J., \& Jonker, C. (2005). The impact of change in cognitive functioning and cognitive decline on disability, well-being, and the use of healthcare services in older persons. Results of Longitudinal Aging Study Amsterdam. Dement Geriatr Cogn Disord, 19(5-6), 316323.

Comijs, H. C., Dik, M. G., Deeg, D. J., \& Jonker, C. (2004). The course of cognitive decline in older persons: results from the Longitudinal Aging Study Amsterdam. Dement Geriatr Cogn Disord, 17(3), 136-142.

Corder, E. H., Saunders, A. M., Strittmatter, W. J., Schmechel, D. E., Gaskell, P. C., Small, G. W., Roses, A. D., Haines, J. L., \& Pericak-Vance, M. A. (1993). Gene dose of apolipoprotein E type 4 allele and the risk of Alzheimer's disease in late onset families. Science, 261(5123), 921-923.

Cuijpers, P., De Graaf, R., \& Van Dorsselaer, S. (2004). Minor depression: risk profiles, functional disability, health care use and risk of developing major depression. J Affect Disord, 79(1-3), 71-79.

Cuijpers, P., Smit, F., Oostenbrink, J., De Graaf, R., Ten Have, M., \& Beekman, A. (2007). Economic costs of minor depression: a population-based study. Acta Psychiatr Scand, 115(3), 229-236.

Da Silva Lima, A. F., \& De Almeida Fleck, M. P. (2007). Subsyndromal depression: an impact on quality of life? J Affect Disord, 100(1-3), 163-169.

De Jong, A., Plat, J., Lütjohann, D., \& Mensink, R. P. (2008). Effects of long-term plant sterol or stanol ester consumption on lipid and lipoprotein metabolism in subjects on statin treatment. $\mathrm{Br} J \mathrm{Nutr}$, 100(5), 937-941.

Deary, I. J., Whalley, L. J., \& Starr, J. M. (2009). A Lifetime of Intelligence: Follow-up Studies of the Scottish Mental Surveys of 1932 and 1947. Washington, DC: American Psychological Association.

Deary, I. J., Whiteman, M. C., Starr, J. M., Whalley, L. J., \& Fox, H. C. (2004). The impact of childhood intelligence on later life: following up the Scottish Mental Surveys of 1932 and 1947. J Pers Soc Psychol, 86(1), 130-147.

Durga, J., Bots, M. L., Schouten, E. G., Kok, F. J., \& Verhoef, P. (2005). Low concentrations of folate, not hyperhomocysteinemia, are associated with carotid intima-media thickness. Atherosclerosis, 179(2), 285-292.

Durga, J., Van Boxtel, M. P. J., Schouten, E. G., Kok, F. J., Jolles, J., Katan, M. B., \& Verhoef, P. (2007). Effect of 3-year folic acid supplementation on cognitive function in older adults in the FACIT trial: a randomised, double blind, controlled trial. Lancet, 369(9557), 208-216.

Duthie, S. J., Whalley, L. J., Collins, A. R., Leaper, S., Berger, K., \& Deary, I. J. (2002). Homocysteine, B vitamin status, and cognitive function in the elderly. Am J Clin Nutr, 75(5), 908-913.

Edwards, R., Peet, M., Shay, J., \& Horrobin, D. (1998). Omega-3 polyunsaturated fatty acid levels in the diet and in red blood cell membranes of depressed patients. J Affect Disord, 48(2-3), 149-155.

Geiselmann, B., Linden, M., \& Helmchen, H. (2001). Psychiatrists' diagnoses of subthreshold depression in old age: frequency and correlates. Psychol Med, 31(1), 51-63.

Goldney, R. D., Fisher, L. J., Dal Grande, E., \& Taylor, A. W. (2004). Subsyndromal depression: prevalence, use of health services and quality of life in an Australian population. Soc Psychiatry Psychiatr Epidemiol, 39(4), 293-298. 
Heinemann, T., Kullak-Ublick, G. A., Pietruck, B., \& Von Bergmann, K. (1991). Mechanisms of action of plant sterols on inhibition of cholesterol absorption. Comparison of sitosterol and sitostanol. Eur J Clin Pharmacol, 40 Suppl 1, S59-63.

Hibbeln, J. R. (1998). Fish consumption and major depression. Lancet, 351(9110), 1213.

Hidalgo, C., \& Núñez, M. T. (2007). Calcium, iron and neuronal function. IUBMB Life, 59(4-5), 280-285.

Horwath, E., Johnson, J., Klerman, G. L., \& Weissman, M. M. (1994). What are the public health implications of subclinical depressive symptoms? Psychiatr $Q$, 65(4), 323-337.

Jolles, J., Houx, P. J., Van Boxtel, M. P. J., \& Ponds, R. W. H. M. (Eds.). (1995). The Maastricht Aging Study: Determinants of Cognitive Aging. Maastricht, The Netherlands: Neuropsych Publishers.

Jones, P. A., \& Takai, D. (2001). The role of DNA methylation in mammalian epigenetics. Science, 293(5532), 1068-1070.

Killip, S., Bennett, J. M., \& Chambers, M. D. (2007). Iron deficiency anemia. Am Fam Physician, 75(5), 671678.

Koziol, J. A., Ho, N. J., Felitti, V. J., \& Beutler, E. (2001). Reference centiles for serum ferritin and percentage of transferrin saturation, with application to mutations of the HFE gene. Clin Chem, 47(10), 1804-1810.

Lee, B. K., Glass, T. A., Wand, G. S., McAtee, M. J., Bandeen-Roche, K., Bolla, K. I., \& Schwartz, B. S. (2008). Apolipoprotein E genotype, cortisol, and cognitive function in community-dwelling older adults. $\mathrm{Am} J$ Psychiatry, 165(11), 1456-1464.

Levenson, J. M., \& Sweatt, J. D. (2005). Epigenetic mechanisms in memory formation. Nat Rev Neurosci, 6(2), 108-118.

Levi, R. S., \& Sanderson, I. R. (2004). Dietary regulation of gene expression. Curr Opin Gastroenterol, 20(2), 139-142.

Levinson, D. F. (2006). The genetics of depression: a review. Biol Psychiatry, 60(2), 84-92.

Marazziti, D., Consoli, G., Picchetti, M., Carlini, M., \& Faravelli, L. (2010). Cognitive impairment in major depression. Eur J Pharmacol, 626(1), 83-86.

Marshall, T. A., Stumbo, P. J., Warren, J. J., \& Xie, X. J. (2001). Inadequate nutrient intakes are common and are associated with low diet variety in rural, community-dwelling elderly. J Nutr, 131(8), 21922196.

Mathers, C. D., \& Loncar, D. (2006). Projections of global mortality and burden of disease from 2002 to 2030. PLoS Med, 3(11), e442.

Metsemakers, J. F. M., Höppener, P., Knottnerus, J. A., Kocken, R. J. J., \& Limonard, C. B. G. (1992). Computerized health information in the Netherlands: a registration network of family practices. $\mathrm{Br} J$ Gen Pract, 42(356), 102-106.

Miettinen, T. A., Puska, P., Gylling, H., Vanhanen, H., \& Vartiainen, E. (1995). Reduction of serum cholesterol with sitostanol-ester margarine in a mildly hypercholesterolemic population. $N$ Engl J Med, 333(20), 1308-1312.

Miller, C. A., \& Sweatt, J. D. (2007). Covalent modification of DNA regulates memory formation. Neuron, 53(6), 857-869.

Payton, A. (2009). The impact of genetic research on our understanding of normal cognitive ageing: 1995 to 2009. Neuropsychol Rev, 19(4), 451-477.

Plat, J., \& Mensink, R. P. (2005). Plant stanol and sterol esters in the control of blood cholesterol levels: mechanism and safety aspects. Am J Cardiol, 96(1A), 15D-22D.

Rapaport, M. H., \& Judd, L. L. (1998). Minor depressive disorder and subsyndromal depressive symptoms: functional impairment and response to treatment. J Affect Disord, 48(2-3), 227-232.

Reichenberg, A., Mill, J., \& MacCabe, J. H. (2009). Epigenetics, genomic mutations and cognitive function. Cogn Neuropsychiatry, 14(4-5), 377-390.

Rogers, P. J. (2001). A healthy body, a healthy mind: long-term impact of diet on mood and cognitive function. Proc Nutr Soc, 60(1), 135-143.

Salthouse, T. A. (1996). The processing-speed theory of adult age differences in cognition. Psychol Rev, 103(3), 403-428. 
Sandstead, H. H. (2000). Causes of iron and zinc deficiencies and their effects on brain. J Nutr, 130(2S Suppl), 347S-349S.

Schönknecht, P., Pantel, J., Kruse, A., \& Schröder, J. (2005). Prevalence and natural course of agingassociated cognitive decline in a population-based sample of young-old subjects. Am J Psychiatry, 162(11), 2071-2077.

Scottish Council for Research in Education (1933). The intelligence of Scottish children: a national survey of an age-group. London: University of London Press.

Tanskanen, A., Hibbeln, J. R., Tuomilehto, J., Uutela, A., Haukkala, A., Viinamäki, H., Lehtonen, J., \& Vartiainen, E. (2001). Fish consumption and depressive symptoms in the general population in Finland. Psychiatry Serv, 52(4), 529-531.

Tiemeier, H., Van Tuijl, H. R., Hofman, A., Meijer, J., Kiliaan, A. J., \& Breteler, M. M. (2002). Vitamin B12, folate, and homocysteine in depression: the Rotterdam Study. Am J Psychiatry, 159(12), 2099-2101.

Tsankova, N., Renthal, W., Kumar, A., \& Nestler, E. J. (2007). Epigenetic regulation in psychiatric disorders. Nat Rev Neurosci, 8(5), 355-367.

Tucker, K. L., Qiao, N., Scott, T., Rosenberg, I., \& Spiro, A., 3rd (2005). High homocysteine and low B vitamins predict cognitive decline in aging men: the Veterans Affairs Normative Aging Study. Am J Clin Nutr, 82(3), 627-635.

United Nations (2002). World population ageing: 1950-2050. New York: United Nations.

Van Boxtel, M. P. J., Buntinx, F., Houx, P. J., Metsemakers, J. F. M., Knottnerus, J. A., \& Jolles, J. (1998). The relation between morbidity and cognitive performance in a normal aging population. $J$ Gerontol A Biol Sci Med Sci, 53(2), M147-M154.

Wilson, R. S., Beckett, L. A., Barnes, L. L., Schneider, J. A., Bach, J., Evans, D. A., \& Bennett, D. A. (2002). Individual differences in rates of change in cognitive abilities of older persons. Psychol Aging, 17(2), 179-193.

Yehuda, S., Rabinovitz, S., \& Mostofsky, D. I. (1999). Essential fatty acids are mediators of brain biochemistry and cognitive functions. J Neurosci Res, 56(6), 565-570.

Youdim, M. B. (2008). Brain iron deficiency and excess; cognitive impairment and neurodegeneration with involvement of striatum and hippocampus. Neurotox Res, 14(1), 45-56. 
CHAPTER 2

Plasma phospholipid fatty acid status and depressive symptoms: association only present in the clinical range

Olga J.G. Schiepers, Renate H.M. de Groot, Jelle Jolles, Martin P.J. van Boxtel 


\begin{abstract}
Long-chain polyunsaturated fatty acids (LCPUFA) have been implicated in depression, but their role in mood variability in the general population is still unclear. We investigated the associations between LCPUFA status or fish consumption on the one hand and depressive symptoms and chronicity of depressed mood on the other in a community-based sample. Plasma phospholipid LCPUFA profiles of 241 participants of the Maastricht Aging Study (MAAS) were determined. Depressive symptoms were measured using the Center for Epidemiologic Studies Depression Scale (CES-D) and Symptom Checklist 90 (SCL-90) questionnaires. Using linear regression analyses, associations between the actual level and longitudinal (12-year) variability in depressive symptoms on the one hand and LCPUFA concentrations or fish consumption on the other were examined. No linear associations were found in the total sample between depressive symptoms and LCPUFA concentrations or fish consumption. Chronicity of depressed mood was also not related to LCPUFA status or fish consumption. Post-hoc analyses, however, showed a negative correlation between docosahexaenoic acid (DHA, 22:6n-3) concentration and depressed mood in persons with CES-D scores above the clinical threshold. Regression analysis suggested a non-linear association between depressive symptoms and DHA concentration in the total sample. This study offers a first indication that a suboptimal LCPUFA status might accompany depressive symptoms primarily within the clinical spectrum.
\end{abstract}




\section{Introduction}

Mood disorders constitute an increasing worldwide health problem (Mathers \& Loncar, 2006), which urges for the identification of the factors involved in the development of depressive symptoms. Long-chain polyunsaturated fatty acids (LCPUFA), present in fish oil, have often been related to depressive symptomatology. Whereas clinical studies generally indicate that depression may be accompanied by suboptimal LCPUFA concentrations (Adams et al., 1996; Edwards et al., 1998; Maes et al., 1999; Maes et al., 1996; McNamara et al., 2007; Peet et al., 1998), population-based studies (Appleton et al., 2008; Conklin et al., 2007; Féart et al., 2008; Jacka et al., 2004; Murakami et al., 2008; Tanskanen et al., 2001; Tiemeier et al., 2003; Timonen et al., 2004) and intervention studies (Grenyer et al., 2007; Jazayeri et al., 2008; Marangell et al., 2003; Mischoulon et al., 2008; Nemets et al., 2006; Peet \& Horrobin, 2002; Rogers et al., 2008; Silvers et al., 2005; Su et al., 2003; Van de Rest et al., 2008) have yielded mixed results. Most of these studies had limitations with respect to statistical power, external validity, or both. They used small sample sizes ( $n<50$ ) (Adams et al., 1996; Edwards et al., 1998; Jazayeri et al., 2008; Maes et al., 1999; Marangell et al., 2003; McNamara et al., 2007; Mischoulon et al., 2008; Nemets et al., 2006; Peet et al., 1998; Su et al., 2003), applied food frequency questionnaires to estimate LCPUFA intake rather than directly measuring LCPUFA status (Jacka et al., 2004; Murakami et al., 2008), used a dichotomous categorisation of depressive symptomatology (Conklin et al., 2007; Jacka et al., 2004; Tanskanen et al., 2001; Tiemeier et al., 2003; Timonen et al., 2004), were conducted in a sample with a narrow age range (Conklin et al., 2007; Féart et al., 2008; Tiemeier et al., 2003; Van de Rest et al., 2008), or were restricted to one gender only (Jacka et al., 2004). Furthermore, most studies were carried out in psychiatric populations (Adams et al., 1996; Edwards et al., 1998; Grenyer et al., 2007; Jazayeri et al., 2008; Maes et al., 1999; Maes et al., 1996; Marangell et al., 2003; McNamara et al., 2007; Mischoulon et al., 2008; Nemets et al., 2006; Peet \& Horrobin, 2002; Peet et al., 1998; Silvers et al., 2005; Su et al., 2003).

Accordingly, at present little is known about the associations between individual LCPUFA status and depressed mood in the general population. This is unfortunate, as subclinical depressive symptoms frequently occur in the community (Kessler et al., 1997), may substantially reduce quality of life (Cuijpers et al., 2004; Rapaport \& Judd, 1998), and increase the risk of developing major depression (Cuijpers et al., 2004; Horwath et al., 1994).

The current study investigated the relationships between plasma phospholipid LCPUFA status, fish consumption, and depressive symptoms in a large community sample with a broad age range. In addition, the present study examined for the first time the association between LCPUFA status and chronicity of depressive symptoms over a 12-year time period. 


\section{Methods}

\section{Study population}

The present study was part of a longitudinal research program into the determinants of cognitive ageing, the Maastricht Aging Study (MAAS) (Jolles et al., 1995). Exclusion criteria at baseline were medically verified chronic neurological pathology, psychiatric disorders, mental retardation, and psychotropic drug use. The study population consisted of 1,823 participants, aged 24 to 81 years at baseline. A detailed description of the MAAS study design can be found elsewhere (Jolles et al., 1995; Van Boxtel et al., 1998).

At 12-year follow-up, venous blood was collected from 241 volunteers in one (of four) demographically identical panels. Volunteers did not differ from the other participants in the panel in terms of age, sex, and level of education. The study was approved by the local Medical Ethics Committee. Prior to enrolment written informed consent was obtained from all participants.

\section{Mood state}

Depressed mood was assessed at baseline and at 6- and 12-year follow-up with the Dutch version of the depression subscale of the Symptom Checklist 90 (SCLdep; range 16-80) (Arrindell \& Ettema, 1986). In addition, at 6- and 12-year follow-up, the Dutch version of the Center for Epidemiologic Studies Depression Scale (CES-D; range 0-60) (Radloff, 1977) was administered. A cut-off score of 16 was adopted to discriminate between subjects with clinically relevant depressive symptoms and those without (Beekman et al., 1997). Since baseline measurements on depressive symptoms in MAAS were available for the SCLdep but not for the CES-D questionnaire, both instruments were used in the present study.

Longitudinal data on depressed mood were used to measure chronicity of depressive symptomatology. Individual changes in depressed mood were calculated over a 12-year time period using SCLdep data, as well as a 6-year follow-up period using both SCLdep and CES-D data. Participants whose absolute change in depression scores fell within a range of -2 to +3 , were considered 'mood stable' (CES-D $D_{6 y}: n$ $=108$; $\operatorname{SCLdep}_{6 \mathrm{y}}: n=131$, and $\operatorname{SCLdep}_{12 \mathrm{y}}: n=118$ ). Individuals with changes in depression scores outside this range were considered 'mood variable', as such changes, which correspond to effect sizes of at least 0.25 (Cohen, 1992), are considered clinically meaningful. The group of stable mood cases was equally divided into a subgroup of persons with 'stable high depression scores' (mean CES- $D_{6 y} \geq 6: n=52$, mean SCLdep Sy $\geq 19: n=66$, and mean SCLdep $12 y=19: n=52$ ) and a subgroup of individuals with 'stable low depression scores' (mean CES- $D_{6 y}<6: n=56$, mean $\operatorname{SCLdep}_{6 y}<19: n=65$, and mean SCLdep $12 \mathrm{y}<19: n=66$ ). 


\section{Fatty acid status}

Plasma was separated from blood cells by centrifugation and collected in tubes, which were closed under nitrogen and stored at $-80^{\circ} \mathrm{C}$ until fatty acid analysis. Fatty acid profiles of phospholipids isolated from venous plasma were determined as described before (De Groot et al., 2004). Total phospholipid-associated fatty acid concentrations were expressed as $\mathrm{mg} / \mathrm{l}$ plasma, and relative fatty acid concentrations as percentages of the total amount of phospholipid-associated fatty acids (\% by weight, \%wt/wt). Forty-two fatty acids were identified; six fatty acids were considered of primary interest in the present study, as they are (precursors of) the main LCPUFA in brain tissue (Martínez \& Mougan, 1998): arachidonic acid (AA, 20:4n-6), eicosapentaenoic acid (EPA, 20:5n-3), adrenic acid (AdrA, 22:4n-6), docosapentaenoic acid (DPA, 22:5n-3), Osbond acid (ObA, 22:5n-6), and docosahexaenoic acid (DHA, 22:6n-3).

\section{Fish consumption}

Fish consumption was measured at 12-year follow-up by means of a short selfreport questionnaire. Fish types were categorised according to DHA content, as DHA is the predominant LCPUFA in fish (Kris-Etherton et al., 2000): low (fish fingers, prawns, pickled herring, cod, mussels, plaice, tuna, and tilapia), intermediate (trout, raw herring, smoked eel, smoked salmon, canned salmon), and high (smoked herring, herring in tomato sauce, mackerel, canned sardines, salmon).

Frequency of consumption (never, once a month, two to three times a month, once a week, more often than once a week) was used to calculate fish consumption within each category: $0,1,2,4$, and 8 for the 'low DHA' category; 0, 2, 4, 8, and 16 for the 'intermediate $\mathrm{DHA}^{\prime}$ category; and $0,3,6,12$, and 24 for the 'high DHA' category. Total fish consumption corresponded to the sum of the scores of the three DHA categories. Overall fish consumption scores range from 0 to 48, indexing a dimensionless estimate of fish intake.

\section{Sociodemographic and lifestyle variables}

Age, sex, level of education (high or low) (De Bie, 1987), alcohol consumption (high or low) (World Health Organization, 2000), smoking (yes or no), and body mass index $\left(\mathrm{BMI}, \mathrm{kg} / \mathrm{m}^{2}\right.$ ) were treated as covariates, as these variables were assumed to be associated with LCPUFA status and fish consumption (Crowe et al., 2008; Féart et al., 2007; Simon et al., 1996). 


\section{Statistical analysis}

Normal P-P plots indicated skewness of CES-D and SCLdep scores, EPA concentration, and fish consumption, which was corrected by log-transformation. Pearson's product-moment correlations were calculated for all variables.

Hierarchical linear regression analyses were performed to test the associations between depressed mood on the one hand and LCPUFA status or fish consumption on the other. In order to include dummy variables for longitudinal variability in depressed mood in the regression models, we designated LCPUFA concentrations as outcome variables and (chronicity of) depressed mood as predictor variable(s), which we considered appropriate since associations rather than causal relations were tested. To allow for possible non-linear effects of age, all regression models included both linear and quadratic terms for age.

Separate regression models were fitted for each fatty acid of interest, as well as fish consumption, adjusting for age, age ${ }^{2}$, sex, level of education, alcohol consumption, smoking, and BMI in the first step. The primary independent variable, depression score, was entered in step 2. In a third step two dummy variables representing longitudinal variability in depressed mood were entered into the regression models, to examine whether chronicity of depressed mood was associated with LCPUFA status.

Post-hoc correlational analyses were performed using the data of individuals with clinically relevant depressive symptoms (CES-D $\geq 16 ; n=35$ ). As DHA showed a significant correlation with depression score, the possibility of a non-linear relationship between DHA concentration and depressive symptoms in the total sample was examined. To this end, the predictive value of the quadratic term for CES-D score (i.e. the residuals of (CES-D score) ${ }^{2}$ after removal of its linear component in regression analysis) was tested in a regression model with DHA concentration as dependent variable, after adjusting for CES-D score. It should be noted that this non-linear association was analysed using the untransformed CES-D scores, since this analysis contained a quadratic term.

Statistical differences were considered significant at $p$-values $<0.05$. All analyses were performed using SPSS 16.0 (SPSS Inc., Chicago, IL, USA).

\section{Results}

\section{Descriptives and correlational analyses}

Table 1 summarises the participants' characteristics at 12-year follow-up. The average score on the SCLdep at baseline was 20.6 (range 16-62, $n=233$ ), and the mean score at 6-year follow-up was 21.6 (range $16-60, n=219$ ). Mean CES-D score 
at 6-year follow-up was 7.8 (range $0-33, n=223$ ). Fish consumption was positively correlated with DHA and EPA concentrations $(r=0.518, p<0.001$ and $r=0.298, p$ $<0.001$, respectively).

Table 1 Characteristics of the participants at 12-year follow-up

\begin{tabular}{ll}
\hline & Total sample \\
\hline$n$ & 241 \\
Age (years) & $59.5(36.5-87.7)$ \\
Female sex (\%) & 50.2 \\
Low level of education (\%) & 75.1 \\
High alcohol consumption (\%) & 5.8 \\
Current smoker (\%) & 22.8 \\
BMI (kg/m ${ }^{2}$ ) & $26.4 \pm 4.6$ \\
SCLdep score & $22.3(16-78)$ \\
CES-D score & $9.1(0-42)$ \\
CES-D $\geq 16^{c}(\%)$ & 14.6 \\
Fish consumption ${ }^{d}$ & $8.5(0-44)$ \\
AA (\%wt/wt) & $9.61 \pm 2.09$ \\
EPA (\%wt/wt) & $0.99 \pm 0.49$ \\
AdrA (\%wt/wt) & $0.29 \pm 0.08$ \\
DPA (\%wt/wt) & $0.92 \pm 0.18$ \\
ObA (\%wt/wt) & $0.22 \pm 0.09$ \\
DHA (\%wt/wt) & $3.45 \pm 1.04$ \\
\hline Note: Values are means (range)
\end{tabular}

Note: Values are means (range) or means \pm SD. BMI, body mass index; SCLdep, depression subscale of the Symptom Checklist 90; CES-D, Center for Epidemiologic Studies Depression Scale; AA, arachidonic acid (20:4n-6); EPA, eicosapentaenoic acid (20:5n-3); AdrA, adrenic acid (22:4n-6); DPA, docosapentaenoic acid (22:5n-3); ObA, Osbond acid (22:5n-6); DHA, docosahexaenoic acid $(22: 6 n-3) ;{ }^{a} n=231 ;{ }^{b} n=$ 240.; ${ }^{\mathrm{c}} n=35 ;{ }^{\mathrm{d}} n=238$; ${ }^{\mathrm{e}}$ Fatty acid concentrations are expressed as percentages of the total amount of plasma phospholipid-associated fatty acids.

\section{Regression analyses}

Figure 1 shows DHA concentration plotted against the raw CES-D score at 12-year follow-up. The other LCPUFA, as well as fish consumption, displayed similar scatterplots. After correction for the covariates, no significant associations were identified between CES-D or SCLdep score at 12-year follow-up and any of the LCPUFA, nor fish consumption (Table 2).

In addition, after adjusting for covariates in step 1 and CES-D or SCLdep score in step 2, no significant associations were found between chronicity of depressive symptomatology and LCPUFA status, nor fish consumption (Table 3 ). 


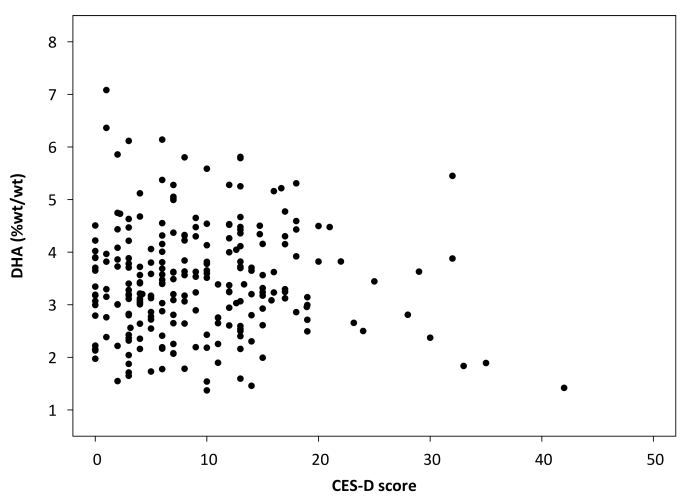

Figure 1 Plasma phospholipid concentration of docosahexaenoic acid (DHA, 22:6n-3) (expressed as percentage of the total amount of plasma phospholipid-associated fatty acids) plotted against the raw Center for Epidemiologic Studies Depression Scale (CES-D) score at 12-year follow-up in the total sample $(n=240)$. Pearson's $r$ for the zero-order correlation between DHA concentration and log-transformed CES-D score is not significant.

Table 2 Associations between depressive symptoms and plasma phospholipid LCPUFA concentrations or fish consumption

\begin{tabular}{lllll}
\hline Dependent variable $^{2}$ & $\boldsymbol{R}^{\mathbf{2}}$ change step $\mathbf{1}^{\text {a }}$ & $\boldsymbol{p}$ & $\boldsymbol{R}^{\mathbf{2}}$ change step $\mathbf{2}$ & $\boldsymbol{p}$ \\
\hline AA & 0.067 & 0.023 & 0.001 & 0.662 \\
EPA $^{\text {b }}$ & 0.159 & 0.000 & 0.000 & 0.904 \\
AdrA & 0.072 & 0.015 & 0.001 & 0.676 \\
DPA & 0.059 & 0.046 & 0.005 & 0.280 \\
ObA & 0.056 & 0.061 & 0.000 & 0.923 \\
DHA & 0.096 & 0.001 & 0.001 & 0.561 \\
Fish consumption $^{\text {b }}$ & 0.033 & 0.357 & 0.009 & 0.140
\end{tabular}

Note: AA, arachidonic acid (20:4n-6); EPA, eicosapentaenoic acid (20:5n-3); AdrA, adrenic acid (22:4n-6); DPA, docosapentaenoic acid (22:5n-3); ObA, Osbond acid (22:5n-6); DHA, docosahexaenoic acid (22:6n$3) ;{ }^{a}$ Change of the proportion of explained variance ( $R^{2}$ change), and significance of $R^{2}$ change after each step in hierarchical linear regression analyses. The covariates age, age ${ }^{2}$, sex, level of education, alcohol consumption, smoking, and body mass index were entered in step 1 and log-transformed Center for Epidemiologic Studies depression scale (CES-D) score in step 2; ${ }^{b}$ Log-transformed data.

\section{Post-hoc analyses}

Post-hoc correlation analyses restricted to the subgroup of participants reporting clinically relevant depressive symptoms (CES-D $\geq 16 ; n=35$ ), revealed a significant negative association between DHA concentration and CES-D score at 12-year followup ( $r=-0.465, p=0.005$ ) (Figure 2 ), which remained significant after adjustment for the covariates in a linear regression analysis $\left(R^{2}\right.$ change $\left.=0.147, p=0.020\right)$. After exclusion of the most influential case with respect to the slope of the fitted regression line (i.e. CES-D score $=42$; DHA $=1.42 \% w t / w t$ ), Pearson's correlation coefficient remained significant $(r=-0.364, p=0.035)$. Mean DHA concentrations did not 
differ between the subgroup of participants with depressive symptoms above the clinical threshold and the rest of the sample $(t=-0.623, p=0.534)$. Post-hoc regression analysis testing the non-linear relationship between depressed mood and DHA concentration in the total sample revealed a significant association between DHA concentration and the quadratic term for CES-D score $\left(R^{2}\right.$ change $=0.019, p=$ 0.035).

Table 3 Associations between chronicity of depressive symptoms and plasma phospholipid LCPUFA concentrations or fish consumption

\begin{tabular}{lllllll}
\hline Dependent variable & $\begin{array}{l}\boldsymbol{R}^{2} \text { change } \\
\text { step 1 }\end{array}$ & $\boldsymbol{p}$ & $\begin{array}{l}\boldsymbol{R}^{\mathbf{2}} \text { change } \\
\text { step 2 }\end{array}$ & $\boldsymbol{p}$ & $\begin{array}{l}\boldsymbol{R}^{2} \text { change } \\
\text { step 3 }\end{array}$ & $\boldsymbol{p}$ \\
\hline AA & 0.074 & 0.018 & 0.001 & 0.712 & 0.014 & 0.189 \\
EPA $^{\text {b }}$ & 0.138 & 0.000 & 0.002 & 0.501 & 0.003 & 0.668 \\
AdrA & 0.081 & 0.010 & 0.000 & 0.945 & 0.008 & 0.375 \\
DPA & 0.066 & 0.038 & 0.001 & 0.653 & 0.005 & 0.549 \\
ObA & 0.069 & 0.029 & 0.001 & 0.594 & 0.004 & 0.645 \\
DHA & 0.083 & 0.008 & 0.003 & 0.387 & 0.005 & 0.526 \\
Fish consumption $^{\text {b }}$ & 0.029 & 0.505 & 0.006 & 0.246 & 0.013 & 0.246 \\
\hline
\end{tabular}

Note: AA, arachidonic acid (20:4n-6); EPA, eicosapentaenoic acid (20:5n-3); AdrA, adrenic acid (22:4n-6); DPA, docosapentaenoic acid (22:5n-3); ObA, Osbond acid (22:5n-6); DHA, docosahexaenoic acid (22:6n-

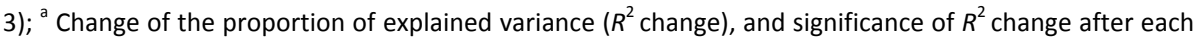
step in hierarchical linear regression analyses. The covariates age, age ${ }^{2}$, sex, level of education, alcohol consumption, smoking, and body mass index were entered in step 1, log-transformed Symptom Checklist 90 depression subscale (SCLdep) score in step 2, and two dummy variables for variability in SCLdep score over 12 years in step $3 ;{ }^{\mathrm{b}}$ Log-transformed data.

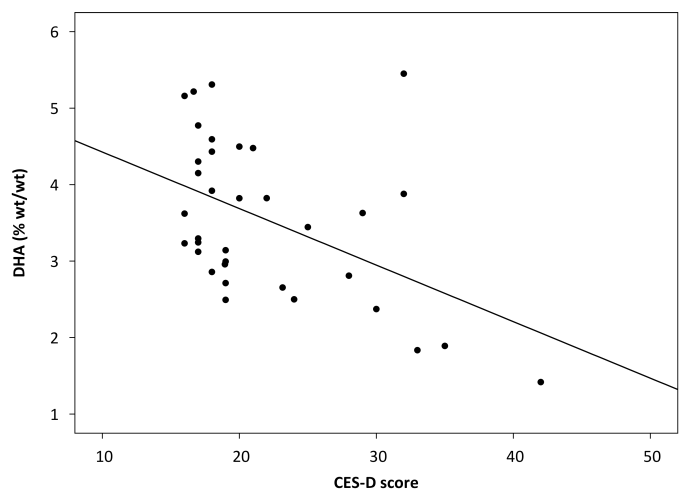

Figure 2 Plasma phospholipid concentration of docosahexaenoic acid (DHA, 22:6n-3) (expressed as percentage of the total amount of plasma phospholipid-associated fatty acids) plotted against the raw Center for Epidemiologic Studies Depression Scale (CES-D) score at 12-year follow-up in individuals with depression scores above the clinical threshold, i.e. CES-D $\geq 16(n=35)$. Pearson's $r$ for the zero-order correlation between DHA concentration and log-transformed CES-D score is significant. The association between depression score and DHA concentration remained significant after correction for the covariates age, age ${ }^{2}$, sex, level of education, alcohol consumption, smoking, and body mass index in linear regression analysis. 


\section{Discussion}

The results of the present study suggest that in the general population there are no linear associations between LCPUFA status or fish consumption on the one hand and depressive symptoms or chronicity of depressive symptomatology on the other. These findings are in agreement with a number of population-based studies reporting the absence of a relationship between depressed mood and LCPUFA status (Appleton et al., 2008; Jacka et al., 2004; Murakami et al., 2008) or fish consumption (Hakkarainen et al., 2004). In addition, they are consistent with results from recent intervention studies, which have not found any beneficial effects of $n-3$ LCPUFA supplementation on depressed mood (Rogers et al., 2008; Van de Rest et al., 2008). On the other hand, the present results are in striking contrast with the rather consistent occurrence of inverse relationships between depressive symptoms and LCPUFA status (Adams et al., 1996; Conklin et al., 2007; Edwards et al., 1998; Féart et al., 2008; Maes et al., 1999; Maes et al., 1996; McNamara et al., 2007; Peet et al., 1998; Tiemeier et al., 2003) or fish consumption (Tanskanen et al., 2001; Timonen et al., 2004) in studies comparing depressed patients with healthy individuals. It is remarkable that no such associations were found in the two studies to date covering the entire range of depressive symptoms in the general population, i.e. our study and a study performed by Appleton et al. (2008).

Interestingly, by investigating the full range of depressive symptomatology, we were able to show in one single study both the lack of a linear relationship between LCPUFA status and mood variability as observed in the general population, and the presence of a significant negative correlation between DHA concentration and depressed mood in a subgroup of participants with depressive symptoms above the clinical threshold.

These findings, combined with the notion that subclinical and clinical manifestations of depression may represent a continuum rather than separate categories (Angst \& Merikangas, 2001; Kessler et al., 1997), prompted us to examine the possibility of a non-linear relationship between LCPUFA status and depressive symptoms in the total sample. We found a significant contribution of the quadratic term for CES-D score in predicting DHA concentration, implying that while the role of LCPUFA status in subclinical manifestations of depressed mood may be negligible, increasingly suboptimal n-3 LCPUFA concentrations may accompany more severe depressive symptomatology. By demonstrating a possible non-linear relationship between $n-3$ LCPUFA status and depressed mood in the general population, the present study extended the findings of previous studies reporting an inverse relationship between $\mathrm{n}-3$ LCPUFA status and severity of depression in persons with clinically relevant depressive symptoms (Edwards et al., 1998; Féart et al., 2008) towards the subclinical range, thereby offering a new explanation for the contrast- 
ing results of studies analysing mood variability in the general population as compared to studies distinguishing between depressed and non-depressed individuals.

Due to the cross-sectional nature of our study, it is unclear whether suboptimal n-3 LCPUFA concentrations may precede or follow depressive symptoms. Changes in the fatty acid composition of membrane phospholipids resulting from a suboptimal n-3 LCPUFA status may not only modify membrane fluidity, thereby affecting signal transduction processes in the brain (Chalon, 2006; Hibbeln \& Salem, 1995; Yehuda et al., 1999), but may also induce immunological alterations, which may further contribute to depressive symptomatology (Kiecolt-Glaser et al., 2007; Schiepers et al., 2005; Smith, 1991). Alternatively, depressed mood may also induce changes in eating habits (Christensen \& Brooks, 2006; Christensen \& Somers, 1994), which may result in suboptimal $n-3$ LCPUFA concentrations.

The main strengths of the present study are its sample characteristics (the population base, broad age range, and inclusion of both sexes), which make it representative of the general population, thereby increasing its external validity. Another strength of our study is the measurement of both fish consumption and plasma phospholipid LCPUFA concentrations. The observed correlations between fish consumption and DHA as well as EPA concentrations indicated that fish consumption, as measured by our questionnaire, reliably estimated $n-3$ LCPUFA intake. Furthermore, the use of continuous data on depressive symptoms not only allowed for assessment of the full range of depressive symptomatology, but also enabled the analysis of linear as well as non-linear relationships between depressed mood and LCPUFA status. In particular, what distinguished the present study from earlier research is the use of 12-year longitudinal data on depressive symptoms to investigate whether LCPUFA status was associated with chronicity of depressive symptomatology.

In conclusion, the present results offer initial support for the notion that LCPUFA status may be normal in persons showing only mild symptoms of depressed mood, whereas $n-3$ LCPUFA concentrations may become increasingly suboptimal toward the clinical spectrum of depressive symptoms. In doing so, our study provides a novel understanding of the apparent discrepancy between the results of population-based and clinical studies investigating the relationships between LCPUFA status and depressed mood.

\section{Acknowledgements}

Fatty acid analyses were financially supported by Efamol Ltd. (Leatherhead, Surrey, United Kingdom). 


\section{References}

Adams, P. B., Lawson, S., Sanigorski, A., \& Sinclair, A. J. (1996). Arachidonic acid to eicosapentaenoic acid ratio in blood correlates positively with clinical symptoms of depression. Lipids, 31(Suppl), S157S161.

Angst, J., \& Merikangas, K. R. (2001). Multi-dimensional criteria for the diagnosis of depression. J Affect Disord, 62(1-2), 7-15.

Appleton, K. M., Gunnell, D., Peters, T. J., Ness, A. R., Kessler, D., \& Rogers, P. J. (2008). No clear evidence of an association between plasma concentrations of $n-3$ long-chain polyunsaturated fatty acids and depressed mood in a non-clinical population. Prostaglandins Leukot Essent Fatty Acids, 78(6), 337342.

Arrindell, W. A., \& Ettema, J. H. M. (1986). SCL-90. Een multidimensionele psychopathologie-indicator [SCL-90. A multidimensional indicator of psychopathology]. Lisse, The Netherlands: Swets \& Zeitlinger.

Beekman, A. T., Deeg, D. J., Van Limbeek, J., Braam, A. W., De Vries, M. Z., \& Van Tilburg, W. (1997). Criterion validity of the Center for Epidemiologic Studies Depression scale (CES-D): results from a community-based sample of older subjects in the Netherlands. Psychol Med, 27(1), 231-235.

Chalon, S. (2006). Omega-3 fatty acids and monoamine neurotransmission. Prostaglandins Leukot Essent Fatty Acids, 75(4-5), 259-269.

Christensen, L., \& Brooks, A. (2006). Changing food preference as a function of mood. J Psychol, 140(4), 293-306.

Christensen, L., \& Somers, S. (1994). Adequacy of the dietary intake of depressed individuals. J Am Coll Nutr, 13(6), 597-600.

Cohen, J. (1992). A power primer. Psychol Bull, 112(1), 155-159.

Conklin, S. M., Manuck, S. B., Yao, J. K., Flory, J. D., Hibbeln, J. R., \& Muldoon, M. F. (2007). High omega-6 and low omega-3 fatty acids are associated with depressive symptoms and neuroticism. Psychosom Med, 69(9), 932-934.

Crowe, F. L., Murray Skeaff, C., Green, T. J., \& Gray, A. R. (2008). Serum n-3 long-chain PUFA differ by sex and age in a population-based survey of New Zealand adolescents and adults. Br J Nutr, 99(1), 168174.

Cuijpers, P., De Graaf, R., \& Van Dorsselaer, S. (2004). Minor depression: risk profiles, functional disability, health care use and risk of developing major depression. J Affect Disord, 79(1-3), 71-79.

De Bie, S. E. (1987). Standaardvragen 1987: Voorstellen voor uniformering van vraagstellingen naar achtergrondkenmerken en interviews [Standard questions 1987: Proposal for uniformization of questions regarding background variables and interviews] (2nd ed.). Leiden, The Netherlands: Leiden University Press.

De Groot, R. H. M., Hornstra, G., Van Houwelingen, A. C., \& Roumen, F. (2004). Effect of $\alpha$-linolenic acid supplementation during pregnancy on maternal and neonatal polyunsaturated fatty acid status and pregnancy outcome. Am J Clin Nutr, 79(2), 251-260.

Edwards, R., Peet, M., Shay, J., \& Horrobin, D. (1998). Omega-3 polyunsaturated fatty acid levels in the diet and in red blood cell membranes of depressed patients. J Affect Disord, 48(2-3), 149-155.

Féart, C., Jutand, M. A., Larrieu, S., Letenneur, L., Delcourt, C., Combe, N., \& Barberger-Gateau, P. (2007). Energy, macronutrient and fatty acid intake of French elderly community dwellers and association with socio-demographic characteristics: data from the Bordeaux sample of the Three-City Study. Br J Nutr, 98(5), 1046-1057.

Féart, C., Peuchant, E., Letenneur, L., Samieri, C., Montagnier, D., Fourrier-Reglat, A., \& BarbergerGateau, P. (2008). Plasma eicosapentaenoic acid is inversely associated with severity of depressive symptomatology in the elderly: data from the Bordeaux sample of the Three-City Study. Am J Clin Nutr, 87(5), 1156-1162. 
Grenyer, B. F., Crowe, T., Meyer, B., Owen, A. J., Grigonis-Deane, E. M., Caputi, P., \& Howe, P. R. (2007). Fish oil supplementation in the treatment of major depression: a randomised double-blind placebocontrolled trial. Prog Neuropsychopharmacol Biol Psychiatry, 31(7), 1393-1396.

Hakkarainen, R., Partonen, T., Haukka, J., Virtamo, J., Albanes, D., \& Lönnqvist, J. (2004). Is low dietary intake of omega-3 fatty acids associated with depression? Am J Psychiatry, 161(3), 567-569.

Hibbeln, J. R., \& Salem, N. J. (1995). Dietary polyunsaturated fatty acids and depression: when cholesterol does not satisfy. Am J Clin Nutr, 62(1), 1-9.

Horwath, E., Johnson, J., Klerman, G. L., \& Weissman, M. M. (1994). What are the public health implications of subclinical depressive symptoms? Psychiatr $Q$, 65(4), 323-337.

Jacka, F. N., Pasco, J. A., Henry, M. J., Kotowicz, M. A., Nicholson, G. C., \& Berk, M. (2004). Dietary omega3 fatty acids and depression in a community sample. Nutr Neurosci, 7(2), 101-106.

Jazayeri, S., Tehrani-Doost, M., Keshavarz, S. A., Hosseini, M., Djazayery, A., Amini, H., Jalali, M., \& Peet, M. (2008). Comparison of therapeutic effects of omega-3 fatty acid eicosapentaenoic acid and fluoxetine, separately and in combination, in major depressive disorder. Aust N Z J Psychiatry, 42(3), 192-198.

Jolles, J., Houx, P. J., Van Boxtel, M. P. J., \& Ponds, R. W. H. M. (Eds.). (1995). The Maastricht Aging Study: Determinants of Cognitive Aging. Maastricht, The Netherlands: Neuropsych Publishers.

Kessler, R. C., Zhao, S., Blazer, D. G., \& Swartz, M. (1997). Prevalence, correlates, and course of minor depression and major depression in the National Comorbidity Survey. J Affect Disord, 45(1-2), 19-30.

Kiecolt-Glaser, J. K., Belury, M. A., Porter, K., Beversdorf, D. Q., Lemeshow, S., \& Glaser, R. (2007). Depressive symptoms, omega-6:omega-3 fatty acids, and inflammation in older adults. Psychosom Med, 69(3), 217-224.

Kris-Etherton, P. M., Taylor, D. S., Yu-Poth, S., Huth, P., Moriarty, K., Fishell, V., Hargrove, R. L., Zhao, G., \& Etherton, T. D. (2000). Polyunsaturated fatty acids in the food chain in the United States. Am J Clin Nutr, 71(1 Suppl), 179S-188S.

Maes, M., Christophe, A., Delanghe, J., Altamura, C., Neels, H., \& Meltzer, H. Y. (1999). Lowered omega 3 polyunsaturated fatty acids in serum phospholipids and cholesteryl esters of depressed patients. Psychiatry Res, 85(3), 275-291.

Maes, M., Smith, R., Christophe, A., Cosyns, P., Desnyder, R., \& Meltzer, H. (1996). Fatty acid composition in major depression: decreased omega-3 fractions in cholesteryl esters and increased C20:4 omega6/C20:5 omega-3 ratio in cholesteryl esters and phospholipids. J Affect Disord, 38(1), 35-46.

Marangell, L. B., Martinez, J. M., Zboyan, H. A., Kertz, B., Kim, H. F., \& Puryear, L. J. (2003). A double-blind, placebo-controlled study of the omega-3 fatty acid docosahexaenoic acid in the treatment of major depression. Am J Psychiatry, 160(5), 996-998.

Martínez, M., \& Mougan, I. (1998). Fatty acid composition of human brain phospholipids during normal development. J Neurochem, 71(6), 2528-2533.

Mathers, C. D., \& Loncar, D. (2006). Projections of global mortality and burden of disease from 2002 to 2030. PLoS Med, 3(11), e442.

McNamara, R. K., Hahn, C. G., Jandacek, R., Rider, T., Tso, P., Stanford, K. E., \& Richtand, N. M. (2007). Selective deficits in the omega-3 fatty acid docosahexaenoic acid in the postmortem orbitofrontal cortex of patients with major depressive disorder. Biol Psychiatry, 62(1), 17-24.

Mischoulon, D., Best-Popescu, C., Laposata, M., Merens, W., Murakami, J. L., Wu, S. L., Papakostas, G. I., Dording, C. M., Sonawalla, S. B., Nierenberg, A. A., Alpert, J. E., \& Fava, M. (2008). A double-blind dose-finding pilot study of docosahexaenoic acid (DHA) for major depressive disorder. Eur Neuropsychopharmacol, 18(9), 639-645.

Murakami, K., Mizoue, T., Sasaki, S., Ohta, M., Sato, M., Matsushita, Y., \& Mishima, N. (2008). Dietary intake of folate, other $\mathrm{B}$ vitamins, and omega-3 polyunsaturated fatty acids in relation to depressive symptoms in Japanese adults. Nutrition, 24(2), 140-147.

Nemets, H., Nemets, B., Apter, A., Bracha, Z., \& Belmaker, R. H. (2006). Omega-3 treatment of childhood depression: a controlled, double-blind pilot study. Am J Psychiatry, 163(6), 1098-1100. 
Peet, M., \& Horrobin, D. F. (2002). A dose-ranging study of the effects of ethyl-eicosapentaenoate in patients with ongoing depression despite apparently adequate treatment with standard drugs. Arch Gen Psychiatry, 59(10), 913-919.

Peet, M., Murphy, B., Shay, J., \& Horrobin, D. (1998). Depletion of omega-3 fatty acid levels in red blood cell membranes of depressive patients. Biol Psychiatry, 43(5), 315-319.

Radloff, L. S. (1977). The CES-D scale: a self-report depression scale for research in the general population. Appl Psychol Meas, 1, 385-401.

Rapaport, M. H., \& Judd, L. L. (1998). Minor depressive disorder and subsyndromal depressive symptoms: functional impairment and response to treatment. J Affect Disord, 48(2-3), 227-232.

Rogers, P. J., Appleton, K. M., Kessler, D., Peters, T. J., Gunnell, D., Hayward, R. C., Heatherley, S. V., Christian, L. M., McNaughton, S. A., \& Ness, A. R. (2008). No effect of n-3 long-chain polyunsaturated fatty acid (EPA and DHA) supplementation on depressed mood and cognitive function: a randomised controlled trial. Br J Nutr, 99(2), 421-431.

Schiepers, O. J. G., Wichers, M. C., \& Maes, M. (2005). Cytokines and major depression. Prog Neuropsychopharmacol Biol Psychiatry, 29(2), 201-217.

Silvers, K. M., Woolley, C. C., Hamilton, F. C., Watts, P. M., \& Watson, R. A. (2005). Randomised doubleblind placebo-controlled trial of fish oil in the treatment of depression. Prostaglandins Leukot Essent Fatty Acids, 72(3), 211-218.

Simon, J. A., Fong, J., Bernert, J. T. J., \& Browner, W. S. (1996). Relation of smoking and alcohol consumption to serum fatty acids. Am J Epidemiol, 144(4), 325-334.

Smith, R. S. (1991). The macrophage theory of depression. Med Hypotheses, 35(4), 298-306.

Su, K. P., Huang, S. Y., Chiu, C. C., \& Shen, W. W. (2003). Omega-3 fatty acids in major depressive disorder. A preliminary double-blind, placebo-controlled trial. Eur Neuropsychopharmacol, 13(4), 267271.

Tanskanen, A., Hibbeln, J. R., Tuomilehto, J., Uutela, A., Haukkala, A., Viinamäki, H., Lehtonen, J., \& Vartiainen, E. (2001). Fish consumption and depressive symptoms in the general population in Finland. Psychiatry Serv, 52(4), 529-531.

Tiemeier, H., Van Tuijl, H. R., Hofman, A., Kiliaan, A. J., \& Breteler, M. M. (2003). Plasma fatty acid composition and depression are associated in the elderly: the Rotterdam Study. Am J Clin Nutr, 78(1), 40-46.

Timonen, M., Horrobin, D., Jokelainen, J., Laitinen, J., Herva, A., \& Räsänen, P. (2004). Fish consumption and depression: the Northern Finland 1966 birth cohort study. J Affect Disord, 82(3), 447-452.

Van Boxtel, M. P. J., Buntinx, F., Houx, P. J., Metsemakers, J. F. M., Knottnerus, J. A., \& Jolles, J. (1998). The relation between morbidity and cognitive performance in a normal aging population. $J$ Gerontol A Biol Sci Med Sci, 53(2), M147-M154.

Van de Rest, O., Geleijnse, J. M., Kok, F. J., Van Staveren, W. A., Hoefnagels, W. H., Beekman, A. T., \& De Groot, C. P. (2008). Effect of fish-oil supplementation on mental well-being in older subjects: a randomized, double-blind, placebo-controlled trial. Am J Clin Nutr, 88(3), 706-713.

World Health Organization (2000). International guide for monitoring alcohol consumption and related harm. Geneva: World Health Organization.

Yehuda, S., Rabinovitz, S., \& Mostofsky, D. I. (1999). Essential fatty acids are mediators of brain biochemistry and cognitive functions. J Neurosci Res, 56(6), 565-570. 
CHAPTER 3

Fish consumption, not fatty acid status, is related to quality of life in a healthy population

Olga J.G. Schiepers, Renate H.M. de Groot, Jelle Jolles, Martin P.J. van Boxtel Prostaglandins Leukot Essent Fatty Acids (2010), 83(1): 31-35 


\begin{abstract}
Depressive symptoms in the community have a considerable impact on quality of life. Although long-chain polyunsaturated fatty acids (LCPUFA) have frequently been implicated in depressed mood, their relationship with quality of life has scarcely been investigated. This study examined the cross-sectional associations between fish consumption and plasma phospholipid LCPUFA status on the one hand, and quality of life, as measured by the Short Form 36 Health Survey, on the other in a population-based sample. The mental health component of quality of life was not associated with LCPUFA status or fish consumption. Fish consumption showed a positive association with physical well-being, which remained significant after correction for LCPUFA status, suggesting that the relationship between fish consumption and physical well-being is independent of the LCPUFA content of fish. These findings indicate that fish consumption may serve as a proxy for a healthy lifestyle or a favourable nutritional status, which is reflected in better quality of life.
\end{abstract}




\section{Introduction}

Depressive symptoms are highly prevalent in the general population (Kessler et al., 1997). Subclinical depressive symptoms not only significantly increase the risk of developing major depression (Cuijpers et al., 2004; Horwath et al., 1994), but are also associated with considerable functional impairment (Cuijpers et al., 2004; Rapaport \& Judd, 1998). The negative impact of subclinical depressive symptoms on both physical and mental functioning is generally reflected in a reduction of quality of life (Da Silva Lima \& De Almeida Fleck, 2007; Goldney et al., 2004). From a public health perspective, it is important to identify the factors involved in the development of depressive symptoms and the concomitant decrease in quality of life.

It has often been suggested that long-chain polyunsaturated fatty acids (LCPUFA), which are primarily found in fish, may lower the risk of developing depressive symptoms (Conklin et al., 2007; Tanskanen et al., 2001; Tiemeier et al., 2003). Strikingly, the relationship between LCPUFA status and quality of life has scarcely been investigated - only one study has addressed this issue to date. In a community-based study, Crowe et al. examined the associations between serum phospholipid LCPUFA status and the physical and mental health components of quality of life (Crowe et al., 2007). Although the authors did not find any associations between mental well-being and the two LCPUFA that are predominant in fish, i.e. eicosapentaenoic acid (EPA, 20:5n-3) and docosahexaenoic acid (DHA, 22:6n-3), they did find a positive relationship between EPA concentration and physical well-being. In addition, Silvers and Scott addressed the relationships between fish consumption and the physical and mental health dimensions of quality of life in a population-based sample (Silvers \& Scott, 2002). Interestingly, this study reported a positive relationship between fish consumption and self-reported mental health, but not physical well-being.

Unfortunately, the two above-mentioned studies solely focused on either LCPUFA status or fish consumption, which makes it difficult to compare their results. An additional limitation of the study by Silvers and Scott is the crude distinction between fish consumers and non-consumers, without taking into account the frequency and/or kind of fish consumption.

The aim of the present study was to investigate the cross-sectional relationships between LCPUFA status, fish intake, and quality of life in a population-based sample. In order to compensate for the limitations of the above-mentioned studies, we included detailed measurements of both fish consumption and plasma phospholipid LCPUFA concentrations in our study. 


\section{Methods}

\section{Design and study population}

The present study was part of a longitudinal research program investigating the determinants and consequences of cognitive ageing, the Maastricht Aging Study (MAAS) (Jolles et al., 1995). Participants were randomly drawn from a register of family practices (Metsemakers et al., 1992). Medically verified exclusion criteria at baseline were chronic neurological pathology, psychiatric disorders, mental retardation, and psychotropic drug use. The study population consisted of 1,823 participants, aged 24 to 81 years at baseline, and comprised four demographically identical panels, each stratified for age, sex, and general ability level. A detailed description of the MAAS study design can be found elsewhere (Jolles et al., 1995; Van Boxtel et al., 1998).

The present study was carried out in one single panel of the MAAS study, consisting of 470 participants at baseline, of whom 301 individuals participated in the 12-year reassessments. During the follow-up period, 169 participants dropped out due to a variety of reasons, including death, serious illnesses, and refusal to participate. The most common reasons for refusal were "being too occupied", "feeling too ill", and "participation is too time-consuming" (Van Beijsterveldt et al., 2002). Dropouts did not differ from the remaining participants in terms of age, sex, level of education, marital status, alcohol consumption, smoking, or body mass index (BMI). At 12-year follow-up, habitual fish consumption and quality of life were measured by means of questionnaires. Participation in a sidearm study that involved blood sampling was voluntary; venous blood was collected from 241 individuals in order to determine individual LCPUFA status. Sixty individuals refused to donate blood. Volunteers did not differ from the other participants in the panel in terms of age, sex, and level of education. The study was approved by the local Medical Ethics Committee. Prior to enrolment all participants signed an informed consent form.

\section{Quality of life assessment}

The Short Form 36 Health Survey (SF-36) is a generic, health-related quality of life questionnaire based on self-report (Ware \& Gandek, 1998). It is composed of thirtysix items, organised into eight multi-item scales measuring physical well-being (physical functioning, role limitations due to physical problems, bodily pain, and general health perception) and mental well-being (vitality, social functioning, role limitations due to emotional problems, and mental health) over the past four weeks. The raw scale scores were standardised and aggregated into a Physical Component Summary score and a Mental Component Summary score (Ware et al., 
1995). The two summary scores range from 0 to 100, with higher scores indicating better quality of life.

\section{Fatty acid status}

Plasma was separated from blood cells by centrifugation and collected in tubes, which were closed under nitrogen and stored at $-80^{\circ} \mathrm{C}$ until fatty acid analysis. Fatty acid profiles of phospholipids isolated from venous plasma were determined as described before (De Groot et al., 2004). Total phospholipid-associated fatty acid concentrations are expressed as $\mathrm{mg} / \mathrm{l}$ plasma, and relative fatty acid concentrations as percentages of the total amount of phospholipid-associated fatty acids (\% by weight, \%wt/wt). Forty-two fatty acids were identified. In the present study, five fatty acids were considered of interest, i.e. arachidonic acid (AA, 20:4n-6), EPA, and DHA, which are implicated in physical and mental health (Horrocks \& Yeo, 1999; Parker et al., 2006; Simopoulos, 2002), the DHA status parameter adrenic acid (AdrA, 22:4n-6), and docosapentaenoic acid (DPA, 22:5n-3), which is a major intermediate in EPA-to-DHA conversion.

\section{Fish consumption}

Fish consumption was measured by means of a validated short self-report questionnaire (De Groot et al., 2009). Fish types were categorised according to DHA content, as DHA is the predominant LCPUFA in fish (Kris-Etherton et al., 2000): low (fish fingers, prawns, pickled herring, cod, mussels, plaice, tuna, and tilapia), intermediate (trout, raw herring, smoked eel, smoked salmon, canned salmon), and high (smoked herring, herring in tomato sauce, mackerel, canned sardines, salmon). Frequency of consumption (never, once a month, two to three times a month, once a week, more often than once a week) was used to calculate fish consumption within each category: 0, 1, 2, 4, and 8 for the 'low DHA' category; 0, 2, 4, 8, and 16 for the 'intermediate $\mathrm{DHA}^{\prime}$ category; and $0,3,6,12$, and 24 for the 'high $\mathrm{DHA}^{\prime}$ category. Total fish consumption corresponded to the sum of the scores of the three DHA categories. Overall fish consumption scores range from 0 to 48, indexing a dimensionless estimate of fish intake.

\section{Sociodemographic and lifestyle variables}

Age, sex, level of education (high or low), marital status (married or living together, or not married), alcohol consumption (high or low), smoking (yes or no), and BMI $\left(\mathrm{kg} / \mathrm{m}^{2}\right.$ ) were treated as covariates (Crowe et al., 2008; Féart et al., 2007; Galobardes et al., 2001; Simon et al., 1996). Level of education, measured by classifying formal schooling according to the Dutch educational system (De Bie, 1987), was 
categorised into 'low' (primary education - junior vocational education) or 'high' (higher secondary education - university education). Alcohol consumption, measured by means of a short self-report questionnaire, was dichotomised into 'low' or 'high' according to WHO standards (World Health Organization, 2000). High alcohol intake corresponded to the consumption of at least two (women) or three (men) alcoholic beverages (standard units, i.e. $8 \mathrm{~g}$ ethanol per drink) per day on average.

\section{Statistical analysis}

Normal P-P plots indicated skewness of EPA concentration and fish consumption, which was corrected by log-transformation. Pearson's product-moment correlations were calculated for all variables. Hierarchical linear regression analyses were performed to investigate the associations between fish consumption or the five fatty acids of interest on the one hand and quality of life on the other. Separate regression models were fitted for the Physical and Mental Component Summary scores of the SF-36, adjusting for age, sex, level of education, marital status, alcohol consumption, smoking, and BMI in the first step. The primary predictor variables, the LCPUFA (Model 1) or fish consumption (Model 2), were entered in step 2. In a third model, the associations between fish consumption and quality of life were additionally adjusted for the LCPUFA, in order to investigate whether the putative associations between fish consumption and quality of life were attributable to the LCPUFA content of fish. To this end, the covariates were entered in step 1, the LCPUFA in step 2, and fish consumption in step 3.

Statistical differences were considered significant at $p$-values $<0.05$. A power calculation assuming a small effect size of 0.04 (Cohen, 1988) revealed a statistical power of 0.86. All analyses were performed using SPSS 16.0 (SPSS Inc., Chicago, IL, USA).

\section{Results}

Data on quality of life and plasma phospholipid LCPUFA concentrations were available for 233 individuals, and information concerning fish consumption was available for 231 participants. The participants' characteristics are summarised in Table 1 . The scores (mean \pm SD) on the eight scales of the SF-36 were $82.7 \pm 21.1$ for physical functioning, $81.0 \pm 33.0$ for role limitations due to physical problems, $80.3 \pm 20.2$ for bodily pain, $67.2 \pm 18.5$ for General Health Perception, $69.9 \pm 17.1$ for vitality, $86.0 \pm$ 18.6 for social functioning, $88.7 \pm 26.9$ for role limitations due to emotional problems, and $79.6 \pm 15.5$ for mental health. These scores were comparable to the age and gender-adjusted means obtained in the Dutch population (Aaronson et al., 
1998). The SF-36 Physical Component Summary scores ranged from 14.7 to 64.8, and the Mental Component Summary scores ranged from 8.8 to 69.9.

Table 1 Participant characteristics

\begin{tabular}{ll}
\hline & Total sample \\
\hline$n$ & 233 \\
Age (years) & $60.0(36-88)$ \\
Female sex (\%) & 50.6 \\
Low level of education (\%) & 70.8 \\
Married (\%) & 79.0 \\
High alcohol consumption (\%) & 6.0 \\
Current smoker (\%) & 23.2 \\
BMI (kg/m ${ }^{2}$ ) & $26.3 \pm 4.3$ \\
Physical Component Summary score & $48.7 \pm 9.7$ \\
Mental Component Summary score & $53.6 \pm 8.7$ \\
Fish consumption & $8.6(0-44)$ \\
AA (\%wt/wt) & $9.62 \pm 2.12$ \\
EPA (\%wt/wt) & $0.99 \pm 0.49$ \\
AdrA (\%wt/wt) & $0.29 \pm 0.08$ \\
DPA (\%wt/wt) & $0.93 \pm 0.19$ \\
DHA (\%wt/wt) & $3.45 \pm 1.04$ \\
\hline NOte: Values are expressed & bs means (range) \\
\hline
\end{tabular}

Note: Values are expressed as means (range) or means \pm SD. BMI, body mass index; AA, arachidonic acid (20:4n-6); EPA, eicosapentaenoic acid (20:5n-3); AdrA, adrenic acid (22:4n-6); DPA, docosapentaenoic acid (22:5n-3); DHA, docosahexaenoic acid (22:6n-3); ${ }^{a} n=231 ;{ }^{b}$ Fatty acid concentrations are expressed as percentages of the total amount of plasma phospholipid-associated fatty acids.

Fish consumption was positively correlated with the plasma phospholipid concentrations of the n-3 fatty acids EPA (Pearson's $r=0.293, p<0.001$ ) and DHA $(r=$ $0.520, p<0.001)$, and negatively correlated with the $n-6$ fatty acid AdrA $(r=0.232, p$ $<0.001)$. The correlations between fish consumption and $A A$, and between fish consumption and DPA were not significant $(r=0.105, p=0.110$ and $r=-0.106, p=$ 0.110 , respectively). The plasma phospholipid concentrations of the fatty acids of interest fell within the normal range for a community-based population, as compared to other studies (Maes et al., 1999; Tiemeier et al., 2003).

Table 2 shows the results of the hierarchical linear regression analyses. After correction for age, sex, level of education, marital status, alcohol consumption, smoking, and BMI, no significant associations were identified between the Mental Component Summary score of the SF-36 and the LCPUFA concentrations, nor fish consumption. The SF-36 Physical Component Summary score showed no significant associations with the fatty acids of interest, whereas a significant positive relationship with fish consumption was found. The association between fish consumption and the Physical Component Summary score remained significant after additional correction for the LCPUFA (Model 3) (Table 2). With respect to the sociodemographic and lifestyle variables, being married was positively related to mental wellbeing ( $p=0.025$ in Model 1 and $p=0.021$ in Model 2), whereas age and BMI nega- 
tively predicted physical well-being ( $p=0.012$ and $p<0.001$ in Model 1 , and $p=$ 0.003 and $p<0.001$ in Model 2, respectively).

Table 2 Associations between quality of life and plasma phospholipid LCPUFA concentrations or fish consumption

\begin{tabular}{|c|c|c|c|c|c|}
\hline Dependent variable & \multicolumn{2}{|c|}{ Independent variable } & \multirow[t]{2}{*}{$R^{2}$ step $1^{\text {a }}$} & \multirow[t]{2}{*}{$\begin{array}{l}R^{2} \text { change } \\
\text { step } 2\end{array}$} & \multirow[t]{2}{*}{$\begin{array}{l}R^{2} \text { change } \\
\text { step } 3\end{array}$} \\
\hline \multicolumn{3}{|c|}{ Physical Component Summary } & & & \\
\hline \multicolumn{6}{|c|}{ Score } \\
\hline & LCPUFA status $^{b}$ & Model 1 & $0.185^{* *}$ & 0.009 & \\
\hline & Fish consumption & Model 2 & $0.187^{* *}$ & $0.015^{*}$ & \\
\hline & & Model 3 & $0.187^{* *}$ & 0.007 & $0.016^{*}$ \\
\hline \multicolumn{6}{|c|}{ Mental Component Summary } \\
\hline \multicolumn{6}{|l|}{ Score } \\
\hline & LCPUFA status & Model 1 & 0.054 & 0.009 & \\
\hline & Fish consumption & Model 2 & 0.053 & 0.000 & \\
\hline & & Model 3 & 0.053 & 0.010 & 0.001 \\
\hline
\end{tabular}

Note: LCPUFA, long-chain polyunsaturated fatty acid; ${ }^{a} R^{2}$ represents the proportion of explained variance, and $R^{2}$ change represents the change in the proportion of explained variance after each step in hierarchical linear regression analyses. The covariates age, sex, level of education, marital status, alcohol consumption, smoking, and body mass index were entered in step 1 and the fatty acids of interest (Model 1) or fish consumption (Model 2) in step 2. In Model 3, the covariates were entered in step 1, the fatty acids of interest in step 2 , and fish consumption in step $3 ;{ }^{b}$ LCPUFA status comprises arachidonic acid (20:4n-6), eicosapentaenoic acid (20:5n-3), adrenic acid (22:4n-6), docosapentaenoic acid (22:5n$3)$, and docosahexaenoic acid $(22: 6 n-3) ;{ }^{*} p<0.05 ;{ }^{* *} p<0.01$.

\section{Discussion}

The present study suggests that fish consumption, but not LCPUFA status, is related to quality of life in the general population. The relationship between fish consumption and quality of life appears to apply specifically to the dimension of physical well-being, and seems to be independent of the fatty acid content of fish. We found no associations between mental well-being and neither LCPUFA status nor fish consumption.

The lack of a relationship between LCPUFA concentrations and subjective mental health is in agreement with the population-based study performed by Crowe et al. (2007) in which no associations between LCPUFA status and mental well-being were found. However, with respect to physical well-being, the authors reported a positive association with serum phospholipid EPA concentrations. Although no associations between LCPUFA concentrations and physical well-being were identified in our study, we did find a positive relationship between fish consumption and physical well-being. Unfortunately, data on fish consumption were not included in the study by Crowe et al., which restricts comparison with the present findings. 
Our findings oppose the results of the study conducted by Silvers and Scott, in which a positive relationship between fish consumption and mental rather than physical well-being was reported (Silvers \& Scott, 2002). Their study showed considerable limitations, however, as fish consumption was recorded on a dichotomous rather than a continuous scale, and their study sample contained relatively few nonfish consumers ( $n=87$ ) compared to the number of regular fish eaters $(n=4,557)$. In addition, LCPUFA concentrations were not measured.

The present finding that fish consumption, but not LCPUFA status, may be related to physical well-being in the general population suggests that frequent dietary intake of fish may exert a beneficial effect on subjective physical health regardless of its fatty acid content. Indeed, no associations between the LCPUFA and physical well-being were found, despite significant correlations between fish intake and the plasma phospholipid concentrations of DHA and EPA. Furthermore, the relationship between fish consumption and physical well-being remained significant after correction for LCPUFA status. It may therefore be argued that other nutrients present in fish, such as vitamins and antioxidants (Berr et al., 2009), might be responsible for the observed association with physical well-being.

Alternatively, fish consumption may also be related to physical health in a more indirect manner, since another, and perhaps more plausible, possibility is that high fish intake may serve as a proxy for a healthy lifestyle or a generally more favourable nutritional status, e.g. resulting from a Mediterranean diet (Simopoulos, 2001; Willett, 2006). It should be noted, however, that due to the cross-sectional nature of the current study, it cannot be ruled out that poor physical health may lead to changes in dietary habits, including decreased fish intake.

The relationships between quality of life and either LCPUFA concentrations or fish consumption may be confounded by a number of variables, including age, sex, BMI, and marital status (Crowe et al., 2008; Féart et al., 2007; Galobardes et al., 2001). The present analyses were corrected for the potential confounders that we considered most likely to influence the associations studied. Altogether, the covariates accounted for up to $19 \%$ of the statistical variance in the regression models, which indicates a large effect (Cohen, 1988). The remaining part of the variance may be explained by predictors of physical and mental well-being that may not be confounders of the studied associations, such as employment status, demography, and social participation, as well as any measurement error associated with the independent and dependent variables.

The additional variance explained by fish consumption in the final regression model was $1.6 \%$, which represents a small effect size (Cohen, 1988). To illustrate the strength of the observed association, as indicated by the standardised regression coefficient for fish consumption $(\beta=0.151)$, an increase in fish consumption by one SD (6.9) corresponds to an increase in Physical Component Summary score by 1.5 points. For example, this implies a 1.5 points higher score on physical well-being for 
someone increasing the consumption of fish of the intermediate DHA category from 'once a week' to 'more often than once a week'. When the predictive value of fish consumption for physical well-being is compared to the relationship with age ( $\beta=-$ 0.183 ) in the same regression model, a 1 SD increase in fish consumption corresponds to the physical well-being of an individual 11 years younger.

Quality of life is a complex concept, with various dimensions. The use of the SF36 questionnaire for evaluating the physical and mental dimensions of quality of life is generally accepted, and its validity and reliability have been demonstrated in many population-based studies (e.g. Aaronson et al., 1998; Haywood et al., 2005; Peek et al., 2004; Qu et al., 2009). Not only was the SF-36 administered in the present study because of its wide acceptance as an appropriate instrument for the assessment of quality of life, it also facilitated the comparison of our findings with the results reported by Crowe et al. and Silvers and Scott, as these authors also used the SF-36 for assessing physical and mental well-being (Crowe et al., 2007; Silvers \& Scott, 2002).

The self-report questionnaire that was used to determine fish consumption has recently been validated in our study population (De Groot et al., 2009). By taking into account the frequency as well as the specific kind of fish consumed, it provides a relatively detailed measure of habitual fish intake, which goes beyond a mere categorisation into fish consumers or non-consumers. A general limitation associated with food frequency questionnaires, however, is the fact that they provide an estimate of individual nutrient intake rather than the exact amounts of nutrients consumed. Although our questionnaire has been proven a reliable measure of LCPUFA intake from fish (De Groot et al., 2009; Schiepers et al., 2009), and strong correlations were found between fish consumption and DHA or EPA concentrations in the present study, the possibility of measurement error cannot be ruled out completely.

Because our study was part of the 12-year follow-up assessments of MAAS, we investigated whether selective attrition might have biased our results. As our study population did not differ from the dropouts in terms of the baseline characteristics age, sex, level of education, marital status, alcohol consumption, smoking, and BMI, we consider this possibility unlikely.

The present study has several strengths. First, we used a non-clinical sample with a broad age range, which increased the external validity of our study. Although our study population was about 10 to 20 times smaller than the samples used by Crowe et al. (2007) and Silvers and Scott (2002), the statistical power of the present study was sufficiently large to detect associations even with small effect sizes. Hence, we consider it unlikely that using a larger sample size would have yielded different results in terms of the nature and the direction of the effects observed. Second, both fish consumption and LCPUFA concentrations were measured, thereby enabling the comparison of these two dietary factors in relation to the different 
dimensions of quality of life. Moreover, these variables were measured on an interval (fish consumption) or continuous (LCPUFA) scale rather than a categorical scale. This not only increased the statistical power of the analyses, but also allowed for a more accurate description of the associations studied. Finally, we corrected our statistical analyses for a number of sociodemographic and lifestyle variables that were considered potential confounders, which contributed to the internal validity of the study by reducing the chance of a type I error.

Similar to the two above-mentioned studies, our study was limited by its crosssectional nature, which does not allow for inferences about the causality of the observed relationship between fish consumption and quality of life.

Summarising, the present study indicates that fish consumption, but not LCPUFA status, may be related to quality of life in the general population. More specifically, fish consumption appears to be associated with subjective physical health rather than mental well-being. This differential finding suggests that fish consumption may serve as a proxy for a healthy lifestyle or a favourable nutritional status, which is reflected in better quality of life. Prospective studies are needed to investigate the causality of the observed relationship between fish consumption and quality of life.

\section{Acknowledgements}

Fatty acid analyses were financially supported by Efamol Ltd. (Leatherhead, Surrey, United Kingdom). 


\section{References}

Aaronson, N. K., Muller, M., Cohen, P. D., Essink-Bot, M. L., Fekkes, M., Sanderman, R., Sprangers, M. A., Te Velde, A., \& Verrips, E. (1998). Translation, validation, and norming of the Dutch language version of the SF-36 Health Survey in community and chronic disease populations. J Clin Epidemiol, 51(11), 1055-1068.

Berr, C., Akbaraly, T., Arnaud, J., Hininger, I., Roussel, A. M., \& Barberger Gateau, P. (2009). Increased selenium intake in elderly high fish consumers may account for health benefits previously ascribed to omega-3 fatty acids. J Nutr Health Aging, 13(1), 14-18.

Cohen, J. (1988). Statistical Power Analysis for the Behavioral Sciences (2nd ed.). Hillsdale, NJ: Erlbaum.

Conklin, S. M., Manuck, S. B., Yao, J. K., Flory, J. D., Hibbeln, J. R., \& Muldoon, M. F. (2007). High omega-6 and low omega-3 fatty acids are associated with depressive symptoms and neuroticism. Psychosom Med, 69(9), 932-934.

Crowe, F. L., Murray Skeaff, C., Green, T. J., \& Gray, A. R. (2008). Serum n-3 long-chain PUFA differ by sex and age in a population-based survey of New Zealand adolescents and adults. Br J Nutr, 99(1), 168174.

Crowe, F. L., Skeaff, C. M., Green, T. J., \& Gray, A. R. (2007). Serum phospholipid n-3 long-chain polyunsaturated fatty acids and physical and mental health in a population-based survey of New Zealand adolescents and adults. Am J Clin Nutr, 86(5), 1278-1285.

Cuijpers, P., De Graaf, R., \& Van Dorsselaer, S. (2004). Minor depression: risk profiles, functional disability, health care use and risk of developing major depression. J Affect Disord, 79(1-3), 71-79.

Da Silva Lima, A. F., \& De Almeida Fleck, M. P. (2007). Subsyndromal depression: an impact on quality of life? J Affect Disord, 100(1-3), 163-169.

De Bie, S. E. (1987). Standaardvragen 1987: Voorstellen voor uniformering van vraagstellingen naar achtergrondkenmerken en interviews [Standard questions 1987: Proposal for uniformization of questions regarding background variables and interviews] (2nd ed.). Leiden, The Netherlands: Leiden University Press.

De Groot, R. H. M., Hornstra, G., Van Houwelingen, A. C., \& Roumen, F. (2004). Effect of $\alpha$-linolenic acid supplementation during pregnancy on maternal and neonatal polyunsaturated fatty acid status and pregnancy outcome. Am J Clin Nutr, 79(2), 251-260.

De Groot, R. H. M., Van Boxtel, M. P. J., Schiepers, O. J. G., Hornstra, G., \& Jolles, J. (2009). Age dependence of plasma phospholipid fatty acid levels: potential role of linoleic acid in the age-associated increase in docosahexaenoic acid and eicosapentaenoic acid concentrations. Br J Nutr, 102(7), 10581064.

Féart, C., Jutand, M. A., Larrieu, S., Letenneur, L., Delcourt, C., Combe, N., \& Barberger-Gateau, P. (2007). Energy, macronutrient and fatty acid intake of French elderly community dwellers and association with socio-demographic characteristics: data from the Bordeaux sample of the Three-City Study. Br J Nutr, 98(5), 1046-1057.

Galobardes, B., Morabia, A., \& Bernstein, M. S. (2001). Diet and socioeconomic position: does the use of different indicators matter? Int J Epidemiol, 30(2), 334-340.

Goldney, R. D., Fisher, L. J., Dal Grande, E., \& Taylor, A. W. (2004). Subsyndromal depression: prevalence, use of health services and quality of life in an Australian population. Soc Psychiatry Psychiatr Epidemiol, 39(4), 293-298.

Haywood, K. L., Garratt, A. M., \& Fitzpatrick, R. (2005). Quality of life in older people: a structured review of generic self-assessed health instruments. Qual Life Res, 14(7), 1651-1668.

Horrocks, L. A., \& Yeo, Y. K. (1999). Health benefits of docosahexaenoic acid (DHA). Pharmacol Res, 40(3), 211-225.

Horwath, E., Johnson, J., Klerman, G. L., \& Weissman, M. M. (1994). What are the public health implications of subclinical depressive symptoms? Psychiatr $Q, 65(4), 323-337$.

Jolles, J., Houx, P. J., Van Boxtel, M. P. J., \& Ponds, R. W. H. M. (Eds.). (1995). The Maastricht Aging Study: Determinants of Cognitive Aging. Maastricht, The Netherlands: Neuropsych Publishers. 
Kessler, R. C., Zhao, S., Blazer, D. G., \& Swartz, M. (1997). Prevalence, correlates, and course of minor depression and major depression in the National Comorbidity Survey. J Affect Disord, 45(1-2), 19-30.

Kris-Etherton, P. M., Taylor, D. S., Yu-Poth, S., Huth, P., Moriarty, K., Fishell, V., Hargrove, R. L., Zhao, G., \& Etherton, T. D. (2000). Polyunsaturated fatty acids in the food chain in the United States. Am J Clin Nutr, 71(1 Suppl), 179S-188S.

Maes, M., Christophe, A., Delanghe, J., Altamura, C., Neels, H., \& Meltzer, H. Y. (1999). Lowered omega 3 polyunsaturated fatty acids in serum phospholipids and cholesteryl esters of depressed patients. Psychiatry Res, 85(3), 275-291.

Metsemakers, J. F. M., Höppener, P., Knottnerus, J. A., Kocken, R. J. J., \& Limonard, C. B. G. (1992). Computerized health information in the Netherlands: a registration network of family practices. $\mathrm{Br} J$ Gen Pract, 42(356), 102-106.

Parker, G., Gibson, N. A., Brotchie, H., Heruc, G., Rees, A. M., \& Hadzi-Pavlovic, D. (2006). Omega-3 fatty acids in mood disorders. Am J Psychiatry, 163(6), 969-978.

Peek, M. K., Ray, L., Patel, K., Stoebner-May, D., \& Ottenbacher, K. J. (2004). Reliability and validity of the SF-36 among older Mexican Americans. Gerontologist, 44(3), 418-425.

Qu, B., Guo, H. Q., Liu, J., Zhang, Y., \& Sun, G. (2009). Reliability and validity testing of the SF-36 questionnaire for the evaluation of the quality of life of Chinese urban construction workers. $J$ Int Med Res, 37(4), 1184-1190.

Rapaport, M. H., \& Judd, L. L. (1998). Minor depressive disorder and subsyndromal depressive symptoms: functional impairment and response to treatment. J Affect Disord, 48(2-3), 227-232.

Schiepers, O. J. G., De Groot, R. H. M., Jolles, J., \& Van Boxtel, M. P. J. (2009). Plasma phospholipid fatty acid status and depressive symptoms: association only present in the clinical range. $J$ Affect Disord, 118(1-3), 209-214.

Silvers, K. M., \& Scott, K. M. (2002). Fish consumption and self-reported physical and mental health status. Public Health Nutr, 5(3), 427-431.

Simon, J. A., Fong, J., Bernert, J. T. J., \& Browner, W. S. (1996). Relation of smoking and alcohol consumption to serum fatty acids. Am J Epidemiol, 144(4), 325-334.

Simopoulos, A. P. (2001). The Mediterranean diets: What is so special about the diet of Greece? The scientific evidence. J Nutr, 131(11 Suppl), 3065S-3073S.

Simopoulos, A. P. (2002). Omega-3 fatty acids in inflammation and autoimmune diseases. J Am Coll Nutr, 21(6), 495-505.

Tanskanen, A., Hibbeln, J. R., Tuomilehto, J., Uutela, A., Haukkala, A., Viinamäki, H., Lehtonen, J., \& Vartiainen, E. (2001). Fish consumption and depressive symptoms in the general population in Finland. Psychiatry Serv, 52(4), 529-531.

Tiemeier, H., Van Tuijl, H. R., Hofman, A., Kiliaan, A. J., \& Breteler, M. M. (2003). Plasma fatty acid composition and depression are associated in the elderly: the Rotterdam Study. Am J Clin Nutr, 78(1), 40-46.

Van Beijsterveldt, C. E. M., Van Boxtel, M. P. J., Bosma, H., Houx, P. J., Buntinx, F., \& Jolles, J. (2002). Predictors of attrition in a longitudinal cognitive aging study: the Maastricht Aging Study (MAAS). J Clin Epidemiol, 55(3), 216-223.

Van Boxtel, M. P. J., Buntinx, F., Houx, P. J., Metsemakers, J. F. M., Knottnerus, J. A., \& Jolles, J. (1998). The relation between morbidity and cognitive performance in a normal aging population. $J$ Gerontol A Biol Sci Med Sci, 53(2), M147-M154.

Ware, J. E., Jr., \& Gandek, B. (1998). Overview of the SF-36 Health Survey and the International Quality of Life Assessment (IQOLA) Project. J Clin Epidemiol, 51(11), 903-912.

Ware, J. E., Jr., Kosinski, M., Bayliss, M. S., McHorney, C. A., Rogers, W. H., \& Raczek, A. (1995). Comparison of methods for the scoring and statistical analysis of SF-36 health profile and summary measures: summary of results from the Medical Outcomes Study. Med Care, 33(4 Suppl), AS264-279.

Willett, W. C. (2006). The Mediterranean diet: science and practice. Public Health Nutr, 9(1A), 105-110.

World Health Organization (2000). International guide for monitoring alcohol consumption and related harm. Geneva: World Health Organization. 

CHAPTER 4 Consuming functional foods enriched with plant sterol or stanol esters for $\mathbf{8 5}$ weeks does not affect neurocognitive functioning or mood in statin-treated hypercholesterolaemic individuals

Olga J.G. Schiepers, Renate H.M. de Groot, Martin P.J. van Boxtel, Jelle Jolles, Ariënne de Jong, Dieter Lütjohann, Jogchum Plat, Ronald P. Mensink 


\begin{abstract}
Recent animal and human studies have shown that plant sterols and stanols, which are used as functional food ingredients to lower increased low-density lipoprotein (LDL) cholesterol concentrations, pass the blood-brain barrier. Whether this affects neurocognitive functioning and mental well-being in humans has, to our knowledge, never been investigated. The aim of the present study was therefore to examine for the first time the effects of long-term plant sterol or stanol consumption on neurocognitive functioning and mood in a randomised, double-blind, placebo-controlled dietary intervention trial. To this end, hypercholesterolaemic individuals, aged 43 to 69 years, on stable statin treatment were randomly assigned to 85-week supplementation with margarines enriched with plant sterol esters $(2.5 \mathrm{~g} / \mathrm{day})$, plant stanol esters ( $2.5 \mathrm{~g} / \mathrm{day})$, or placebo. At baseline and at the end of the intervention period, all participants underwent a cognitive assessment. In addition, subjective cognitive functioning and mood were assessed by means of questionnaires (Cognitive Failure Questionnaire (CFQ) and depression subscale of the Symptom Checklist 90 (SCLdep), respectively). Long-term supplementation with plant sterol or stanol esters did not affect cognitive performance (memory, simple information processing speed, complex information processing speed, Letter-Digit Substitution Test (LDST) performance), subjective cognitive functioning, or mood. In conclusion, the present results indicate that long-term use of plant sterols or stanols at recommended intakes of $2.5 \mathrm{~g} /$ day does not affect neurocognitive functioning or mood in hypercholesterolaemic individuals on statin treatment.
\end{abstract}




\section{Introduction}

Plant sterols and their saturated derivates the plant stanols, which are primarily found in vegetables, vegetable oils, fruits, and cereals (Normén et al., 1999; Valsta et al., 2004), are known for their cholesterol-lowering properties (Heinemann et al., 1991; Miettinen et al., 1995; Normén et al., 2000). Because of their effects on intestinal cholesterol absorption, these compounds are incorporated into the socalled 'functional foods' (Anonymous, 1999).

The use of foods enriched with plant sterols and stanols, e.g. as an adjunctive cholesterol-lowering treatment in hypercholesterolaemic patients on statin therapy (Blair et al., 2000), is generally considered safe (Hendriks et al., 2003; Plat \& Mensink, 2005). Only a relatively small fraction of plant sterols (0.4 to $3.5 \%)$ and stanols $(0.02$ to $0.3 \%)$ is absorbed in the intestine, and therefore the serum levels of these compounds are rather low (Heinemann et al., 1993; Ostlund et al., 2002). Repeatdose toxicology studies in rats have indicated that dietary intake of plant sterols or stanols up to $4 \mathrm{~g} / \mathrm{kg} /$ day, which is equivalent to about $280 \mathrm{~g} /$ day in humans (i.e. approximately 100 times higher than the recommended intake of $2.5 \mathrm{~g} / \mathrm{day}$ ) (Hallikainen et al., 2000; Plat et al., 2000), does not have any adverse physiological effects (Hepburn et al., 1999; Turnbull et al., 1999). Since intestinal absorption of sterols is similar in rats and humans (Borgström, 1968; Heinemann et al., 1993; Sanders et al., 2000), it seems legitimate to extrapolate these results to the human population.

So far, no animal or human studies have, to our knowledge, assessed the possible effects of supplementation with plant sterol or stanol ester-enriched foods on neurocognitive functioning and mental well-being, as it was long thought that circulating plant sterols and stanols could not pass the blood-brain barrier (BBB). This notion was primarily based on their structural resemblance to cholesterol, which does not enter the brain from circulation, but is produced in situ by the central nervous system (CNS) (Dietschy \& Turley, 2004; Jurevics \& Morell, 1995). Recent studies, however, including a human post-mortem study, have demonstrated the presence of plant sterols and stanols in the brain (Fricke et al., 2007; Heverin et al., 2004; Jansen et al., 2006; Lütjohann et al., 2002; Plat et al., 2008; Teunissen et al., 2001; Yu et al., 2004). Whereas plant sterol and stanol concentrations in the brain normally range from 10 to $80 \mathrm{ng} / \mathrm{mg}$ brain tissue (Fricke et al., 2007; Heverin et al., 2004; Jansen et al., 2006; Lütjohann et al., 2002; Teunissen et al., 2001; Yu et al., 2004), supplementation with these compounds may increase their brain concentrations by more than 200\% (Fricke et al., 2007; Plat et al., 2008). In addition, dysfunction of the BBB, as, for example, in Alzheimer's disease, may also result in an increased influx of plant sterols and stanols from the blood stream into the brain (Heverin et al., 2004; Lütjohann et al., 2002; Teunissen et al., 2001). 
Elevated levels of plant sterols and stanols in the CNS may have important consequences for brain functioning. Plant sterols and stanols are easily incorporated into cellular membranes, which may change their functional properties (Halling \& Slotte, 2004) and reduce their fluidity (Leikin \& Brenner, 1989), thereby affecting (synaptic) signal transduction in the brain. Alternatively, plant sterols and stanols might also influence brain functioning by means of their cholesterol-lowering actions. Since cholesterol is the main lipid constituent of cellular membranes and myelin (Dietschy \& Turley, 2004; Jurevics \& Morell, 1995), and plays an important supportive role in signal transduction processes in the brain (Pucadyil \& Chattopadhyay, 2006; Wasser et al., 2007), a reduction in brain cholesterol may have a negative impact on neurocognitive functioning (Kotti et al., 2006).

The present study examined the consequences of long-term consumption of plant sterol and stanol esters on neurocognitive functioning and mood in statintreated hypercholesterolaemic individuals in a randomised, double-blind, placebocontrolled dietary intervention trial. Since supplementation with plant sterols and stanols as adjunctive cholesterol-lowering treatment typically involves consumption for long periods of time, the trial duration was 85 weeks.

\section{Methods}

\section{Participants}

The present study was part of a larger study investigating the long-term effects of combining statin treatment with plant sterol or stanol ester-enriched functional foods on markers of endothelial dysfunction and arterial stiffness (De Jong et al., 2008). Inclusion criteria were stable statin treatment, age between 18 and 70 years, body mass index $(\mathrm{BMI}) \leq 32 \mathrm{~kg} / \mathrm{m}^{2}$, diastolic blood pressure $\leq 95 \mathrm{~mm} \mathrm{Hg}$, and systolic blood pressure $\leq 200 \mathrm{~mm} \mathrm{Hg}$. Individuals with proteinuria, glucosuria, clinical manifestations of hepatic disorders, diabetes mellitus, or active cardiovascular disease within a period of 6 months preceding the study, were excluded. The study was approved by the local Medical Ethics Committee. Prior to enrolment, all participants signed an informed consent form.

\section{Diets and design}

The present study was a randomised, double-blind, placebo-controlled dietary intervention trial. Participants were asked to replace their usual spread with an experimental 'light' margarine (40\% fat). During the first 5 weeks (run-in period), the participants used control margarine. Hereafter, the participants were randomly allocated to one of three experimental groups, stratified for age and sex. The study 
continued with an 85-week intervention period during which the first group continued with the control margarine, the second group with a plant sterol ester (2.5 $\mathrm{g} /$ day) enriched margarine, and the third group with a plant stanol ester $(2.5 \mathrm{~g} /$ day $)$ enriched margarine (Table 1). In the margarines, plant sterols (sitosterol (49\%), campesterol (31\%), and stigmasterol (16\%)) (Unilever, Vlaardingen, The Netherlands) and plant stanols (sitostanol (70\%) and campestanol (29\%)) (Walter Rau Neusser Öl und Fett AG, Neuss, Germany) were esterified with sunflower oil. The three spreads, which were similar in appearance, taste, absorbable fat content, and energy content, were numerically coded. The margarines were packed in tubs of $250 \mathrm{~g}$; participants were advised to weigh the tubs daily to ensure a consumption of $30 \mathrm{~g} /$ day. Participants were asked not to change their habitual diet, level of physical exercise, smoking habits, or alcohol consumption during the study, and to write down in a diary any signs of illness, change of medication, and the daily amount of margarine used. In weeks 5, 50, and 90, the participants returned the used tubs of the previous 8 weeks, which were weighed in order to calculate weekly margarine intake. In addition, individual energy and nutrient intake during the previous 4 weeks was recorded by means of a food-frequency questionnaire (Plat \& Mensink, 2000). Venous blood samples were collected from fasting participants for analysis of serum plant sterol and stanol concentrations at weeks 4, 5, 49, 50, 89, and 90. At the end of the run-in period (week 5), and again after the 85-week intervention period (week 90), the participants underwent a cognitive assessment and completed two self-report questionnaires.

Table 1 Composition of the control and experimental margarines

\begin{tabular}{llll}
\hline Ingredient & Control margarine & $\begin{array}{l}\text { Plant sterol ester } \\
\text { margarine }\end{array}$ & $\begin{array}{l}\text { Plant stanol ester } \\
\text { margarine }\end{array}$ \\
\hline Protein & 0 & \multicolumn{1}{c}{$g / 100 \mathrm{~g}$ margarine } & \\
Carbohydrates & 2.5 & 0 & 0 \\
Total fat $^{\mathrm{a}}$ & 35.4 & 2.2 & 2.8 \\
SFA & 7.6 & 35.2 & 35.0 \\
MUFA & 7.5 & 8.0 & 8.7 \\
PUFA & 20.1 & 7.4 & 8.7 \\
Trans fat & 0.4 & 19.7 & 17.4 \\
Total sterol & 0.2 & 0.6 & 0.5 \\
Cholesterol & $\mathrm{NA}$ & 7.7 & 8.0 \\
Sitosterol & & $<0.1$ & $<0.1$ \\
Campesterol & & 3.6 & 0.2 \\
Stigmasterol & & 2.0 & 0.2 \\
Sitostanol & & 1.5 & 0 \\
Campestanol & & $<0.1$ & 5.3 \\
Other plant sterols & & $<0.1$ & 2.1 \\
\hline Note: SFA, saturated & 0.5 & 0 \\
\hline
\end{tabular}

Note: SFA, saturated fatty acid; MUFA, monounsaturated fatty acid; PUFA, polyunsaturated fatty acid; NA, not analysed; ${ }^{\text {a }}$ Digestible fat, excluding the plant sterols; ${ }^{b}$ Total amount of sterol equivalents added in esterified form. 


\section{Plant sterol and stanol analysis}

Serum plant sterol (sitosterol and campesterol) and plant stanol (sitostanol and campestanol) concentrations in venous blood were analysed by gas chromatography-mass spectrometry, as described before (Lütjohann et al., 2002). Total serum cholesterol concentrations were analysed as described by Plat \& Mensink (2000). Samples of weeks 4 and 5, weeks 49 and 50, and weeks 89 and 90 were pooled before analysis. All samples from one individual were analysed within the same sequence. Absolute plant sterol and stanol serum concentrations are expressed as $\mu \mathrm{mol} / \mathrm{l}$, and cholesterol-standardised serum concentrations as $10^{2} \times \mu \mathrm{mol} / \mathrm{mmol}$ cholesterol.

\section{Cognitive test battery}

The Mini-Mental State Examination (MMSE) was used to screen for symptoms of dementia (Folstein et al., 1975). The maximum test score is 30 . Individuals with an overall test score of 24 or less, which was considered an indication of an increased risk for dementia, were excluded from statistical analysis.

The Visual Verbal Word Learning Task (WLT) was used to assess learning capacity, as well as recall and retrieval from long-term memory (Van der Elst et al., 2005). In five trials, fifteen frequently occurring Dutch words were visually presented in a fixed order at 2-s intervals. Total free recall (WLTtot), delayed recall after $20 \mathrm{~min}$ (WLTdr), and recognition (WLTrec) were measured.

The Stroop Color-Word Interference Test was used to test selective attention (Van der Elst et al., 2006c). Participants were required to read aloud colour names printed in black (subtask I), name the colour of coloured patches (subtask II), and name the ink colour of colour names printed in an incongruous colour (subtask III). The outcome parameters were speed on subtask I (Str1), speed on subtask II (Str2), and speed on subtask III (Str3).

The Concept Shifting Test (CST) is a test of behavioural planning (Van der Elst et al., 2006a). Participants were asked to cross out sixteen items presented on a test sheet as fast as possible in the right order (1-2-3-4 (subtask A), A-B-C-D (subtask $B), 1-A-2-B$ (subtask $C)$ ). The outcome parameters were speed on subtask A (CSTa), speed on subtask B (CSTb), and speed on subtask C (CSTC).

We used the Letter-Digit Substitution Test (LDST) to measure efficiency of operations in working memory (Van der Elst et al., 2006b). Participants were asked to replace letters presented on a test sheet by their corresponding digits, as indicated by a key showing nine numbers paired with different letters. The total number of correct substitutions completed within $90 \mathrm{~s}$ was used as a measure of LDST performance. 


\section{Data reduction}

To limit the number of dependent variables and to improve the robustness of the underlying cognitive construct, we clustered the raw test scores into three composite performance indices (Lezak et al., 2004). First, the raw test scores were transformed into Z-scores by subtracting the mean score of the pooled measurements (i.e. baseline and 85 weeks of follow-up) from the individual test score and dividing this by the mean SD of the pooled measurements $(Z=(x-$ mean $) / S D)$. Hereafter, the $Z$-scores were averaged, resulting in the following composite scores: memory $((Z \mathrm{WLT}$ tot $+Z \mathrm{WLTdr}+Z \mathrm{WLTrec}) / 3)$, simple information processing speed ((ZStr1 + $Z S t r 2+Z C S T a+Z C S T b) / 4)$, and complex information processing speed ((ZStr3 + $Z C S T c) / 2$ ). The signs of the two speed scores were inverted in order to reflect above normal performance when positive, and below normal when negative. For means of comparison, LDST performance was also transformed into a Z-score.

\section{Questionnaires}

We used the Cognitive Failure Questionnaire (CFQ) to measure the frequency of cognitive failures in every day life (Broadbent et al., 1982; Ponds, 1998). A higher overall score (range 0-100) indicates decreased subjective cognitive functioning.

Mood was assessed with the depression subscale of the Symptom Checklist 90 (SCLdep) (Arrindell \& Ettema, 1986). Higher sum scores (range 16-80) represent increased depressed mood.

\section{Education}

Level of education, assessed by classifying formal schooling according to the Dutch educational system (De Bie, 1987), was categorised into either 'low' or 'average/high' (Van der Elst et al., 2005, 2006b, 2006c).

\section{Statistical analysis}

Normal P-P plots indicated skewness of SCLdep scores, which was corrected by logtransformation. Homogeneity of variances was assessed with Levene's test for equality of error variances. Chi-square tests were used to determine whether the experimental groups differed in terms of sex and level of education. We used oneway ANOVA to assess possible group differences in terms of age and the serum concentrations of the plant sterols and stanols at baseline, as well as the serum concentration of sitosterol at the end of the intervention period. In the case of overall significant group differences, post-hoc Dunnett's $t$ tests were performed to compare the two intervention groups with the control group. Because of heterogeneity of variances, group differences in the serum concentrations of campesterol, 
sitostanol, and campestanol at the end of the intervention period were assessed by means of the non-parametric Kruskal-Wallis test. We used Mann-Whitney $U$ tests to compare the two intervention groups with the control group. In addition, these non-parametric tests were used to examine group differences in absolute changes in serum plant sterol concentrations from baseline to the end of the intervention period.

To investigate the effects of plant sterol or stanol ester consumption on cognitive performance, subjective cognitive functioning, and self-reported mood, univariate ANCOVA were performed. In each analysis, baseline test score of the dependent variable was included as a covariate. The between-subjects factor 'group' was used to evaluate the overall intervention effect. A power calculation for ANCOVA on the primary outcome measures with a medium effect size of 0.15 (Cohen, 1988) revealed a statistical power of 0.79 .

Data are presented as means \pm SD. Statistical differences were considered significant at $p$-values $<0.05$. All analyses were performed using SPSS 16.0 (SPSS Inc., Chicago, IL, USA).

\section{Results}

\section{Participants}

Ninety-two persons showed interest in our study (Figure 1). After screening, fiftynine individuals were considered eligible for study entry. Two individuals withdrew before the start of the study. Because of diagnosis of type 2 diabetes mellitus, one person in the plant sterol group dropped out in week 40. Two individuals in the plant stanol group dropped out; one in week 48, because of discontinuation of statin treatment due to side effects, and the other in week 70, when starting in a weight loss program. In total, fifty-four individuals (thirty-two men, twenty-two women) completed the study. The test results of one male participant in the plant stanol group were excluded from statistical analyses because of a low MMSE score $(<24)$.

The three experimental groups did not differ significantly in terms of age, sex, level of education, and baseline serum concentrations of the plant sterols and stanols (Table 2 and Supplementary Table 1). Energy intake, the proportions of energy from macronutrients, cholesterol intake, and BMI did not differ between the three groups at baseline and did not change significantly during the study. With respect to cognitive performance, all individuals performed within the limits for non-pathological neurocognitive functioning (Van der Elst et al., 2005, 2006a, 2006b, 2006c). 


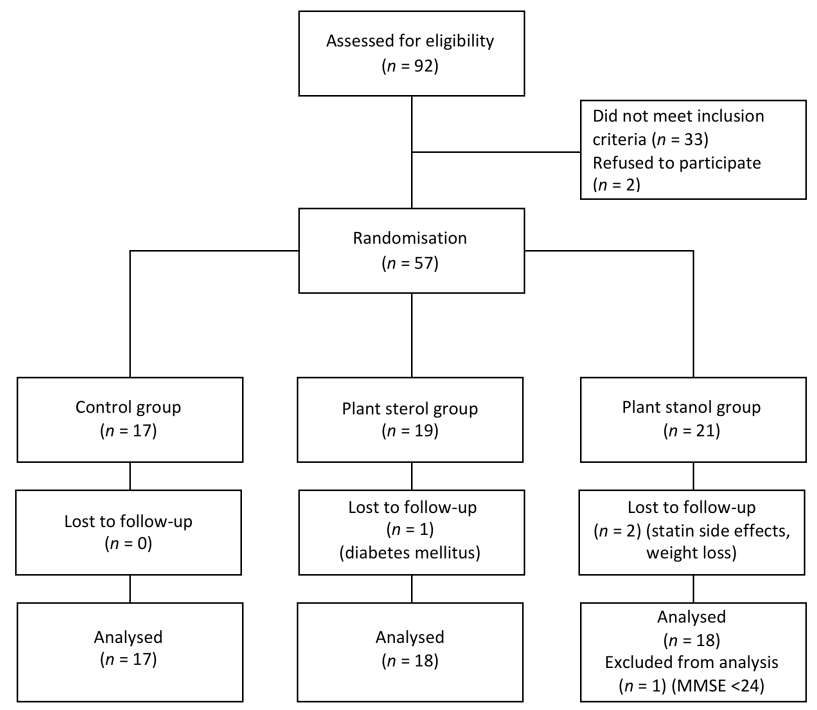

Figure 1 Participant flow diagram of the present study

Compliance with the trial protocol, as indicated by tub weighing and blood sampling, was excellent. At the end of the intervention period, serum plant sterol concentrations differed significantly between the plant sterol group and the control group, whereas serum plant stanol concentrations were significantly different between the plant stanol group and the control group (Table 2).

Table 2 Participant characteristics at baseline and after 85 weeks of supplementation with control margarine, plant sterol ester-enriched margarine, or plant stanol ester-enriched margarine

\begin{tabular}{llll}
\hline & Control & Plant sterol & Plant stanol \\
\hline$n$ & 17 & 18 & 18 \\
Age (years) & $60.4 \pm 7.4$ & $59.8 \pm 6.2$ & $59.0 \pm 7.1$ \\
$\begin{array}{l}\text { Female sex } \\
\text { Low level of education }\end{array}$ & $6(35.3)$ & $8(44.4)$ & $8(44.4)$ \\
$\begin{array}{l}\text { Sitosterol } \\
\quad \text { Baseline }\end{array}$ & $5(29.4)$ & $9(50.0)$ & $7(38.9)$ \\
$\quad$ End of intervention period & $174.4 \pm 62.7$ & $212.4 \pm 109.2$ & $164.5 \pm 84.8$ \\
$\quad$ Campesterol & $178.1 \pm 75.1$ & $296.7 \pm 122.4^{*}$ & $136.9 \pm 62.4$ \\
$\quad \begin{array}{l}\text { Baseline } \\
\text { End of intervention period }\end{array}$ & $265.8 \pm 112.3$ & $330.7 \pm 177.6$ & $255.3 \pm 141.6$ \\
Sitostanol & $242.2 \pm 99.8$ & $685.6 \pm 287.8^{*}$ & $184.6 \pm 72.6$ \\
$\quad$ Baseline & & & \\
$\quad$ End of intervention period & $2.9 \pm 0.8$ & $3.2 \pm 1.1$ & $3.1 \pm 1.3$ \\
Campestanol & $2.9 \pm 0.8$ & $2.6 \pm 0.7$ & $23.3 \pm 16.3^{*}$ \\
$\quad$ Baseline & & & \\
$\quad$ End of intervention period & $3.3 \pm 0.7$ & $3.8 \pm 1.3$ & $3.5 \pm 1.2$ \\
\hline
\end{tabular}

Note: Values are means \pm SD or $n(\%) ;{ }^{a}$ Plant sterol and stanol concentrations in serum are expressed as $10^{2} \times \mu \mathrm{mol} / \mathrm{mmol}$ cholesterol; ${ }^{*}$ Different from control group $(p<0.05)$. 
After 85 weeks of supplementation, serum sitosterol and campesterol concentrations were significantly increased in the plant sterol group as compared to the control group ( $p<0.05$ for the difference in absolute changes). In the plant stanol group, serum sitostanol and campestanol concentrations were markedly elevated in comparison with the control group ( $p<0.05$ for the difference in absolute changes).

The effects of supplementation with plant sterol or stanol esters on serum cholesterol concentrations in the present study have been described in detail by De Jong et al. (2008). In short, in comparison with the control group total serum cholesterol concentrations were reduced by $5.1 \%$ in the plant sterol group ( $p=0.09$ for the difference in absolute changes) and $9.4 \%$ in the plant stanol group $(p<0.05)$ after 85 weeks of intervention, while serum LDL-cholesterol concentrations were lowered by $8.7 \%$ in the plant sterol group $(p=0.08)$ and $13.1 \%$ in the plant stanol group $(p<0.05)$.

\section{Neurocognitive functioning and self-reported mood}

Plant sterol or stanol ester supplementation did not affect memory, simple information processing speed, complex information processing speed, or LDST performance (Table 3).

Table 3 Effects of 85-week consumption of plant sterol or plant stanol ester-enriched margarines on neurocognitive functioning and mood in hypercholesterolaemic individuals on statin treatment

\begin{tabular}{|c|c|c|c|c|}
\hline & Control & Plant sterol & Plant stanol & $p$ \\
\hline$n$ & 17 & 18 & 18 & \\
\hline Memory $^{a}$ & & & & 0.25 \\
\hline Baseline & $-0.14 \pm 0.54$ & $-0.06 \pm 0.87$ & $-0.16 \pm 0.97$ & \\
\hline End of intervention period & $-0.06 \pm 0.84$ & $0.12 \pm 0.96$ & $0.29 \pm 0.77$ & \\
\hline Simple speed ${ }^{\mathrm{a}}$ & & & & 0.24 \\
\hline Baseline & $0.06 \pm 0.74$ & $-0.24 \pm 0.58$ & $0.27 \pm 0.81$ & \\
\hline End of intervention period & $-0.02 \pm 0.85$ & $-0.22 \pm 0.61$ & $0.02 \pm 1.17$ & \\
\hline Complex speed $^{\mathrm{a}}$ & & & & 0.55 \\
\hline Baseline & $-0.05 \pm 0.78$ & $-0.25 \pm 1.03$ & $0.15 \pm 0.95$ & \\
\hline End of intervention period & $0.02 \pm 0.69$ & $-0.23 \pm 0.63$ & $0.23 \pm 1.00$ & \\
\hline LDST performance $^{a}$ & & & & 0.75 \\
\hline Baseline & $0.06 \pm 0.93$ & $-0.20 \pm 0.86$ & $0.20 \pm 1.03$ & \\
\hline End of intervention period & $-0.05 \pm 0.92$ & $-0.24 \pm 1.22$ & $0.23 \pm 1.02$ & \\
\hline Subjective cognitive functioning ${ }^{b}$ & & & & 0.64 \\
\hline Baseline & $27.0 \pm 11.6$ & $33.8 \pm 11.2$ & $31.6 \pm 12.2$ & \\
\hline End of intervention period & $27.7 \pm 12.2$ & $33.0 \pm 8.1$ & $28.7 \pm 9.2$ & \\
\hline $\operatorname{Mood}^{b}$ & & & & 0.53 \\
\hline Baseline & $20.1 \pm 3.8$ & $23.1 \pm 7.3$ & $22.7 \pm 7.3$ & \\
\hline End of intervention period & $19.8 \pm 3.7$ & $22.5 \pm 6.7$ & $20.8 \pm 5.3$ & \\
\hline
\end{tabular}

Note: Values are means \pm SD. LDST, Letter-Digit Substitution Test; ${ }^{\text {a }}$ Cognitive performance indices and Letter-Digit Substitution Test performance are expressed as Z-scores; ${ }^{b}$ Subjective cognitive functioning and mood are expressed as overall scores on the Cognitive Failures Questionnaire and the depression subscale of the Symptoms Checklist 90, respectively. 
In addition, long-term administration of plant sterol or stanol esters did not have any significant effects on subjective cognitive functioning or mood (Table 3 ).

\section{Discussion}

In this study, we showed for the first time, to our knowledge, that long-term administration of plant sterol and stanol esters did not have any effects on cognitive performance, subjective cognitive functioning, or self-reported mood in statintreated hypercholesterolaemic individuals, despite a pronounced increase in the serum concentrations of these compounds.

Consistent with the present findings, there have not been any reports suggesting abnormal neurocognitive functioning in sitosterolaemic patients, who have genetically determined high concentrations of plant sterols and stanols in serum and tissues (Kidambi \& Patel, 2008; Salen et al., 2002), although mouse models have indicated that sitosterolaemia may be accompanied by elevated brain levels of plant sterols and stanols (Yu et al., 2004). It should be noted, however, that extensive research on cognitive performance in sitosterolaemic individuals appears to be lacking.

The absence of any effects of plant sterols and stanols on cognitive performance and mood suggests that, in contrast with peripheral cellular membranes, these compounds may not be incorporated into neuronal membranes, thereby leaving membrane fluidity and signal transduction processes in the brain unaffected. In addition, the present results suggest that the cholesterol-lowering properties of plant sterols and stanols may not affect brain cholesterol levels, which is supported by animal studies (Fricke et al., 2007; Jansen et al., 2006) and the finding that serum concentrations of 24(S)-hydroxycholesterol, a surrogate marker for brain cholesterol homeostasis (Lütjohann et al., 1996), remained unchanged over the 85-week intervention period (De Jong et al., 2008).

Some methodological aspects of our study deserve to be addressed in order to put the present results in perspective. One of the strengths of the present study is the 85 -week duration of the intervention period, which enabled us to investigate the effects of genuine long-term supplementation with plant sterols and stanols, closely resembling the conditions of administration as adjunctive cholesterollowering treatment. In addition, we assigned our participants to separate experimental plant sterol and stanol groups, which allowed the neurocognitive effects of plant sterols and stanols to be compared.

Second, from the observed significant changes in the serum concentrations of plant sterols and stanols in the two intervention groups as compared to the control group, it may be concluded that the intervention was successful. Although it has not yet been evaluated in humans, we inferred from animal studies that dietary sup- 
plementation with plant sterols and stanols would increase the brain levels of these compounds (Fricke et al., 2007; Jansen et al., 2006; Plat et al., 2008).

Third, the cognitive test battery used in the present study has been proven a sensitive tool for assessing neurocognitive functioning (De Groot et al., 2006; Van Boxtel et al., 2004). The use of composite scores for individual performance on the various cognitive domains, which improves the robustness of the underlying cognitive construct (Lezak et al., 2004), particularly facilitated the detection of possible changes in cognitive performance due to supplementation with plant sterol or stanol esters (Durga et al., 2007). The data distribution of the cognitive performance indices in the present study is comparable to that reported in other populationbased studies using a Z-transformation of cognitive test scores (Dullemeijer et al., 2007; Van Boxtel et al., 2004).

Fourth, the statistical power (i.e. 0.79) was deemed sufficiently large to detect possible effects of the intervention on cognitive performance and mood. Nevertheless, the present sample size did not allow for the detection of very small effects of the intervention, and therefore we cannot rule out completely that plant sterols and stanols might exert some minor effects on neurocognitive functioning.

Finally, it should be noted that the present results were obtained in a study sample of hypercholesterolaemic individuals on stable statin treatment. The various statins used by the participants in the present study have been reported by De Jong et al. (2008). About one-half of the participants in each experimental group used lipophilic statins, which may enter the brain. It is unlikely, however, that the use of statins may have influenced the present results. In the first place, statin treatment does not seem to alter brain cholesterol metabolism in hypercholesterolaemic patients (Thelen et al., 2006). In addition, although rare instances of statinassociated memory loss have been described (Wagstaff et al., 2003), animal studies have indicated that the concentrations needed for memory impairment are generally much higher than the dose normally used in cholesterol-lowering therapy (Kotti et al., 2006). Furthermore, various clinical trials have reported no significant effects of statins on cognitive performance (Cutler et al., 1995; Harrison \& Ashton, 1994; Heart Protection Study Collaborative Group, 2002; Kostis et al., 1994). Finally, it is worth noting that statins tend to increase serum plant sterol and stanol levels (Miettinen et al., 2000), which makes individuals on statin treatment an excellent population to study the effects of plant sterols and stanols.

The main benefit of including only hypercholesterolaemic persons in the present study is that it increased the probability of detecting putative effects of plant sterols and stanols on neurocognitive functioning, by reducing statistical variance among the participants. A disadvantage of the concomitant increase in the study's internal validity, however, is a reduction in its external validity. Therefore, the present findings cannot simply be generalised to the general population. Clearly, although hypercholesterolaemic patients on statin treatment are a target popula- 
tion for plant sterol and stanol supplementation, future studies should also investigate the suitability of long-term use of plant sterols and stanols in healthy individuals and sitosterolaemic patients, particularly since dietary supplementation with plant stanols in sitosterolaemic individuals may result in prolonged retention of these compounds in plasma (Connor et al., 2005).

In conclusion, long-term use of plant sterols and stanols at recommended intakes of $2.5 \mathrm{~g} /$ day, which was already regarded safe from a physiological perspective, does not appear to exert any effects on the level of neurocognitive functioning and mood in humans. Nevertheless, further research is warranted to elucidate the exact fate and possible effects of plant sterols and stanols in the human brain.

\section{Acknowledgements}

This study was supported by the Netherlands Organisation for Health Research and Development (Program Nutrition: Health, Safety, and Sustainability, grant 014-12010). 


\section{References}

Anonymous (1999). Scientific concepts of functional foods in Europe. Consensus document. Br J Nutr, 81(Suppl 1), S1-27.

Arrindell, W. A., \& Ettema, J. H. M. (1986). SCL-90. Een multidimensionele psychopathologie-indicator [SCL-90. A multidimensional indicator of psychopathology]. Lisse, The Netherlands: Swets \& Zeitlinger.

Blair, S. N., Capuzzi, D. M., Gottlieb, S. O., Nguyen, T., Morgan, J. M., \& Cater, N. B. (2000). Incremental reduction of serum total cholesterol and low-density lipoprotein cholesterol with the addition of plant stanol ester-containing spread to statin therapy. Am J Cardiol, 86(1), 46-52.

Borgström, B. (1968). Quantitative aspects of the intestinal absorption and metabolism of cholesterol and $\beta$-sitosterol in the rat. $J$ Lipid Res, 9(4), 473-481.

Broadbent, D. E., Cooper, P. F., FitzGerald, P., \& Parkes, K. R. (1982). The Cognitive Failures Questionnaire (CFQ) and its correlates. Br J Clin Psychol, 21 (Pt 1), 1-16.

Cohen, J. (1988). Statistical Power Analysis for the Behavioral Sciences (2nd ed.). Hillsdale, NJ: Erlbaum.

Connor, W. E., Lin, D. S., Pappu, A. S., Frohlich, J., \& Gerhard, G. (2005). Dietary sitostanol and campestanol: accumulation in the blood of humans with sitosterolemia and xanthomatosis and in rat tissues. Lipids, 40(9), 919-923.

Cutler, N., Sramek, J., Veroff, A., Block, G., Stauffer, L., \& Lines, C. (1995). Effects of treatment with simvastatin and pravastatin on cognitive function in patients with hypercholesterolaemia. $\mathrm{Br} J \mathrm{Clin}$ Pharmacol, 39(3), 333-336.

De Bie, S. E. (1987). Standaardvragen 1987: Voorstellen voor uniformering van vraagstellingen naar achtergrondkenmerken en interviews [Standard questions 1987: Proposal for uniformization of questions regarding background variables and interviews] (2nd ed.). Leiden, The Netherlands: Leiden University Press.

De Groot, R. H. M., Vuurman, E. F., Hornstra, G., \& Jolles, J. (2006). Differences in cognitive performance during pregnancy and early motherhood. Psychol Med, 36(7), 1023-1032.

De Jong, A., Plat, J., Lütjohann, D., \& Mensink, R. P. (2008). Effects of long-term plant sterol or stanol ester consumption on lipid and lipoprotein metabolism in subjects on statin treatment. Br J Nutr, 100(5), 937-941.

Dietschy, J. M., \& Turley, S. D. (2004). Thematic review series: Brain Lipids. Cholesterol metabolism in the central nervous system during early development and in the mature animal. $J$ Lipid Res, 45(8), 13751397.

Dullemeijer, C., Durga, J., Brouwer, I. A., Van de Rest, O., Kok, F. J., Brummer, R. J., Van Boxtel, M. P. J., \& Verhoef, P. (2007). n-3 Fatty acid proportions in plasma and cognitive performance in older adults. Am J Clin Nutr, 86(5), 1479-1485.

Durga, J., Van Boxtel, M. P. J., Schouten, E. G., Kok, F. J., Jolles, J., Katan, M. B., \& Verhoef, P. (2007). Effect of 3-year folic acid supplementation on cognitive function in older adults in the FACIT trial: a randomised, double blind, controlled trial. Lancet, 369(9557), 208-216.

Folstein, M. F., Folstein, S. E., \& McHugh, P. R. (1975). "Mini-mental state". A practical method for grading the cognitive state of patients for the clinician. J Psychiatr Res, 12(3), 189-198.

Fricke, C. B., Schroder, M., Poulsen, M., Von Bergmann, K., Wester, I., Knudsen, I., Mortensen, A., \& Lütjohann, D. (2007). Increased plant sterol and stanol levels in brain of Watanabe rabbits fed rapeseed oil derived plant sterol or stanol esters. Br J Nutr, 98(5), 890-899.

Hallikainen, M. A., Sarkkinen, E. S., \& Uusitupa, M. I. (2000). Plant stanol esters affect serum cholesterol concentrations of hypercholesterolemic men and women in a dose-dependent manner. $J$ Nutr, 130(4), 767-776.

Halling, K. K., \& Slotte, J. P. (2004). Membrane properties of plant sterols in phospholipid bilayers as determined by differential scanning calorimetry, resonance energy transfer and detergent-induced solubilization. Biochim Biophys Acta, 1664(2), 161-171. 
Harrison, R. W., \& Ashton, C. H. (1994). Do cholesterol-lowering agents affect brain activity? A comparison of simvastatin, pravastatin, and placebo in healthy volunteers. Br J Clin Pharmacol, 37(3), 231236.

Heart Protection Study Collaborative Group (2002). MRC/BHF Heart Protection Study of cholesterol lowering with simvastatin in 20,536 high-risk individuals: a randomised placebo-controlled trial. Lancet, 360(9326), 7-22.

Heinemann, T., Axtmann, G., \& Von Bergmann, K. (1993). Comparison of intestinal absorption of cholesterol with different plant sterols in man. Eur J Clin Invest, 23(12), 827-831.

Heinemann, T., Kullak-Ublick, G. A., Pietruck, B., \& Von Bergmann, K. (1991). Mechanisms of action of plant sterols on inhibition of cholesterol absorption. Comparison of sitosterol and sitostanol. Eur J Clin Pharmacol, 40 Suppl 1, S59-63.

Hendriks, H. F., Brink, E. J., Meijer, G. W., Princen, H. M., \& Ntanios, F. Y. (2003). Safety of long-term consumption of plant sterol esters-enriched spread. Eur J Clin Nutr, 57(5), 681-692.

Hepburn, P. A., Horner, S. A., \& Smith, M. (1999). Safety evaluation of phytosterol esters. Part 2. Subchronic 90-day oral toxicity study on phytosterol esters-a novel functional food. Food Chem Toxicol, $37(5)$, 521-532.

Heverin, M., Bogdanovic, N., Lütjohann, D., Bayer, T., Pikuleva, I., Bretillon, L., Diczfalusy, U., Winblad, B., \& Björkhem, I. (2004). Changes in the levels of cerebral and extracerebral sterols in the brain of patients with Alzheimer's disease. J Lipid Res, 45(1), 186-193.

Jansen, P. J., Lütjohann, D., Abildayeva, K., Vanmierlo, T., Plosch, T., Plat, J., Von Bergmann, K., Groen, A. K., Ramaekers, F. C., Kuipers, F., \& Mulder, M. (2006). Dietary plant sterols accumulate in the brain. Biochim Biophys Acta, 1761(4), 445-453.

Jurevics, H., \& Morell, P. (1995). Cholesterol for synthesis of myelin is made locally, not imported into brain. J Neurochem, 64(2), 895-901.

Kidambi, S., \& Patel, S. B. (2008). Sitosterolaemia: pathophysiology, clinical presentation and laboratory diagnosis. J Clin Pathol, 61(5), 588-594.

Kostis, J. B., Rosen, R. C., \& Wilson, A. C. (1994). Central nervous system effects of HMG CoA reductase inhibitors: lovastatin and pravastatin on sleep and cognitive performance in patients with hypercholesterolemia. J Clin Pharmacol, 34(10), 989-996.

Kotti, T. J., Ramirez, D. M., Pfeiffer, B. E., Huber, K. M., \& Russell, D. W. (2006). Brain cholesterol turnover required for geranylgeraniol production and learning in mice. Proc Natl Acad Sci USA, 103(10), 38693874.

Leikin, A. I., \& Brenner, R. R. (1989). Fatty acid desaturase activities are modulated by phytosterol incorporation in microsomes. Biochim Biophys Acta, 1005(2), 187-191.

Lezak, M. D., Howieson, D. B., \& Loring, D. W. (2004). Neuropsychological Assessment (4th ed.). New York: Oxford University Press.

Lütjohann, D., Breuer, O., Ahlborg, G., Nennesmo, I., Sidén, A., Diczfalusy, U., \& Björkhem, I. (1996). Cholesterol homeostasis in human brain: evidence for an age-dependent flux of 24Shydroxycholesterol from the brain into the circulation. Proc Natl Acad Sci USA, 93(18), 9799-9804.

Lütjohann, D., Brzezinka, A., Barth, E., Abramowski, D., Staufenbiel, M., Von Bergmann, K., Beyreuther, K., Multhaup, G., \& Bayer, T. A. (2002). Profile of cholesterol-related sterols in aged amyloid precursor protein transgenic mouse brain. J Lipid Res, 43(7), 1078-1085.

Miettinen, T. A., Puska, P., Gylling, H., Vanhanen, H., \& Vartiainen, E. (1995). Reduction of serum cholesterol with sitostanol-ester margarine in a mildly hypercholesterolemic population. $N$ Engl J Med, 333(20), 1308-1312.

Miettinen, T. A., Strandberg, T. E., \& Gylling, H. (2000). Noncholesterol sterols and cholesterol lowering by long-term simvastatin treatment in coronary patients: relation to basal serum cholestanol. Arterioscler Thromb Vasc Biol, 20(5), 1340-1346.

Normén, L., Dutta, P., Lia, A., \& Andersson, H. (2000). Soy sterol esters and $\beta$-sitostanol ester as inhibitors of cholesterol absorption in human small bowel. Am J Clin Nutr, 71(4), 908-913. 
Normén, L., Johnsson, M., Andersson, H., Van Gameren, Y., \& Dutta, P. (1999). Plant sterols in vegetables and fruits commonly consumed in Sweden. Eur J Nutr, 38(2), 84-89.

Ostlund, R. E., Jr., McGill, J. B., Zeng, C. M., Covey, D. F., Stearns, J., Stenson, W. F., \& Spilburg, C. A. (2002). Gastrointestinal absorption and plasma kinetics of soy delta(5)-phytosterols and phytostanols in humans. Am J Physiol Endocrinol Metab, 282(4), E911-916.

Plat, J., De Jong, A., Volger, O. L., Princen, H. M., \& Mensink, R. P. (2008). Preferential campesterol incorporation into various tissues in apolipoprotein $E^{*} 3$-Leiden mice consuming plant sterols or stanols. Metabolism, 57(9), 1241-1247.

Plat, J., Kerckhoffs, D. A., \& Mensink, R. P. (2000). Therapeutic potential of plant sterols and stanols. Curr Opin Lipidol, 11(6), 571-576.

Plat, J., \& Mensink, R. P. (2000). Vegetable oil based versus wood based stanol ester mixtures: effects on serum lipids and hemostatic factors in non-hypercholesterolemic subjects. Atherosclerosis, 148(1), 101-112.

Plat, J., \& Mensink, R. P. (2005). Plant stanol and sterol esters in the control of blood cholesterol levels: mechanism and safety aspects. Am J Cardiol, 96(1A), 15D-22D.

Ponds, R. W. H. M. (1998). Forgetfulness and Cognitive Aging: Prevalence, Characteristics, and Determinants. Maastricht, The Netherlands: Neuropsych Publishers.

Pucadyil, T. J., \& Chattopadhyay, A. (2006). Role of cholesterol in the function and organization of Gprotein coupled receptors. Prog Lipid Res, 45(4), 295-333.

Salen, G., Patel, S., \& Batta, A. K. (2002). Sitosterolemia. Cardiovasc Drug Rev, 20(4), 255-270.

Sanders, D. J., Minter, H. J., Howes, D., \& Hepburn, P. A. (2000). The safety evaluation of phytosterol esters. Part 6. The comparative absorption and tissue distribution of phytosterols in the rat. Food Chem Toxicol, 38(6), 485-491.

Teunissen, C. E., Mulder, M., De Vente, J., Von Bergmann, K., De Bruijn, C., Steinbusch, H. W., \& Lütjohann, D. (2001). Concentrations of different sterols in the striatum and serum of 3-nitropropionic acid-treated Wistar and Lewis rats. Neurochem Res, 26(11), 1237-1244.

Thelen, K. M., Laaksonen, R., Päivä, H., Lehtimaki, T., \& Lütjohann, D. (2006). High-dose statin treatment does not alter plasma marker for brain cholesterol metabolism in patients with moderately elevated plasma cholesterol levels. J Clin Pharmacol, 46(7), 812-816.

Turnbull, D., Whittaker, M. H., Frankos, V. H., \& Jonker, D. (1999). 13-week Oral toxicity study with stanol esters in rats. Regul Toxicol Pharmacol, 29(2 Pt 1), 216-226.

Valsta, L. M., Lemström, A., Ovaskainen, M. L., Lampi, A. M., Toivo, J., Korhonen, T., \& Piironen, V. (2004). Estimation of plant sterol and cholesterol intake in Finland: quality of new values and their effect on intake. BrJ Nutr, 92(4), 671-678.

Van Boxtel, M. P. J., Menheere, P. P. C. A., Bekers, O., Hogervorst, E., \& Jolles, J. (2004). Thyroid function, depressed mood, and cognitive performance in older individuals: the Maastricht Aging Study. Psychoneuroendocrinology, 29(7), 891-898.

Van der Elst, W., Van Boxtel, M. P. J., Van Breukelen, G. J. P., \& Jolles, J. (2005). Rey's verbal learning test: normative data for 1855 healthy participants aged 24-81 years and the influence of age, sex, education, and mode of presentation. J Int Neuropsychol Soc, 11(3), 290-302.

Van der Elst, W., Van Boxtel, M. P. J., Van Breukelen, G. J. P., \& Jolles, J. (2006a). The Concept Shifting Test: adult normative data. Psychol Assess, 18(4), 424-432.

Van der Elst, W., Van Boxtel, M. P. J., Van Breukelen, G. J. P., \& Jolles, J. (2006b). The Letter Digit Substitution Test: normative data for 1,858 healthy participants aged 24-81 from the Maastricht Aging Study (MAAS): influence of age, education, and sex. J Clin Exp Neuropsychol, 28(6), 998-1009.

Van der Elst, W., Van Boxtel, M. P. J., Van Breukelen, G. J. P., \& Jolles, J. (2006c). The Stroop Color-Word test: influence of age, sex, and education; and normative data for a large sample across the adult age range. Assessment, 13(1), 62-79.

Wagstaff, L. R., Mitton, M. W., Arvik, B. M., \& Doraiswamy, P. M. (2003). Statin-associated memory loss: analysis of 60 case reports and review of the literature. Pharmacotherapy, 23(7), 871-880. 
Wasser, C. R., Ertunc, M., Liu, X., \& Kavalali, E. T. (2007). Cholesterol-dependent balance between evoked and spontaneous synaptic vesicle recycling. J Physiol, 579(Pt 2), 413-429.

Yu, L., Von Bergmann, K., Lütjohann, D., Hobbs, H. H., \& Cohen, J. C. (2004). Selective sterol accumulation in ABCG5/ABCG8-deficient mice. J Lipid Res, 45(2), 301-307. 
Supplementary Table 1 Absolute serum concentrations of plant sterols and stanols and after 85 weeks of supplementation with control margarine, plant sterol ester-enriched margarine, or plant stanol esterenriched margarine

\begin{tabular}{|c|c|c|c|}
\hline & Control & Plant sterol & Plant stanol \\
\hline \multirow[t]{2}{*}{$n$} & 17 & 18 & 18 \\
\hline & \multicolumn{3}{|c|}{$\mu \mathrm{mol} / \mathrm{l}$} \\
\hline \multicolumn{4}{|l|}{ Sitosterol } \\
\hline Baseline & $9.01 \pm 3.41$ & $10.89 \pm 5.03$ & $8.99 \pm 4.42$ \\
\hline End of intervention period & $9.47 \pm 4.24$ & $14.83 \pm 5.49^{*}$ & $6.91 \pm 2.90$ \\
\hline \multicolumn{4}{|l|}{ Campesterol } \\
\hline Baseline & $13.67 \pm 5.63$ & $17.25 \pm 8.91$ & $13.97 \pm 7.44$ \\
\hline End of intervention period & $12.86 \pm 5.48$ & $34.40 \pm 13.35^{*}$ & $9.46 \pm 3.78$ \\
\hline \multicolumn{4}{|l|}{ Sitostanol } \\
\hline Baseline & $0.15 \pm 0.04$ & $0.16 \pm 0.05$ & $0.17 \pm 0.07$ \\
\hline End of intervention period & $0.15 \pm 0.04$ & $0.13 \pm 0.03$ & $1.14 \pm 0.72^{*}$ \\
\hline \multicolumn{4}{|l|}{ Campestanol } \\
\hline Baseline & $0.17 \pm 0.03$ & $0.20 \pm 0.06$ & $0.19 \pm 0.07$ \\
\hline End of intervention period & $0.17 \pm 0.03$ & $0.17 \pm 0.04$ & $1.00 \pm 0.61^{*}$ \\
\hline
\end{tabular}

Note: Values are means $\pm \mathrm{SD} ;{ }^{*}$ Different from control group $(p<0.05)$. 
CHAPTER 5

\section{Serum iron parameters, HFE $282 \mathrm{C} \rightarrow Y$ genotype, and cognitive performance in older adults: results from the FACIT study}

Olga J.G. Schiepers, Martin P.J. van Boxtel, Renate H.M. de Groot, Jelle Jolles, Wim L.A.M. de Kort, Dorine W. Swinkels, Frans J. Kok, Petra Verhoef, Jane Durga 


\begin{abstract}
Although iron homeostasis is essential for brain functioning, the effects of iron levels on cognitive performance in older individuals have scarcely been investigated. In the present study, serum iron parameters and haemochromatosis (HFE) $282 \mathrm{C} \rightarrow \mathrm{Y}$ genotype were determined in 818 older individuals who participated in a 3-year randomised, placebo-controlled, double-blind trial examining the effects of folic acid on carotid intima-media thickness. All participants had slightly elevated homocysteine levels and were vitamin $B_{12}$ replete. Cognitive functioning was assessed at baseline and after 3 years by means of a neuropsychological test battery. At baseline, increased serum ferritin was associated with decreased sensorimotor speed, complex speed, and information processing speed; and increased serum iron was associated with decreased sensorimotor speed. Cognitive performance over 3 years was not associated with HFE $282 \mathrm{C} \rightarrow \mathrm{Y}$ genotype or iron parameters. In conclusion, serum iron parameters do not show a straightforward relationship with cognitive functioning, although elevated iron levels may decrease cognitive speed in older individuals susceptible to cognitive impairment.
\end{abstract}




\section{Introduction}

Cognitive function declines with age, even in otherwise healthy individuals. In the last decades, identifying biological determinants of age-related cognitive decline has become an increasingly important goal of ageing research. The putative role of nutritional factors in modifying the risk of cognitive impairment has widely been studied (Carter et al., 2009; Petursdottir et al., 2008; Stephan et al., 2010). In this respect, disturbed iron homeostasis, which may be genetically or environmentally determined, has been coined as one suspected risk factor for age-related cognitive decline (Youdim, 2008).

Iron deficiency is the most common nutritional deficiency worldwide, with a prevalence of 5 to 20\% among adults in Western countries (Ahmed et al., 2008; Brussaard et al., 1997; Lahti-Koski et al., 2003; Milman et al., 2000). A depletion of body iron stores may result from insufficient dietary intake, hampered absorption, or excessive losses (Killip et al., 2007; Sandstead, 2000). In addition, regular whole blood donation may also lower body iron concentrations (Milman et al., 2000).

As a constituent of various enzymes, iron is essential for several physiological functions, including oxygen transport and DNA synthesis (Murray et al., 1996). The brain in particular has a high demand for iron, not only since it is the main oxygenconsuming organ in the human body, but also because many neurobiological processes, including myelination, neurotransmitter synthesis, and synaptic plasticity, are iron-dependent (Beard \& Connor, 2003; Hidalgo \& Núñez, 2007; Thompson et al., 2001). Consequently, one of the major symptoms of iron deficiency is reduced cognitive performance (Beard \& Connor, 2003; Hidalgo \& Núñez, 2007; Sandstead, 2000; Youdim, 2008).

Although the effects of iron deficiency on cognitive functioning have frequently been investigated in children and young adults (Bruner et al., 1996; Halterman et al., 2001; Lozoff et al., 2000; McCann \& Ames, 2007; Murray-Kolb \& Beard, 2007), research performed in older persons is rather limited (Gao et al., 2008; La Rue et al., 1997; Lam et al., 2008). Iron deficiency in older individuals may be due to poor dietary habits, gastrointestinal malignancies, or diseases characterised by chronic inflammation (Handelman \& Levin, 2008; Killip et al., 2007; Marshall et al., 2001; Weiss, 2009).

Elevated body iron levels might also impair brain functioning. Since body iron concentrations tend to increase with age, particularly in women who reached the menopause (Koziol et al., 2001), increased iron concentrations are more frequent in older persons as compared to young adults; elevated iron levels may be present in up to $20 \%$ of community-dwelling individuals aged 50 years or older (Ahmed et al., 2008; Fleming et al., 2001; Milman et al., 2000).

Elevated iron concentrations may also be observed in carriers of the $282 \mathrm{C} \rightarrow \mathrm{Y}$ mutation of the haemochromatosis gene (HFE), which causes increased iron absorp- 
tion (Koziol et al., 2001; Njajou et al., 2003). The HFE 282C $\rightarrow Y$ mutation has a prevalence of around 10\% in communities of Northern European descent (Njajou et al., 2003; Wrede et al., 2004). This mutation has been associated with neurodegenerative disorders (Schmechel et al., 2006; Thompson et al., 2001), including Parkinson's disease (Guerreiro et al., 2006) and Alzheimer's disease (Lehmann et al., 2006; Robson et al., 2004). It should be noted, however, that a number of studies did not find any evidence for such a relationship in patients with Alzheimer's disease (Berlin et al., 2004) or Parkinson's disease (Biasiotto et al., 2008). In addition, it has also been suggested that the HFE $282 \mathrm{C} \rightarrow \mathrm{Y}$ mutation might have a protective role in Alzheimer's disease (Correia et al., 2009).

Despite the fact that both iron deficiency and elevated iron levels frequently occur in older individuals, and are associated with negative effects on cognitive functioning, only a small number of studies have investigated the effects of iron parameters on cognitive performance in later stages of life. The results of these cross-sectional studies are mixed. Whereas Gao and coworkers (2008) did not find any associations between plasma iron and cognitive functioning, Lam et al. (2008) found an inverted $U$-shaped relationship between serum iron and cognitive functioning in men, and an inverse relationship in women. In addition, La Rue and colleagues (1997) reported that serum transferrin was positively correlated with cognitive performance in older individuals.

The objective of the present study was to examine the cross-sectional and longitudinal associations between iron parameters and cognitive functioning in a large sample of healthy older adults. This study investigated linear and quadratic associations between serum iron parameters and cognitive performance, as well as the relationship between the HFE $282 \mathrm{C} \rightarrow \mathrm{Y}$ mutation and cognitive performance.

\section{Methods}

\section{Study population}

The study population consisted of 818 men and women who participated in the Folic Acid and Carotid Intima-Media Thickness (FACIT) study. This randomised, double-blind, placebo-controlled trial was originally designed to investigate the effects of 3-year folic acid supplementation on the risk of cardiovascular disease as measured by carotid intima-media thickness (Durga et al., 2007). The study sample included a relatively large proportion of blood donors (54\%), as participants were recruited from blood bank registries as well as from municipal registries. All participants were aged between 50 and 70 years, and, specifically for women, had reached the menopause at least 2 years before. Exclusion criteria were plasma total homocysteine concentrations $<13 \mu \mathrm{mol} / \mathrm{l}$ or $>26 \mu \mathrm{mol} / \mathrm{l}$, use of B-vitamin supplements or 
drugs that could affect atherosclerotic progression (e.g. lipid-lowering or hormone replacement therapies), or self-reported intestinal disease. We also excluded individuals with elevated homocysteine concentrations due to factors other than suboptimal folate concentrations, including serum vitamin $B_{12}$ concentrations $<200$ $\mathrm{pmol} / \mathrm{l}$, self-reported medical diagnosis of renal or thyroid disorders, or selfreported use of medications that influence folate metabolism. The Medical Ethics Committee at Wageningen University approved the study and all participants gave written informed consent.

\section{Cognitive functioning}

Cognitive functioning on the domains of memory, sensorimotor speed, complex speed, information processing speed, and word fluency was assessed at baseline and at 3-year follow-up by means of a neuropsychological test battery, consisting of the Visual Verbal Word Learning Task (Van der Elst et al., 2005), the Stroop ColorWord Interference Test (Van der Elst et al., 2006d), the Concept Shifting Test (Van der Elst et al., 2006b), the Letter-Digit Substitution Test (Van der Elst et al., 2006c), and the Verbal Fluency Test (Van der Elst et al., 2006a). A detailed description of the cognitive test battery and the method used for creating cognitive performance indices based on the raw test scores can be found elsewhere (Durga et al., 2007).

\section{Blood measurements}

The iron parameters measured were total serum iron; total iron binding capacity, which is a measure of the serum concentration of the iron transport protein transferrin (Gambino et al., 1997; Vernet \& Le Gall, 1998); transferrin saturation, which is expressed as the ratio $(\times 100 \%)$ of serum iron concentration and total iron binding capacity; serum ferritin, an indicator of total body iron stores (Cook et al., 1974); and non-transferrin bound iron (Breuer et al., 2000; Hider, 2002).

At baseline and at 3-year follow-up, fasting venous blood samples were collected, centrifuged within 2 hours, and the serum supernatant was stored in multiple aliquots at $-80^{\circ} \mathrm{C}$. Within 15 months of storage samples were thawed for serum measurements. Serum iron and total iron binding capacity were measured using Hitachi 747 (Roche Diagnostics, Basel, Switzerland). Serum ferritin was determined on the Immulite 1 of DPC (Diagnostic Products Corporation, Los Angeles, CA, USA) using a two-site immunometric assay (reference values: 15-190 $\mu \mathrm{g} / \mathrm{l}$ for postmenopausal women and 15-280 $\mu \mathrm{g} / \mathrm{l}$ for men). Non-transferrin bound iron, which was measured at baseline only, was determined by a fluorescence-based one-step chelation method (Breuer \& Cabantchik, 2001). Serum high-sensitivity C-reactive protein was determined at baseline with enzyme-linked immunosorbent assay using polyclonal antibodies (Dako, Glostrup, Denmark). An automated haematology 
analyser (Sysmex, Hamburg, Germany) was used to measure serum haemoglobin. For active blood donors, blood samples were collected at least 6 weeks after the most recent blood donation.

\section{Genotyping}

Genomic DNA was extracted from whole blood samples using a Qiamp 96 DNA blood kit (Qiagen, Venlo, The Netherlands). DNA samples were stored at $-80{ }^{\circ} \mathrm{C}$ until further analysis. HFE $282 \mathrm{C} \rightarrow \mathrm{Y}$ genotype was determined by an automated method using minor-groove binding DNA oligonucleotides (MGB-probes) (De Kok et al., 2002). The presence of a $282 C \rightarrow Y$ allele was confirmed by conventional polymerase chain reaction with restriction fragment length polymorphism analysis (Jeffrey et al., 1999; Lynas, 1997). Apolipoprotein E (APOE) genotype was determined as described elsewhere (Durga et al., 2007).

\section{Other measurements}

Level of education, measured at baseline by classifying formal schooling according to the Dutch educational system, was categorised into 'low', 'middle', or 'high', i.e. corresponding to primary education, junior vocational training, and senior vocational or academic training, respectively (De Bie, 1987). Alcohol consumption (g/day) and current smoking (yes or no) were ascertained at baseline by means of self-report questionnaires, which were reviewed by a trained research assistant. Body mass index (BMI, $\mathrm{kg} / \mathrm{m}^{2}$ ) was calculated from height and weight, and physical activity was estimated using the Physical Activity Scale for the Elderly (Washburn et al., 1993).

\section{Statistical analysis}

\section{Cross-sectional analyses}

The cross-sectional associations between iron parameters and cognitive functioning were assessed by means of hierarchical linear regression analysis. The iron parameters considered relevant in relation to cognitive performance were total serum iron, ferritin, and non-transferrin bound iron. These parameters represent the different sources of iron in the blood, i.e. total circulating iron, a reflection of total stored body iron, and circulating iron not bound to the plasma transport protein transferrin, respectively (Breuer et al., 2000; Cook et al., 1974; Hider, 2002). Transferrin saturation and total iron binding capacity were not included in the regression analyses, not only because they are indirect measures of body iron levels, but also because including these variables in the statistical models would have introduced multicollinearity. 
Separate regression models were fitted for the five cognitive performance indices. The covariates age, sex, level of education, alcohol consumption, smoking, BMI, physical activity, C-reactive protein, haemoglobin, and APOE E4 carrier status were entered in step 1 , followed by the iron parameters in step 2. Similar regression analyses were performed to examine the associations between the HFE 282C $\rightarrow Y$ mutation and cognitive performance. The variables age, level of education, alcohol consumption, smoking, BMI, and physical activity were confounders in our study. Although sex, C-reactive protein, haemoglobin, and APOE E4 carrier status were no actual confounders in our analyses, we included these variables as covariates to enable comparison with other studies investigating the associations between body iron levels and cognitive performance (Ahmed et al., 2008; Cunietti et al., 2004; Lam et al., 2008; Pulliam et al., 2003; Shah et al., 2009). We also tested for a possible confounding effect of homocysteine, as all participants had slightly elevated plasma total homocysteine levels. However, the results were similar regardless if homocysteine was included in the analyses. Therefore, we did not include this variable in the final statistical models.

To examine the possible non-linear relationships between iron parameters and cognitive performance, regression models were fitted for each cognitive performance index, with quadratic terms for iron parameters as the independent variables, adjusting for covariates and linear terms for iron parameters in step 1.

\section{Longitudinal analyses}

First, we tested whether treatment with folic acid was an effect modifier in our dataset, as folic acid was found to exert a positive effect on cognitive performance (Durga et al., 2007), and previous research suggested that folate might interact with iron metabolism (Mitsopoulos et al., 2006). We found that folic acid supplementation was not an effect modifier in our dataset; the interaction terms for iron parameters and treatment condition were not statistically significant (Supplementary Table 1). Furthermore, the serum iron parameters did not significantly differ between the placebo group and the treatment group at the end of the study ( $p=$ 0.972 for serum iron and $p=0.892$ for ferritin), indicating that folic acid supplementation did not influence body iron levels in our study. Therefore, the longitudinal analyses were performed in the total sample.

Using linear mixed models, we investigated the associations between iron parameters and cognitive performance over 3 years of follow-up, adjusting for covariates. This analysis method takes into account the correlation between repeated measurements and allows the inclusion of participants with missing observations at follow-up (Verbeke \& Molenberghs, 2000). Separate models were fitted for each iron parameter in relation to each of the five cognitive performance indices. An unstructured covariance structure was used. Time (measured in years since baseline) was included to estimate the change in cognitive performance over 3 
years of follow-up. The longitudinal effect of the iron parameters was estimated by the two-way interaction between time and the specific iron parameter, which represents the rate of change in cognitive performance over 3 years as a function of this iron parameter. The longitudinal associations between the HFE $282 \mathrm{C} \rightarrow \mathrm{Y}$ mutation and cognitive performance were examined in a similar manner.

In secondary analyses, we stratified the study population by sex, donor status, and $A P O E$ E4 carrier status to determine whether the cross-sectional and longitudinal associations between iron parameters on the one hand and cognitive functioning on the other differed between men and women, blood donors and non-donors, or carriers and non-carriers of the APOE E4 allele. One-sample $t$ tests were used to determine whether serum iron, serum ferritin, and cognitive functioning changed over the 3-year follow-up period. Chi-square tests and independent samples $t$ tests were used to investigate whether serum iron, total iron binding capacity, and nontransferrin bound iron, as well as the background variables age, sex, level of education, alcohol consumption, smoking, BMI, physical activity, C-reactive protein, haemoglobin, and APOE E4 status differed between carriers and non-carriers of the HFE $282 \mathrm{C} \rightarrow \mathrm{Y}$ mutation. Because of heterogeneity of error variances, the nonparametric Mann-Whitney $U$ test was performed to test for differences in serum ferritin and transferrin saturation between carriers and non-carriers of the HFE $282 \mathrm{C} \rightarrow \mathrm{Y}$ mutation. Hardy-Weinberg equilibrium was assessed using a Chi-square test. Normality of the standardised residuals of the regression analyses was ascertained by means of normal P-P plots.

The statistical power of the cross-sectional and longitudinal analyses was $>0.90$ (small effect size, $f^{2}=0.02$ ). Statistical differences were considered significant at $p$ values <0.05. All analyses were performed using SPSS 16.0 (SPSS Inc., Chicago, IL, USA).

\section{Results}

\section{Participants}

Table 1 shows the baseline characteristics of the participants. Forty-three individuals $(5.3 \%)$ showed depleted iron stores, as indicated by serum ferritin concentrations below the lower normal limit (i.e. $15 \mu \mathrm{g} / \mathrm{l}$ ). Thirty-two individuals $(3.9 \%)$ showed serum haemoglobin concentrations characteristic of anaemia according to WHO criteria, i.e. $<7.5 \mathrm{mmol} / \mathrm{l}$ for women and $<8.1 \mathrm{mmol} / \mathrm{l}$ for men. The combination of both low ferritin and low haemoglobin levels, that is, iron deficiency anaemia, was present in only seven participants $(0.9 \%)$. In total, fifty-three participants (6.5\%) showed serum ferritin concentrations above the upper normal limit (i.e. $190 \mu \mathrm{g} / \mathrm{l}$ for women and $280 \mu \mathrm{g} / \mathrm{l}$ for men). Among non-donors, the prevalence 
of low serum ferritin was $0.8 \%$, and the prevalence of high serum ferritin was $13.1 \%$, and among blood donors, these percentages were $11.3 \%$ and $0.9 \%$, respectively.

Eighty individuals were identified as carriers of the HFE 282C $\rightarrow Y$ mutation (10.5\%); two individuals were homozygous $(0.3 \%)$ and 78 persons were heterozygous (10.2\%). The allele frequencies of the HFE $282 \mathrm{C} \rightarrow \mathrm{Y}$ polymorphism did not significantly differ from the expected distribution predicted by the Hardy-Weinberg equilibrium ( $p=0.860$ ) and were comparable to the frequencies reported in other population-based studies (Njajou et al., 2003; Wrede et al., 2004).

Table 1 Baseline characteristics of the study population according to HFE 282C $\rightarrow Y$ genotype

\begin{tabular}{|c|c|c|c|c|}
\hline & Total sample & $\begin{array}{l}\text { HFE } 282 \mathrm{C} \rightarrow \mathrm{Y} \\
\text { non-carriers }\end{array}$ & $\begin{array}{l}\text { HFE } 282 C \rightarrow Y \\
\text { carriers }\end{array}$ & $p^{\mathrm{a}}$ \\
\hline$n$ & 818 & 685 & 80 & \\
\hline Age (years) & $60.3 \pm 5.6$ & $60.3 \pm 5.6$ & $59.8 \pm 5.6$ & 0.508 \\
\hline Female sex (\%) & 28.4 & 27.9 & 30.0 & 0.690 \\
\hline $\begin{array}{l}\text { Level of education, } \\
\text { low / middle / high (\%) }\end{array}$ & 22.4 / $38.1 / 39.5$ & $21.8 / 38.4$ / 39.9 & $28.8 / 31.2 / 40.0$ & 0.282 \\
\hline Alcohol consumption (g/day) ${ }^{b}$ & $12.5(4.4 ; 23.5)$ & $12.5(4.4 ; 23.4)$ & $14.3(3.7 ; 26.1)$ & 0.447 \\
\hline Current smoker (\%) & 20.4 & 20.0 & 23.8 & 0.431 \\
\hline $\mathrm{BMI}\left(\mathrm{kg} / \mathrm{m}^{2}\right)$ & $26.6 \pm 3.6$ & $26.5 \pm 3.6$ & $26.6 \pm 3.5$ & 0.846 \\
\hline Physical activity (PASE score) & $152.8 \pm 68.6$ & $153.3 \pm 69.3$ & $153.1 \pm 65.4$ & 0.981 \\
\hline $\begin{array}{l}\text { Blood donor, } \\
\text { current / former / never (\%) }\end{array}$ & 54.2 / $14.7 / 31.2$ & $54.5 / 14.7 / 30.8$ & $53.8 / 15.0 / 31.2$ & 0.993 \\
\hline APOE E4 alleles, 0 / 1 / $2(\%)^{c}$ & 67.9 / 29.2 / 2.8 & $69.4 / 28.0 / 2.6$ & $58.8 / 38.8 / 2.5$ & 0.134 \\
\hline Serum C-reactive protein $(\mathrm{mg} / \mathrm{dl})^{\mathrm{b}, \mathrm{d}}$ & $1.1(0.6 ; 2.3)$ & $1.1(0.6 ; 2.3)$ & $1.1(0.6 ; 2.1)$ & 0.956 \\
\hline Serum haemoglobin (mmol/l) & $8.9 \pm 0.7$ & $8.9 \pm 0.7$ & $9.0 \pm 0.7$ & 0.088 \\
\hline Serum iron parameters & & & & \\
\hline Serum iron $(\mu \mathrm{mol} / \mathrm{l})$ & $18.5 \pm 6.4$ & $18.2 \pm 6.2$ & $21.4 \pm 7.3$ & $<0.001$ \\
\hline $\begin{array}{l}\text { Total iron binding capacity } \\
(\mu \mathrm{mol} / \mathrm{l})\end{array}$ & $60.0 \pm 8.1$ & $60.4 \pm 8.1$ & $56.9 \pm 7.8$ & $<0.001$ \\
\hline Transferrin saturation (\%) & $31.4 \pm 11.5$ & $30.6 \pm 10.8$ & $38.7 \pm 15.8$ & $<0.001$ \\
\hline Ferritin $(\mu \mathrm{g} / \mathrm{l})^{\mathrm{b}}$ & $67.0(35.0 ; 131.0)$ & $65.0(34.0 ; 125.0)$ & $86.5(47.8 ; 138.8)$ & 0.063 \\
\hline $\begin{array}{l}\text { Non-transferrin bound iron } \\
(\mu \mathrm{mol} / \mathrm{l})^{\mathrm{e}}\end{array}$ & $2.4 \pm 0.9$ & $2.4 \pm 0.9$ & $2.8 \pm 1.0$ & $<0.001$ \\
\hline
\end{tabular}

Note: Values are means \pm SD. BMI, body mass index; PASE, Physical Activity Scale for the Elderly; APOE, apolipoprotein $\mathrm{E} ;{ }^{a} P$-values for the differences between carriers and non-carriers of the $H F E 282 C \rightarrow Y$ mutation using Chi-square tests, independent samples $t$ tests, or non-parametric Mann-Whitney $U$ tests;

${ }^{\mathrm{b}}$ Median value (interquartile range) is given because of skewed data distribution; ${ }^{\mathrm{C}} n=814$ in the total sample, $n=682$ in HFE 282C $\rightarrow$ Y non-carriers, and $n=80$ in HFE $282 \mathrm{C} \rightarrow Y$ carriers; ${ }^{\mathrm{d}} n=803$ in the total sample, $n=678$ in HFE $282 \mathrm{C} \rightarrow \mathrm{Y}$ non-carriers, and $n=78$ in HFE $282 \mathrm{C} \rightarrow \mathrm{Y}$ carriers; ${ }^{\mathrm{e}} n=808$ in the total sample, $n=678$ in HFE 282C $\rightarrow$ Y non-carriers, and $n=78$ in HFE 282C $\rightarrow$ Y carriers.

Serum iron, transferrin saturation, and non-transferrin bound iron were significantly increased in carriers of the HFE $282 \mathrm{C} \rightarrow \mathrm{Y}$ mutation as compared with non-carriers, whereas total iron binding capacity was decreased in carriers of the HFE 282C $\rightarrow Y$ mutation as compared with non-carriers (Table 1). Serum ferritin and haemoglobin 
concentrations, as well as the background variables, did not significantly differ between carriers and non-carriers of the HFE 282C $\rightarrow$ Y mutation (Table 1). Table 2 presents the serum iron parameters in carriers and non-carriers of the HFE $282 \mathrm{C} \rightarrow \mathrm{Y}$ mutation, stratified by $A P O E$ E4 carrier status.

Table 2 Serum iron parameters in carriers and non-carriers of the HFE $282 C \rightarrow Y$ mutation at baseline, stratified by $A P O E$ E4 carrier status

\begin{tabular}{|c|c|c|c|c|c|c|}
\hline \multirow[t]{2}{*}{ Serum iron parameter } & \multicolumn{3}{|c|}{ HFE $282 \mathrm{C} \rightarrow \mathrm{Y}$ non-carriers } & \multicolumn{3}{|c|}{ HFE $282 C \rightarrow Y$ carriers } \\
\hline & $\begin{array}{l}A P O E \text { E4 non- } \\
\text { carriers }\end{array}$ & APOE E4 carriers & $p^{\mathrm{a}}$ & $\begin{array}{l}A P O E \text { E4 non- } \\
\text { carriers }\end{array}$ & APOE E4 carriers & $p$ \\
\hline$n$ & 473 & 209 & & 47 & 33 & \\
\hline Serum iron $(\mu \mathrm{mol} / \mathrm{l})$ & $18.2 \pm 6.5$ & $18.1 \pm 5.8$ & 0.966 & $21.2 \pm 7.7$ & $21.6 \pm 6.9$ & 0.819 \\
\hline Total iron binding capacity ( $\mu \mathrm{mol} / \mathrm{l})$ & $60.5 \pm 8.2$ & $60.2 \pm 7.7$ & 0.691 & $55.5 \pm 6.4$ & $58.8 \pm 9.2$ & 0.064 \\
\hline Transferrin saturation (\%) & $30.6 \pm 11.1$ & $30.6 \pm 9.9$ & 0.958 & $39.0 \pm 16.3$ & $38.4 \pm 15.3$ & 0.862 \\
\hline Ferritin $(\mu \mathrm{g} / \mathrm{l})^{\mathrm{b}}$ & $67.0(35.0 ; 131.0)$ & $63.0(30.0 ; 119.0)$ & 0.251 & $91.0(50.0 ; 139.0)$ & $79.0(26.0 ; 147.0)$ & 0.479 \\
\hline Non-transferrin bound iron $(\mu \mathrm{mol} / \mathrm{l})^{c}$ & ${ }^{c} 2.4 \pm 0.9$ & $2.4 \pm 0.8$ & 0.369 & $2.8 \pm 1.0$ & $2.9 \pm 1.1$ & 0.661 \\
\hline Haemoglobin $(\mathrm{mmol} / \mathrm{l})$ & $8.9 \pm 0.7$ & $8.8 \pm 0.6$ & 0.086 & $9.1 \pm 0.6$ & $9.0 \pm 0.7$ & 0.728 \\
\hline
\end{tabular}

Note: Values are means \pm SD. APOE, apolipoprotein $\mathrm{E} ;{ }^{a} P$-values for independent samples $t$ tests or nonparametric Mann-Whitney $U$ tests; ${ }^{b}$ Median value (interquartile range) is given because of skewed data distribution; ${ }^{\mathrm{C}} \mathrm{HFE} 282 \mathrm{C} \rightarrow \mathrm{Y}-/$ APOE E4-,$n=469 ; \mathrm{HFE} 282 \mathrm{C} \rightarrow \mathrm{Y}-/$ APOE E4+, $n=206 ; \mathrm{HFE} \mathrm{282C} \rightarrow \mathrm{Y}+/$ APOE $\mathrm{E} 4-, n=46 ; \mathrm{HFE} 282 \mathrm{C} \rightarrow \mathrm{Y}+/ \mathrm{APOE} \mathrm{E} 4+, n=32$.

\section{Cross-sectional associations between serum iron parameters and cognitive functioning}

The regression analyses including quadratic terms for the iron parameters did not reveal any curvilinear relationships between iron parameters and cognitive functioning (data not shown). Cross-sectional linear regression analyses indicated that higher serum ferritin levels were significantly associated with decreased sensorimotor speed, complex speed, and information processing speed, after adjustment for age, sex, level of education, alcohol consumption, smoking, BMI, physical activity, C-reactive protein, haemoglobin, and APOE E4 carrier status (Table 3). In addition, higher serum iron was associated with decreased sensorimotor speed (Table 3). In order to better understand the strength of the associations, when the predictive value of serum iron for cognitive performance is compared to the relationship with age in the same regression model, an increase of $10 \mu \mathrm{mol} / \mathrm{l}$ serum iron corresponds to a lower performance on sensorimotor speed similar to an individual 5.9 years older. Likewise, a $100 \mu \mathrm{g} / \mathrm{l}$ increase in serum ferritin corresponds to the sensorimotor speed and information processing speed of someone 1.2 years older and the complex speed of an individual 1.3 years older. In contrast to serum iron and serum ferritin, non-transferrin bound iron was not significantly associated with cognitive performance. 
Table 3 Associations between iron parameters and cognitive performance at baseline in healthy older adults $^{\mathrm{a}}$

\begin{tabular}{|c|c|c|c|c|c|c|c|}
\hline \multirow{2}{*}{$\begin{array}{l}\text { Cognitive performance } \\
\text { index }\end{array}$} & \multirow[t]{2}{*}{$n$} & \multicolumn{6}{|c|}{ Standardised regression coefficient $(\beta)$} \\
\hline & & Serum iron & $p$ & Ferritin & $p$ & $\begin{array}{l}\text { Non- } \\
\text { transferrin } \\
\text { bound iron }\end{array}$ & $p$ \\
\hline Memory & 794 & -0.019 & 0.807 & 0.002 & 0.951 & 0.070 & 0.362 \\
\hline Sensorimotor speed & 789 & -0.185 & 0.012 & -0.073 & 0.033 & 0.141 & 0.054 \\
\hline Complex speed & 788 & -0.081 & 0.296 & -0.077 & 0.019 & 0.081 & 0.266 \\
\hline Information processing speed & 791 & -0.109 & 0.141 & -0.069 & 0.046 & 0.078 & 0.291 \\
\hline Word fluency & 794 & -0.050 & 0.519 & -0.062 & 0.092 & 0.057 & 0.462 \\
\hline
\end{tabular}

adjusted for the covariates age, sex, level of education, alcohol consumption, smoking, body mass index, physical activity, apolipoprotein E4 carrier status, serum C-reactive protein, and haemoglobin concentration in hierarchical linear regression analyses.

The observed associations between iron parameters and cognitive performance did not differ between men and women, except for the relationship between ferritin and sensorimotor speed, which was significant in men $(\beta=-0.089, p=0.029)$, but not in women $(\beta=0.048, p=0.498)$. When the analyses were stratified by donor status, only non-donors showed a negative association between serum iron and sensorimotor speed $(\beta=-0.313, p=0.003$, as compared to $\beta=-0.093, p=0.409$ in donors), which was stronger than the association found in the total sample. Statistical significance of the other associations between iron parameters and cognitive performance that were found in the total sample was eliminated upon stratification by donor status. Stratification by APOE E4 carrier status showed that the observed relationship between ferritin and sensorimotor speed was significant only in carriers of one or two APOE E4 alleles $(n=80)(\beta=-0.150, p=0.023$, as compared to $\beta=-$ $0.044, p=0.287$ in the non-carrier group); in comparison with the total sample, the negative relationship between ferritin and sensorimotor speed was more pronounced in APOE E4 carriers. In APOE E4 carriers, the negative association between serum iron and sensorimotor speed was similar to the relationship observed in the total sample, although it was not statistically significant.

Overall, the cross-sectional associations between iron parameters and cognitive performance in the analyses stratified by sex, donor status, or APOE E4 carrier status pointed in the same direction as the associations observed in the total sample, with few differences between the groups, although they tended not to reach statistical significance.

In post-hoc analyses, we stratified by serum C-reactive protein concentration (normal, $\leq 3 \mathrm{mg} / \mathrm{dl}$; elevated, $>3 \mathrm{mg} / \mathrm{dl}$ (Ridker, 2003)) to ascertain whether serum ferritin was associated with cognitive functioning in the absence of inflammation. Higher serum ferritin predicted slower sensorimotor speed $(p=0.008)$, complex speed $(p=0.007)$, and information processing speed $(p=0.018)$ in individuals with normal C-reactive protein concentrations $(n=659)$, but not in persons with elevated 
C-reactive protein levels indicative of inflammation $(n=144)(p=0.574, p=0.777$, and $p=0.945$, respectively).

\section{Longitudinal associations between serum iron parameters and cognitive functioning}

Cognitive performance significantly declined over the 3-year follow-up period on the domains of sensorimotor speed (mean change $[95 \% \mathrm{Cl}]=-0.08[-0.11 ;-0.05], p$ $<0.001$ ), complex speed (mean change $[95 \% \mathrm{Cl}]=-0.06[-0.10 ;-0.02], p=0.004$ ), and information processing speed (mean change $[95 \% \mathrm{Cl}]=-0.11[-0.15 ;-0.08], p$ $<0.001$ ), whereas memory improved significantly (mean change $[95 \% \mathrm{Cl}]=0.39$ $[0.34 ; 0.44], p=0.000$ ) due to the effect of procedural learning. Word fluency did not significantly change over 3 years (mean change $[95 \% \mathrm{Cl}]=0.03[-0.03 ; 0.09], p=$ 0.320). Ferritin concentrations increased significantly over the 3-year follow-up period (mean change $[95 \% \mathrm{Cl}]=16.6 \mu \mathrm{g} / \mathrm{l}[6.7 ; 26.4], p=0.001$ ), whereas serum iron showed a non-significant decrease (mean change $[95 \% \mathrm{Cl}]=-0.5 \mu \mathrm{mol} / \mathrm{l}[-1.0$; 0.01 ], $p=0.055$ ). Three-year changes in serum iron and ferritin did not differ between the two experimental groups ( $p=0.268$ for serum iron and $p=0.707$ for ferritin), or between men and women ( $p=0.637$ for serum iron and $p=0.480$ for ferritin). In addition, the longitudinal changes in serum iron and ferritin did not differ significantly between blood donors and non-donors ( $p=0.965$ for serum iron and $p=0.088$ for ferritin), although blood donors showed a larger 3-year increase in ferritin than non-donors (mean change $[95 \% \mathrm{Cl}]=24.4 \mu \mathrm{g} / \mathrm{l}[8.1 ; 40.7]$ in donors and $7.1 \mu \mathrm{g} / \mathrm{l}[-2.4 ; 16.7]$ in non-donors).

Linear mixed models revealed no significant longitudinal associations between any of the iron parameters and cognitive functioning (Table 4), implying that the rate of cognitive change over 3 years did not vary according to body iron concentrations. However, stratifying our analyses by donor status indicated that higher serum iron significantly predicted less decline in sensorimotor speed over 3 years in nondonors (parameter estimate $=0.005, p=0.010$, as compared with parameter estimate $=-0.001, p=0.253$ in blood donors), and less decline in word fluency over 3 years in blood donors (parameter estimate $=0.006, p=0.012$, as compared with parameter estimate $=-0.004, p=0.165$ in non-donors), indicating effect modification by donor status. Stratification by sex or APOE E4 carrier status did not reveal any differences between men and women, or between carriers and non-carriers of the $A P O E$ E4 allele. Overall, the longitudinal associations between iron parameters and cognitive performance in the analyses stratified by sex, donor status, or APOE E4 carrier status were fairly inconsistent in terms of size and direction. 
Table 4 Longitudinal associations between iron parameters and cognitive performance over 3 years of follow-up in healthy older adults ${ }^{a}$

\begin{tabular}{|c|c|c|c|c|c|c|c|}
\hline \multirow{2}{*}{$\begin{array}{l}\text { Cognitive performance } \\
\text { index }\end{array}$} & \multirow[t]{2}{*}{$n$} & \multicolumn{6}{|c|}{ Parameter estimate for longitudinal effect } \\
\hline & & Serum iron & $p$ & Ferritin & $p$ & $\begin{array}{l}\text { Non- } \\
\text { transferrin } \\
\text { bound iron }^{\text {b }}\end{array}$ & $p$ \\
\hline Memory & 800 & 0.002 & 0.307 & -0.001 & 0.292 & 0.000 & 0.965 \\
\hline Sensorimotor speed & 799 & 0.001 & 0.396 & 0.000 & 0.806 & 0.001 & 0.925 \\
\hline Complex speed & 798 & -0.002 & 0.086 & -0.001 & 0.221 & -0.016 & 0.052 \\
\hline Information processing speed & 799 & 0.001 & 0.501 & 0.000 & 0.578 & -0.005 & 0.446 \\
\hline Word fluency & 800 & 0.002 & 0.215 & 0.000 & 0.991 & 0.018 & 0.121 \\
\hline
\end{tabular}

${ }^{a}$ Adjusted for the covariates age, sex, level of education, alcohol consumption, smoking, body mass index, physical activity, apolipoprotein E4 carrier status, serum C-reactive protein, and haemoglobin concentration in linear mixed models; ${ }^{b}$ Non-transferrin bound iron was measured at baseline only. Memory, $n=794$; sensorimotor speed, $n=793$; complex speed, $n=792$; information processing speed, $n=793 ;$ word fluency, $n=794$.

\section{Associations between the $H F E$ 282C $\rightarrow$ Y mutation and cognitive functioning}

To investigate the influence of lifelong exposure to elevated iron levels on cognitive performance in later life, we assessed the associations between the HFE $282 \mathrm{C} \rightarrow \mathrm{Y}$ mutation and cognitive functioning on each of the five domains. The HFE $282 \mathrm{C} \rightarrow \mathrm{Y}$ mutation was not associated with cognitive performance in both the cross-sectional and longitudinal analyses (Supplementary Table 2).

\section{Discussion}

In the present study, none of the serum iron parameters, nor HFE $282 \mathrm{C} \rightarrow \mathrm{Y}$ genotype, were related to cognitive performance over 3 years of follow-up. However, the results from the cross-sectional analyses suggest that in older individuals serum ferritin and serum iron may be negatively related to the speed of cognitive functioning. Whereas higher ferritin concentrations were associated with decreased cognitive functioning across the three different speed measures at baseline, serum iron appeared to be negatively related to sensorimotor speed only. Memory processes, on the other hand, did not seem to be related to ferritin, nor any other serum iron parameter. In addition, non-transferrin bound iron and the $H F E 282 \mathrm{C} \rightarrow \mathrm{Y}$ mutation were not associated with cognitive functioning in the cross-sectional analyses.

Carriers of the HFE 282C $\rightarrow$ Y mutation tend to show higher body iron concentrations than non-carriers (Njajou et al., 2003). As genetic factors cannot be influenced by cognitive functioning, investigating the associations between HFE genotype and cognitive performance has the benefit of reducing confounding and ruling out the possibility of reverse causation (Tobin et al., 2004). In the present study, we found that the HFE $282 \mathrm{C} \rightarrow \mathrm{Y}$ mutation was associated with significantly increased concen- 
trations of serum iron and non-transferrin bound iron, as well as a statistically nonsignificant increase in serum ferritin. Contrary to expectation, we did not find any associations between $H F E 282 C \rightarrow Y$ genotype and cognitive functioning. A possible explanation for the lack of such a relationship is the relatively small percentage of carriers of the HFE $282 \mathrm{C} \rightarrow \mathrm{Y}$ mutation (10.5\%), which might have reduced the probability of detecting potential associations. In addition, no data were available concerning another common polymorphism of the HFE gene, $63 \mathrm{H} \rightarrow \mathrm{D}$, which has been found to interact with the HFE 282C $\rightarrow$ Y genotype in determining individual iron levels (Gómez-Llorente et al., 2005; Njajou et al., 2003). Future studies investigating the associations between HFE genotype and cognitive functioning might increase statistical power by including both polymorphisms of the HFE gene in their analyses. Furthermore, it should be noted that the generalisability of our study was limited by the nature of the study population; the present study sample was not representative of the general population, as participants had slightly elevated plasma total homocysteine concentrations and were vitamin $\mathrm{B}_{12}$ replete.

Non-transferrin bound iron has been hypothesised to be involved in neurodegenerative disorders characterised by iron deposition in the brain (Breuer et al., 2000; Kartikasari et al., 2006). The putative relationship between non-transferrin bound iron and cognitive performance, however, has not been investigated before. The present results do not offer support for an association between non-transferrin bound iron and cognitive performance or age-related cognitive decline. Serum nontransferrin bound iron concentrations are generally very low in healthy individuals, while individuals heterozygous for the HFE 282C $\rightarrow$ Y mutation show slightly elevated non-transferrin bound iron concentrations (De Valk et al., 2000). In haemochromatosis homozygotes, non-transferrin bound iron is typically present in much larger amounts (De Valk et al., 2000). However, as the present study included only two individuals homozygous for the HFE $282 \mathrm{C} \rightarrow \mathrm{Y}$ mutation, the range of serum nontransferrin bound iron concentrations might have been too small for any associations with cognitive performance to become manifest. In addition, non-transferrin bound iron was only measured at baseline, thereby limiting the interpretation of the longitudinal analyses investigating the association of this iron parameter with cognitive functioning over 3 years.

Although elevated serum ferritin concentrations generally reflect increased body iron stores (Cook et al., 1974), serum ferritin levels also tend to be higher in conditions of inflammation, as ferritin is an acute-phase reactant (Cunietti et al., 2004; Handelman \& Levin, 2008). In the present study, we controlled for this confounding effect of inflammation by including serum C-reactive protein concentration as a covariate in the statistical models. Post-hoc analyses showed that the inverse relationship between ferritin and cognitive speed was independent of $\mathrm{C}$ reactive protein concentration, indicating that the observed cross-sectional associa- 
tion between serum ferritin and cognitive speed could not be attributed to the presence of inflammation.

The present finding that higher serum ferritin levels were related to slower sensorimotor speed in carriers, but not in non-carriers of the APOE E4 allele, suggests that APOE E4 carrier status may modify the effect of elevated body iron stores on cognitive functioning. Although $A P O E$ E4 carrier status has been implicated in age-related cognitive decline and neurodegenerative processes (Deary et al., 2002; Smith, 2002), it is unclear which mechanisms might be responsible for the putative interplay between APOE E4 carrier status and serum ferritin in affecting cognitive performance.

To date, only a few other population-based studies have investigated the relationship between iron parameters and cognitive performance in older individuals. These cross-sectional studies have yielded conflicting results. Whereas Gao and co-workers (2008) did not find any associations between serum iron and cognitive performance in a relatively small sample of 94 men and 94 women, La Rue et al. (1997) reported a positive correlation between serum transferrin and cognitive functioning, i.e. memory, visuospatial skills, and abstract reasoning, in a small sample of 67 men and 70 women. However, this association was not corrected for potential confounders, such as age, sex, BMI, and alcohol consumption.

A recent cross-sectional study performed by Lam et al. (2008) in a large population-based sample consisting of 602 men and 849 women, has shown an inverse linear association between serum iron and performance on memory tests in older women. Interestingly, in older men, Lam et al. found an inverted U-shaped relationship between serum iron and memory performance. Since we hypothesised that both low and high body iron levels would be associated with cognitive impairment, we also expected to find an inverted U-shaped relationship between body iron levels and cognitive performance. However, although the number of men in our sample ( $n=586$ ) was comparable to the number of men included in the study by Lam and colleagues, thereby yielding similar statistical power, no curvilinear associations became apparent between the iron parameters and cognitive functioning in the present study, neither in the total sample, nor after stratification by sex. The lack of curvilinear associations in our study may be due to the relatively small percentage of individuals with body iron levels below or above the normal limits. Therefore, possible non-linear associations between iron parameters and cognitive functioning may have remained undetected. Indeed, serum iron concentrations in the study by Lam et al. showed higher means and a broader range as compared with our study $(21.7 \pm 7.2 \mu \mathrm{mol} / \mathrm{l}$ in men and $19.4 \pm 6.2 \mu \mathrm{mol} / \mathrm{l}$ in women, as compared with $19.0 \pm 6.8 \mu \mathrm{mol} / \mathrm{l}$ in men and $17.1 \pm 4.8 \mu \mathrm{mol} / \mathrm{l}$ in women in our study).

It is worth noting that the prevalence of depleted iron stores in our study sample was slightly higher than that reported in other population-based studies in older individuals (i.e. $5.3 \%$ as compared with 0.3 to $3 \%$ ) (Ahmed et al., 2008; 
Fleming et al., 2001). In addition, our study showed a lower percentage of ferritin levels above the upper normal limit than other studies performed in older community-dwelling individuals, which used similar or even higher serum ferritin cut-off values (i.e. $6.5 \%$ as compared with 12 to $20 \%$ ) (Ahmed et al., 2008; Fleming et al., 2001). This may be explained by the large number of blood donors in our study sample, as regular whole blood donation has been shown to lower body iron concentrations (Milman et al., 2000). Indeed, whereas $0.8 \%$ of non-donors showed ferritin levels below the lower normal limit and $13.1 \%$ showed ferritin levels above the upper normal limit, the prevalence among blood donors was $11.3 \%$ and $0.9 \%$, respectively.

Upon stratification of the cross-sectional analyses by donor status, we found that higher serum iron was associated with decreased sensorimotor speed in nondonors, but not in blood donors. When the longitudinal analyses were stratified by donor status, we found that higher serum iron not only predicted less decline in sensorimotor speed over 3 years in non-donors, but also less decline in word fluency over 3 years in blood donors. Although these findings are not unequivocal, they do suggest that donor status may influence the nature of the associations between serum iron parameters and cognitive performance. The underlying mechanism has yet to be elucidated.

We observed a significant increase in serum ferritin concentrations over the 3year follow-up period, which is consistent with earlier reports indicating that body iron stores increase with ageing (Koziol et al., 2001). Although the difference was not statistically significant, serum ferritin showed a greater 3-year increase in donors as compared with non-donors. This difference may be related to the potential discontinuation of blood donation in regular whole blood donors during the course of the study. Unfortunately, we were not able to verify this assumption, as we did not monitor donor status during the 3-year follow-up period. Serum iron tended to decrease during the follow-up period, but this change was not statistically significant. Although the factors underlying the 3-year change in serum iron are not exactly clear, it is worth noting that they are not likely to be due to diurnal variation in serum iron levels (Dale et al., 2002), as we collected the 3-year blood samples at the same time of day as the baseline samples.

In the present study, we used serum iron parameters as a proxy measure for brain iron levels, even though the exact correlation between central and peripheral iron levels is unclear. Nonetheless, epidemiological studies have found evidence for a positive association between the two, by showing a significant correlation between iron concentrations in serum and cerebrospinal fluid in older individuals (Mizuno et al., 2005). On the other hand, it has also been suggested that brain iron levels may be relatively well isolated from peripheral iron levels, for example in carriers of the HFE $282 \mathrm{C} \rightarrow \mathrm{Y}$ mutation (Haba-Rubio et al., 2005). Thus, given the 
inability to measure cerebrospinal fluid or brain iron levels in volunteers, the use of serum iron parameters should be considered a shortcoming.

The main strengths of the present study are the use of longitudinal data, the measurement of several iron parameters as well as HFE $282 \mathrm{C} \rightarrow \mathrm{Y}$ genotype, the use of a large community-based sample, and a very low attrition rate in the longitudinal phase (2\%) (Durga et al., 2007). In addition, the cognitive test battery administered in the present study has been proven a sensitive and robust tool for detecting subtle changes in specific domains of cognitive functioning (Van der Elst et al., 2005, 2006a, 2006b, 2006c, 2006d). Furthermore, the inclusion of both men and women, as well as blood donors and non-donors in our study, enabled us to investigate the relationship between iron parameters and cognitive functioning within these individual groups. The relevance of taking into account donor status in populationbased studies is emphasised by the present finding that regular whole blood donation may modify the associations between iron parameters and cognitive performance. Indeed, the lack of documenting donor status might have confounded several other population-based studies investigating these associations, including those performed by Lam et al. (2008), Gao et al. (2008), and La Rue et al. (1997).

In conclusion, the lack of any longitudinal associations between iron parameters and cognitive performance, as well as the lack of a relationship between HFE $282 \mathrm{C} \rightarrow \mathrm{Y}$ genotype and cognitive functioning, suggests that there is no clear-cut relationship between serum iron parameters and cognitive functioning or agerelated cognitive decline in older community-dwelling individuals. However, the present study offers indications for a more intricate relationship between body iron levels and cognitive performance, which may be present only in a subsample of the community, e.g. in individuals carrying the APOE E4 allele.

To our knowledge, our study is the first to address the putative associations between the HFE 282C $\rightarrow Y$ mutation and cognitive performance in healthy older individuals, as well as the possible interactions between iron parameters and APOE E4 carrier status or donor status in relation to cognitive functioning. Prospective studies using large population-based samples are needed to further investigate the associations between iron parameters and cognitive performance, and to establish whether these associations may differ across selected groups, e.g. based on sex, donor status, APOE E4 carrier status, or other risk factors associated with cognitive decline. In addition, more research is necessary to identify the exact mechanisms by which iron parameters may influence cognitive functioning.

\section{Acknowledgements}

This work was supported by the Netherlands Organisation for Health Research and Development (grant number 200110002), Sanquin Blood Bank (grant number 02001), Wageningen University, and Top Institute Food and Nutrition. 
The authors would like to thank Dr. Berry van Tits, Department of General Internal Medicine, Radboud University Nijmegen Medical Centre, Nijmegen, the Netherlands, for the measurement of non-transferrin bound iron. 


\section{References}

Ahmed, F., Coyne, T., Dobson, A., \& McClintock, C. (2008). Iron status among Australian adults: findings of a population based study in Queensland, Australia. Asia Pac J Clin Nutr, 17(1), 40-47.

Beard, J. L., \& Connor, J. R. (2003). Iron status and neural functioning. Annu Rev Nutr, 23, 41-58.

Berlin, D., Chong, G., Chertkow, H., Bergman, H., Phillips, N. A., \& Schipper, H. M. (2004). Evaluation of HFE (hemochromatosis) mutations as genetic modifiers in sporadic AD and $\mathrm{MCl}$. Neurobiol Aging, 25(4), 465-474.

Biasiotto, G., Goldwurm, S., Finazzi, D., Tunesi, S., Zecchinelli, A., Sironi, F., Pezzoli, G., \& Arosio, P. (2008). HFE gene mutations in a population of Italian Parkinson's disease patients. Parkinsonism Relat Disord, 14(5), 426-430.

Breuer, W., \& Cabantchik, Z. I. (2001). A fluorescence-based one-step assay for serum non-transferrinbound iron. Anal Biochem, 299(2), 194-202.

Breuer, W., Hershko, C., \& Cabantchik, Z. I. (2000). The importance of non-transferrin bound iron in disorders of iron metabolism. Transfus Sci, 23(3), 185-192.

Bruner, A. B., Joffe, A., Duggan, A. K., Casella, J. F., \& Brandt, J. (1996). Randomised study of cognitive effects of iron supplementation in non-anaemic iron-deficient adolescent girls. Lancet, 348(9033), 992-996.

Brussaard, J. H., Brants, H. A., Bouman, M., \& Lowik, M. R. (1997). Iron intake and iron status among adults in the Netherlands. Eur J Clin Nutr, 51 Supp/ 3, S51-58.

Carter, C. S., Leeuwenburgh, C., Daniels, M., \& Foster, T. C. (2009). Influence of calorie restriction on measures of age-related cognitive decline: role of increased physical activity. J Gerontol A Biol Sci Med Sci, 64(8), 850-859.

Cook, J. D., Lipschitz, D. A., Miles, L. E., \& Finch, C. A. (1974). Serum ferritin as a measure of iron stores in normal subjects. Am J Clin Nutr, 27(7), 681-687.

Correia, A. P., Pinto, J. P., Dias, V., Mascarenhas, C., Almeida, S., \& Porto, G. (2009). CAT53 and HFE alleles in Alzheimer's disease: a putative protective role of the C282Y HFE mutation. Neurosci Lett, 457(3), 129-132.

Cunietti, E., Chiari, M. M., Monti, M., Engaddi, I., Berlusconi, A., Neri, M. C., \& De Luca, P. (2004). Distortion of iron status indices by acute inflammation in older hospitalized patients. Arch Gerontol Geriatr, 39(1), 35-42.

Dale, J. C., Burritt, M. F., \& Zinsmeister, A. R. (2002). Diurnal variation of serum iron, iron-binding capacity, transferrin saturation, and ferritin levels. Am J Clin Pathol, 117(5), 802-808.

De Bie, S. E. (1987). Standaardvragen 1987: Voorstellen voor uniformering van vraagstellingen naar achtergrondkenmerken en interviews [Standard questions 1987: Proposal for uniformization of questions regarding background variables and interviews] (2nd ed.). Leiden, The Netherlands: Leiden University Press.

De Kok, J. B., Wiegerinck, E. T., Giesendorf, B. A., \& Swinkels, D. W. (2002). Rapid genotyping of single nucleotide polymorphisms using novel minor groove binding DNA oligonucleotides (MGB probes). Hum Mutat, 19(5), 554-559.

De Valk, B., Addicks, M. A., Gosriwatana, I., Lu, S., Hider, R. C., \& Marx, J. J. (2000). Non-transferrin-bound iron is present in serum of hereditary haemochromatosis heterozygotes. Eur J Clin Invest, 30(3), 248251.

Deary, I. J., Whiteman, M. C., Pattie, A., Starr, J. M., Hayward, C., Wright, A. F., Carothers, A., \& Whalley, L. J. (2002). Cognitive change and the APOE $\varepsilon 4$ allele. Nature, 418(6901), 932.

Durga, J., Van Boxtel, M. P. J., Schouten, E. G., Kok, F. J., Jolles, J., Katan, M. B., \& Verhoef, P. (2007). Effect of 3-year folic acid supplementation on cognitive function in older adults in the FACIT trial: a randomised, double blind, controlled trial. Lancet, 369(9557), 208-216.

Fleming, D. J., Jacques, P. F., Tucker, K. L., Massaro, J. M., D'Agostino, R. B., Sr., Wilson, P. W., \& Wood, R. J. (2001). Iron status of the free-living, elderly Framingham Heart Study cohort: an iron-replete population with a high prevalence of elevated iron stores. Am J Clin Nutr, 73(3), 638-646. 
Gambino, R., Desvarieux, E., Orth, M., Matan, H., Ackattupathil, T., Lijoi, E., Wimmer, C., Bower, J., \& Gunter, E. (1997). The relation between chemically measured total iron-binding capacity concentrations and immunologically measured transferrin concentrations in human serum. Clin Chem, 43(12), 2408-2412.

Gao, S., Jin, Y., Unverzagt, F. W., Ma, F., Hall, K. S., Murrell, J. R., Cheng, Y., Shen, J., Ying, B., Ji, R., Matesan, J., Liang, C., \& Hendrie, H. C. (2008). Trace element levels and cognitive function in rural elderly Chinese. J Gerontol A Biol Sci Med Sci, 63(6), 635-641.

Gómez-Llorente, C., Miranda-León, M. T., Blanco, S., Gandia-Pla, S., Gómez-Capilla, J. A., \& Fárez-Vidal, M. E. (2005). Frequency and clinical expression of HFE gene mutations in a Spanish population of subjects with abnormal iron metabolism. Ann Hematol, 84(10), 650-655.

Guerreiro, R. J., Bras, J. M., Santana, I., Januario, C., Santiago, B., Morgadinho, A. S., Ribeiro, M. H., Hardy, J., Singleton, A., \& Oliveira, C. (2006). Association of HFE common mutations with Parkinson's disease, Alzheimer's disease and mild cognitive impairment in a Portuguese cohort. BMC Neurol, 6, 24.

Haba-Rubio, J., Staner, L., Petiau, C., Erb, G., Schunck, T., \& Macher, J. P. (2005). Restless legs syndrome and low brain iron levels in patients with haemochromatosis. J Neurol Neurosurg Psychiatry, 76(7), 1009-1010.

Halterman, J. S., Kaczorowski, J. M., Aligne, C. A., Auinger, P., \& Szilagyi, P. G. (2001). Iron deficiency and cognitive achievement among school-aged children and adolescents in the United States. Pediatrics, 107(6), 1381-1386.

Handelman, G. J., \& Levin, N. W. (2008). Iron and anemia in human biology: a review of mechanisms. Heart Fail Rev, 13(4), 393-404.

Hidalgo, C., \& Núñez, M. T. (2007). Calcium, iron and neuronal function. IUBMB Life, 59(4-5), 280-285.

Hider, R. C. (2002). Nature of nontransferrin-bound iron. Eur J Clin Invest, 32 Suppl 1, 50-54.

Jeffrey, G. P., Chakrabarti, S., Hegele, R. A., \& Adams, P. C. (1999). Polymorphism in intron 4 of HFE may cause overestimation of $\mathrm{C} 282 \mathrm{Y}$ homozygote prevalence in haemochromatosis. Nat Genet, 22(4), 325-326.

Kartikasari, A. E., Georgiou, N. A., Visseren, F. L., Van Kats-Renaud, H., Van Asbeck, B. S., \& Marx, J. J. (2006). Endothelial activation and induction of monocyte adhesion by nontransferrin-bound iron present in human sera. FASEB J, 20(2), 353-355.

Killip, S., Bennett, J. M., \& Chambers, M. D. (2007). Iron deficiency anemia. Am Fam Physician, 75(5), 671678.

Koziol, J. A., Ho, N. J., Felitti, V. J., \& Beutler, E. (2001). Reference centiles for serum ferritin and percentage of transferrin saturation, with application to mutations of the HFE gene. Clin Chem, 47(10), 1804-1810.

La Rue, A., Koehler, K. M., Wayne, S. J., Chiulli, S. J., Haaland, K. Y., \& Garry, P. J. (1997). Nutritional status and cognitive functioning in a normally aging sample: a 6-y reassessment. Am J Clin Nutr, 65(1), 2029.

Lahti-Koski, M., Valsta, L. M., Alfthan, G., Tapanainen, H., \& Aro, A. (2003). Iron status of adults in the capital area of Finland. Eur J Nutr, 42(5), 287-292.

Lam, P. K., Kritz-Silverstein, D., Barrett Connor, E., Milne, D., Nielsen, F., Gamst, A., Morton, D., \& Wingard, D. (2008). Plasma trace elements and cognitive function in older men and women: the Rancho Bernardo study. J Nutr Health Aging, 12(1), 22-27.

Lehmann, D. J., Worwood, M., Ellis, R., Wimhurst, V. L., Merryweather-Clarke, A. T., Warden, D. R., Smith, A. D., \& Robson, K. J. (2006). Iron genes, iron load and risk of Alzheimer's disease. J Med Genet, 43(10), e52.

Lozoff, B., Jimenez, E., Hagen, J., Mollen, E., \& Wolf, A. W. (2000). Poorer behavioral and developmental outcome more than 10 years after treatment for iron deficiency in infancy. Pediatrics, 105(4), E51.

Lynas, C. (1997). A cheaper and more rapid polymerase chain reaction-restriction fragment length polymorphism method for the detection of the HLA-H gene mutations occurring in hereditary hemochromatosis. Blood, 90(10), 4235-4236. 
Marshall, T. A., Stumbo, P. J., Warren, J. J., \& Xie, X. J. (2001). Inadequate nutrient intakes are common and are associated with low diet variety in rural, community-dwelling elderly. J Nutr, 131(8), 21922196.

McCann, J. C., \& Ames, B. N. (2007). An overview of evidence for a causal relation between iron deficiency during development and deficits in cognitive or behavioral function. Am J Clin Nutr, 85(4), 931-945.

Milman, N., Byg, K. E., \& Ovesen, L. (2000). Iron status in Danes 1994. II: Prevalence of iron deficiency and iron overload in 1319 Danish women aged 40-70 years. Influence of blood donation, alcohol intake and iron supplementation. Ann Hematol, 79(11), 612-621.

Mitsopoulos, E., Zanos, S., Ginikopoulou, E., Tsiatsiou, M., Giannakou, A., Pavlitou, A., \& Sakellariou, G. (2006). Do serum and red blood cell folate levels indicate iron response in hemodialysis patients? Asaio J, 52(2), 163-168.

Mizuno, S., Mihara, T., Miyaoka, T., Inagaki, T., \& Horiguchi, J. (2005). CSF iron, ferritin and transferrin levels in restless legs syndrome. J Sleep Res, 14(1), 43-47.

Murray, R. K., Granner, D. K., Mayes, P. A., \& Rodwell, V. W. (1996). Harper's Biochemistry (24th ed.). Stamford, CT: Appleton \& Lange.

Murray-Kolb, L. E., \& Beard, J. L. (2007). Iron treatment normalizes cognitive functioning in young women. Am J Clin Nutr, 85(3), 778-787.

Njajou, O. T., Houwing-Duistermaat, J. J., Osborne, R. H., Vaessen, N., Vergeer, J., Heeringa, J., Pols, H. A., Hofman, A., \& Van Duijn, C. M. (2003). A population-based study of the effect of the HFE C282Y and H63D mutations on iron metabolism. Eur J Hum Genet, 11(3), 225-231.

Petursdottir, A. L., Farr, S. A., Morley, J. E., Banks, W. A., \& Skuladottir, G. V. (2008). Effect of dietary n-3 polyunsaturated fatty acids on brain lipid fatty acid composition, learning ability, and memory of senescence-accelerated mouse. J Gerontol A Biol Sci Med Sci, 63(11), 1153-1160.

Pulliam, J. F., Jennings, C. D., Kryscio, R. J., Davis, D. G., Wilson, D., Montine, T. J., Schmitt, F. A., \& Markesbery, W. R. (2003). Association of HFE mutations with neurodegeneration and oxidative stress in Alzheimer's disease and correlation with APOE. Am J Med Genet B Neuropsychiatr Genet, $119 B(1), 48-53$.

Ridker, P. M. (2003). Clinical application of C-reactive protein for cardiovascular disease detection and prevention. Circulation, 107(3), 363-369.

Robson, K. J., Lehmann, D. J., Wimhurst, V. L., Livesey, K. J., Combrinck, M., Merryweather-Clarke, A. T., Warden, D. R., \& Smith, A. D. (2004). Synergy between the C2 allele of transferrin and the C282Y allele of the haemochromatosis gene (HFE) as risk factors for developing Alzheimer's disease. J Med Genet, 41(4), 261-265.

Sandstead, H. H. (2000). Causes of iron and zinc deficiencies and their effects on brain. J Nutr, 130(2S Suppl), 347S-349S.

Schmechel, D. E., Browndyke, J., \& Ghio, A. (2006). Strategies for dissecting genetic-environmental interactions in neurodegenerative disorders. Neurotoxicology, 27(5), 637-657.

Shah, R. C., Wilson, R. S., Tang, Y., Dong, X., Murray, A., \& Bennett, D. A. (2009). Relation of hemoglobin to level of cognitive function in older persons. Neuroepidemiology, 32(1), 40-46.

Smith, J. D. (2002). Apolipoproteins and aging: emerging mechanisms. Ageing Res Rev, 1(3), 345-365.

Stephan, B. C., Wells, J. C., Brayne, C., Albanese, E., \& Siervo, M. (2010). Increased fructose intake as a risk factor for dementia. J Gerontol A Biol Sci Med Sci, 65(8), 809-814.

Thompson, K. J., Shoham, S., \& Connor, J. R. (2001). Iron and neurodegenerative disorders. Brain Res Bull, 55(2), 155-164.

Tobin, M. D., Minelli, C., Burton, P. R., \& Thompson, J. R. (2004). Commentary: development of Mendelian randomization: from hypothesis test to 'Mendelian deconfounding'. Int J Epidemiol, 33(1), 26-29.

Van der Elst, W., Van Boxtel, M. P. J., Van Breukelen, G. J. P., \& Jolles, J. (2005). Rey's verbal learning test: normative data for 1855 healthy participants aged 24-81 years and the influence of age, sex, education, and mode of presentation. J Int Neuropsychol Soc, 11(3), 290-302. 
Van der Elst, W., Van Boxtel, M. P. J., Van Breukelen, G. J. P., \& Jolles, J. (2006a). Normative data for the Animal, Profession and Letter $M$ Naming verbal fluency tests for Dutch speaking participants and the effects of age, education, and sex. J Int Neuropsychol Soc, 12(1), 80-90.

Van der Elst, W., Van Boxtel, M. P. J., Van Breukelen, G. J. P., \& Jolles, J. (2006b). The Concept Shifting Test: adult normative data. Psychol Assess, 18(4), 424-432.

Van der Elst, W., Van Boxtel, M. P. J., Van Breukelen, G. J. P., \& Jolles, J. (2006c). The Letter Digit Substitution Test: normative data for 1,858 healthy participants aged 24-81 from the Maastricht Aging Study (MAAS): influence of age, education, and sex. J Clin Exp Neuropsychol, 28(6), 998-1009.

Van der Elst, W., Van Boxtel, M. P. J., Van Breukelen, G. J. P., \& Jolles, J. (2006d). The Stroop Color-Word test: influence of age, sex, and education; and normative data for a large sample across the adult age range. Assessment, 13(1), 62-79.

Verbeke, G., \& Molenberghs, G. (2000). Linear Mixed Models for Longitudinal Data. New York: Springer.

Vernet, M., \& Le Gall, J. Y. (1998). Transferrin saturation and screening of genetic hemochromatosis. Clin Chem, 44(2), 360-362.

Washburn, R. A., Smith, K. W., Jette, A. M., \& Janney, C. A. (1993). The Physical Activity Scale for the Elderly (PASE): development and evaluation. J Clin Epidemiol, 46(2), 153-162.

Weiss, G. (2009). Iron metabolism in the anemia of chronic disease. Biochim Biophys Acta, 1790(7), 682693.

Wrede, C. E., Hutzler, S., Bollheimer, L. C., Buettner, R., Hellerbrand, C., Schoelmerich, J., \& Palitzsch, K. D. (2004). Correlation between iron status and genetic hemochromatosis (codon C282Y) in a large German population. Isr Med Assoc J, 6(1), 30-33.

Youdim, M. B. (2008). Brain iron deficiency and excess; cognitive impairment and neurodegeneration with involvement of striatum and hippocampus. Neurotox Res, 14(1), 45-56. 
Supplementary Table 1 Interaction between iron parameters and folic acid treatment in relation to cognitive performance over 3 years of follow-up in healthy older adults ${ }^{a}$

\begin{tabular}{|c|c|c|c|c|c|c|c|}
\hline \multirow{2}{*}{$\begin{array}{l}\text { Cognitive performance } \\
\text { index }\end{array}$} & \multirow[t]{2}{*}{$n$} & \multicolumn{6}{|c|}{ Parameter estimate for longitudinal interaction effect } \\
\hline & & Serum iron & $p$ & Ferritin & $p$ & $\begin{array}{l}\text { Non- } \\
\text { transferrin } \\
\text { bound iron }\end{array}$ & $p$ \\
\hline Memory & 800 & 0.001 & 0.702 & 0.001 & 0.280 & 0.000 & 0.984 \\
\hline Sensorimotor speed & 799 & 0.001 & 0.662 & 0.000 & 0.492 & -0.003 & 0.831 \\
\hline Complex speed & 798 & 0.002 & 0.388 & 0.002 & 0.082 & 0.005 & 0.735 \\
\hline Information processing speed & 799 & -0.001 & 0.557 & 0.001 & 0.256 & -0.013 & 0.333 \\
\hline Word fluency & 800 & -0.006 & 0.117 & 0.000 & 0.919 & -0.004 & 0.849 \\
\hline
\end{tabular}

adjusted for the covariates age, sex, level of education, alcohol consumption, smoking, body mass index, physical activity, apolipoprotein E4 carrier status, serum C-reactive protein, and haemoglobin concentration in linear mixed models; ${ }^{b}$ Non-transferrin bound iron was measured at baseline only. Memory, $n=794$; sensorimotor speed, $n=793$; complex speed, $n=792$; information processing speed, $n$ = 793; word fluency, $n=794$.

Supplementary Table 2 Cross-sectional and longitudinal (3-year) associations between the HFE 282C $\rightarrow$ Y mutation and cognitive performance in healthy older adults ${ }^{*}$

\begin{tabular}{|c|c|c|c|c|c|}
\hline \multirow{2}{*}{$\begin{array}{l}\text { Cognitive performance } \\
\text { index }\end{array}$} & \multirow[t]{2}{*}{$n$} & \multicolumn{2}{|c|}{ Cross-sectional analyses } & \multicolumn{2}{|c|}{ Longitudinal analyses } \\
\hline & & $\begin{array}{l}\text { Standardised regression } \\
\text { coefficient }(\beta)\end{array}$ & $p$ & $\begin{array}{l}\text { Parameter estimate } \\
\text { for longitudinal effect }\end{array}$ & $p$ \\
\hline Memory & 753 & -0.033 & 0.332 & -0.005 & 0.845 \\
\hline Sensorimotor speed & 748 & -0.003 & 0.930 & -0.024 & 0.183 \\
\hline Complex speed & 748 & 0.029 & 0.389 & -0.022 & 0.343 \\
\hline Information processing speed & 750 & -0.010 & 0.772 & -0.009 & 0.659 \\
\hline Word fluency & 753 & -0.003 & 0.943 & -0.031 & 0.376 \\
\hline \multicolumn{6}{|c|}{$\begin{array}{l}\text { Displayed are the standardised regression coefficients }(\beta) \text { for the cross-sectional effect of the } H F E \\
282 \mathrm{C} \rightarrow \mathrm{Y} \text { mutation }(1=282 \mathrm{C} \rightarrow \mathrm{Y} \text { homozygous or heterozygous, } 0=\text { wildtype) in hierarchical linear } \\
\text { regression analyses and the parameter estimates for the longitudinal effect of the HFE } 282 \mathrm{C} \rightarrow \mathrm{Y} \text { mutation } \\
\text { in linear mixed models. Cross-sectional and longitudinal associations were adjusted for the covariates }\end{array}$} \\
\hline
\end{tabular}



CHAPTER 6

\section{Genetic variation in folate metabolism is not associated with cognitive functioning or mood in healthy adults}

Olga J.G. Schiepers, Martin P.J. van Boxtel, Renate H.M. de Groot, Jelle Jolles, Otto Bekers, Frans J. Kok, Petra Verhoef, Jane Durga

Revised version published in Prog Neuropsychopharmacol Biol Psychiatry (2011), 35: 1682-1688 


\begin{abstract}
Low folate concentrations have been implicated in various age-related disorders, including cognitive impairment and Alzheimer's disease. The present study examined the associations between genetic variation in folate metabolism on the one hand and cognitive functioning and mood on the other in healthy individuals. Two independent population-based samples were used, including 777 participants, aged 24 to 82 years, of the Maastricht Aging Study (MAAS); and 818 participants, aged 50 to 70 years, of the Folic Acid and Carotid Intima-Media Thickness (FACIT) study. Thymidylate synthase (TS) $2 \mathrm{R} \rightarrow 3 \mathrm{R}$ and serine hydroxymethyltransferase (SHMT1) $1420 \mathrm{C} \rightarrow \mathrm{T}$ polymorphisms were determined in both populations. In addition, the 5,10-methylenetetrahydrofolate reductase (MTHFR) $677 \mathrm{C} \rightarrow T$ polymorphism was determined in the MAAS population. Cognitive performance was assessed using a neuropsychological test battery in both populations. In the MAAS population only, cognitive performance was retested after 12 years of follow-up $(n=612)$, and mood was measured at baseline $(n=772)$ and 12 -year follow-up $(n=565)$ by means of the depression subscale of the Symptom Checklist 90. We found that in both study populations, cognitive performance was not associated with $T S 2 R \rightarrow 3 R$ or SHMT1 $1420 \mathrm{C} \rightarrow \mathrm{T}$ polymorphisms at baseline, after correction for age, sex, and level of education. The MTHFR $677 C \rightarrow$ T polymorphism was not associated with cognitive performance in the MAAS population. None of the polymorphisms in the MAAS population were related to mood at baseline or over 12 years. In conclusion, genetic variation in folate metabolism was not associated with cognitive performance or mood in healthy individuals.
\end{abstract}




\section{Introduction}

Low folate concentrations have been implicated in various age-related disorders, including cognitive impairment and Alzheimer's disease (Duthie et al., 2002; Mattson \& Shea, 2003; Tucker et al., 2005). In addition, low folate levels have been related to depressive symptoms, which are highly prevalent in the ageing population (Tiemeier et al., 2002).

There are two main mechanisms by which a low folate status may have a negative impact on cognitive functioning and mood. First, low folate levels impair the conversion of homocysteine into methionine, which increases homocysteine concentrations. Elevated homocysteine levels may serve as a risk factor for cognitive decline by exerting neurotoxic effects, or by promoting vascular disease (Mattson \& Shea, 2003). Second, the impaired conversion of homocysteine into methionine may contribute to cognitive impairment or neurodegeneration by reducing the availability of methyl donors for methylation processes that play an essential role in neurotransmitter and phospholipid metabolism, stabilisation of myelin, and regulation of gene expression (Fuso et al., 2005; Tchantchou et al., 2006).

Elevated homocysteine levels and reduced methylation capacity may not only result from low dietary folate intake, but may also be due to genetic variation in folate metabolism (Frosst et al., 1995; Heil et al., 2001). For example, the common $677 \mathrm{C} \rightarrow \mathrm{T}$ mutation of the gene encoding 5,10-methylenetetrahydrofolate reductase (MTHFR), which is associated with reduced enzyme activity, may lead to elevated homocysteine concentrations (Frosst et al., 1995) and decreased methylation capacity (Castro et al., 2004). This polymorphism has been implicated in age-related cognitive decline and depressed mood, although results from population-based studies have yielded conflicting results. A number of studies have not found any relationship between the MTHFR $677 \mathrm{C} \rightarrow \mathrm{T}$ polymorphism and cognitive performance (Almeida et al., 2005; Bathum et al., 2007; De Lau et al., 2010; Gussekloo et al., 1999; Visscher et al., 2003) or depressive symptoms (Almeida et al., 2005; Gaysina et al., 2008). Several other studies have reported that the MTHFR 677TT genotype was predictive of decreased cognitive functioning (Elkins et al., 2007), greater agerelated cognitive decline (Elkins et al., 2007), clinically diagnosed depression (Hickie et al., 2001; Kelly et al., 2004), or depressive symptoms as observed in the general population (Bjelland et al., 2003).

In a randomised controlled trial, we found that 3-year supplementation with folic acid improved cognitive functioning in healthy older adults (Durga et al., 2007). In the same study population, individuals carrying the MTHFR 677TT genotype showed better cognitive performance than CC homozygotes or CT heterozygotes, despite significantly higher homocysteine levels (Durga et al., 2006). We speculated that the observed association between the MTHFR $677 \mathrm{C} \rightarrow$ T mutation and cognitive 
performance might be exerted through a homocysteine-independent mechanism (Durga et al., 2006). By causing a shift in the distribution of folate derivatives from methylated folates to formylated folates (Bagley \& Selhub, 1998), the MTHFR $677 C \rightarrow T$ polymorphism may not only lower methylation capacity, but may also favour DNA synthesis and repair, as these processes depend on non-methylated folates (Skibola et al., 2002) (Figure 1).

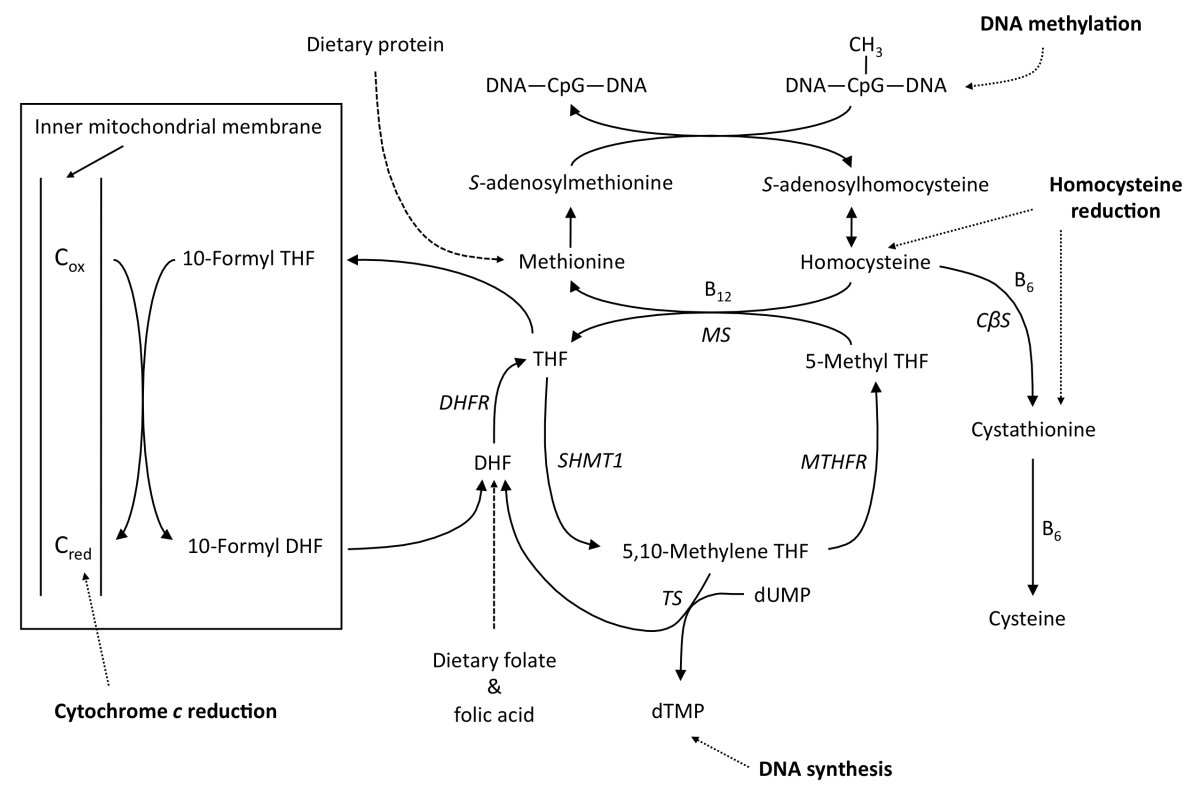

Figure 1 Overview of the human folate metabolic pathway. The MTHFR 677C $\rightarrow$ T polymorphism, involving a $C$ to $T$ substitution at the 677 base of the gene encoding MTHFR, is associated with reduced enzyme activity. Individuals with the MTHFR 677TT genotype have elevated homocysteine levels, a lower capacity of methyl transfer, and increased availability of 5,10-methylenetetrahydrofolate for TS, thereby preventing dUMP accumulation, which has been related to increased uracil misincorporation in DNA. The presence of a triple (3R3R) versus double tandem repeat (2R2R) in the regulatory region of the TS gene is associated with increased enzyme activity, thereby enhancing DNA synthesis and repair. The SHMT1 $1420 \mathrm{C} \rightarrow$ T polymorphism has been linked to reduced availability of methyl derivates for DNA synthesis and remethylation of homocysteine. Note: $C \beta S$, cystathionine $\beta$-synthase; $C_{o x}$, oxidised cytochrome $c$; $C_{\text {red }}$, reduced cytochrome $c$; DHF, dihydrofolate; DHFR, dihydrofolate reductase; DNACPG_DNA, DNA cytosine guanine dinucleotide sequence; dUMP, deoxyuridylate; dTMP, thymidylate; MS, methionine synthase; MTHFR, 5,10-methylenetetrahydrofolate reductase; SHMT1, serine hydroxymethyltransferase; THF, tetrahydrofolate; TS, thymidylate synthase.

Evidence for a clinical effect of the MTHFR $677 C \rightarrow$ T polymorphism has been provided by epidemiological studies reporting a decreased risk of colon cancer in TT homozygotes (Férnandez-Peralta et al., 2010; Taioli et al., 2009). It has been suggested that such a protective effect of the TT genotype on carcinogenesis may be related to increased DNA synthesis and repair (Blount et al., 1997). 
DNA synthesis and fidelity may also be influenced by mutations in the gene encoding the enzyme thymidylate synthase (TS), which plays a critical role in preventing chromosomal damage by lowering the incorporation of the abnormal nucleotide uracil in DNA (Horie et al., 1995). The presence of a triple versus double tandem repeat sequence in the regulatory region of the TS gene enhances its expression, thereby increasing DNA synthesis and repair (Horie et al., 1995). In addition, the $1420 \mathrm{C} \rightarrow$ T polymorphism of the serine hydroxymethyltransferase (SHMT1) gene has been associated with reduced folate and increased homocysteine levels in CC homozygotes (Heil et al., 2001). It has been suggested that impaired SHMT activity may result in a lower availability of folate derivatives for DNA synthesis and the remethylation of homocysteine (Hishida et al., 2003). Similar to the MTHFR 677TT genotype, both TS 3R and SHMT1 1420T variants have been associated with a reduced cancer risk (Hishida et al., 2003; Skibola et al., 2002).

On the functional level, the MTHFR $677 C \rightarrow T, T S 2 R \rightarrow 3 R$, and SHMT1 1420C $\rightarrow T$ polymorphisms may be hypothesised to affect cognitive functioning and depressive symptoms by influencing the fate of methyl donors. However, the associations between the TS and SHMT1 polymorphisms and cognitive functioning or mood have not yet been investigated. Therefore, the aim of the present study was to examine the associations between the MTHFR $677 \mathrm{C} \rightarrow \mathrm{T}, \mathrm{TS} 2 \mathrm{R} \rightarrow 3 \mathrm{R}$, and SHMT1 1420C $\rightarrow \mathrm{T}$ polymorphisms on the one hand and cognitive functioning and mood on the other in healthy individuals.

\section{Methods}

\section{Participants}

The present study was carried out using data from two studies, the populationbased Maastricht Aging Study (MAAS) and the Folic Acid and Carotid Intima-Media Thickness (FACIT) study.

MAAS is a longitudinal research program investigating the determinants and consequences of cognitive ageing (Jolles et al., 1995). Participants were randomly drawn from a register of family practices. Medically verified exclusion criteria at baseline were chronic neurological pathology, psychiatric disorders, mental retardation, and psychotropic drug use. The study population consisted of 1,823 participants, aged 24 to 81 years at baseline, and comprised four demographically identical panels, each stratified for age, sex, and level of occupational achievement. A detailed description of the MAAS study design can be found elsewhere (Jolles et al., 1995; Van Boxtel et al., 1998). Between 1993 and 1995 (baseline), all participants completed a general health and lifestyle questionnaire and underwent an extensive medical and neuropsychological examination. Participation in the blood sampling 
procedure was voluntary; venous blood samples for genotyping were collected for 779 individuals. Twelve years after the baseline assessments, the participants were invited to take part in the follow-up examinations. During follow-up, 167 participants had dropped out due to various reasons, including death, illness, and refusal to participate. Demographic, neuropsychological, and genetic information was available for 777 individuals at baseline and 612 individuals at 12-year follow-up.

The FACIT study is a randomised, double-blind, placebo-controlled trial, originally designed to investigate the effects of 3-year folic acid supplementation on the risk of cardiovascular disease as measured by carotid intima-media thickness (Durga et al., 2007). The study population consisted of 818 men and women. Participants were recruited from blood bank registries as well as from municipal registries. At screening, individuals were included if between the ages of 50 and 70 years, and, specifically for women, had reached the menopause at least 2 years before. Exclusion criteria were plasma total homocysteine concentrations $<13 \mu \mathrm{mol} / \mathrm{l}$ or $>26$ umol/l, use of B-vitamin supplements or drugs that could affect atherosclerotic progression (e.g. lipid-lowering or hormone replacement therapies), or selfreported intestinal disease. Individuals with elevated homocysteine concentrations due to factors other than suboptimal folate concentrations, including serum vitamin $B_{12}$ concentrations $<200 \mathrm{pmol} / \mathrm{l}$, self-reported medical diagnosis of renal or thyroid disorders, or self-reported use of medications that influence folate metabolism, were also excluded. Venous blood samples were collected for genotyping at baseline. Cognitive functioning was assessed at baseline and after 3 years by means of a neuropsychological test battery.

The MAAS study was approved by the Medical Ethics Committee of the Maastricht University Medical Centre, and the FACIT study by the Medical Ethics Committee of Wageningen University. Prior to enrolment all participants signed an informed consent.

\section{Cognitive functioning}

Cognitive functioning was assessed by means of a neuropsychological test battery, consisting of five cognitive tests. The Visual Verbal Word Learning Task (WLT) was used to assess learning capacity, as well as recall and retrieval from long-term memory (Van der Elst et al., 2005). In three trials, fifteen commonly used monosyllabic words were visually presented in a fixed order at 2-s intervals. Maximum and total immediate recall (WLTmax and WLTtot, respectively), as well as delayed recall after $20 \mathrm{~min}$ (WLTdr), were recorded.

The Stroop Color-Word Interference Test was used to test selective attention and interference susceptibility (Van der Elst et al., 2006d). Three subtasks were presented on separate test sheets containing four rows of ten columns of colour names or coloured patches. Participants were required to read aloud colour names 
printed in black (subtask I), name the colour of coloured patches (subtask II), and name the ink colour of colour names printed in an incongruous colour (subtask III). The outcome parameters were speed on subtask I (Str1) and subtask III (Str3).

The Concept Shifting Test (CST) is a test of behavioural planning and cognitive flexibility (Van der Elst et al., 2006b). Participants were asked to cross out sixteen items presented in small circles on a test sheet as fast as possible in the right order (1-2-3-4 [subtask A], A-B-C-D [subtask B], 1-A-2-B [subtask C]). In a final subtask (subtask $O$ ), individuals were instructed to cross out empty circles as fast as possible, in order to measure general motor speed. The outcome parameters were speed on subtask A (CSTa), subtask B (CSTb), subtask C (CSTc), and subtask O (CSTO).

The Letter-Digit Substitution Test (LDST) was used to measure information processing speed and efficiency of operations in working memory (Van der Elst et al., 2006c). Participants were asked to replace letters presented on a test sheet by their corresponding digits, as indicated by a key showing nine numbers paired with different letters. The total number of correct substitutions completed within $90 \mathrm{~s}$ was recorded.

The Verbal Fluency Test measures the ability to recollect clusters of related words from encyclopedic memory (Van der Elst et al., 2006a). Participants were instructed to name as many animals as possible in $60 \mathrm{~s}$. The outcome measure was the total number of different animals named.

\section{Data reduction}

In order to limit the number of dependent variables and to improve the robustness of the underlying cognitive construct, the raw test scores of the WLT, the Stroop Color-Word Interference Test, and the CST were clustered into three a-priori defined composite performance indices (Lezak et al., 2004). The raw test scores were transformed into $Z$-scores by subtracting the mean score from the individual test score and dividing this by the mean SD $(Z=(x-$ mean $) / S D)$. For the cross-sectional analyses, the means and SD's of the baseline test scores were used to calculate the $Z$-scores per test. For the longitudinal analyses in the MAAS population, the grand means and SD's of the pooled measurements (i.e. baseline and 12-year follow-up) were used to calculate the Z-scores for both time points, thereby creating test scores referring to the same Z-distribution, which enabled the inclusion of both baseline and follow-up scores in one statistical model. The Z-scores were averaged, resulting in the following composite scores: memory ([ZWLTmax + ZWLTtot + ZWLTdr]/3), sensorimotor speed ([ZStr1 + ZCSTa + ZCSTb + ZCST0]/4), and complex speed $([Z \mathrm{Str} 3+Z \mathrm{CST}] / 2)$. The signs of the two speed scores were inverted in order to reflect above normal performance when positive, and below normal when negative. Cognitive performance on the domains of information processing speed and word fluency was represented by the Z-score of the LDST test and the Z-score of the Verbal Fluency Test, respectively. 


\section{Mood}

In the MAAS population, mood was assessed at baseline and after 12 years of follow-up by means of the Dutch version of the depression subscale of the Symptom Checklist 90 (SCLdep) (Arrindell \& Ettema, 1986). Sum scores range from 16 to 80, with higher scores representing higher levels of depressed mood. In total, 772 individuals completed the SCLdep at baseline, as well as 565 individuals at 12-year follow-up.

\section{Genotyping}

Genomic DNA was isolated from EDTA blood samples using an MN blood kit (Bioké, Leiden, The Netherlands). MTHFR $677 \mathrm{C} \rightarrow \mathrm{T}$ genotype was determined by polymerase chain reaction (PCR) with restriction fragment length polymorphism analysis with Hinfl (Frosst et al., 1995). TS genotype was determined by PCR, followed by gel electrophoresis to show the presence of double (2R2R) or triple (3R3R) tandem repeats in the promoter region (Horie et al., 1995). SHMT1 1420C $\rightarrow$ T genotype was determined using fluorogenic probes in real-time PCR assay (Skibola et al., 2002). Apolipoprotein $\mathrm{E}(A P O E)$ genotype was determined by PCR followed by restriction digestion with Hhal (Bekers et al., 2002).

\section{Blood measurements}

In the FACIT population, fasting venous blood samples were collected at baseline, directly processed, and stored at $-80^{\circ} \mathrm{C}$. Serum folate was measured using a chemiluminescent immunoassay (Immulite 2000, Diagnostic Products Corporation, Los Angeles, CA, USA). Erythrocyte folate was determined in duplicate and the average was taken to reduce measurement error. Erythrocyte folate concentrations were calculated by means of the following formula: (unadjusted erythrocyte folate/hematocrit) - ([1 - hematocrit]/hematocrit) $\times$ serum folate. Plasma total homocysteine was determined by high-performance liquid chromatography and fluorimetric detection, as described previously (Ubbink et al., 1991).

\section{Education}

Level of education was measured by classifying formal schooling according to the Dutch educational system (De Bie, 1987), and categorised into 'low', 'middle', or 'high', i.e. corresponding to primary education, junior vocational training, and senior vocational or academic training, respectively. 


\section{Statistical analysis}

Normal P-P plots indicated skewness of SCLdep scores, which was corrected by logtransformation. Baseline data were used to assess the cross-sectional associations between the three genotypes and cognitive functioning or mood in both study populations. It should be noted that the cross-sectional relationship between MTHFR genotype and cognitive performance was not analysed in the FACIT population, as these associations had been reported elsewhere (Durga et al., 2006).

Univariate ANCOVA were performed for each polymorphism in relation to each of the five cognitive performance indices, as well as mood. The analyses were corrected for age, sex, and level of education in order to reduce residual variance in the outcome measures, thereby increasing statistical power. The cross-sectional analyses with MTHFR genotype as the independent variable in the MAAS population were repeated in a subsample of individuals aged 50 to 70 years ( $n=285$ ), in order to compare the results of the MAAS population with the results previously obtained in the FACIT study (Durga et al., 2006).

Longitudinal analyses were restricted to the MAAS population, as the follow-up of the FACIT study involved 3-year supplementation with folic acid, which may influence both the phenotypic expression of the polymorphisms studied (Girelli et al., 1998) and cognitive performance (Durga et al., 2007). Power calculations showed that including only the placebo group $(n=413)$ in the longitudinal analyses would not yield sufficient statistical power. Repeated-measures ANCOVA with time as within-subjects variable and genotype as between-subjects variable were used to investigate the longitudinal associations between each of the three genotypes and cognitive performance over 12 years of follow-up, which were represented by the time $\times$ genotype interaction. The analyses were adjusted for age, age ${ }^{2}$ (to control for non-linear effects of age), sex, and level of education. Similar analyses were performed with mood as the dependent variable.

In secondary analyses, we stratified both study populations by APOE E4 carrier status (defined as E4+ or E4-, depending on the presence of at least one E4 allele) to determine whether the cross-sectional and longitudinal associations between the genotypes and cognitive functioning differed between carriers and non-carriers of the $A P O E$ E4 allele, as $A P O E$ E4 carrier status may interact with a low folate status or high homocysteine levels in increasing individual susceptibility to cognitive impairment (Shea et al., 2004). In addition, the FACIT sample was stratified by folate status (low-normal, erythrocyte folate $<501 \mathrm{nmol} /$; ; high-normal, erythrocyte folate $\geq 501$ $\mathrm{nmol} / \mathrm{l}$ ) (Durga et al., 2006), as folate concentrations may influence phenotypic expression of the genotypes studied (Girelli et al., 1998). The MAAS sample was not stratified by folate status, as information on folate concentrations was not available.

Homogeneity of error variances was ascertained by means of Levene's test for equality of error variances. Hardy-Weinberg equilibrium was assessed using Chisquare tests. The statistical power of the cross-sectional and longitudinal analyses 
to detect small effects in both populations was high, i.e. $>0.90$. Statistical differences were considered significant at $p$-values $<0.05$. All analyses were performed using SPSS 16.0 (SPSS Inc., Chicago, IL, USA).

\section{Results}

Table 1 summarises the baseline characteristics of the participants in both study populations. The MTHFR, TS, and SHMT1 allele frequencies were in Hardy-Weinberg equilibrium and were comparable to the frequencies reported in other healthy populations (Elkins et al., 2007; Skibola et al., 2002; Visscher et al., 2003). In the FACIT population, univariate ANOVA indicated that baseline total homocysteine concentrations did not significantly differ according to $T S$ genotype (mean $\pm \mathrm{SD}=$ $13.4 \pm 2.9 \mu \mathrm{mol} / \mathrm{I}$ in 2R2R homozygotes, $13.2 \pm 2.8 \mu \mathrm{mol} / \mathrm{I}$ in 2R3R heterozygotes, and $13.4 \pm 2.7 \mu \mathrm{mol} / \mathrm{I}$ in 3R3R homozygotes; $p=0.707$ ) or SHMT1 genotype (mean \pm $\mathrm{SD}=13.2 \pm 2.7 \mu \mathrm{mol} / \mathrm{l}$ in CC homozygotes, $13.5 \pm 3.1 \mu \mathrm{mol} / \mathrm{l}$ in CT heterozygotes, and $13.4 \pm 2.8 \mu \mathrm{mol} / \mathrm{l}$ in TT homozygotes; $p=0.409$ ).

Table 1 Participant characteristics at baseline

\begin{tabular}{|c|c|c|}
\hline & MAAS population & FACIT population \\
\hline$n$ & 777 & 818 \\
\hline Age (years) & $50.4 \pm 14.7$ & $60.3 \pm 5.6$ \\
\hline Female sex (\%) & 53.0 & 28.4 \\
\hline Level of education, low / middle / high (\%) & 8.2 / $63.7 / 28.1$ & $22.4 / 38.1 / 39.5$ \\
\hline APOE E4 alleles, 0 / 1 / $2(\%)^{\mathrm{a}}$ & $72.2 / 25.7 / 2.1$ & 67.9 / 29.2 / 2.8 \\
\hline MTHFR 677C $\rightarrow$ T genotype, CC / CT / TT (\%) & $41.5 / 47.0 / 11.5$ & 38.2 / 46.4 / 15.4 \\
\hline$T S 2 R \rightarrow 3 R$ genotype, $2 R 2 R / 2 R 3 R / 3 R 3 R(\%)^{c}$ & $20.6 / 51.6 / 27.8$ & $22.3 / 47.5 / 30.2$ \\
\hline SHMT1 1420C $\rightarrow$ T genotype, CC / CT / TT (\%) ${ }^{d}$ & $49.8 / 40.4$ / 9.8 & $48.1 / 41.9 / 10.0$ \\
\hline
\end{tabular}

Note: Values are means \pm SD. APOE, apolipoprotein E; MTHFR, 5,10-methylenetetrahydrofolate reductase; TS, thymidylate synthase; SHMT1, serine hydroxymethyltransferase; ${ }^{a} n=814$ in the FACIT population; ${ }^{b} n=775$ in the MAAS population and $n=814$ in the FACIT population; ${ }^{c} n=771$ in the MAAS population and $n=815$ in the FACIT population; ${ }^{d} n=773$ in the MAAS population and $n=813$ in the FACIT population.

At baseline, none of the genetic polymorphisms were associated with cognitive performance on any of the domains measured in the MAAS population (Table 2) or the FACIT population (Table 3). In addition, the different genotypes did not show any relationship with mood in the MAAS population (Table 2). Repeating the analyses on MTHFR in a subsample of MAAS participants aged 50 to 70 years, in order to compare the present results with those previously obtained in the FACIT study (Durga et al., 2006), did not reveal any significant associations between MTHFR genotype and cognitive performance. 


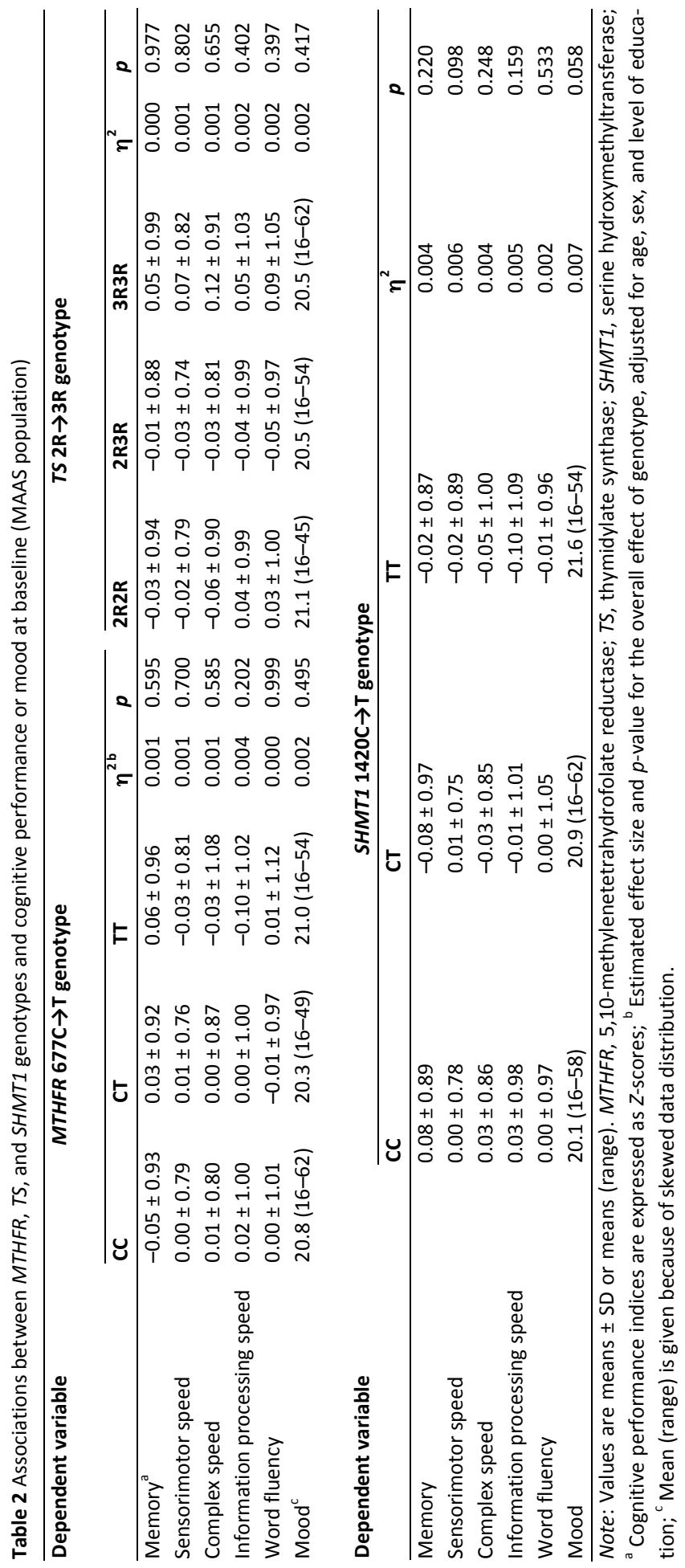




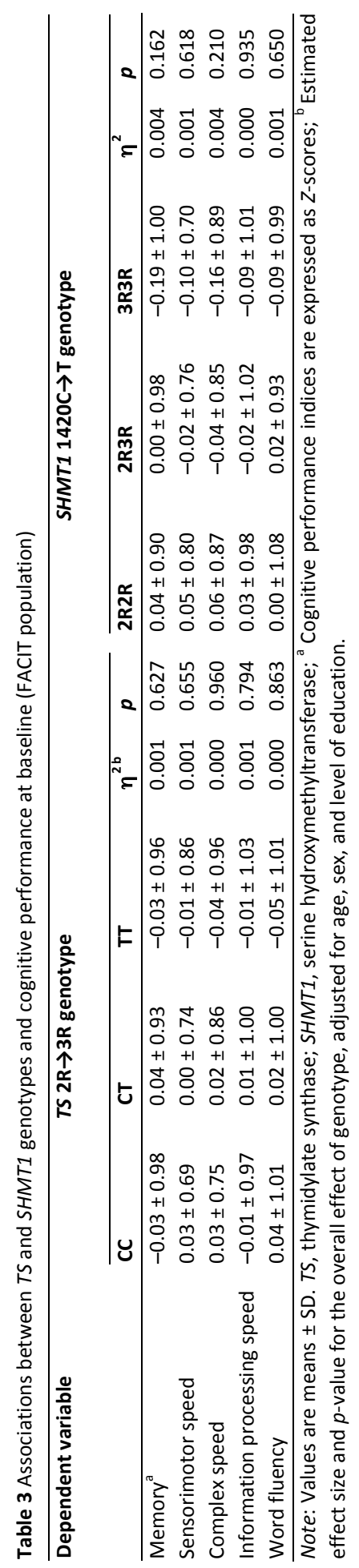




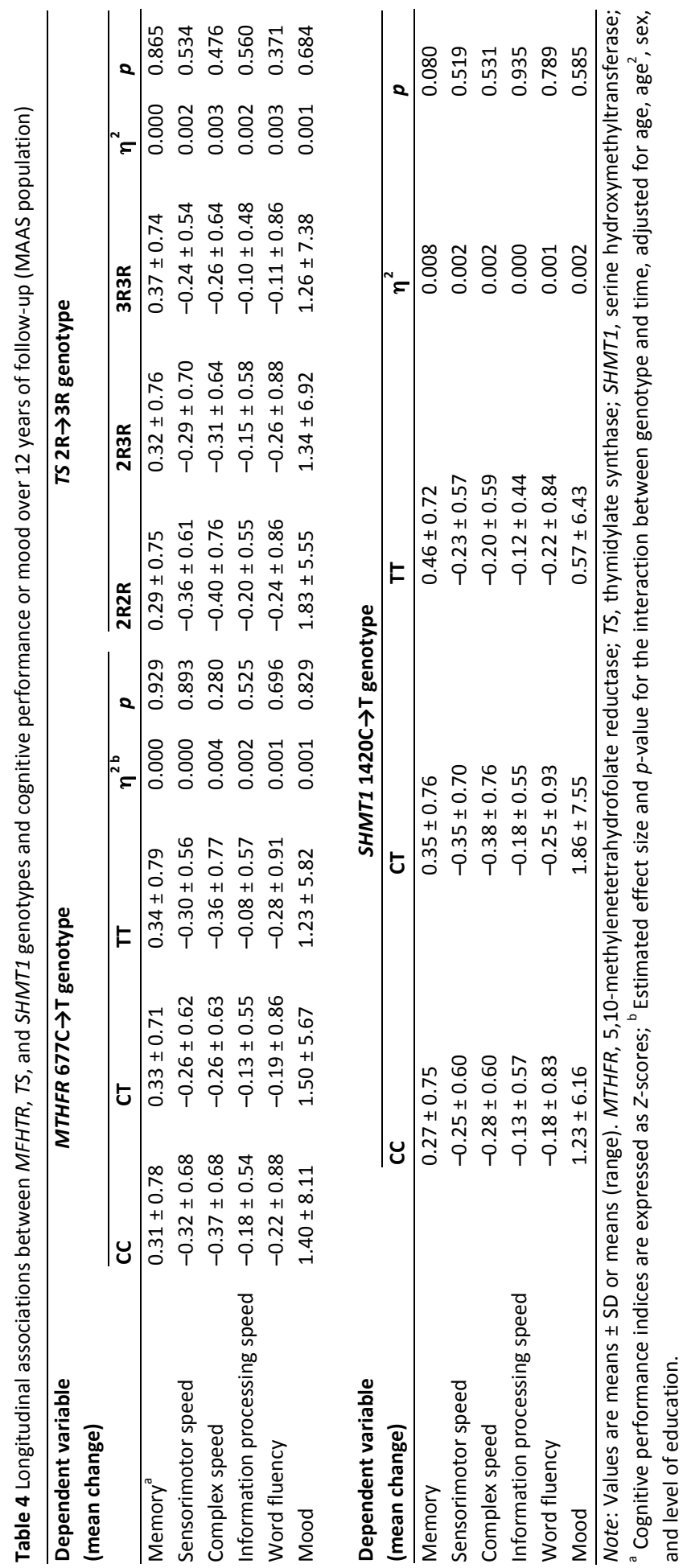


One sample $t$ tests indicated that cognitive performance in the MAAS population significantly declined over the 12-year follow-up period on the domains of sensorimotor speed (mean change $\pm S D=-0.29 \pm 0.64, p<0.001$ ), complex speed (mean change $\pm S D=-0.33 \pm 0.79, p<0.001$ ), information processing speed (mean change $\pm \mathrm{SD}=-0.14 \pm 0.55, p<0.001$ ), and word fluency (mean change $\pm \mathrm{SD}=-0.21 \pm 0.87$, $p<0.001$ ). Memory performance significantly improved (mean change $\pm \mathrm{SD}=0.32 \pm$ $0.75, p<0.001$ ), which is due to the effect of procedural learning. Depressive symptoms significantly increased over the 12-year follow-up period, as indicated by higher SCLdep scores (mean change \pm SD $=1.42 \pm 6.78, p<0.001$ ). In the longitudinal analyses, we found no significant associations between the MTHFR 677C $\rightarrow$ T, TS $2 \mathrm{R} \rightarrow 3 \mathrm{R}$, and $S H M T 11420 \mathrm{C} \rightarrow \mathrm{T}$ polymorphisms on the one hand and cognitive functioning and mood over 12 years on the other (Table 4).

To examine whether folate status might influence the associations between the TS or SHMT1 polymorphisms and cognitive performance, the FACIT population was stratified by erythrocyte folate concentration. The stratification procedure did not reveal any significant results, suggesting that folate status did not modify the putative associations between the two genotypes and cognitive performance.

Both study populations were stratified by $A P O E$ E4 allele carrier status to determine whether possession of the APOE E4 allele influenced the associations between the three genotypes and cognitive performance. The results of the crosssectional and longitudinal analyses in the MAAS sample did not differ between carriers and non-carriers of the APOE E4 allele, indicating that this variable was no effect modifier in this study population. In the FACIT sample, however, the SHMT1 1420TT genotype was associated with decreased memory performance at baseline (mean $\pm \mathrm{SD}=-0.33 \pm 1.03$ ) as compared with CC homozygotes (mean \pm SD $=0.04 \pm$ $0.90)$ and CT heterozygotes (mean $\pm \mathrm{SD}=-0.04 \pm 0.96)$ in non-carriers $(p=0.015)$, but not in carriers of the APOE E4 allele $(p=0.675)$.

\section{Discussion}

The present study showed that the MTHFR $677 \mathrm{C} \rightarrow \mathrm{T}, \mathrm{TS} 2 \mathrm{R} \rightarrow 3 \mathrm{R}$, and SHMT1 $1420 C \rightarrow T$ polymorphisms are not related to cognitive performance or mood in healthy individuals. These findings do not support the hypothesis that genetic variation in folate metabolism might be involved in increasing the risk of depression or age-related cognitive decline.

The present findings are in line with other cross-sectional studies reporting the lack of any significant associations between MTHFR genotype and cognitive performance in older individuals (Almeida et al., 2005; Bathum et al., 2007; De Lau et al., 2010; Gussekloo et al., 1999; Visscher et al., 2003). In addition, our longitudinal results are in concordance with a population-based study in 1,581 Danish nonagen- 
arians showing no impact of the MTHFR 677TT genotype on cognitive decline over 5 years (Bathum et al., 2007).

In contrast to the present findings, Elkins et al. (2007) found that the MTHFR 677TT genotype was associated with decreased information processing speed, as well as greater annual cognitive decline as indicated by Mini-Mental State Examination score, in a US population-based sample of 6,653 older women. However, their longitudinal results should be interpreted with caution, as the Mini-Mental State Examination is a relatively crude indicator of cognitive functioning. Originally designed to screen for symptoms of cognitive impairment (Folstein et al., 1975), this test is fairly insensitive to individual variation in cognitive performance in healthy ageing individuals.

The present results on mood are in line with a number of studies that found no significant relationship between the MTHFR $677 \mathrm{C} \rightarrow$ T polymorphism and depressive symptoms (Almeida et al., 2005; Gaysina et al., 2008). In contrast, the MTHFR 677TT genotype was reported to be related to an increased risk of depression in a large population-based study of 5,948 older Norwegian individuals (Bjelland et al., 2003), a case-control study of 78 older Australian patients with late-onset depression and 22 healthy controls (Hickie et al., 2001), and a case-control study carried out in Northern Ireland, including 100 patients with major depressive disorder matched with 89 controls (Kelly et al., 2004). An important methodological difference between the present study and most of the above-mentioned studies is that we did not use a dichotomous measure of depressive symptoms. Instead, we measured depressive symptoms on a continuous scale, which not only increased statistical power, but also allowed for the detection of subclinical depressive symptoms, which are highly prevalent in the general population (Kessler et al., 1997). Although the studies comparing depressed persons with non-depressed individuals suggest that the MTHFR $677 \mathrm{C} \rightarrow \mathrm{T}$ polymorphism might increase the risk of depression, our results indicate that this genetic polymorphism might not be related to subclinical depressive symptoms in the general population. Similar to our study, Almeida et al. (2005), who also used a continuous measurement of depressive symptoms, did not find any significant associations between MHTFR genotype and mood in a study sample of 240 community-dwelling women.

We previously found that the MTHFR 677TT genotype was associated with increased sensorimotor speed, despite elevated homocysteine levels, in the FACIT population (Durga et al., 2006). In the present study, we failed to replicate these findings in the MAAS population. Performing our analyses in a subsample of the MAAS study population including only participants aged 50 to 70 years indicated that these conflicting results could not be attributed to differences in the age range of the two populations. It is also unlikely that the lack of significant associations was due to insufficient statistical power, as our study had sufficient power to detect small associations in both study samples. However, as the effect sizes of quantita- 
tive traits tend to be very small (Houlihan et al., 2009; Visscher, 2008), it cannot be ruled out completely that very modest associations were not detected.

In our previous study, we showed that the MTHFR $677 \mathrm{C} \rightarrow$ T polymorphism was associated with increased complex speed in individuals with erythrocyte folate concentrations below the median (Durga et al., 2006). As folate status may influence phenotypic expression of the polymorphisms studied (Girelli et al., 1998; Religa et al., 2003), it cannot be ruled out that the lack of stratification by folate concentrations in the MAAS population might have obscured any potential associations between the MTHFR $677 \mathrm{C} \rightarrow \mathrm{T}$ polymorphism and cognitive performance. With respect to the $T S 2 R \rightarrow 3 R$ and SHMT1 $1420 C \rightarrow T$ polymorphisms, however, it is not very likely that the null findings in the MAAS population may be accounted for by the lack of stratification by folate status, as the stratified analyses in the FACIT population suggest that folate status is not an effect modifier of the putative associations between these polymorphisms and cognitive performance.

In contrast to the MTHFR 677TT genotype, which was associated with elevated homocysteine concentrations in the FACIT sample (Durga et al., 2006), plasma total homocysteine levels did not appear to vary according to TS or SHMT1 genotype in our study, which might offer an explanation for the lack of any associations between the $T S 2 R \rightarrow 3 R$ and SHMT1 $1420 C \rightarrow T$ polymorphisms and cognitive functioning.

However, it may also be argued that the polymorphisms studied may simultaneously exert detrimental as well as beneficial effects, thereby causing no actual behavioural changes. For example, the MTHFR $677 \mathrm{C} \rightarrow$ T polymorphism may both increase homocysteine concentrations by impairing its conversion into methionine, and stimulate DNA synthesis by increasing the availability of 5,10-methylenetetrahydrofolate for the TS enzyme.

The lack of any significant associations in the present study might also be due to the possibility that more than one genetic polymorphism might need to be present in order to significantly influence cognitive performance. However, there were too few individuals homozygous for either all three mutations $(n=3)$, or two out of three mutations studied ( $n=56$ ), to yield sufficient statistical power for detecting potential associations within these subsamples.

To investigate the possibility that an additional risk factor for cognitive impairment, such as APOE E4 carrier status (Caselli et al., 2009; Deary et al., 2002), must be present for cognitive effects of any of the genetic polymorphisms to become apparent, we stratified our analyses by APOE E4 allele carrier status. In the FACIT sample, we found that the SHMT1 1420TT genotype was associated with decreased memory performance in non-carriers of the APOE E4 allele. Taking into account multiple testing, it cannot be excluded that this significant association might be a chance finding. In the MAAS population, however, results did not differ between carriers and non-carriers of the APOE E4 allele. Overall, the present findings did not support the hypothesis that APOE E4 carrier status may interact with MTHFR, TS, or 
SHMT1 genotypes to influence cognitive decline. Our results are in line with a casecontrol study performed in patients with Alzheimer's disease, which did not show any interaction between the MTHFR $677 \mathrm{C} \rightarrow$ T polymorphism and APOE E4 carrier status in mediating Alzheimer's disease risk (Brunelli et al., 2001).

Our study had several strengths, such as the use of two population-based samples, the measurement of three different genotypes related to folate metabolism, and the inclusion of 12-year longitudinal data on cognitive performance and mood. To our knowledge, our study was the first to explore the $T S 2 R \rightarrow 3 R$ and $S H M T 11420 C \rightarrow T$ polymorphisms in relation to cognitive functioning and depressive symptoms.

In conclusion, the present study suggests that there are no associations between the MTHFR $677 \mathrm{C} \rightarrow \mathrm{T}, \mathrm{TS} 2 \mathrm{R} \rightarrow 3 \mathrm{R}$ and SHMT1 $1420 \mathrm{C} \rightarrow \mathrm{T}$ polymorphisms, which are known to affect enzyme activity in folate metabolism, on the one hand and cognitive performance, age-related cognitive decline, or mood on the other in healthy individuals. Although we previously demonstrated that long-term supplementation with folic acid improved cognitive performance in healthy older adults (Durga et al., 2007), we did not find evidence for the involvement of polymorphisms that may lead to mild disturbances in folate metabolism in cognitive functioning.

Large population-based studies are needed to replicate the present findings on the TS $2 \mathrm{R} \rightarrow 3 \mathrm{R}$ and SHMT1 $1420 \mathrm{C} \rightarrow \mathrm{T}$ polymorphisms. These studies should not only take into account biochemical parameters, such as folate status and homocysteine levels, but may also address combinations of different genetic polymorphisms, in order to further investigate the relationships between genetic and environmental determinants of folate metabolism and cognitive functioning.

\section{Acknowledgements}

MAAS was supported by the Dutch Government, the Dutch Research Foundation, and Maastricht University. The FACIT study was supported by the Netherlands Organisation for Health Research and Development (grant number 200110002), Sanquin Blood Bank (grant number 02-001), Wageningen University, and Top Institute Food and Nutrition. 


\section{References}

Almeida, O. P., Flicker, L., Lautenschlager, N. T., Leedman, P., Vasikaran, S., \& Van Bockxmeer, F. M. (2005). Contribution of the MTHFR gene to the causal pathway for depression, anxiety and cognitive impairment in later life. Neurobiol Aging, 26(2), 251-257.

Arrindell, W. A., \& Ettema, J. H. M. (1986). SCL-90. Een multidimensionele psychopathologie-indicator [SCL-90. A multidimensional indicator of psychopathology]. Lisse, The Netherlands: Swets \& Zeitlinger.

Bagley, P. J., \& Selhub, J. (1998). A common mutation in the methylenetetrahydrofolate reductase gene is associated with an accumulation of formylated tetrahydrofolates in red blood cells. Proc Natl Acad Sci USA, 95(22), 13217-13220.

Bathum, L., Von Bornemann Hjelmborg, J., Christiansen, L., McGue, M., Jeune, B., \& Christensen, K. (2007). Methylenetetrahydrofolate reductase $677 C>T$ and methionine synthase $2756 \mathrm{~A}>\mathrm{G}$ mutations: no impact on survival, cognitive functioning, or cognitive decline in nonagenarians. J Gerontol A Biol Sci Med Sci, 62(2), 196-201.

Bekers, O., Op den Buijsch, R. A., De Vries, J. E., Wijnen, P. A., \& Van Dieijen-Visser, M. P. (2002). Capillary electrophoretic detection in apolipoprotein E genotyping. Electrophoresis, 23(12), 1878-1881.

Bjelland, I., Tell, G. S., Vollset, S. E., Refsum, H., \& Ueland, P. M. (2003). Folate, vitamin B12, homocysteine, and the MTHFR $677 \mathrm{C} \rightarrow \mathrm{T}$ polymorphism in anxiety and depression: the Hordaland Homocysteine Study. Arch Gen Psychiatry, 60(6), 618-626.

Blount, B. C., Mack, M. M., Wehr, C. M., MacGregor, J. T., Hiatt, R. A., Wang, G., Wickramasinghe, S. N., Everson, R. B., \& Ames, B. N. (1997). Folate deficiency causes uracil misincorporation into human DNA and chromosome breakage: implications for cancer and neuronal damage. Proc Natl Acad Sci USA, 94(7), 3290-3295.

Brunelli, T., Bagnoli, S., Giusti, B., Nacmias, B., Pepe, G., Sorbi, S., \& Abbate, R. (2001). The C677T methylenetetrahydrofolate reductase mutation is not associated with Alzheimer's disease. Neurosci Lett, 315(1-2), 103-105.

Caselli, R. J., Dueck, A. C., Osborne, D., Sabbagh, M. N., Connor, D. J., Ahern, G. L., Baxter, L. C., Rapcsak, S. Z., Shi, J., Woodruff, B. K., Locke, D. E., Snyder, C. H., Alexander, G. E., Rademakers, R., \& Reiman, E. M. (2009). Longitudinal modeling of age-related memory decline and the APOE $\varepsilon 4$ effect. $N$ Engl J Med, 361(3), 255-263.

Castro, R., Rivera, I., Ravasco, P., Camilo, M. E., Jakobs, C., Blom, H. J., \& De Almeida, I. T. (2004). 5,10methylenetetrahydrofolate reductase (MTHFR) $677 \mathrm{C} \rightarrow \mathrm{T}$ and $1298 \mathrm{~A} \rightarrow \mathrm{C}$ mutations are associated with DNA hypomethylation. J Med Genet, 41(6), 454-458.

De Bie, S. E. (1987). Standaardvragen 1987: Voorstellen voor uniformering van vraagstellingen naar achtergrondkenmerken en interviews [Standard questions 1987: Proposal for uniformization of questions regarding background variables and interviews] (2nd ed.). Leiden, The Netherlands: Leiden University Press.

De Lau, L. M., Van Meurs, J. B., Uitterlinden, A. G., Smith, A. D., Refsum, H., Johnston, C., \& Breteler, M. M. (2010). Genetic variation in homocysteine metabolism, cognition, and white matter lesions. Neurobiol Aging, 31(11), 2020-2022.

Deary, I. J., Whiteman, M. C., Pattie, A., Starr, J. M., Hayward, C., Wright, A. F., Carothers, A., \& Whalley, L. J. (2002). Cognitive change and the APOE $\varepsilon 4$ allele. Nature, 418(6901), 932.

Durga, J., Van Boxtel, M. P. J., Schouten, E. G., Bots, M. L., Kok, F. J., \& Verhoef, P. (2006). Folate and the methylenetetrahydrofolate reductase $677 \mathrm{C} \rightarrow \mathrm{T}$ mutation correlate with cognitive performance. Neurobiol Aging, 27(2), 334-343.

Durga, J., Van Boxtel, M. P. J., Schouten, E. G., Kok, F. J., Jolles, J., Katan, M. B., \& Verhoef, P. (2007). Effect of 3-year folic acid supplementation on cognitive function in older adults in the FACIT trial: a randomised, double blind, controlled trial. Lancet, 369(9557), 208-216.

Duthie, S. J., Whalley, L. J., Collins, A. R., Leaper, S., Berger, K., \& Deary, I. J. (2002). Homocysteine, B vitamin status, and cognitive function in the elderly. Am J Clin Nutr, 75(5), 908-913. 
Elkins, J. S., Johnston, S. C., Ziv, E., Kado, D., Cauley, J. A., \& Yaffe, K. (2007). Methylenetetrahydrofolate reductase C677T polymorphism and cognitive function in older women. Am J Epidemiol, 166(6), 672678.

Férnandez-Peralta, A. M., Daimiel, L., Nejda, N., Iglesias, D., Medina Arana, V., \& González-Aguilera, J. J. (2010). Association of polymorphisms MTHFR C677T and A1298C with risk of colorectal cancer, genetic and epigenetic characteristic of tumors, and response to chemotherapy. Int J Colorectal Dis, 25(2), 141-151.

Folstein, M. F., Folstein, S. E., \& McHugh, P. R. (1975). "Mini-mental state". A practical method for grading the cognitive state of patients for the clinician. J Psychiatr Res, 12(3), 189-198.

Frosst, P., Blom, H. J., Milos, R., Goyette, P., Sheppard, C. A., Matthews, R. G., Boers, G. J. H., Den Heijer, M., Kluijtmans, L. A., Van den Heuvel, L. P., \& Rozen, R. (1995). A candidate genetic risk factor for vascular disease: a common mutation in methylenetetrahydrofolate reductase. Nat Genet, 10(1), 111-113.

Fuso, A., Seminara, L., Cavallaro, R. A., D’Anselmi, F., \& Scarpa, S. (2005). S-adenosylmethionine/homocysteine cycle alterations modify DNA methylation status with consequent deregulation of PS1 and BACE and beta-amyloid production. Mol Cell Neurosci, 28(1), 195-204.

Gaysina, D., Cohen, S., Craddock, N., Farmer, A., Hoda, F., Korszun, A., Owen, M. J., Craig, I. W., \& McGuffin, P. (2008). No association with the 5,10-methylenetetrahydrofolate reductase gene and major depressive disorder: results of the Depression Case Control (DeCC) study and a meta-analysis. Am J Med Genet B Neuropsychiatr Genet, 147B(6), 699-706.

Girelli, D., Friso, S., Trabetti, E., Olivieri, O., Russo, C., Pessotto, R., Faccini, G., Pignatti, P. F., Mazzucco, A., \& Corrocher, R. (1998). Methylenetetrahydrofolate reductase C677T mutation, plasma homocysteine, and folate in subjects from Northern Italy with or without angiographically documented severe coronary atherosclerotic disease: evidence for an important genetic-environmental interaction. Blood, 91(11), 4158-4163.

Gussekloo, J., Heijmans, B. T., Slagboom, P. E., Lagaay, A. M., Knook, D. L., \& Westendorp, R. G. (1999). Thermolabile methylenetetrahydrofolate reductase gene and the risk of cognitive impairment in those over 85. J Neurol Neurosurg Psychiatry, 67(4), 535-538.

Heil, S. G., Van der Put, N. M., Waas, E. T., Den Heijer, M., Trijbels, F. J., \& Blom, H. J. (2001). Is mutated serine hydroxymethyltransferase (SHMT) involved in the etiology of neural tube defects? Mol Genet Metab, 73(2), 164-172.

Hickie, I., Scott, E., Naismith, S., Ward, P. B., Turner, K., Parker, G., Mitchell, P., \& Wilhelm, K. (2001). Lateonset depression: genetic, vascular and clinical contributions. Psychol Med, 31(8), 1403-1412.

Hishida, A., Matsuo, K., Hamajima, N., Ito, H., Ogura, M., Kagami, Y., Taji, H., Morishima, Y., Emi, N., \& Tajima, K. (2003). Associations between polymorphisms in the thymidylate synthase and serine hydroxymethyltransferase genes and susceptibility to malignant lymphoma. Haematologica, 88(2), 159-166.

Horie, N., Aiba, H., Oguro, K., Hojo, H., \& Takeishi, K. (1995). Functional analysis and DNA polymorphism of the tandemly repeated sequences in the 5 -terminal regulatory region of the human gene for thymidylate synthase. Cell Struct Funct, 20(3), 191-197.

Houlihan, L. M., Harris, S. E., Luciano, M., Gow, A. J., Starr, J. M., Visscher, P. M., \& Deary, I. J. (2009). Replication study of candidate genes for cognitive abilities: the Lothian Birth Cohort 1936. Genes Brain Behav, 8(2), 238-247.

Jolles, J., Houx, P. J., Van Boxtel, M. P. J., \& Ponds, R. W. H. M. (Eds.). (1995). The Maastricht Aging Study: Determinants of Cognitive Aging. Maastricht, The Netherlands: Neuropsych Publishers.

Kelly, C. B., McDonnell, A. P., Johnston, T. G., Mulholland, C., Cooper, S. J., McMaster, D., Evans, A., \& Whitehead, A. S. (2004). The MTHFR C677T polymorphism is associated with depressive episodes in patients from Northern Ireland. J Psychopharmacol, 18(4), 567-571.

Kessler, R. C., Zhao, S., Blazer, D. G., \& Swartz, M. (1997). Prevalence, correlates, and course of minor depression and major depression in the National Comorbidity Survey. J Affect Disord, 45(1-2), 1930. 
Lezak, M. D., Howieson, D. B., \& Loring, D. W. (2004). Neuropsychological Assessment (4th ed.). New York: Oxford University Press.

Mattson, M. P., \& Shea, T. B. (2003). Folate and homocysteine metabolism in neural plasticity and neurodegenerative disorders. Trends Neurosci, 26(3), 137-146.

Religa, D., Styczynska, M., Peplonska, B., Gabryelewicz, T., Pfeffer, A., Chodakowska, M., Luczywek, E., Wasiak, B., Stepien, K., Golebiowski, M., Winblad, B., \& Barcikowska, M. (2003). Homocysteine, apolipoproteine $\mathrm{E}$ and methylenetetrahydrofolate reductase in Alzheimer's disease and mild cognitive impairment. Dement Geriatr Cogn Disord, 16(2), 64-70.

Shea, T. B., Ortiz, D., \& Rogers, E. (2004). Differential susceptibility of transgenic mice lacking one or both apolipoprotein alleles to folate and vitamin E deprivation. J Alzheimers Dis, 6(3), 269-273.

Skibola, C. F., Smith, M. T., Hubbard, A., Shane, B., Roberts, A. C., Law, G. R., Rollinson, S., Roman, E., Cartwright, R. A., \& Morgan, G. J. (2002). Polymorphisms in the thymidylate synthase and serine hydroxymethyltransferase genes and risk of adult acute lymphocytic leukemia. Blood, 99(10), 37863791.

Taioli, E., Garza, M. A., Ahn, Y. O., Bishop, D. T., Bost, J., Budai, B., Chen, K., Gemignani, F., Keku, T., Lima, C. S., Le Marchand, L., Matsuo, K., Moreno, V., Plaschke, J., Pufulete, M., Thomas, S. B., Toffoli, G., Wolf, C. R., Moore, C. G., \& Little, J. (2009). Meta- and pooled analyses of the methylenetetrahydrofolate reductase (MTHFR) C677T polymorphism and colorectal cancer: a HuGE-GSEC review. Am J Epidemiol, 170(10), 1207-1221.

Tchantchou, F., Graves, M., Ortiz, D., Chan, A., Rogers, E., \& Shea, T. B. (2006). S-adenosyl methionine: A connection between nutritional and genetic risk factors for neurodegeneration in Alzheimer's disease. J Nutr Health Aging, 10(6), 541-544.

Tiemeier, H., Van Tuijl, H. R., Hofman, A., Meijer, J., Kiliaan, A. J., \& Breteler, M. M. (2002). Vitamin B12, folate, and homocysteine in depression: the Rotterdam Study. Am J Psychiatry, 159(12), 2099-2101.

Tucker, K. L., Qiao, N., Scott, T., Rosenberg, I., \& Spiro, A., 3rd (2005). High homocysteine and low B vitamins predict cognitive decline in aging men: the Veterans Affairs Normative Aging Study. Am J Clin Nutr, 82(3), 627-635.

Ubbink, J. B., Hayward-Vermaak, W. J., \& Bissbort, S. (1991). Rapid high-performance liquid chromatographic assay for total homocysteine levels in human serum. J Chromatogr, 565(1-2), 441-446.

Van Boxtel, M. P. J., Buntinx, F., Houx, P. J., Metsemakers, J. F. M., Knottnerus, J. A., \& Jolles, J. (1998). The relation between morbidity and cognitive performance in a normal aging population. $J$ Gerontol A Biol Sci Med Sci, 53(2), M147-M154.

Van der Elst, W., Van Boxtel, M. P. J., Van Breukelen, G. J. P., \& Jolles, J. (2005). Rey's verbal learning test: normative data for 1855 healthy participants aged 24-81 years and the influence of age, sex, education, and mode of presentation. J Int Neuropsychol Soc, 11(3), 290-302.

Van der Elst, W., Van Boxtel, M. P. J., Van Breukelen, G. J. P., \& Jolles, J. (2006a). Normative data for the Animal, Profession and Letter $\mathrm{M}$ Naming verbal fluency tests for Dutch speaking participants and the effects of age, education, and sex. J Int Neuropsychol Soc, 12(1), 80-90.

Van der Elst, W., Van Boxtel, M. P. J., Van Breukelen, G. J. P., \& Jolles, J. (2006b). The Concept Shifting Test: adult normative data. Psychol Assess, 18(4), 424-432.

Van der Elst, W., Van Boxtel, M. P. J., Van Breukelen, G. J. P., \& Jolles, J. (2006c). The Letter Digit Substitution Test: normative data for 1,858 healthy participants aged 24-81 from the Maastricht Aging Study (MAAS): influence of age, education, and sex. J Clin Exp Neuropsychol, 28(6), 998-1009.

Van der Elst, W., Van Boxtel, M. P. J., Van Breukelen, G. J. P., \& Jolles, J. (2006d). The Stroop Color-Word test: influence of age, sex, and education; and normative data for a large sample across the adult age range. Assessment, 13(1), 62-79.

Visscher, P. M. (2008). Sizing up human height variation. Nat Genet, 40(5), 489-490.

Visscher, P. M., Tynan, M., Whiteman, M. C., Pattie, A., White, I., Hayward, C., Wright, A. F., Starr, J. M., Whalley, L. J., \& Deary, I. J. (2003). Lack of association between polymorphisms in angiotensinconverting-enzyme and methylenetetrahydrofolate reductase genes and normal cognitive ageing in humans. Neurosci Lett, 347(3), 175-178. 
CHAPTER 7

\section{MTHFR polymorphisms and cognitive ageing in the ninth decade: the Lothian Birth Cohort 1921}

Olga J.G. Schiepers, Martin P.J. van Boxtel, Sarah E. Harris, Alan J. Gow, Alison Pattie, Caroline E. Brett, Renate H.M. de Groot, Jelle Jolles, John M. Starr, Ian J. Deary

Revised version published in Genes Brain Behav (2011), 10: 354-364 


\begin{abstract}
Low blood levels of B vitamins have been implicated in age-associated cognitive impairment. The present study investigated the association between genetic variation in folate metabolism and age-related cognitive decline in the ninth decade of life. Both the 677C $\rightarrow T$ ( $r$ 1801133) polymorphism and the scarcely-studied $1298 \mathrm{~A} \rightarrow \mathrm{C}$ ( $\mathrm{rs} 1801131)$ polymorphism of the 5,10-methylenetetrahydrofolate reductase (MTHFR) gene were assessed in relation to cognitive change over 8 years in older community-dwelling individuals. MTHFR genotype was determined in 476 participants of the Lothian Birth Cohort 1921, whose intelligence was measured in childhood in the Scottish Mental Survey of 1932. Cognitive performance on the domains of verbal memory, abstract reasoning, and verbal fluency was assessed at mean age $79(n=476)$, and again at mean ages of $83(n=275)$ and $87(n=180)$. Using linear mixed models, the MTHFR $677 \mathrm{C} \rightarrow \mathrm{T}$ and $1298 \mathrm{~A} \rightarrow \mathrm{C}$ variants were not associated with the rate of cognitive change between 79 and 87 years, neither in the total sample, nor in a subsample of individuals with erythrocyte folate levels below the median. Apolipoprotein E (APOE) E4 allele carrier status did not interact with MTHFR genotype in affecting change in cognitive performance over 8 years. No significant combined effect of the two polymorphisms was found. In conclusion, MTHFR $677 \mathrm{C} \rightarrow$ T and $1298 \mathrm{~A} \rightarrow \mathrm{C}$ polymorphisms were not associated with individual change in cognitive functioning in the ninth decade of life. Although polymorphisms in the MTHFR gene may cause disturbances in folate metabolism, they do not appear to be accompanied by changes in cognitive functioning in old age.
\end{abstract}




\section{Introduction}

Low blood levels of B vitamins, such as folate and vitamin $B_{12}$, have been implicated in age-associated cognitive impairment (Clarke et al., 2007; Kado et al., 2005). A low folate status may result from poor dietary intake, or from genetic disturbances in folate metabolism. For example, the common $677 \mathrm{C} \rightarrow T$ ( $\mathrm{rs1801133)}$ and $1298 \mathrm{~A} \rightarrow \mathrm{C}$ (rs1801131) polymorphisms of the 5,10-methylenetetrahydrofolate reductase (MTHFR) gene may mimic dietary folate deficiency by reducing folate metabolism (Frosst et al., 1995; Weisberg et al., 1998). The non-synonymous MTHFR 677C $\rightarrow$ T and $1298 \mathrm{~A} \rightarrow \mathrm{C}$ polymorphisms are associated with decreased MTHFR activity (Frosst et al., 1995; Weisberg et al., 1998), resulting in reduced availability of 5methyltetrahydrofolate for the conversion of homocysteine into methionine. Both polymorphisms have been found to increase homocysteine levels, although the effects of the $1298 \mathrm{~A} \rightarrow \mathrm{C}$ polymorphism are somewhat less pronounced than those associated with the $677 \mathrm{C} \rightarrow$ T polymorphism (Friedman et al., 1999).

In addition, by reducing the availability of methyl donors, MTHFR 677C $\rightarrow T$ and $1298 \mathrm{~A} \rightarrow \mathrm{C}$ polymorphisms may impair DNA methylation processes (Castro et al., 2004; Friso et al., 2002), which play a key role in regulating gene expression. As both DNA hypomethylation and elevated homocysteine levels have been related to deficits in cognitive functioning (Levenson \& Sweatt, 2005; Mattson \& Shea, 2003; Zhao et al., 2003), we hypothesised that the MTHFR 677C $\rightarrow$ T and $1298 \mathrm{~A} \rightarrow \mathrm{C}$ polymorphisms might confer increased susceptibility to cognitive impairment and agerelated cognitive decline.

To date, a number of studies have examined the associations between the MTHFR $677 \mathrm{C} \rightarrow$ T polymorphism and cognitive functioning in older individuals (Almeida et al., 2005; Bathum et al., 2007; Durga et al., 2006; Elkins et al., 2007; Gussekloo et al., 1999; Visscher et al., 2003), albeit with mixed results. The possible relationship between the $1298 \mathrm{~A} \rightarrow \mathrm{C}$ polymorphism and cognitive performance, however, has scarcely been investigated (De Lau et al., 2010).

It should be noted that most of the previous studies were cross-sectional. Few studies have addressed the relationship between MTHFR genotype and longitudinal change in cognitive functioning in the ageing population (Bathum et al., 2007; Elkins et al., 2007). Whereas the MTHFR 677TT genotype was associated with greater annual cognitive decline in a large population-based sample of older women (Elkins et al., 2007), no such associations were found in community-dwelling nonagenarians whose cognitive performance was assessed over 5 years (Bathum et al., 2007).

In some of the above-mentioned studies, possible associations between MTHFR genotype and cognitive performance might have been obscured by not taking into account individual variation in folate status, because phenotypic expression of the MTHFR 677TT genotype is most pronounced when folate status is low (Girelli et al., 1998). 
In addition, few of the earlier studies controlled for prior cognitive ability, which may confound the relationship between MTHFR polymorphisms and age-related cognitive change, because childhood mental ability accounts for about one-half of the variance associated with cognitive ability in adulthood (Deary et al., 2004).

Furthermore, APOE E4 carrier status has been suggested to interact with a low $B$ vitamin status to increase individual vulnerability to cognitive impairment (Bunce et al., 2004; Shea et al., 2004). However, the putative interactions between MTHFR genotype and APOE E4 carrier status have rarely been studied.

The objective of the present study was, therefore, to examine the longitudinal associations between the MTHFR $677 \mathrm{C} \rightarrow \mathrm{T}$ and $1298 \mathrm{~A} \rightarrow \mathrm{C}$ polymorphisms and key domains of cognitive functioning in the healthy ageing population, while taking into account folate status, prior cognitive ability, and APOE E4 allele carrier status. We assessed cognitive performance three times between mean ages of 79 and 87 in a sample of older individuals whose mental ability was measured in childhood: the Lothian Birth Cohort 1921 (Deary et al., 2004). By using a cohort with very little age variation, any problems associated with heterogeneity of MTHFR's effect on cognitive performance at different ages were excluded.

\section{Methods}

\section{Study population}

The study population was the Lothian Birth Cohort 1921. This cohort consisted of 550 surviving participants of the Scottish Mental Survey 1932, which tested cognitive ability in almost all children born in 1921 and attending school in Scotland, United Kingdom, in June 1932 (Scottish Council for Research in Education, 1933). Participants living in Edinburgh and the surrounding areas were recruited for medical and cognitive retesting via general practitioner's patient lists and advertisements in the media, as described in detail elsewhere (Deary et al., 2009; Deary et al., 2004).

All participants who had completed the initial reassessments at mean age 79 years (old age baseline), excluding those who had withdrawn or were known to have died, were invited to participate in the follow-up measurements at mean age 83. In addition, all participants who had completed the assessments at mean age 83, excluding those who had withdrawn or were known to have died, were invited to take part in the follow-up measurements at mean age 87. Of the 454 participants invited to take part at age 83, 335 agreed to participate, and 321 were tested. At mean age 87, 268 participants were invited, and 207 were tested (Gow et al., 2011). Reasons for not attending included withdrawal ( $n=16$ at age 83; $n=4$ at age 87), inability or refusal to participate ( $n=80$ at age $83 ; n=42$ at age 87 ), having moved 
away ( $n=13$ at age $83 ; n=4$ at age 87 ), exclusion due to dementia or memory problems ( $n=3$ at age 87 ), and death ( $n=10$ at age $83 ; n=8$ at age 87 ) (Gow et al., 2008; Starr et al., 2010). Of the total sample of 550 individuals, 229 had died during the course of the study. At baseline, all participants lived independently in the community and most were in good general health.

Baseline data on cognitive functioning were lacking for two individuals. At baseline, five participants reported a history of dementia-related illness, and nine individuals scored $<24$ on the Mini-Mental State Examination (MMSE) (Folstein et al., 1975), which may suggest possible dementia. These individuals were excluded from statistical analysis, along with 27 participants who maintained contact with the study and developed symptoms of dementia during follow-up. MTHFR genotyping was successful for all but 31 of the 507 participants with valid cognitive data at baseline. The resulting study sample consisted of 476 individuals (192 men, 284 women) at baseline, 275 individuals (118 men, 157 women) at mean age 83, and 180 individuals (77 men, 103 women) at mean age 87.

The Multi-Centre Research Ethics Committee for Scotland and the Lothian Research Ethics Committee approved the study. All participants gave written, informed consent.

\section{Cognitive tests}

In the Scottish Mental Survey of 1932, a version of the Moray House Test No. 12 (MHT) was administered as a measure of general cognitive ability at age 11 years (Scottish Council for Research in Education, 1933). Although it is primarily focused on verbal reasoning, this test also assesses numerical, spatial, and general reasoning. The MHT, consisting of 71 numbered items, 75 items in total, is to be completed within $45 \mathrm{~min}$, and has a maximum test score of 76. Raw MHT test scores were corrected for age in days at the time of testing and converted to IQ-type scores ( mean $=100, \mathrm{SD}=15)$.

At each wave of testing in old age, a battery of cognitive tests was administered to assess the important cognitive domains of verbal fluency, verbal memory, and abstract reasoning. The Verbal Fluency Test (Lezak, 1995) provides a measure of executive functioning. Participants are required to name as many words as possible beginning with the letter $\mathrm{C}$ in $1 \mathrm{~min}$. This process is repeated for the letters $\mathrm{F}$ and $\mathrm{L}$. The overall test score is the total number of correct words named, excluding proper names, numbers, and repeated words. Verbal declarative memory was assessed by means of the Logical Memory subtest from the Wechsler Memory Scale-Revised (Wechsler, 1987). Two short stories, each containing twenty-five memory items, are read aloud. Immediately after each story, the participants recall as much of the story as possible ('immediate recall'). After a delay of about $25 \mathrm{~min}$, the participants are again asked to recall as much as they can ('delayed recall'). The total score is the 
sum of the two immediate and two delayed recall scores. Maximum possible overall test score is 100. Raven's Standard Progressive Matrices (Raven et al., 1977) was used to measure abstract reasoning. The test consists of sixty items, each presenting a pattern that needs to be completed. Participants complete as many items as possible in $20 \mathrm{~min}$. The outcome measure is the total number of correctly completed items.

\section{Genotyping}

MTHFR genotype was determined at as described previously (Houlihan et al., 2010). In short, for 542 of the 550 participants in the LBC1921, genomic DNA was isolated from whole blood by standard procedure at Medical Research Council Technology, Western General Hospital, Edinburgh. Sixteen samples failed quality control preceding the genotyping procedure. The remaining 526 samples were genotyped by the Wellcome Trust Clinical Research Facility (WTCRF) Genetics Core with the Illumina Human610-Quadv1 chip. These samples were then subjected to quality-control procedures. All individuals were checked for disagreement between genetic and reported gender $(n=1)$. Relatedness between participants was investigated and, for any related pair of individuals, one was removed $(n=1)$. Samples with a call rate $\leq 0.95(n=5)$, and those showing evidence of non-Caucasian descent by multidimensional scaling, were also removed $(n=2)$. The MTHFR $677 \mathrm{C} \rightarrow \mathrm{T}$ and $1298 \mathrm{~A} \rightarrow \mathrm{C}$ polymorphisms met the following conditions: call rate $\geq 0.98$, minor allele frequency $\geq 0.01$, and Hardy-Weinberg equilibrium test with $p \geq 0.001$. In total, 517 samples remained.

$A P O E$ genotype was determined by polymerase chain reaction amplification of a 227-bp fragment of the APOE gene containing two polymorphic sites that account for the three alleles, E2, E3, and E4 (Wenham et al., 1991), followed by restriction digest with $\mathrm{Cfol}$ and electrophoresis in $4 \%$ NuSieve gel.

\section{Blood measurements}

Venous blood samples were collected at baseline and at mean age 87 . The blood samples were processed and stored at $-80^{\circ} \mathrm{C}$ until analysed. Erythrocyte folate concentrations were measured by immunoassay (Advia Centaur Immuno Assay System, Siemens Healthcare Diagnostics, Deerfield, IL, USA). Data on erythrocyte folate status were available for 399 individuals at baseline, and 128 individuals at mean age 87 . 


\section{Lifestyle and health-related variables}

Body mass index (BMI, $\mathrm{kg} / \mathrm{m}^{2}$ ), smoking status (current smoking, yes or no), and alcohol consumption (standard units per week) were recorded at baseline. Physical activity, recorded as the frequency (days per month) of sport or physical exercise lasting at least $20 \mathrm{~min}$ at a time, was assessed at baseline. As these lifestyle and health-related variables may confound the associations between folate metabolism and cognitive performance (Feng et al., 2006; Kado et al., 2005; Koike et al., 2008), they were included as covariates in the statistical models to reduce residual variation in the outcome measures.

\section{Statistical analysis}

Normality of data distributions was ascertained by means of normal Q-Q plots. The MTHFR genotypes were defined as rare variant (677TT or $1298 \mathrm{CC}$ ) or common variant (677CC/677CT or $1298 \mathrm{AA} / 1298 \mathrm{AC})$. A recessive genetic model was used to test the associations between MTHFR genotype and cognitive performance, as previous studies have indicated that plasma homocysteine concentrations were significantly increased in persons with the MTHFR 677TT rare variant, but not in persons with the 677CC and 677CT common variants (Frosst et al., 1995; Weisberg et al., 1998).

The cross-sectional and longitudinal associations between the MTHFR polymorphisms and cognitive functioning were assessed by means of linear mixed models (Verbeke \& Molenberghs, 2000). This analysis method takes into account the intraindividual correlation between repeated measurements and allows the inclusion of participants with incomplete data at follow-up. Changes over time within individuals, i.e. the longitudinal effect, are distinguished from differences among individuals at baseline, i.e. the cross-sectional effect. Akaike's Information Criterion indicated that a Toeplitz covariance structure best fitted the data. Separate models were fitted for the MTHFR $677 \mathrm{C} \rightarrow$ T and $1298 \mathrm{~A} \rightarrow \mathrm{C}$ genotypes in relation to each of the dependent cognitive variables, i.e. Verbal Fluency, Logical Memory, and Raven's Matrices. Time (measured in years since baseline, which is acceptable because there is very little age variation among the participants within each wave) was included to estimate the change in cognitive performance between 79 and 87 years. The main effect of MTHFR genotype represents the cross-sectional association between MTHFR genotype and cognitive performance at baseline. The longitudinal effect of MTHFR genotype was estimated by the two-way interaction between time and MTHFR genotype, which represents the rate of change in cognitive performance as a function of MTHFR genotype. The statistical models were adjusted for a number of covariates in three consecutive steps. In Model 1, the analyses were corrected for the demographic variables age (in days), age ${ }^{2}$ (to test for non-linear effects of age), and sex. Age was centred around the mean to reduce the correlation 
between the terms for age and age $^{2}$. In Model 2, the analyses were additionally adjusted for age $11 \mathrm{MHT}$ IQ to reduce the confounding effect of prior cognitive ability on age-related change in cognitive performance. In Model 3, the lifestyle and health-related variables BMI, smoking status, alcohol consumption, and physical activity were entered.

The analyses were repeated in a subsample of individuals with erythrocyte folate concentrations below the median, i.e. $314 \mu \mathrm{g} / \mathrm{l}(n=203)$, as low folate concentrations may increase the phenotypic expression of the genotypes studied (Girelli et al., 1998). In addition, the analyses were stratified by APOE E4 carrier status (defined as E4+ or E4-, depending on the presence or absence of at least one E4 allele) to investigate whether the longitudinal associations between the MTHFR polymorphisms and cognitive functioning differed between carriers and non-carriers of the $A P O E$ E4 allele.

In secondary analyses, linear mixed models, corrected for demographic and health-related variables, were performed for both the MTHFR 677C $\rightarrow T$ and $1298 \mathrm{~A} \rightarrow \mathrm{C}$ polymorphisms to examine the possibility of a linear trend in cognitive performance associated with the presence of zero, one, or two variant alleles. In addition, as the MTHFR $677 \mathrm{C} \rightarrow \mathrm{T}$ and $1298 \mathrm{~A} \rightarrow \mathrm{C}$ polymorphisms are in linkage disequilibrium (Stegmann et al., 1999), linear mixed models, corrected for demographic and health-related variables, were performed to investigate the combined effect of these polymorphisms on cognitive performance. To this end, the combined MTHFR $677 \mathrm{C} \rightarrow \mathrm{T} / 1298 \mathrm{~A} \rightarrow \mathrm{C}$ genotypes were classified as 677CC/1298AA, 677CC/1298AC, 677CC/1298CC, 677CT/1298AA, 677CT/1298AC, or 677TT/1298AA.

Statistical differences were considered significant at $p$-values $<0.05$. All analyses were performed using SPSS 16.0 (SPSS Inc., Chicago, IL, USA).

\section{Results}

\section{Descriptives}

Table 1 shows the baseline characteristics of the study sample. Chi-square tests indicated that the MTHFR $677 \mathrm{C} \rightarrow \mathrm{T}$ and $1298 \mathrm{~A} \rightarrow \mathrm{C}$ genotypes were in HardyWeinberg equilibrium ( $p=0.797$ and $p=0.982$, respectively). The allele frequencies were as follows: $677 \mathrm{C}=0.65,677 \mathrm{~T}=0.35,1298 \mathrm{~A}=0.71$, and $1298 \mathrm{C}=0.29$. These frequencies are comparable to those reported in other population-based samples (Elkins et al., 2007; Weisberg et al., 1998). Distribution of the combined $677 \mathrm{C} \rightarrow \mathrm{T} / 1298 \mathrm{~A} \rightarrow \mathrm{C}$ genotypes was as follows: 677CC/1298AA, $n=67(14.1 \%)$; 677CC/1298AC, $n=97$ (20.4\%); 677CC/1298CC, $n=38$ (8.0\%); 677CT/1298AA, $n=$ 112 (23.5\%); 677CT/1298AC, $n=99$ (20.8\%); and 677TT/1298AA, $n=63$ (13.2\%). Individuals with the rare variant of one polymorphism (677TT or 1298CC) were 
always homozygous wildtype for the other polymorphism (1298AA or 677CC, respectively); none of the participants had more than two variant alleles.

Table 1 Participant characteristics at baseline

\begin{tabular}{|c|c|}
\hline & Total sample \\
\hline$n$ & 476 \\
\hline Age (years) & $79.0 \pm 0.6$ \\
\hline Female sex & $284(59.7 \%)$ \\
\hline Age $11 I^{a}$ & $100.9 \pm 14.4$ \\
\hline $\mathrm{BMI}\left(\mathrm{kg} / \mathrm{m}^{2}\right)$ & $26.3 \pm 4.1$ \\
\hline Current smoker & $32(6.7 \%)$ \\
\hline Alcohol consumption (standard units/week) & $1.0(0.5 ; 7.0)$ \\
\hline Physical activity (days/month) ${ }^{\mathrm{b}}$ & $2.0(0.0 ; 10.0)$ \\
\hline Erythrocyte folate $(\mu \mathrm{g} / \mathrm{l})$ & $344.2 \pm 155.3$ \\
\hline MTHFR 677C $\rightarrow$ T genotype, CC / CT / TT (\%) & $42.4 / 44.3 / 13.2$ \\
\hline MTHFR 1298A $\rightarrow$ C genotype, AA / AC / CC (\%) & $50.8 / 41.2 / 8.0$ \\
\hline$A P O E$ E4 carrier status & $126(26.5 \%)$ \\
\hline
\end{tabular}

Note: Values represent means \pm SD or $n(\%)$. BMI, body mass index; MTHFR, 5,10-methylenetetrahydrofolate reductase; $A P O E$, apolipoprotein $\mathrm{E} ;{ }^{a}$ Based on Moray House Test No. 12 score, corrected for age at the time of testing; ${ }^{b}$ Median value (interquartile range) is given because of skewed data distribution.

Erythrocyte folate concentrations did not differ significantly between individuals homozygous for the rare $677 \mathrm{~T}$ or $1298 \mathrm{C}$ polymorphism and individuals carrying the common variants ( $p=0.079$ and $p=0.440$, respectively). Independent samples $t$ tests and Chi-square tests indicated that the covariates did not differ between individuals with the 677TT or 1298CC genotype and the other participants, except for age at baseline, which was higher in individuals with the $1298 \mathrm{CC}$ genotype as compared with the rest of the sample (mean $\pm S D=79.3 \pm 0.6$ and $79.0 \pm 0.6$, respectively; $p=0.004$ ). Participants homozygous for the $677 \mathrm{C} \rightarrow \mathrm{T}$ or $1298 \mathrm{~A} \rightarrow \mathrm{C}$ rare variant did not differ from the other participants in terms of cognitive test performance at baseline or at follow-up (Tables 2 and 3).

Logistic regression analysis revealed that dropout was not associated with MTHFR $677 \mathrm{C} \rightarrow \mathrm{T}$ or $1298 \mathrm{~A} \rightarrow \mathrm{C}$ genotype ( $p=0.544$ and $p=0.570$, respectively). However, lower cognitive scores at baseline significantly predicted dropout at follow-up ( $p<0.01$ for each of the three cognitive measures). Chi-square tests indicated that participants who were lost to follow-up did not differ from the remaining participants in terms of demographic or health-related characteristics, except for smoking, which significantly increased the likelihood of dropping out ( $p=$ 0.023). 
Table 2 Cognitive performance at mean ages of 79 (baseline), 83, and 87 years according to MTHFR $677 \mathrm{C} \rightarrow \mathrm{T}$ genotype

\begin{tabular}{|c|c|c|c|c|c|c|c|c|}
\hline \multirow[t]{3}{*}{ Cognitive test } & \multicolumn{4}{|c|}{ Completers $^{\mathrm{a}}$} & \multicolumn{4}{|c|}{ All data } \\
\hline & MTHFR 677TT & MTHFR 677CC / & $t$ (df) & $p^{b}$ & MTHFR 677TT & MTHFR 677CC / & $t$ (df) & $p$ \\
\hline & genotype & 677CT genotype & & & genotype & 677CT genotype & & \\
\hline \multicolumn{9}{|l|}{ Age 79 (baseline) } \\
\hline$n$ & 26 & 154 & & & 63 & 413 & & \\
\hline Verbal Fluency & $43.3 \pm 11.6$ & $42.5 \pm 11.4$ & $-0.33(177)$ & 0.742 & $42.3 \pm 12.5$ & $40.2 \pm 12.0$ & $-1.24(471)$ & 0.216 \\
\hline Logical Memory & $33.1 \pm 9.9$ & $36.2 \pm 13.4$ & $1.38(178)$ & 0.175 & $33.1 \pm 10.9$ & $32.3 \pm 13.2$ & $-0.51(474)$ & 0.612 \\
\hline Raven's Matrices & $36.4 \pm 6.4$ & $33.6 \pm 8.4$ & $-1.64(177)$ & 0.102 & $33.5 \pm 9.4$ & $31.6 \pm 8.5$ & $-1.66(469)$ & 0.099 \\
\hline \multicolumn{9}{|l|}{ Age 83} \\
\hline$n$ & 26 & 154 & & & 41 & 234 & & \\
\hline Verbal Fluency & $44.7 \pm 11.2$ & $40.9 \pm 12.1$ & $-1.48(176)$ & 0.141 & $44.0 \pm 13.9$ & $40.1 \pm 12.6$ & $-1.85(272)$ & 0.065 \\
\hline Logical Memory & $33.0 \pm 11.5$ & $36.8 \pm 14.3$ & $1.29(176)$ & 0.198 & $35.1 \pm 11.5$ & $34.4 \pm 14.7$ & $-0.30(272)$ & 0.766 \\
\hline Raven's Matrices & $33.0 \pm 6.5$ & $32.0 \pm 8.2$ & $-0.59(173)$ & 0.559 & $32.3 \pm 8.8$ & $30.6 \pm 8.9$ & $-1.10(269)$ & 0.273 \\
\hline \multicolumn{9}{|l|}{ Age 87} \\
\hline$n$ & 26 & 154 & & & & & & \\
\hline Verbal Fluency & $42.3 \pm 12.6$ & $40.6 \pm 11.9$ & $-0.65(176)$ & 0.519 & & & & \\
\hline Logical Memory & $30.6 \pm 11.1$ & $35.2 \pm 14.4$ & $1.56(176)$ & 0.122 & & & & \\
\hline Raven's Matrices & $30.0 \pm 8.2$ & $28.7 \pm 8.8$ & $-0.68(172)$ & 0.497 & & & & \\
\hline
\end{tabular}

Note: Values represent means \pm SD. MTHFR, 5,10-methylenetetrahydrofolate reductase; ${ }^{\text {a }}$ All participants who completed the three waves of cognitive testing at mean ages of 79, 83, and 87 years $(n=180)$;

${ }^{\mathrm{b}} P$-values for independent samples $t$ tests.

Table 3 Cognitive performance at mean ages of 79 (baseline), 83, and 87 years according to MTHFR $1298 \mathrm{~A} \rightarrow$ C genotype

\begin{tabular}{|c|c|c|c|c|c|c|c|c|}
\hline \multirow[t]{4}{*}{ Cognitive test } & \multicolumn{4}{|c|}{ Completers $^{\mathrm{a}}$} & \multicolumn{4}{|c|}{ All data } \\
\hline & MTHFR 1298CC & MTHFR & $t$ (df) & $p^{b}$ & MTHFR 1298CC & MTHFR & $t(\mathrm{df})$ & $p$ \\
\hline & genotype & \multicolumn{3}{|c|}{ 1298AA/1298AC } & genotype & \multicolumn{3}{|l|}{ 1298AA/1298A } \\
\hline & & \multicolumn{3}{|l|}{ genotype } & & \multicolumn{2}{|l|}{ C genotype } & \\
\hline \multicolumn{9}{|l|}{ Age 79 (baseline) } \\
\hline$n$ & 16 & 164 & & & 38 & 438 & & \\
\hline Verbal Fluency & $43.3 \pm 12.1$ & $42.5 \pm 11.4$ & $-0.24(177)$ & 0.808 & $40.4 \pm 10.5$ & $40.5 \pm 12.3$ & 0.08 (471) & 0.940 \\
\hline Logical Memory & $36.4 \pm 11.6$ & $35.7 \pm 13.1$ & $-0.20(178)$ & 0.839 & $30.0 \pm 11.8$ & $32.6 \pm 13.0$ & $1.20(474)$ & 0.232 \\
\hline Raven's Matrices & $32.1 \pm 8.9$ & $34.1 \pm 8.1$ & 0.94 (177) & 0.348 & $30.1 \pm 8.7$ & $32.0 \pm 8.6$ & 1.31 (469) & 0.189 \\
\hline \multicolumn{9}{|l|}{ Age 83} \\
\hline$n$ & 16 & 164 & & & 21 & 254 & & \\
\hline Verbal Fluency & $43.8 \pm 12.8$ & $41.3 \pm 12.0$ & $-0.81(176)$ & 0.418 & $41.3 \pm 13.0$ & $40.6 \pm 12.8$ & $-0.25(272)$ & 0.800 \\
\hline Logical Memory & $37.3 \pm 11.3$ & $36.2 \pm 14.2$ & $-0.31(176)$ & 0.760 & $36.4 \pm 11.1$ & $34.3 \pm 14.5$ & $-0.66(272)$ & 0.511 \\
\hline Raven's Matrices & $28.8 \pm 10.2$ & $32.4 \pm 7.7$ & $1.73(173)$ & 0.085 & $30.1 \pm 9.6$ & $30.9 \pm 8.8$ & $0.38(269)$ & 0.704 \\
\hline \multicolumn{9}{|l|}{ Age 87} \\
\hline$n$ & 16 & 164 & & & & & & \\
\hline Verbal Fluency & $39.6 \pm 12.7$ & $41.0 \pm 11.9$ & $0.43(176)$ & 0.668 & & & & \\
\hline Logical Memory & $32.0 \pm 12.7$ & $34.7 \pm 14.1$ & $0.72(176)$ & 0.471 & & & & \\
\hline Raven's Matrices & $26.4 \pm 11.1$ & $29.1 \pm 8.5$ & $1.13(172)$ & 0.262 & & & & \\
\hline
\end{tabular}

Note: Values represent means \pm SD. MTHFR, 5,10-methylenetetrahydrofolate reductase; ${ }^{\text {a }}$ All participants who completed the three waves of cognitive testing at mean ages of 79,83 , and 87 years $(n=180)$.

${ }^{\mathrm{b}} P$-values for independent samples $t$ tests. 


\section{Associations between MTHFR polymorphisms and cognitive decline}

Tables 4 and 5 show the results of the linear mixed model analyses. Cognitive performance on the domains of verbal fluency and abstract reasoning declined by $2.0 \%$ and $13.3 \%$, respectively, between 79 and 87 years, while Logical Memory scores did not show a significant decline over the 8-year follow-up period. For verbal fluency, the effect of time was statistically significant in the models with MTHFR $677 \mathrm{C} \rightarrow$ T genotype as the independent variable (Table 4), but not in the models with MTHFR $1298 \mathrm{~A} \rightarrow C$ genotype as the independent variable (Table 5 ). This discrepancy can be explained by the fact that part of the variance associated with time was accounted for by the interaction term for time $\times$ genotype; the main effect of time was similar in both models when no interaction term was included, i.e. parameter estimate $(95 \% \mathrm{Cl})=-0.20(-0.38 ;-0.03), p=0.025$ in the fully adjusted models.

The MTHFR $677 \mathrm{C} \rightarrow \mathrm{T}$ and $1298 \mathrm{~A} \rightarrow \mathrm{C}$ polymorphisms were not significantly associated with individual change in cognitive performance between 79 and 87 years on any of the domains measured. Stratifying the analyses by APOE E4 carrier status did not yield any significant results, indicating that APOE E4 allele did not modify the putative longitudinal associations between MTHFR genotype and cognitive performance. Performing separate analyses for individuals with a low folate status did not reveal any associations between MTHFR polymorphisms and individual variation in the rate of cognitive change. Post-hoc analyses using linear mixed models with erythrocyte folate concentration as the independent variable revealed that folate status was not directly associated with individual change in cognitive performance between 79 and 87 years.

Linear mixed models investigating a linear trend in cognitive performance associated with the number of variant alleles did not reveal any significant results (data not shown), implying that the MTHFR $677 \mathrm{C} \rightarrow$ T or $1298 \mathrm{~A} \rightarrow \mathrm{C}$ polymorphisms did not show a dose-effect relationship with individual change in cognitive performance between mean ages of 79 and 87 years. When the combined effect of both polymorphisms was examined, no significant associations were identified (Table 6), indicating that the two polymorphisms did not interact in affecting age-related cognitive decline over 8 years. 


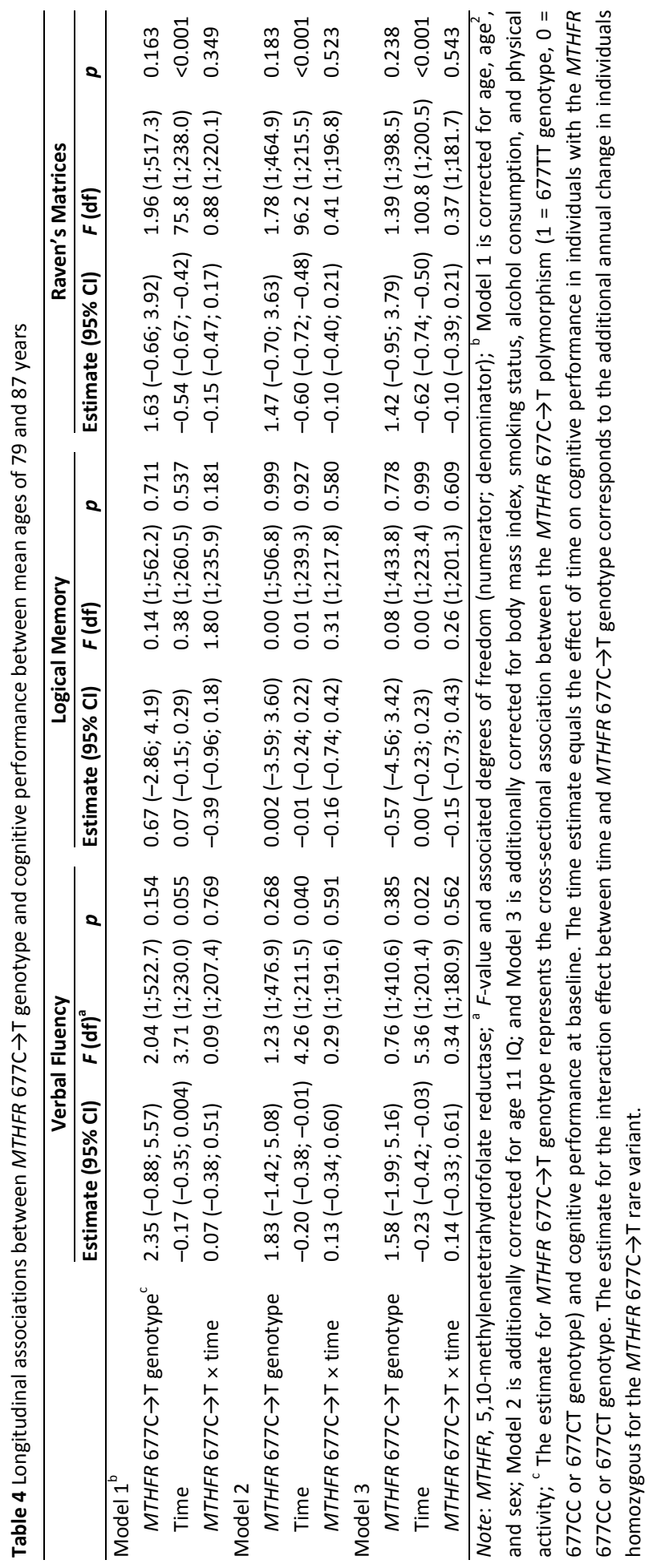




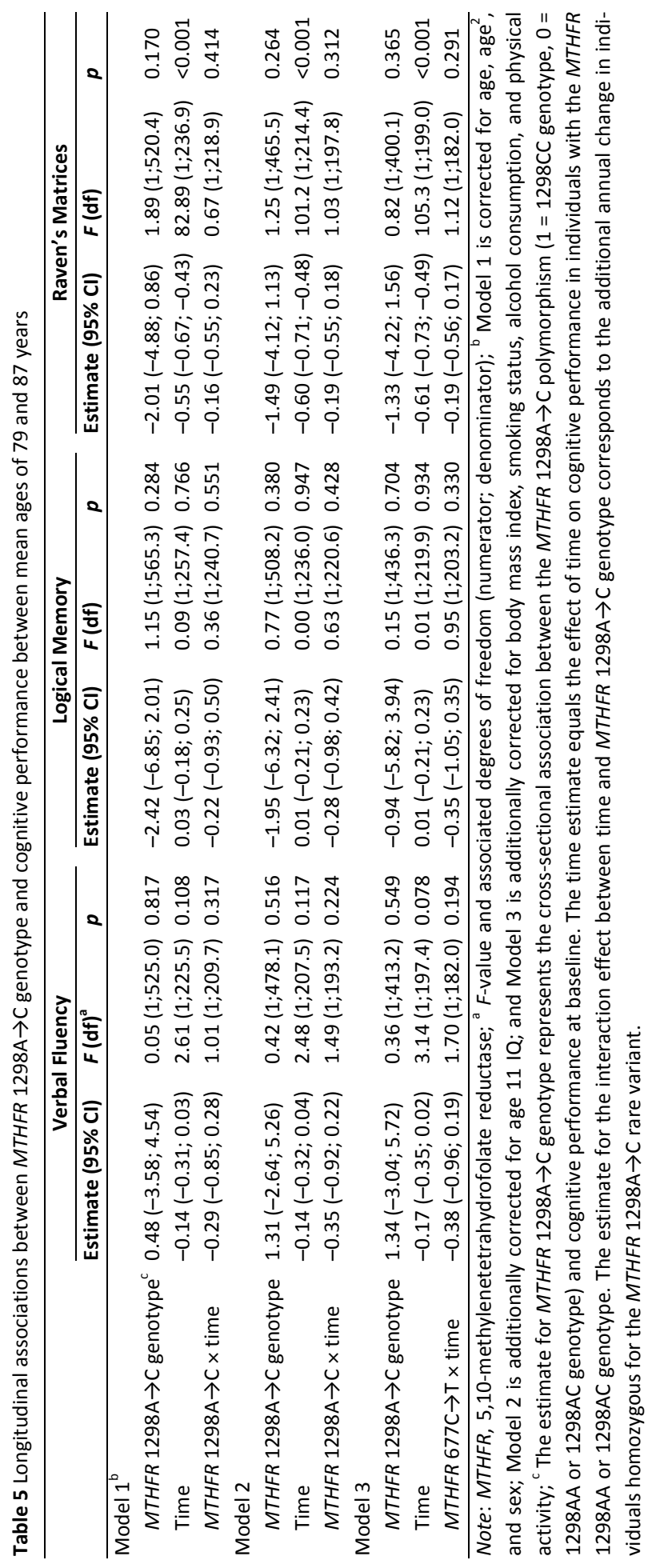




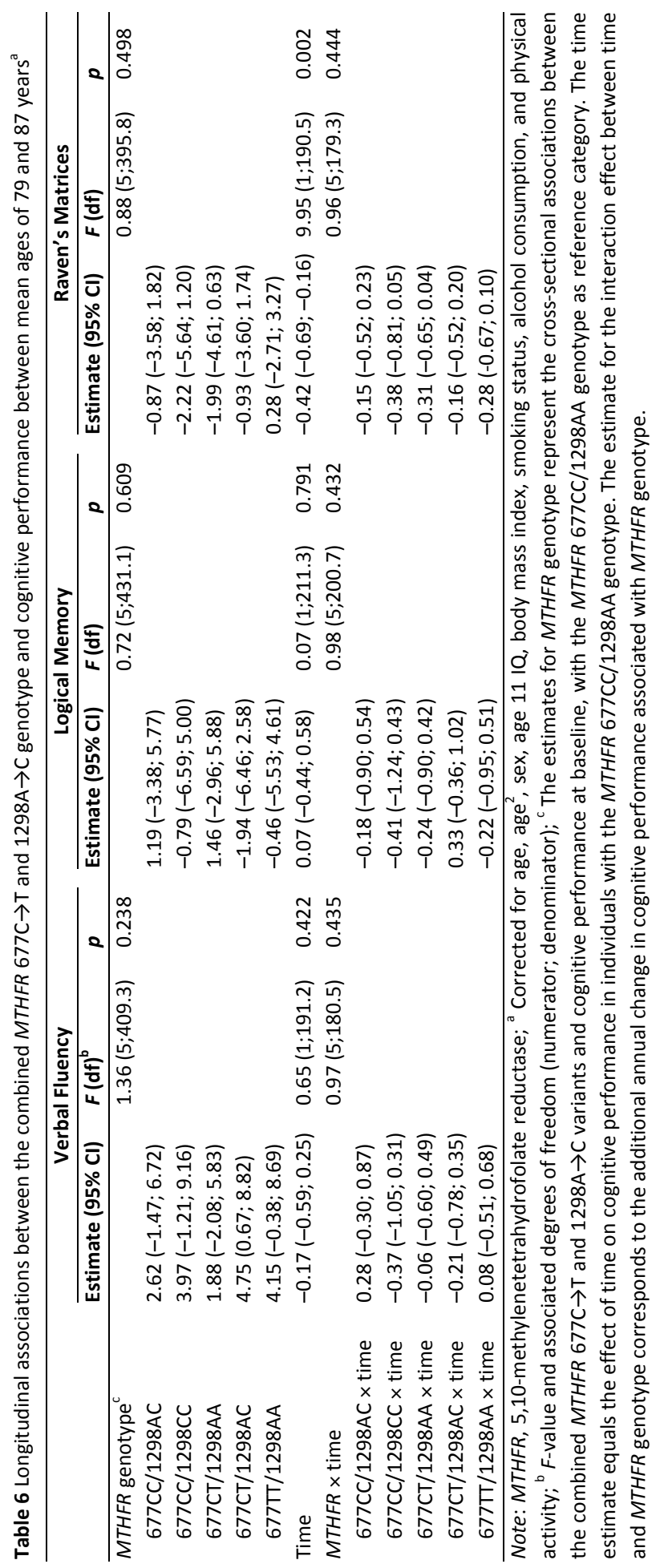




\section{Discussion}

We showed that the MTHFR $677 \mathrm{C} \rightarrow \mathrm{T}$ and $1298 \mathrm{~A} \rightarrow \mathrm{C}$ polymorphisms were not associated with individual change in cognitive performance on the domains of verbal fluency, verbal memory, and abstract reasoning between 79 and 87 years in older community-dwelling individuals. The present results suggest that altered folate metabolism due to reduced MTHFR activity does not influence cognitive performance or age-related cognitive decline in the ninth decade in the healthy ageing population.

Our findings are in line with earlier studies reporting the lack of a relationship between MTHFR genotype and cognitive performance in older adults (Almeida et al., 2005; Bathum et al., 2007; De Lau et al., 2010; Gussekloo et al., 1999; Visscher et al., 2003). However, Elkins et al. (2007) found that the MTHFR 677TT genotype was related to decreased information processing speed and executive functioning, as well as a small excess annual decline in global cognitive functioning in women aged 65 years or older. In contrast, Durga and colleagues (2006) reported a positive crosssectional association between the 677TT genotype and sensorimotor speed in community-dwelling individuals aged 50 to 70 years.

An important difference between the two above-mentioned studies and our study is the mean age of the study samples, as the participants in the studies by Elkins et al. and Durga et al. were considerably younger than those included in the present study. Interestingly, it has been found that the effect of the MTHFR 677C $\rightarrow$ T polymorphism on homocysteine levels decreases with advancing age (Husemoen et al., 2003), implying that phenotypic expression of the 677TT genotype is weaker in older adults as compared with younger individuals. It might be hypothesised that the relationship between MTHFR genotype and cognitive performance may be more prominent in younger populations, thereby leading to contrasting results when different age groups are compared. The interaction between MTHFR genotype and age seems to offer a reasonable explanation for the lack of a significant relationship between MTHFR polymorphisms and cognitive performance in the present study. In this respect, it is worth noting that most of the other studies reporting null findings on the relationship between MTHFR genotype and cognitive performance were also performed in study populations with a higher mean age than the samples used by Elkins et al. and Durga et al. (Almeida et al., 2005; Bathum et al., 2007; Gussekloo et al., 1999).

Although phenotypic expression of the MTHFR 677TT genotype may decrease with advancing age, it may increase in the presence of a low folate status (Girelli et al., 1998). Therefore, we performed secondary analyses to determine whether MTHFR genotype was associated with cognitive performance in individuals with erythrocyte folate concentrations below the median. However, no significant associations were identified, which might have been related to the small number of 
participants with erythrocyte folate levels indicative of folate deficiency, i.e. below $140 \mu \mathrm{g} / \mathrm{l}(n=14)$.

The present findings might imply that the MTHFR $677 \mathrm{C} \rightarrow \mathrm{T}$ and $1298 \mathrm{~A} \rightarrow \mathrm{C}$ polymorphisms do not influence homocysteine levels or DNA methylation capacity to such an extent that cognitive performance is affected in the ninth decade. On the other hand, it might also be argued that these polymorphisms may simultaneously exert detrimental as well as beneficial effects, thereby causing no detectable changes in cognitive performance. For example, the MTHFR $677 \mathrm{C} \rightarrow$ T polymorphism may have a negative impact on cognitive functioning by elevating homocysteine concentrations (Frosst et al., 1995) and impairing DNA methylation (Castro et al., 2004; Friso et al., 2002), but it might also exert positive effects by increasing the availability of 5,10-methylenetetrahydrofolate for DNA synthesis (Skibola et al., 1999).

The present results did not offer support for the hypothesis that APOE E4 allele carrier status, which has been shown to increase the risk of cognitive impairment in older individuals (Caselli et al., 2009; Deary et al., 2002), might modify the putative associations between MTHFR genotype and cognitive performance. Our findings are in concordance with previous research, indicating that APOE E4 carrier status and disturbances in folate metabolism might represent two distinct routes to cognitive impairment (Gottfries et al., 2001). In a similar vein, Religa and colleagues (2003) reported that the association between APOE E4 carrier status and Alzheimer's disease was unrelated to homocysteine levels, folate status, and MTHFR genotype. Furthermore, a case-control study by Brunelli et al. (2001) showed that MTHFR genotype was not associated with Alzheimer's disease and did not interact with APOE E4 allele carrier status in mediating Alzheimer's disease risk.

Previously, we found that folate status was positively correlated with cognitive performance in healthy ageing individuals (Duthie et al., 2002; Starr et al., 2005). However, we did not find any evidence for a cross-sectional relationship between the MTHFR $677 \mathrm{C} \rightarrow \mathrm{T}$ polymorphism on the one hand and cognitive performance in old age or lifetime cognitive change on the other (Visscher et al., 2003). The present study further extends these observations by showing that neither the $677 \mathrm{C} \rightarrow \mathrm{T}$ nor the $1298 \mathrm{~A} \rightarrow \mathrm{C}$ polymorphism were related to individual variation in the rate of cognitive decline between 79 and 87 years.

A common limitation of longitudinal studies is selective dropout. Statistical testing indicated that dropout was not related to MTHFR genotype in the present study. This finding was further supported by the fact that the MTHFR allele frequencies in our study were comparable to those reported for younger populations (Friedman et al., 1999; Frosst et al., 1995; Weisberg et al., 1998). However, dropout was significantly associated with a lower level of cognitive performance at baseline. The use of a statistical method that allows for the inclusion of participants with missing data at follow-up enabled us to compensate, at least in part, for this selection bias. 
Another potential limitation of longitudinal studies is the repeated administration of cognitive tests, which may introduce learning effects. Learning effects on cognitive tests might be considered a disadvantage, as they may obscure age-related cognitive decline. In contrast to verbal fluency and abstract reasoning, which showed a gradual decline over 8 years of follow-up, verbal memory performance did not show a significant decline between 79 and 87 years in our study. This may be due to the effects of procedural learning. However, it is unlikely that learning effects on the Logical Memory test might have contributed to the lack of significant results in the present study, as longitudinal variability in cognitive performance is generally well preserved, thereby allowing for the detection of individual differences in the rate of age-associated cognitive change.

The present study was characterised by substantial dropout (62\%), due to the old age of the study participants. Although we used a statistical method that allowed for the inclusion of individuals with missing data at follow-up, thereby preventing a large decrease in statistical power, we cannot rule out completely that our study might not have been able to detect very modest associations between MTHFR genotype and individual change in cognitive performance over 8 years.

The strengths of our study were its longitudinal design, the use of sensitive, domain-specific cognitive tests, the narrow chronological age range of the sample, and the adjustment for a number of potential confounders. In addition, not only did we investigate the relationship between cognitive performance and the common MTHFR $677 C \rightarrow T$ polymorphism, we also assessed the rarely-studied MTHFR $1298 \mathrm{~A} \rightarrow \mathrm{C}$ polymorphism. Furthermore, correcting the analyses for childhood intelligence enabled us to examine individual variation in the rate of cognitive change in old age, whilst eliminating the confounding influence of the stable trait of general mental ability (Deary et al., 2004).

We conclude that the MTHFR $677 \mathrm{C} \rightarrow \mathrm{T}$ and $1298 \mathrm{~A} \rightarrow \mathrm{C}$ polymorphisms are not associated with individual change in cognitive functioning in the ninth decade of the life course. Although polymorphisms in the MTHFR gene may cause disturbances in folate metabolism, they do not appear to be accompanied by changes on the level of cognitive functioning in later life. Future studies are necessary to further investigate the extent to which genetic and environmental factors underlying individual differences in folate metabolism may be involved in age-related cognitive decline.

\section{Acknowledgements}

We thank the LBC1921 participants and Beverly Roberts and Martha Whiteman for some data collection. We also thank the Scottish Council for Research in Education for allowing access to the Scottish Mental Survey 1932. The Biotechnology and Biological Sciences Research Council funded data collection for Wave 1; a Royal Society-Wolfson Research Merit Award to Ian J. Deary funded data collection for 
Wave 2; a grant from the Scottish Government's Health Directorates Chief Scientist Office supported data collection in Wave 3. The work was undertaken by The University of Edinburgh Centre for Cognitive Ageing and Cognitive Epidemiology, part of the cross council Lifelong Health and Wellbeing Initiative (G0700704/84698). Funding from the Biotechnology and Biological Sciences Research Council (BBSRC), Engineering and Physical Sciences Research Council (EPSRC), Economic and Social Research Council (ESRC), and Medical Research Council (MRC) is gratefully acknowledged. 


\section{References}

Almeida, O. P., Flicker, L., Lautenschlager, N. T., Leedman, P., Vasikaran, S., \& Van Bockxmeer, F. M. (2005). Contribution of the MTHFR gene to the causal pathway for depression, anxiety and cognitive impairment in later life. Neurobiol Aging, 26(2), 251-257.

Bathum, L., Von Bornemann Hjelmborg, J., Christiansen, L., McGue, M., Jeune, B., \& Christensen, K. (2007). Methylenetetrahydrofolate reductase $677 \mathrm{C}>\mathrm{T}$ and methionine synthase 2756A $>\mathrm{G}$ mutations: no impact on survival, cognitive functioning, or cognitive decline in nonagenarians. J Gerontol A Biol Sci Med Sci, 62(2), 196-201.

Brunelli, T., Bagnoli, S., Giusti, B., Nacmias, B., Pepe, G., Sorbi, S., \& Abbate, R. (2001). The C677T methylenetetrahydrofolate reductase mutation is not associated with Alzheimer's disease. Neurosci Lett, 315(1-2), 103-105.

Bunce, D., Kivipelto, M., \& Wahlin, A. (2004). Utilization of cognitive support in episodic free recall as a function of apolipoprotein E and vitamin B12 or folate among adults aged 75 years and older. Neuropsychology, 18(2), 362-370.

Caselli, R. J., Dueck, A. C., Osborne, D., Sabbagh, M. N., Connor, D. J., Ahern, G. L., Baxter, L. C., Rapcsak, S. Z., Shi, J., Woodruff, B. K., Locke, D. E., Snyder, C. H., Alexander, G. E., Rademakers, R., \& Reiman, E. M. (2009). Longitudinal modeling of age-related memory decline and the APOE $\varepsilon 4$ effect. $N$ Engl J Med, 361(3), 255-263.

Castro, R., Rivera, I., Ravasco, P., Camilo, M. E., Jakobs, C., Blom, H. J., \& De Almeida, I. T. (2004). 5,10methylenetetrahydrofolate reductase (MTHFR) $677 \mathrm{C} \rightarrow \mathrm{T}$ and $1298 \mathrm{~A} \rightarrow \mathrm{C}$ mutations are associated with DNA hypomethylation. J Med Genet, 41(6), 454-458.

Clarke, R., Birks, J., Nexo, E., Ueland, P. M., Schneede, J., Scott, J., Molloy, A., \& Evans, J. G. (2007). Low vitamin B-12 status and risk of cognitive decline in older adults. Am J Clin Nutr, 86(5), 1384-1391.

De Lau, L. M., Van Meurs, J. B., Uitterlinden, A. G., Smith, A. D., Refsum, H., Johnston, C., \& Breteler, M. M. (2010). Genetic variation in homocysteine metabolism, cognition, and white matter lesions. Neurobiol Aging, 31(11), 2020-2022.

Deary, I. J., Whalley, L. J., \& Starr, J. M. (2009). A Lifetime of Intelligence: Follow-up Studies of the Scottish Mental Surveys of 1932 and 1947. Washington, DC: American Psychological Association.

Deary, I. J., Whiteman, M. C., Pattie, A., Starr, J. M., Hayward, C., Wright, A. F., Carothers, A., \& Whalley, L. J. (2002). Cognitive change and the APOE \&4 allele. Nature, 418(6901), 932.

Deary, I. J., Whiteman, M. C., Starr, J. M., Whalley, L. J., \& Fox, H. C. (2004). The impact of childhood intelligence on later life: following up the Scottish Mental Surveys of 1932 and 1947. J Pers Soc Psychol, 86(1), 130-147.

Durga, J., Van Boxtel, M. P. J., Schouten, E. G., Bots, M. L., Kok, F. J., \& Verhoef, P. (2006). Folate and the methylenetetrahydrofolate reductase $677 \mathrm{C} \rightarrow \mathrm{T}$ mutation correlate with cognitive performance. Neurobiol Aging, 27(2), 334-343.

Duthie, S. J., Whalley, L. J., Collins, A. R., Leaper, S., Berger, K., \& Deary, I. J. (2002). Homocysteine, B vitamin status, and cognitive function in the elderly. Am J Clin Nutr, 75(5), 908-913.

Elkins, J. S., Johnston, S. C., Ziv, E., Kado, D., Cauley, J. A., \& Yaffe, K. (2007). Methylenetetrahydrofolate reductase C677T polymorphism and cognitive function in older women. Am J Epidemiol, 166(6), 672678.

Feng, L., Ng, T. P., Chuah, L., Niti, M., \& Kua, E. H. (2006). Homocysteine, folate, and vitamin B-12 and cognitive performance in older Chinese adults: findings from the Singapore Longitudinal Ageing Study. Am J Clin Nutr, 84(6), 1506-1512.

Folstein, M. F., Folstein, S. E., \& McHugh, P. R. (1975). "Mini-mental state". A practical method for grading the cognitive state of patients for the clinician. J Psychiatr Res, 12(3), 189-198.

Friedman, G., Goldschmidt, N., Friedlander, Y., Ben-Yehuda, A., Selhub, J., Babaey, S., Mendel, M., Kidron, M., \& Bar-On, H. (1999). A common mutation A1298C in human methylenetetrahydrofolate reductase gene: association with plasma total homocysteine and folate concentrations. J Nutr, 129(9), 1656-1661. 
Friso, S., Choi, S. W., Girelli, D., Mason, J. B., Dolnikowski, G. G., Bagley, P. J., Olivieri, O., Jacques, P. F., Rosenberg, I. H., Corrocher, R., \& Selhub, J. (2002). A common mutation in the 5,10methylenetetrahydrofolate reductase gene affects genomic DNA methylation through an interaction with folate status. Proc Natl Acad Sci USA, 99(8), 5606-5611.

Frosst, P., Blom, H. J., Milos, R., Goyette, P., Sheppard, C. A., Matthews, R. G., Boers, G. J. H., Den Heijer, M., Kluijtmans, L. A., Van den Heuvel, L. P., \& Rozen, R. (1995). A candidate genetic risk factor for vascular disease: a common mutation in methylenetetrahydrofolate reductase. Nat Genet, 10(1), 111-113.

Girelli, D., Friso, S., Trabetti, E., Olivieri, O., Russo, C., Pessotto, R., Faccini, G., Pignatti, P. F., Mazzucco, A., \& Corrocher, R. (1998). Methylenetetrahydrofolate reductase C677T mutation, plasma homocysteine, and folate in subjects from Northern Italy with or without angiographically documented severe coronary atherosclerotic disease: evidence for an important genetic-environmental interaction. Blood, 91(11), 4158-4163.

Gottfries, J., Blennow, K., Lehmann, M. W., Regland, B., \& Gottfries, C. G. (2001). One-carbon metabolism and other biochemical correlates of cognitive impairment as visualized by principal component analysis. J Geriatr Psychiatry Neurol, 14(3), 109-114.

Gow, A. J., Johnson, W., Pattie, A., Brett, C. E., Roberts, B., Starr, J. M., \& Deary, I. J. (2011). Stability and change in intelligence from age 11 to ages 70, 79 and 87: the Lothian Birth Cohorts of 1921 and 1936. Psychol Aging, 26(1), 232-240.

Gow, A. J., Johnson, W., Pattie, A., Whiteman, M. C., Starr, J., \& Deary, I. J. (2008). Mental ability in childhood and cognitive aging. Gerontology, 54(3), 177-186.

Gussekloo, J., Heijmans, B. T., Slagboom, P. E., Lagaay, A. M., Knook, D. L., \& Westendorp, R. G. (1999). Thermolabile methylenetetrahydrofolate reductase gene and the risk of cognitive impairment in those over 85. J Neurol Neurosurg Psychiatry, 67(4), 535-538.

Houlihan, L. M., Davies, G., Tenesa, A., Harris, S. E., Luciano, M., Gow, A. J., McGhee, K. A., Liewald, D. C., Porteous, D. J., Starr, J. M., Lowe, G. D., Visscher, P. M., \& Deary, I. J. (2010). Common variants of large effect in F12, KNG1, and HRG are associated with activated partial thromboplastin time. Am J Hum Genet, 86(4), 626-631.

Husemoen, L. L., Thomsen, T. F., Fenger, M., Jørgensen, H. L., \& Jørgensen, T. (2003). Contribution of thermolabile methylenetetrahydrofolate reductase variant to total plasma homocysteine levels in healthy men and women. Inter99 (2). Genet Epidemiol, 24(4), 322-330.

Kado, D. M., Karlamangla, A. S., Huang, M. H., Troen, A., Rowe, J. W., Selhub, J., \& Seeman, T. E. (2005). Homocysteine versus the vitamins folate, B6, and B12 as predictors of cognitive function and decline in older high-functioning adults: MacArthur Studies of Successful Aging. Am J Med, 118(2), 161-167.

Koike, T., Kuzuya, M., Kanda, S., Okada, K., Izawa, S., Enoki, H., \& Iguchi, A. (2008). Raised homocysteine and low folate and vitamin B-12 concentrations predict cognitive decline in community-dwelling older Japanese adults. Clin Nutr, 27(6), 865-871.

Levenson, J. M., \& Sweatt, J. D. (2005). Epigenetic mechanisms in memory formation. Nat Rev Neurosci, 6(2), 108-118.

Lezak, M. D. (1995). Neuropsychological Testing. Oxford, England: Oxford University Press.

Mattson, M. P., \& Shea, T. B. (2003). Folate and homocysteine metabolism in neural plasticity and neurodegenerative disorders. Trends Neurosci, 26(3), 137-146.

Raven, J. C., Court, J. H., \& J., R. (1977). Manual for Raven's Progressive Matrices and Vocabulary Scales. London: H. K. Lewis.

Religa, D., Styczynska, M., Peplonska, B., Gabryelewicz, T., Pfeffer, A., Chodakowska, M., Luczywek, E., Wasiak, B., Stepien, K., Golebiowski, M., Winblad, B., \& Barcikowska, M. (2003). Homocysteine, apolipoproteine $\mathrm{E}$ and methylenetetrahydrofolate reductase in Alzheimer's disease and mild cognitive impairment. Dement Geriatr Cogn Disord, 16(2), 64-70.

Scottish Council for Research in Education (1933). The intelligence of Scottish Children: A national survey of an age-group. London: University of London Press. 
Shea, T. B., Ortiz, D., \& Rogers, E. (2004). Differential susceptibility of transgenic mice lacking one or both apolipoprotein alleles to folate and vitamin E deprivation. J Alzheimers Dis, 6(3), 269-273.

Skibola, C. F., Smith, M. T., Kane, E., Roman, E., Rollinson, S., Cartwright, R. A., \& Morgan, G. (1999). Polymorphisms in the methylenetetrahydrofolate reductase gene are associated with susceptibility to acute leukemia in adults. Proc Natl Acad Sci USA, 96(22), 12810-12815.

Starr, J. M., Kilgour, A., Pattie, A., Gow, A., Bates, T. C., \& Deary, I. J. (2010). Height and intelligence in the Lothian Birth Cohort 1921: a longitudinal study. Age Ageing, 39(2), 272-275.

Starr, J. M., Pattie, A., Whiteman, M. C., Deary, I. J., \& Whalley, L. J. (2005). Vitamin B-12, serum folate, and cognitive change between 11 and 79 years. J Neurol Neurosurg Psychiatry, 76(2), 291-292.

Stegmann, K., Ziegler, A., Ngo, E. T., Kohlschmidt, N., Schroter, B., Ermert, A., \& Koch, M. C. (1999). Linkage disequilibrium of MTHFR genotypes 677C/T-1298A/C in the German population and association studies in probands with neural tube defects (NTD). Am J Med Genet, 87(1), 23-29.

Verbeke, G., \& Molenberghs, G. (2000). Linear Mixed Models for Longitudinal Data. New York: Springer.

Visscher, P. M., Tynan, M., Whiteman, M. C., Pattie, A., White, I., Hayward, C., Wright, A. F., Starr, J. M., Whalley, L. J., \& Deary, I. J. (2003). Lack of association between polymorphisms in angiotensinconverting-enzyme and methylenetetrahydrofolate reductase genes and normal cognitive ageing in humans. Neurosci Lett, 347(3), 175-178.

Wechsler, D. (1987). Wechsler Memory Scale-Revised. New York: Psychological Corporation.

Weisberg, I., Tran, P., Christensen, B., Sibani, S., \& Rozen, R. (1998). A second genetic polymorphism in methylenetetrahydrofolate reductase (MTHFR) associated with decreased enzyme activity. $\mathrm{Mol} \mathrm{Ge}-$ net Metab, 64(3), 169-172.

Wenham, P. R., Price, W. H., \& Blandell, G. (1991). Apolipoprotein E genotyping by one-stage PCR. Lancet, 337(8750), 1158-1159.

Zhao, X., Ueba, T., Christie, B. R., Barkho, B., McConnell, M. J., Nakashima, K., Lein, E. S., Eadie, B. D., Willhoite, A. R., Muotri, A. R., Summers, R. G., Chun, J., Lee, K. F., \& Gage, F. H. (2003). Mice lacking methyl-CpG binding protein 1 have deficits in adult neurogenesis and hippocampal function. Proc Natl Acad Sci USA, 100(11), 6777-6782. 



\section{CHAPTER 8 DNA methylation and cognitive functioning in healthy older adults}

Olga J.G. Schiepers, Martin P.J. van Boxtel, Renate H.M. de Groot, Jelle Jolles, Frans J. Kok, Petra Verhoef, Jane Durga

Published as a short report in Br J Nutr (2011) - Epub ahead of print 


\begin{abstract}
Long-term supplementation with folic acid may improve cognitive performance in older individuals. The relationship between folate status and cognitive performance might be mediated by changes in methylation capacity, as methylation reactions are important for normal brain functioning. Although aberrant DNA methylation has been implicated in neurodevelopmental disorders, the relationship between DNA methylation status and non-pathological cognitive functioning in humans has not yet been investigated. The present study investigated the associations between global DNA methylation and key domains of cognitive functioning in healthy older adults. Global DNA methylation, defined as the percentage of methylated to total cytosine, was measured in leukocytes in $\mathbf{2 1 5}$ men and women, aged 50 to 70 years, who participated in the Folic Acid and Carotid Intima-Media Thickness (FACIT) study. Cognitive performance was assessed by means of a comprehensive neuropsychological test battery. The associations between DNA methylation status and the various domains of cognitive functioning were assessed by means of hierarchical linear regression analyses. After adjustment for confounders, global DNA methylation was not associated with cognitive performance on any of the domains measured. In conclusion, global DNA methylation is not related to cognitive functioning in older community-dwelling adults. It is unlikely that the beneficial effects of folic acid on cognitive functioning in the FACIT trial are mediated by the extent to which cytosine residues in DNA are methylated.
\end{abstract}




\section{Introduction}

Most cognitive functioning declines with advancing age, and identifying the risk factors for age-related cognitive decline has become a topic of increasing interest. Previous research into the determinants of cognitive ageing has indicated that a low folate status might increase the risk of cognitive impairment (Kado et al., 2005; Koike et al., 2008). Although some studies did not find any associations between folate status and cognitive functioning (Clarke et al., 2007; Starr et al., 2005), several other studies have suggested a positive relationship between folate and cognitive performance in healthy humans (Duthie et al., 2002; Feng et al., 2006). In a 3-year randomised controlled trial, we found that folic acid supplementation significantly improved age-related cognitive decline on the domains of memory and informationprocessing speed (Durga et al., 2007). However, the potential biological mechanisms underlying the relationship between folate status and cognitive functioning remain to be elucidated.

One possible mechanism that might explain the involvement of folate status in cognitive performance is DNA methylation, which refers to the epigenetic modification of gene expression by the addition of methyl groups to cytosine residues in DNA (Costello \& Plass, 2001). Extensive methylation of cytosine guanine dinucleotides sequences (CpG islands) in the promoter region of a gene interferes with transcription factor binding, thereby affecting gene expression (Jones et al., 1998). Recent animal studies have suggested that DNA methylation may be involved in regulating synaptic plasticity in hippocampal neurons, thereby influencing learning and memory processes (Levenson et al., 2006; Levenson \& Sweatt, 2005; Miller \& Sweatt, 2007; Zhao et al., 2003). In addition, dysregulation of DNA methylation was found to be associated with learning deficits, anxiety, and depression in mice (Allan et al., 2008). In humans, both hypomethylation and hypermethylation of DNA have been implicated in psychiatric disorders, including schizophrenia (Costa et al., 2002), neurodegenerative disorders, such as Alzheimer's disease (Gräff \& Mansuy, 2009; Wang et al., 2008), and syndromes associated with mental retardation, e.g. Fragile $X$ syndrome and Prader-Willi syndrome (Tsankova et al., 2007).

Methyl groups for DNA methylation are provided by the universal methyl donor $S$-adenosylmethionine, which is synthesised from methionine, a key component in the folate-homocysteine cycle (Ulrey et al., 2005) (Figure 1). Folic acid may increase the availability of $S$-adenosylmethionine by promoting the conversion of homocysteine into methionine, thereby influencing DNA methylation status (Niculescu \& Zeisel, 2002). Indeed, an intervention study in older women has shown that low dietary folate intake was associated with global DNA hypomethylation, which could be reversed by folate repletion (Jacob et al., 1998). In addition, the common MTHFR $677 \mathrm{C} \rightarrow \mathrm{T}$ polymorphism, which mimics folate deficiency by impairing the conversion 
of homocysteine into methionine, has also been related to DNA hypomethylation (Castro et al., 2004; Friso et al., 2002).

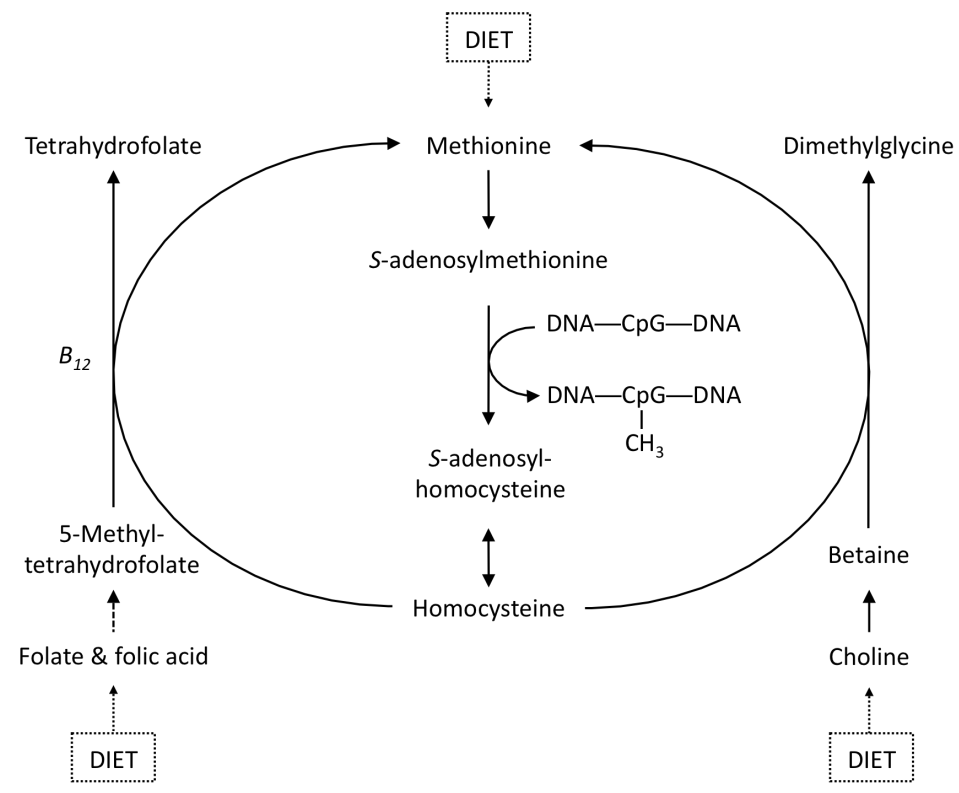

Figure 1 Metabolic pathways involved in DNA methylation. DNA methylation entails the transfer of methyl groups to cytosine residues in DNA, mostly within cytosine guanine dinucleotide sequences. Methyl groups for DNA methylation are derived from $S$-adenosylmethionine, which is synthesised from methionine. Methionine may partly be provided by the diet, but is also produced upon remethylation of homocysteine. Methyl groups for the conversion of homocysteine into methionine may be provided by the folate derivate 5-methyltetrahydrofolate, using vitamin $B_{12}$ as a co-factor, or the choline derivate betaine. Note: $\mathrm{B}_{12}$, vitamin $\mathrm{B}_{12} ;-\mathrm{CH}_{3}$, methyl group; DNA-CpG-DNA, cystosine guanine dinucleotide sequence.

Given the role of folate metabolism in generating methyl donors for methylation processes, and the involvement of DNA methylation in brain functioning, it seems reasonable to hypothesise that folate status might influence cognitive functioning by exerting effects on DNA methylation. However, the association between DNA methylation status and cognitive performance in the general population has not yet been investigated. Therefore, the present study examined whether leukocyte global DNA methylation was associated with cognitive performance in healthy older adults. We used data from the Folic Acid and Carotid Intima-Media Thickness (FACIT) study, in which beneficial effects of long-term folic acid supplementation on cognitive functioning were found (Durga et al., 2007). 


\section{Methods}

\section{Study population}

The present study was performed using data from the FACIT study, a randomised, double-blind, placebo-controlled trial, originally designed to investigate the effects of 3-year folic acid supplementation on the risk of cardiovascular disease as measured by carotid intima-media thickness (Durga et al., 2007). The study population consisted of 818 men and women. Participants were recruited from blood bank registries as well as from municipal registries. Individuals were included if between the ages of 50 and 70 years, and, specifically for women, had reached the menopause at least 2 years before. Exclusion criteria were plasma total homocysteine concentrations $<13 \mu \mathrm{mol} / \mathrm{l}$ or $>26 \mu \mathrm{mol} / \mathrm{l}$, use of B-vitamin supplements or drugs that could affect atherosclerotic progression (e.g. lipid-lowering or hormone replacement therapies), or self-reported intestinal disease. We also excluded individuals with elevated homocysteine concentrations due to factors other than suboptimal folate concentrations, including serum vitamin $B_{12}$ concentrations $<200$ pmol/l, self-reported medical diagnosis of renal or thyroid disorders, or selfreported use of medications that influence folate metabolism.

Cognitive functioning was assessed at baseline and at 3-year follow-up by means of a neuropsychological test battery. Venous blood samples were collected at baseline. To test the hypothesis that folic acid might influence cognitive functioning through changes in DNA methylation status, leukocyte global DNA methylation was determined in a subsample of 216 participants. First, the study population was stratified by MTHFR 677C $\rightarrow$ T genotype, to ensure equal distribution of MTHFR $677 C \rightarrow T$ genotypes in the final sample. Thereafter, participants in the folate treatment group were randomly selected from the three strata and individually matched with participants in the placebo group on the variables age, sex, smoking status, and MTHFR $677 C \rightarrow$ T genotype, as these variables may influence DNA methylation (Brait et al., 2009; Castro et al., 2004; Drinkwater et al., 1989; Friso et al., 2002). Some samples were not measured due to human error in sample retrieval. Valid DNA methylation data were available for 111 participants in the treatment group and 105 participants in the placebo group. As valid data on cognitive functioning were lacking for one participant in the folate treatment group, the final study sample consisted of 215 individuals.

The Medical Ethics Committee of Wageningen University approved the study. Written informed consent was obtained from all the participants. 


\section{Cognitive functioning}

Cognitive functioning was assessed by means of a comprehensive neuropsychological test battery. The Visual Verbal Word Learning Task (WLT) was used to test learning capacity, as well as recall and retrieval from long-term memory (Van der Elst et al., 2005). In three trials, fifteen commonly used monosyllabic words were visually presented in a fixed order at 2-s intervals. The outcome measures were maximum and total immediate recall (WLTmax and WLTtot, respectively), as well as delayed recall after $20 \mathrm{~min}$ (WLTdr).

The Stroop Color-Word Interference Test was used to assess selective attention and interference susceptibility (Van der Elst et al., 2006d). Three subtasks were presented on separate test sheets containing four rows of ten columns of colour names or coloured patches. Participants were asked to read aloud colour names printed in black (subtask I), name the colour of coloured patches (subtask II), and name the ink colour of colour names printed in an incongruous colour (subtask III). The outcome parameters were speed on subtask I (Str1) and subtask III (Str3).

The Concept Shifting Test (CST) was used to measure behavioural planning and cognitive flexibility (Van der Elst et al., 2006b). Participants were instructed to cross out sixteen items presented in small circles on a test sheet as fast as possible in the right order (1-2-3-4 [subtask A], A-B-C-D [subtask B], 1-A-2-B [subtask C]). In a fourth subtask (subtask $O$ ), individuals were instructed to cross out empty circles as fast as possible, in order to measure general motor speed. The outcome measures were speed on subtask A (CSTa), subtask B (CSTb), subtask C (CSTc), and subtask $O$ (CSTO).

The Letter-Digit Substitution Test (LDST) was used to determine efficiency of operations in working memory (Van der Elst et al., 2006c). Participants were asked to replace letters presented on a test sheet by their corresponding digits, as indicated by a key showing nine numbers paired with different letters. The total number of correct substitutions completed within $90 \mathrm{~s}$ was recorded.

The Verbal Fluency Test was used to assess the ability to recollect clusters of related words from encyclopedic memory (Van der Elst et al., 2006a). Participants were instructed to name as many animals as possible in $60 \mathrm{~s}$. The outcome parameter was the total number of different animals named.

\section{Data reduction}

The raw test scores of the WLT, the Stroop Color-Word Interference Test, and the CST were clustered into three a-priori defined composite performance indices, in order to limit the number of dependent variables and to improve the robustness of the underlying cognitive construct (Lezak et al., 2004). First, the raw test scores were transformed into $Z$-scores by subtracting the mean score from the individual test score and dividing this by the mean SD $(Z=(x-$ mean)/SD). Second, $Z$-scores were averaged, resulting in the following composite scores: memory ([ZWLTmax + 
ZWLTtot + ZWLTdr]/3), sensorimotor speed ([ZStr1 + ZCSTa + ZCSTb + ZCST0]/4), and complex speed $([Z S t r 3+Z C S T c] / 2)$. Finally, the signs of the two speed scores were inverted in order to reflect above normal performance when positive, and below normal when negative. Cognitive performance on the domains of information processing speed and word fluency was represented by the Z-score of the LDST test and the Z-score of the Verbal Fluency Test, respectively.

\section{DNA methylation status and genotyping}

Genomic DNA was isolated from peripheral blood leukocytes at baseline. Global DNA methylation was determined by liquid chromatography-tandem mass spectrometry, as described previously (Kok et al., 2007). Genomic DNA methylation status was calculated as the percentage of methylated to total cytosine (mCyt/tCyt) using the following formula: (nmol mCyt/[nmol mCyt + nmol Cyt $]$ ) $\times 100 \%$ (Kok et al., 2007).

MTHFR $677 \mathrm{C} \rightarrow$ T genotype was determined by polymerase chain reaction with restriction fragment length polymorphism analysis with Hinfl (Frosst et al., 1995), and was defined as common variant (CC or CT genotype) or rare variant (TT genotype).

\section{Blood measurements}

Fasting venous blood samples were collected at baseline, directly processed, and stored at $-80^{\circ} \mathrm{C}$. Serum folate was measured using a chemiluminescent immunoassay (Immulite 2000, Diagnostic Products Corporation). Erythrocyte folate was determined in duplicate and the average was taken to reduce measurement error. Erythrocyte folate concentrations were calculated by means of the following formula: (unadjusted erythrocyte folate/hematocrit) - ([1 - hematocrit]/hematocrit) $\times$ serum folate. Plasma total homocysteine was determined by high-performance liquid chromatography and fluorimetric detection, as described previously (Ubbink et al., 1991).

\section{Demographic and lifestyle variables}

Level of education was measured by classifying formal schooling according to the Dutch educational system (De Bie, 1987), and categorised into 'low', 'middle', or 'high', i.e. corresponding to primary education, junior vocational training, and senior vocational/academic training, respectively. Alcohol consumption (g/day) and current smoking (yes or no) were ascertained by means of self-report questionnaires, which were reviewed by a trained research assistant. Body mass index (BMI, $\mathrm{kg} / \mathrm{m}^{2}$ ) 
was calculated from height and weight, and physical activity was estimated using the Physical Activity Scale for the Elderly (Washburn et al., 1993).

\section{Statistical analysis}

Normality of data distributions was ascertained by normal P-P plots. Baseline data were used to assess the cross-sectional associations between global DNA methylation status and cognitive functioning. Zero-order correlations were calculated for all continuous variables. Independent samples $t$ tests and univariate ANOVA were carried out to examine whether DNA methylation status varied according to sex, level of education, smoking status, or MTHFR 677C $\rightarrow$ T genotype.

Hierarchical linear regression analyses were performed for DNA methylation status in relation to each of the five cognitive performance indices. The analyses were corrected for sociodemographic and lifestyle variables that were considered potential confounders, i.e. age, sex, level of education, alcohol consumption, smoking status, physical activity, erythrocyte folate concentration, and MTHFR 677C $\rightarrow$ T genotype (Brait et al., 2009; Castro et al., 2004; Drinkwater et al., 1989; Friso et al., 2002; Yuasa et al., 2009).

To investigate the possibility of a non-linear relationship between global DNA methylation and cognitive performance, the analyses were repeated with the quadratic term for DNA methylation status as the independent variable, adjusted for covariates and the linear term for DNA methylation status. The quadratic term for DNA methylation status was expressed as the residuals of regressing (DNA methylation $)^{2}$ on DNA methylation, i.e. the quadratic component that is orthogonal to the linear component of DNA methylation.

Statistical differences were considered significant at $p$-values $<0.05$. All analyses were performed using SPSS 16.0 (SPSS Inc., Chicago, IL, USA).

\section{Results}

Table 1 summarises the baseline characteristics of the study population. The percentage of methylated to total cytosine residues in leukocyte DNA ranged from 4.0 to $5.6 \%$, which was comparable to the range reported by other population-based studies (Friso et al., 2002; Kok et al., 2007; Romerio et al., 2005). Global DNA methylation showed a significant positive correlation with erythrocyte folate concentration ( $r=0.143, p=0.036)$ and physical activity $(r=0.138, p=0.043)$. Age showed a negative, albeit statistically non-significant, correlation with DNA methylation ( $r=-0.092, p=0.178$ ). Plasma total homocysteine, alcohol consumption, and BMI were not significantly correlated with DNA methylation status $(r=-0.055, p=$ 0.424; Spearman's rank correlation coefficient $=-0.097, p=0.155$; and $r=0.024, p=$ 
0.731, respectively). In addition, the extent of global DNA methylation did not vary according to sex $(t=-1.285, p=0.200)$, level of education $(F=0.611, p=0.544)$, smoking status $(t=1.611, p=0.109)$, or MTHFR $677 C \rightarrow$ T genotype $(t=-0.907, p=$ 0.365).

Table 1 Characteristics of the study population

\begin{tabular}{|c|c|}
\hline & Total sample \\
\hline$n$ & 215 \\
\hline Age (years) & $60.9 \pm 5.4$ \\
\hline Female sex (\%) & 34.9 \\
\hline Level of education, low / middle / high (\%) & $26.0 / 39.1 / 34.9$ \\
\hline Alcohol consumption (g/day) ${ }^{\mathrm{a}}$ & $12.6(4.5 ; 23.5)$ \\
\hline Current smoker (\%) & 14.9 \\
\hline $\mathrm{BMI}\left(\mathrm{kg} / \mathrm{m}^{2}\right)$ & $26.7 \pm 3.9$ \\
\hline Physical activity (PASE score) & $149.2 \pm 64.8$ \\
\hline Erythrocyte folate $(\mathrm{nmol} / \mathrm{l})$ & $716.0 \pm 258.8$ \\
\hline Plasma total homocysteine ( $\mu \mathrm{mol} / \mathrm{l})$ & $13.4 \pm 3.1$ \\
\hline MTHFR 677C $\rightarrow$ T genotype, CC / CT / TT (\%) & $34.9 / 32.6 / 32.6$ \\
\hline DNA methylation status (\%) & $4.6 \pm 0.2$ \\
\hline
\end{tabular}

Note: Values are means \pm SD. BMI, body mass index; PASE, Physical Activity Scale for the Elderly; MTHFR, 5,10-methylenetetrahydrofolate reductase; ${ }^{a}$ Median (interquartile range) is given because of skewed data distribution; ${ }^{\mathrm{b}}$ Defined as the percentage of methylated to total cytosine (mCyt/tCyt).

Hierarchical linear regression analyses corrected for age, sex, level of education, alcohol consumption, smoking status, and physical activity, erythrocyte folate concentration, and MTHFR $677 C \rightarrow$ T genotype, did not reveal any significant associations between leukocyte global DNA methylation and cognitive performance on any of the domains measured (Table 2 ). In addition, repeating the analyses with the quadratic term for DNA methylation status as the independent variable did not yield any significant results (data not shown), implying that global DNA methylation did not show a non-linear relationship with cognitive performance.

Table 2 Cross-sectional associations between global DNA methylation and cognitive performance in older adults

\begin{tabular}{llllll}
\hline Cognitive performance index $^{\mathrm{a}}$ & $\boldsymbol{R}^{2}$ step $^{\mathrm{b}}$ & $\boldsymbol{p}$ & $\boldsymbol{R}^{2}$ change step 2 & $\mathbf{B}(\mathbf{9 5 \%} \mathbf{~ C l})^{\mathbf{c}}$ & $\boldsymbol{p}$ \\
\hline Memory & 0.201 & $<0.001$ & 0.006 & $0.35(-0.19 ; 0.90)$ & 0.204 \\
Sensorimotor speed & 0.231 & $<0.001$ & 0.006 & $0.30(-0.16 ; 0.75)$ & 0.202 \\
Complex speed & 0.197 & $<0.001$ & 0.000 & $-0.08(-0.60 ; 0.43)$ & 0.755 \\
Information processing speed & 0.212 & $<0.001$ & 0.000 & $0.10(-0.48 ; 0.68)$ & 0.736 \\
Word fluency & 0.141 & $<0.001$ & 0.008 & $0.43(-0.18 ; 1.03)$ & 0.164
\end{tabular}

${ }^{a}$ Cognitive performance indices are expressed as $Z$-scores; ${ }^{b} R^{2}$ represents the proportion of explained variance, and $R^{2}$ change represents the change in the proportion of explained variance after each step in hierarchical linear regression analyses. The covariates age, sex, level of education, alcohol consumption, smoking status, physical activity, erythrocyte folate concentration, and MTHFR $677 \mathrm{C} \rightarrow \mathrm{T}$ genotype, were entered in step 1 and DNA methylation status in step 2; ${ }^{c}$ Unstandardised regression coefficient $(95 \% \mathrm{Cl})$ for DNA methylation status in step 2. 


\section{Discussion}

We have shown that the epigenetic mechanism of DNA methylation, which controls gene expression, is not associated with cognitive performance in healthy older adults. The present study did not support the hypothesis that individual variation in cognitive functioning might be related to the extent of leukocyte global DNA methylation.

Although there are no previous studies investigating the relationship between DNA methylation and cognitive functioning in healthy humans, animal research has suggested that DNA methylation may be involved in learning and memory processes (Allan et al., 2008; Levenson et al., 2006; Levenson \& Sweatt, 2005; Miller \& Sweatt, 2007; Zhao et al., 2003). For example, mice lacking the key proteins involved in repressing the transcription of genes with methylated promoter regions, showed decreased hippocampal neurogenesis and neuronal differentiation, reduced synaptic plasticity, and impaired learning ability (Zhao et al., 2003). In addition, these animals exhibited symptoms of anxiety and depression, as well as reduced social interaction (Allan et al., 2008), which suggests that disturbances in DNA methylation-mediated gene expression might cause behavioural and cognitive deficits. In humans, aberrant DNA methylation has been implicated in a number of pathological conditions associated with cognitive impairment, including neurodevelopmental disorders (Tsankova et al., 2007), psychiatric diseases (Costa et al., 2002), and neurodegenerative disorders (Gräff \& Mansuy, 2009; Wang et al., 2008).

Whereas previous studies have indicated that dysregulation of DNA methylation might be associated with deficits in cognitive functioning, we did not find any evidence for a connection between global DNA methylation and cognitive performance in healthy adults. The present results might imply that there is no functional relationship between the extent of cytosine methylation within DNA and individual differences in cognitive performance in the general population. In line with earlier reports (Kok et al., 2007; Romerio et al., 2005), we observed that global DNA methylation has a relatively narrow distribution in healthy individuals. These findings suggest that under non-pathological conditions, there appears to be little interindividual variation in DNA methylation-based regulation of gene expression, which decreases the likelihood that individual differences in cognitive performances may be mediated by this epigenetic mechanism.

Although global DNA methylation might not be involved in cognitive functioning, the present results do not rule out the possibility that DNA methylation at specific loci may be related to cognitive performance. Indeed, such dissociation between global and gene-specific methylation patterns has been reported before. For example, animal studies have shown that dietary folate deficiency, which caused cognitive impairment and reduced methylation capacity as measured by the availability of the methyl donor S-adenosylmethionine, was associated with in- 
creased expression of the Presenilin 1 (PS1) gene, which is involved in the cleavage of amyloid precursor protein, without causing changes in global DNA methylation (Fuso et al., 2005). In humans, gene-specific alterations in DNA methylation patterns have been associated with a number of pathological conditions characterised by cognitive deficits. For example, hypomethylation of the promoter region of the PS1 gene, which leads to increased production of $\beta$-amyloid peptide, has been implicated in the aetiology of Alzheimer's disease (Scarpa et al., 2003; Wang et al., 2008). In addition, schizophrenia has been associated with reduced expression of the gene encoding the protein Reelin, which is involved in neurodevelopment and synaptic plasticity, due to hypermethylation of the gene's promoter region (Costa et al., 2002). However, although it may be speculated that gene-specific changes in DNA methylation might underlie part of the individual differences in non-pathological cognitive functioning, little is known about the genetic correlates of cognitive performance in healthy humans.

An alternative explanation for the present null findings is that cognitive performance might be related to short-term changes, i.e. within the range of hours, in DNA methylation patterns rather than individual variation in the extent of global DNA methylation. Indeed, previous animal studies have reported that dynamic and reversible changes in DNA methylation are crucial for synaptic plasticity, learning, and memory processes (Levenson et al., 2006; Miller \& Sweatt, 2007). From this point of view, cognitive performance may not vary according to the extent of global DNA methylation, although short-term changes in this epigenetic mechanism might still be involved in the regulation of cognitive functioning. It has been suggested that memory formation may be regulated by the transient methylation and demethylation of DNA in response to environmental stimulation (Miller \& Sweatt, 2007). It might be complicated, however, to measure such short-term changes in DNA methylation in volunteers, which makes it rather difficult to test this possibility.

From a methodological perspective, the fact that we determined DNA methylation status in leukocytes rather than brain tissue should be considered a limitation, as the extent of DNA methylation might differ between cells derived from the periphery and the brain. For example, a recent study comparing DNA methylation profiles in several human tissues, including monocytes and the brain, has indicated that DNA methylation patterns might be tissue-specific (Schilling \& Rehli, 2007). However, no direct measures of DNA methylation status in the central nervous system were available, given the inability to measure cerebrospinal fluid or brain DNA methylation status in volunteers.

It might also be argued that due to the relatively small sample size, the present study might have been underpowered to detect very modest associations. However, it should be noted that our study had $80 \%$ power to detect a $3 \%$ change in the proportion of explained variance, which may be considered a small effect size (Cohen, 1988). 
The present study did not support the notion that folate metabolism may influence cognitive performance through the mechanism of global DNA methylation, as measured in leukocytes. In line with the present findings, we found that long-term supplementation with folic acid, which significantly improved cognitive performance in the FACIT population (Durga et al., 2007), did not have any effect on leukocyte global DNA methylation status (A. Jung, Y. Smulders, P. Verhoef, F.J. Kok, H. Blom, R. Kok, E. Schouten, E. Kampman, J. Durga, 2010; unpublished results). Although folate metabolism may increase methylation capacity via the conversion of homocysteine into methionine, it is not the sole source of methyl groups for methylation reactions. Methyl groups may also be provided by the dietary intake of methionine, or by betaine-mediated remethylation of homocysteine, which is dependent on the availability of betaine or choline from the diet (Niculescu \& Zeisel, 2002) (Figure 1). Thus, methylation capacity is not exclusively dependent on folate status, which might explain the observed lack of any effect of long-term folic acid supplementation on global DNA methylation.

Another potential mechanism, through which folate status might exert beneficial effects on cognitive functioning, is the reduction of plasma homocysteine concentrations. In the FACIT study, we observed that 3-year supplementation with folic acid was accompanied by a significant decrease in plasma total homocysteine of about $25 \%$ (Durga et al., 2007). Low folate concentrations impair the remethylation of homocysteine, thereby increasing homocysteine concentrations. Elevated plasma homocysteine concentrations have been associated with vascular disease (Selhub et al., 1995), which, in turn, may increase the risk of cognitive impairment and Alzheimer's disease (Dolan et al., 2010; Gorgone et al., 2009). The 'homocysteine hypothesis' of cognitive decline proposes that folate might contribute to preserve cognitive function by preventing cerebrovascular damage (Calvaresi \& Bryan, 2001).

To the best of our knowledge, this is the first study to investigate the relationship between leukocyte global DNA methylation and non-pathological cognitive functioning in community-dwelling older adults. Due to its sample size, we were able to take into account a number of potential confounders. In addition, we used sensitive cognitive tests, which allowed for examining the associations between DNA methylation and key domains of cognitive functioning.

Clearly, folate status and cognitive performance show an intricate relationship, and the underlying mechanisms remain to be identified. Future studies are necessary to explain the associations between folate metabolism and brain functioning. 


\section{Acknowledgements}

The FACIT study was supported by the Netherlands Organisation for Health Research and Development (grant number 200110002), Sanquin Blood Bank (grant number 02-001), Wageningen University, and Top Institute Food and Nutrition. 


\section{References}

Allan, A. M., Liang, X., Luo, Y., Pak, C., Li, X., Szulwach, K. E., Chen, D., Jin, P., \& Zhao, X. (2008). The loss of methyl-CpG binding protein 1 leads to autism-like behavioral deficits. Hum Mol Genet, 17(13), 20472057.

Brait, M., Ford, J. G., Papaiahgari, S., Garza, M. A., Lee, J. I., Loyo, M., Maldonado, L., Begum, S., McCaffrey, L., Howerton, M., Sidransky, D., Emerson, M. R., Ahmed, S., Williams, C. D., \& Hoque, M. O. (2009). Association between lifestyle factors and CpG island methylation in a cancer-free population. Cancer Epidemiol Biomarkers Prev, 18(11), 2984-2991.

Calvaresi, E., \& Bryan, J. (2001). B vitamins, cognition, and aging: a review. J Gerontol B Psychol Sci Soc Sci, 56(6), P327-339.

Castro, R., Rivera, I., Ravasco, P., Camilo, M. E., Jakobs, C., Blom, H. J., \& De Almeida, I. T. (2004). 5,10methylenetetrahydrofolate reductase (MTHFR) $677 \mathrm{C} \rightarrow \mathrm{T}$ and $1298 \mathrm{~A} \rightarrow \mathrm{C}$ mutations are associated with DNA hypomethylation. J Med Genet, 41(6), 454-458.

Clarke, R., Birks, J., Nexo, E., Ueland, P. M., Schneede, J., Scott, J., Molloy, A., \& Evans, J. G. (2007). Low vitamin B-12 status and risk of cognitive decline in older adults. Am J Clin Nutr, 86(5), 1384-1391.

Cohen, J. (1988). Statistical Power Analysis for the Behavioral Sciences (2nd ed.). Hillsdale, NJ: Erlbaum.

Costa, E., Chen, Y., Davis, J., Dong, E., Noh, J. S., Tremolizzo, L., Veldic, M., Grayson, D. R., \& Guidotti, A. (2002). REELIN and schizophrenia: a disease at the interface of the genome and the epigenome. Mol Interv, 2(1), 47-57.

Costello, J. F., \& Plass, C. (2001). Methylation matters. J Med Genet, 38(5), 285-303.

De Bie, S. E. (1987). Standaardvragen 1987: Voorstellen voor uniformering van vraagstellingen naar achtergrondkenmerken en interviews [Standard questions 1987: Proposal for uniformization of questions regarding background variables and interviews] (2nd ed.). Leiden, The Netherlands: Leiden University Press.

Dolan, H., Crain, B., Troncoso, J., Resnick, S. M., Zonderman, A. B., \& Obrien, R. J. (2010). Atherosclerosis, dementia, and Alzheimer disease in the Baltimore Longitudinal Study of aging cohort. Ann Neurol, 68(2), 231-240.

Drinkwater, R. D., Blake, T. J., Morley, A. A., \& Turner, D. R. (1989). Human lymphocytes aged in vivo have reduced levels of methylation in transcriptionally active and inactive DNA. Mutat Res, 219(1), 29-37.

Durga, J., Van Boxtel, M. P. J., Schouten, E. G., Kok, F. J., Jolles, J., Katan, M. B., \& Verhoef, P. (2007). Effect of 3-year folic acid supplementation on cognitive function in older adults in the FACIT trial: a randomised, double blind, controlled trial. Lancet, 369(9557), 208-216.

Duthie, S. J., Whalley, L. J., Collins, A. R., Leaper, S., Berger, K., \& Deary, I. J. (2002). Homocysteine, B vitamin status, and cognitive function in the elderly. Am J Clin Nutr, 75(5), 908-913.

Feng, L., Ng, T. P., Chuah, L., Niti, M., \& Kua, E. H. (2006). Homocysteine, folate, and vitamin B-12 and cognitive performance in older Chinese adults: findings from the Singapore Longitudinal Ageing Study. Am J Clin Nutr, 84(6), 1506-1512.

Friso, S., Choi, S. W., Girelli, D., Mason, J. B., Dolnikowski, G. G., Bagley, P. J., Olivieri, O., Jacques, P. F., Rosenberg, I. H., Corrocher, R., \& Selhub, J. (2002). A common mutation in the 5,10methylenetetrahydrofolate reductase gene affects genomic DNA methylation through an interaction with folate status. Proc Natl Acad Sci USA, 99(8), 5606-5611.

Frosst, P., Blom, H. J., Milos, R., Goyette, P., Sheppard, C. A., Matthews, R. G., Boers, G. J. H., Den Heijer, M., Kluijtmans, L. A., Van den Heuvel, L. P., \& Rozen, R. (1995). A candidate genetic risk factor for vascular disease: a common mutation in methylenetetrahydrofolate reductase. Nat Genet, 10(1), 111-113.

Fuso, A., Seminara, L., Cavallaro, R. A., D’Anselmi, F., \& Scarpa, S. (2005). S-adenosylmethionine/homocysteine cycle alterations modify DNA methylation status with consequent deregulation of PS1 and BACE and beta-amyloid production. Mol Cell Neurosci, 28(1), 195-204. 
Gorgone, G., Ursini, F., Altamura, C., Bressi, F., Tombini, M., Curcio, G., Chiovenda, P., Squitti, R., Silvestrini, M., lentile, R., Pisani, F., Rossini, P. M., \& Vernieri, F. (2009). Hyperhomocysteinemia, intimamedia thickness and C677T MTHFR gene polymorphism: a correlation study in patients with cognitive impairment. Atherosclerosis, 206(1), 309-313.

Gräff, J., \& Mansuy, I. M. (2009). Epigenetic dysregulation in cognitive disorders. Eur J Neurosci, 30(1), 18.

Jacob, R. A., Gretz, D. M., Taylor, P. C., James, S. J., Pogribny, I. P., Miller, B. J., Henning, S. M., \& Swendseid, M. E. (1998). Moderate folate depletion increases plasma homocysteine and decreases lymphocyte DNA methylation in postmenopausal women. J Nutr, 128(7), 1204-1212.

Jones, P. L., Veenstra, G. J., Wade, P. A., Vermaak, D., Kass, S. U., Landsberger, N., Strouboulis, J., \& Wolffe, A. P. (1998). Methylated DNA and MeCP2 recruit histone deacetylase to repress transcription. Nat Genet, 19(2), 187-191.

Kado, D. M., Karlamangla, A. S., Huang, M. H., Troen, A., Rowe, J. W., Selhub, J., \& Seeman, T. E. (2005). Homocysteine versus the vitamins folate, B6, and B12 as predictors of cognitive function and decline in older high-functioning adults: MacArthur Studies of Successful Aging. Am J Med, 118(2), 161-167.

Koike, T., Kuzuya, M., Kanda, S., Okada, K., Izawa, S., Enoki, H., \& Iguchi, A. (2008). Raised homocysteine and low folate and vitamin B-12 concentrations predict cognitive decline in community-dwelling older Japanese adults. Clin Nutr, 27(6), 865-871.

Kok, R. M., Smith, D. E., Barto, R., Spijkerman, A. M., Teerlink, T., Gellekink, H. J., Jakobs, C., \& Smulders, Y. M. (2007). Global DNA methylation measured by liquid chromatography-tandem mass spectrometry: analytical technique, reference values and determinants in healthy subjects. Clin Chem Lab Med, 45(7), 903-911.

Levenson, J. M., Roth, T. L., Lubin, F. D., Miller, C. A., Huang, I. C., Desai, P., Malone, L. M., \& Sweatt, J. D. (2006). Evidence that DNA (cytosine-5) methyltransferase regulates synaptic plasticity in the hippocampus. J Biol Chem, 281(23), 15763-15773.

Levenson, J. M., \& Sweatt, J. D. (2005). Epigenetic mechanisms in memory formation. Nat Rev Neurosci, 6(2), 108-118.

Lezak, M. D., Howieson, D. B., \& Loring, D. W. (2004). Neuropsychological Assessment (4th ed.). New York: Oxford University Press.

Miller, C. A., \& Sweatt, J. D. (2007). Covalent modification of DNA regulates memory formation. Neuron, 53(6), 857-869.

Niculescu, M. D., \& Zeisel, S. H. (2002). Diet, methyl donors and DNA methylation: interactions between dietary folate, methionine and choline. J Nutr, 132(8 Suppl), 2333S-2335S.

Romerio, A. S., Fiorillo, G., Terruzzi, I., Senesi, P., Testolin, G., \& Battezzati, A. (2005). Measurement of DNA methylation using stable isotope dilution and gas chromatography-mass spectrometry. Anal Biochem, 336(2), 158-163.

Scarpa, S., Fuso, A., D’Anselmi, F., \& Cavallaro, R. A. (2003). Presenilin 1 gene silencing by S-adenosylmethionine: a treatment for Alzheimer disease? FEBS Lett, 541(1-3), 145-148.

Schilling, E., \& Rehli, M. (2007). Global, comparative analysis of tissue-specific promoter CpG methylation. Genomics, 90(3), 314-323.

Selhub, J., Jacques, P. F., Bostom, A. G., D'Agostino, R. B., Wilson, P. W., Belanger, A. J., O'Leary, D. H., Wolf, P. A., Schaefer, E. J., \& Rosenberg, I. H. (1995). Association between plasma homocysteine concentrations and extracranial carotid-artery stenosis. N Engl J Med, 332(5), 286-291.

Starr, J. M., Pattie, A., Whiteman, M. C., Deary, I. J., \& Whalley, L. J. (2005). Vitamin B-12, serum folate, and cognitive change between 11 and 79 years. J Neurol Neurosurg Psychiatry, 76(2), 291-292.

Tsankova, N., Renthal, W., Kumar, A., \& Nestler, E. J. (2007). Epigenetic regulation in psychiatric disorders. Nat Rev Neurosci, 8(5), 355-367.

Ubbink, J. B., Hayward-Vermaak, W. J., \& Bissbort, S. (1991). Rapid high-performance liquid chromatographic assay for total homocysteine levels in human serum. J Chromatogr, 565(1-2), 441-446.

Ulrey, C. L., Liu, L., Andrews, L. G., \& Tollefsbol, T. O. (2005). The impact of metabolism on DNA methylation. Hum Mol Genet, 14(Spec No 1), R139-147. 
Van der Elst, W., Van Boxtel, M. P. J., Van Breukelen, G. J. P., \& Jolles, J. (2005). Rey's verbal learning test: normative data for 1855 healthy participants aged 24-81 years and the influence of age, sex, education, and mode of presentation. J Int Neuropsychol Soc, 11(3), 290-302.

Van der Elst, W., Van Boxtel, M. P. J., Van Breukelen, G. J. P., \& Jolles, J. (2006a). Normative data for the Animal, Profession and Letter $\mathrm{M}$ Naming verbal fluency tests for Dutch speaking participants and the effects of age, education, and sex. J Int Neuropsychol Soc, 12(1), 80-90.

Van der Elst, W., Van Boxtel, M. P. J., Van Breukelen, G. J. P., \& Jolles, J. (2006b). The Concept Shifting Test: adult normative data. Psychol Assess, 18(4), 424-432.

Van der Elst, W., Van Boxtel, M. P. J., Van Breukelen, G. J. P., \& Jolles, J. (2006c). The Letter Digit Substitution Test: normative data for 1,858 healthy participants aged 24-81 from the Maastricht Aging Study (MAAS): influence of age, education, and sex. J Clin Exp Neuropsychol, 28(6), 998-1009.

Van der Elst, W., Van Boxtel, M. P. J., Van Breukelen, G. J. P., \& Jolles, J. (2006d). The Stroop Color-Word test: influence of age, sex, and education; and normative data for a large sample across the adult age range. Assessment, 13(1), 62-79.

Wang, S. C., Oelze, B., \& Schumacher, A. (2008). Age-specific epigenetic drift in late-onset Alzheimer's disease. PLoS One, 3(7), e2698.

Washburn, R. A., Smith, K. W., Jette, A. M., \& Janney, C. A. (1993). The Physical Activity Scale for the Elderly (PASE): development and evaluation. J Clin Epidemiol, 46(2), 153-162.

Yuasa, Y., Nagasaki, H., Akiyama, Y., Hashimoto, Y., Takizawa, T., Kojima, K., Kawano, T., Sugihara, K., Imai, K., \& Nakachi, K. (2009). DNA methylation status is inversely correlated with green tea intake and physical activity in gastric cancer patients. Int J Cancer, 124(11), 2677-2682.

Zhao, X., Ueba, T., Christie, B. R., Barkho, B., McConnell, M. J., Nakashima, K., Lein, E. S., Eadie, B. D., Willhoite, A. R., Muotri, A. R., Summers, R. G., Chun, J., Lee, K. F., \& Gage, F. H. (2003). Mice lacking methyl-CpG binding protein 1 have deficits in adult neurogenesis and hippocampal function. Proc Natl Acad Sci USA, 100(11), 6777-6782. 
CHAPTER 9

\section{APOE E4 status predicts age-related cognitive decline in the ninth decade: longitudinal follow-up of the Lothian Birth Cohort 1921}

Olga J.G. Schiepers, Sarah E. Harris, Alan J. Gow, Alison Pattie, Caroline E. Brett, John M. Starr, Ian J. Deary

Mol Psychiatry (2011) - Epub ahead of print 


\begin{abstract}
Carriers of the apolipoprotein E (APOE) E4 allele have an increased risk of developing Alzheimer's disease. However, it is less clear whether APOE E4 status may also be involved in non-pathological cognitive ageing. The present study investigated the associations between $A P O E$ genotypes and cognitive change over 8 years in older community-dwelling individuals. APOE genotype was determined in 501 participants of the Lothian Birth Cohort 1921, whose intelligence had been measured in childhood in the Scottish Mental Survey 1932. A polymorphic variant of translocase of outer mitochondrial membrane 40 homolog (TOMM40) (rs10524523) was included to differentiate between the effects of the APOE E3 and E4 allelic variants. Cognitive performance on the domains of verbal memory, abstract reasoning, and verbal fluency was assessed at mean age 79 years $(n=501)$, and again at mean ages of 83 ( $n=284)$ and $87(n=187)$. Using linear mixed models adjusted for demographic variables, vascular risk factors, and IQ at age 11 years, possession of the APOE E4 allele was associated with a higher relative rate of cognitive decline over the subsequent 8 years for verbal memory and abstract reasoning. Individuals with the long allelic variant of TOMM40, which is linked to $A P O E \mathrm{E} 4$, showed similar results. Verbal fluency was not affected by APOE E4 status. APOE E2 status was not associated with change in cognitive performance over 8 years. In non-demented older individuals, possession of the APOE E4 allele predicted a higher rate of cognitive decline on tests of verbal memory and abstract reasoning between 79 and 87 years. Thus, possession of the APOE E4 allele may not only predispose to Alzheimer's disease, but also appears to be a risk factor for non-pathological decline in verbal memory and abstract reasoning in the ninth decade of life.
\end{abstract}




\section{Introduction}

Possession of the apolipoprotein E (APOE) E4 allele is a well-established risk factor for Alzheimer's disease (Corder et al., 1993). It has been implicated in both the age of onset (Slooter et al., 1998a) and the rate of cognitive decline associated with this disease (Cosentino et al., 2008). The lipid transport protein APOE is encoded by the polymorphic $A P O E$ gene, which has three allelic variants, E2, E3, and E4. Whereas the APOE2 protein may exert a protective effect from Alzheimer's disease (Corder et al., 1994), the APOE4 isoform has been related to reduced neuronal survival and cognitive impairment (Mahley \& Rall, 2000; Smith, 2002).

Although individuals carrying at least one copy of the APOE E4 allele have an increased risk of developing Alzheimer's disease, it is less clear whether the APOE genotype may also be involved in non-pathological cognitive ageing: several studies indicate that possession of the APOE E4 allele relates to increased cognitive decline during normal ageing (Blair et al., 2005; Bretsky et al., 2003; Caselli et al., 2009; Deary et al., 2002; Deary et al., 2004a; Fillenbaum et al., 2001; Luciano et al., 2009a; Packard et al., 2007), but other studies do not find evidence for such an association (Bunce et al., 2004; Deary et al., 2003; Jorm et al., 2007; Luciano et al., 2009b).

Various explanations for these conflicting results may be put forward. First, cross-sectional studies assessing interindividual differences in the level of cognitive performance may yield results that differ from those obtained in studies examining the change of cognitive performance within individuals over time. Only longitudinal studies are able to determine definitely whether possession of the APOE E4 allele is associated with within-person cognitive changes. However, such studies have not unequivocally offered support for the possible involvement of APOE E4 carrier status in age-related cognitive decline (Blair et al., 2005; Bretsky et al., 2003; Bunce et al., 2004; Caselli et al., 2009; Fillenbaum et al., 2001; Packard et al., 2007; Small et al., 1998).

Second, in light of the involvement of the APOE E4 allele in Alzheimer's disease, it is important to exclude from the study participants with possible dementia, in order to avoid overestimating the association between APOE E4 status and nonpathological age-related cognitive decline. Failing to exclude cases of incipient dementia, particularly at follow-up, was an important limitation of some of the above-mentioned longitudinal studies (Bretsky et al., 2003; Fillenbaum et al., 2001).

Third, although APOE E4 status might differentially affect various cognitive functions, such as episodic memory and executive functioning (Small et al., 2004; Wisdom et al., 2011), some studies only focused on general cognitive ability rather than assessing a range of specific cognitive domains (Bunce et al., 2004; Fillenbaum et al., 2001). Furthermore, few of the earlier studies have controlled for prior cognitive ability, which may confound the relationship between APOE E4 allele status and age-related cognitive decline, as childhood mental ability accounts for 
about $50 \%$ of the variance associated with cognitive ability in adulthood (Deary et al., 2004b). Thus, even in old age, the level of cognitive function tested is a combination of at least three things: the level of the longstanding stable trait of intelligence, any age-related change that has taken place, and error of measurement. Finally, although vascular risk factors, such as hypertension, diabetes, and smoking, are associated with APOE genotype as well as cognitive performance (Haan et al., 1999; Slooter et al., 1998b), few of the above-mentioned studies correct for these potential confounders.

None of these earlier studies have taken into account the possible influence of the translocase of outer mitochondrial membrane 40 homolog (TOMM40) variablelength polymorphism (rs10524523) on the relationship between APOE allele status and cognitive performance in old age. The TOMM4O gene, which encodes an essential mitochondrial protein, is adjacent to and in linkage disequilibrium with $A P O E$ (Lai et al., 1998). The TOMM40 polymorphism is characterised by a variable number of $T$ residues (poly- $T$ repeat) that may be categorised into 'short' ( $<20$ T residues), 'long' ( $\geq 20$ T residues), or 'very long' ( $\geq 30$ T residues) (Lutz et al., 2010). Linkage with $A P O E$ is such that the APOE E4 allele is almost always linked to a long poly-T repeat, whereas the APOE E3 allele is linked to either a short or a very long poly-T repeat (Roses et al., 2009). Relevant to the present study, longer TOMM40 poly-T repeats have been associated with an earlier onset of Alzheimer's disease (Roses et al., 2009). It has been suggested that the risk of Alzheimer's disease in APOE E3 carriers with a very long TOMM4O poly-T repeat might equal, or even exceed, the risk generally associated with the APOE E4 allele (Lutz et al., 2010). It is not known whether the TOMM40 poly-T variants might also play a role in non-pathological cognitive decline. Therefore, it is important to consider both APOE E4 carrier status and TOMM4O poly-T repeat status when assessing age-related cognitive decline in older individuals.

Previously, we investigated the influence of $A P O E$ E4 allele status on cognitive performance in a non-demented sample of older community-dwelling individuals, the Lothian Birth Cohort 1921 (Deary et al., 2002; Deary et al., 2004a). In crosssectional analyses, we found that possession of the APOE E4 allele was associated with lower verbal memory performance at age 79 years (Deary et al., 2004a). However, verbal fluency and abstract reasoning were not affected by APOE E4 carrier status (Deary et al., 2004a). In addition, by assessing cognitive performance across the life course, we demonstrated that the APOE E4 allele significantly predicted cognitive change from childhood to old age (Deary et al., 2002).

The present study was undertaken to extend further our previous research by investigating the longitudinal associations between APOE genotypes and cognitive change from mean age 79 years to mean age 87 in participants of the Lothian Birth Cohort 1921. We attempted to compensate for the above-mentioned limitations accompanying earlier research, by using a longitudinal design, excluding cases of 
possible dementia at baseline as well as at follow-up, assessing different domains of cognitive functioning, and correcting the analyses for prior mental ability as well as a large number of potential confounders. In addition, we analysed the effects of the TOMM40 poly-T polymorphism, to assess whether linkage with TOMM40 might influence the relationship between $A P O E$ E3 or E4 carrier status and cognitive performance. Moreover, by using a narrow age cohort, any problems associated with heterogeneity of $A P O E^{\prime}$ 's effect on cognitive function at different ages were excluded.

\section{Methods}

\section{Study population}

The study population was the Lothian Birth Cohort 1921. This cohort consists of 550 surviving participants of the Scottish Mental Survey 1932, which tested cognitive ability in almost all children born in 1921 and attending school in Scotland, United Kingdom, in June 1932 (Scottish Council for Research in Education, 1933). Participants living in the Edinburgh area were recruited for medical and cognitive retesting via general practitioner's patient lists and advertisements in the media, as described elsewhere (Deary et al., 2009; Deary et al., 2004b).

All participants who had completed the initial reassessments at mean age 79 years (old age baseline), excluding those who had withdrawn or were known to have died, were invited to take part in the follow-up measurements at mean ages of 83 ( $n=454$, of whom 335 agreed to participate) and 87 years $(n=268$ ). Of the participants invited, 321 were tested at age 83 , and 207 at age 87 . Reasons for not attending included withdrawal ( $n=16$ at age $83 ; n=4$ at age 87 ), inability or refusal to participate ( $n=80$ at age $83 ; n=42$ at age 87 ), having moved away ( $n=13$ at age $83 ; n=4$ at age 87 ), exclusion due to dementia or memory problems ( $n=3$ at age 87 ), and death ( $n=10$ at age 83; $n=8$ at age 87) (Gow et al., 2011; Gow et al., 2008). Of the total sample of 550 individuals, 229 had died during the course of the study. All participants lived independently in the community at baseline and most were in good general health.

At baseline, five participants reported a history of dementia-related illness, and nine individuals scored $<24$ on the Mini-Mental State Examination (MMSE) (Folstein et al., 1975), which may suggest possible dementia. These individuals were excluded from statistical analysis, along with participants who maintained contact with the study and developed symptoms of dementia during the follow-up period ( $n=27$ ). $A P O E$ genotyping was successful for all but six of the participants with valid cognitive data at baseline $(n=507)$. The resulting study sample consisted of 501 individu- 
als (204 men, 297 women) at age 79 years, 284 individuals (123 men, 161 women) at age 83 , and 187 individuals ( 82 men, 105 women) at age 87 .

\section{Cognitive tests}

The MMSE (Folstein et al., 1975) was used as a brief screening test for possible dementia. The maximum score is 30 . An overall score $<24$ was considered an indication of possible cognitive pathology. In the Scottish Mental Survey 1932, the Moray House Test No. 12 was administered as a measure of general cognitive ability at age 11 years (Scottish Council for Research in Education, 1933). This test consists of 75 items, has a maximum score of 76, and has to be completed within $45 \mathrm{~min}$. Raw test scores were corrected for age in days at the time of testing and converted to IQtype scores (mean $=100, \mathrm{SD}=15)$.

At each wave of testing in old age, a battery of cognitive tests was administered to assess important cognitive domains. The Verbal Fluency Test (Lezak, 1995) provides a measure of executive functioning. Participants are required to name as many words as possible beginning with the letter $C$ in $1 \mathrm{~min}$. This process is repeated for the letters $\mathrm{F}$ and $\mathrm{L}$. The overall test score is the total number of correct words named. Verbal declarative memory was assessed by means of the Logical Memory subtest from the Wechsler Memory Scale-Revised (Wechsler, 1987). Two short stories, each containing twenty-five memory items, are read aloud. Immediate recall, as well as delayed recall after about $25 \mathrm{~min}$, are recorded. The total score, which has a maximum of 100 , is the sum of the two immediate and two delayed recall scores. Raven's Standard Progressive Matrices (Raven et al., 1977) was used to measure abstract reasoning. The test consists of sixty items, each presenting a pattern that needs to be completed. The outcome measure used here is the total number of items correctly completed within $20 \mathrm{~min}$.

\section{Genotyping}

Genomic DNA was isolated from venous blood. APOE genotype was determined by polymerase chain reaction (PCR) amplification of a 227-bp fragment of the APOE gene containing two polymorphic sites that account for the three alleles, E2, E3, and E4 (Wenham et al., 1991), followed by restriction digest with Cfol, and electrophoresis in $4 \%$ NuSieve gel.

The TOMM40 poly-T variant ( $r$ 10524523) was genotyped by Polymorphic DNA Technologies (Alameda, CA, USA) using PCR amplification of the target sequence followed by automated Sanger sequencing. The method exploits the fact that fluorescence-based Sanger sequencing reactions introduce an extra fluorescent ' $A$ ' residue on fully extended primer-extension products. Rather than directly analysing the poly-T region, the pattern of these terminal A-peaks in the sequencing elec- 
tropherogram was used to determine the lengths of the various alleles present. Two independent assays: 'Assay 1 ' and 'Assay 2' were used. To achieve a high level of specific amplification, a two-step, nested PCR strategy to amplify the region flanking the length polymorphism was used. The primers used in Assay 1 for these amplifications were as follows:

Outer: 5'-CTGGGCTCAAATGAACC-3' and 5'-CAAATGTGATTTTATAGGGCCA-3' Inner: 5'-GAGATGGGGTCTCACT-3' and 5'-ACAGGGAAAGAAAACAAGCCTG-3'

The primers used in Assay 2 for these amplifications were as follows:

Outer: 5'-TGGCCTCCCAAACTG-3' and 5'-GGCGTGGTGGCAC-3' Inner: 5'-GTTAGATGAAGTTTTTAAATTTTTTGTAG-3' and 5'-GAGAAGGGAGGATTGCT$3^{\prime}$

The first 'outer' PCR was performed in a 384-well plate by combining in each well approximately $10 \mathrm{ng}$ of genomic DNA with 1 unit of Klen Taq (Ab Peptides, Inc., St. Louis, MO, USA), $0.5 \mu$ l of 10 X PCR Buffer, $1.0 \mu$ l of $5.0 \mathrm{M}$ betaine, $0.175 \mu$ l dimethyl sulfoxide (DMSO), $0.8 \mu$ l of a mixture of deoxynucleotide triphosphates (dNTPs) (2.5 $\mathrm{mM}$ each), $2 \mu \mathrm{M}$ of each of the two outer oligonucleotide primers plus water to bring the entire reaction volume per well to a total of $5.0 \mu \mathrm{l}$. The second 'inner' PCR was performed in a 384-well plate by combining in each well $0.8 \mu \mathrm{L}$ of the product from the first PCR with 0.25 units of Klen Taq, $0.5 \mu$ of 10 X PCR Buffer, $1.0 \mu$ l of 5.0 M betaine, $0.175 \mu \mathrm{LMSO}, 0.2 \mu \mathrm{L}$ of a mixture of dNTPs (2.5 mM each), $2 \mu \mathrm{M}$ of each of the two inner oligonucleotide primers, plus water to bring the entire reaction volume per well to a total of $5.0 \mu \mathrm{l}$. PCR conditions for both reactions were 40 cycles of $94^{\circ} \mathrm{C}$ for $20 \mathrm{~s}, 55^{\circ} \mathrm{C}$ for $25 \mathrm{~s}$, and $72^{\circ} \mathrm{C}$ for $60 \mathrm{~s}$. The 'inner' PCR products were then purified using PCR Cleanup Plates (MultiScreen384 PCR, Millipore Corp., Billerica, MA, USA), with a final elution of each sample using $16 \mu$ l of water. An internal standard was added to each amplified sample product prior to running of the Sanger sequencing reactions. Using the mixed template described above, fluorescent Sanger sequencing reactions were performed using the forward 'inner' PCR primer as a sequencing primer. Reactions were carried out in a 384-well plate using $0.8 \mu \mathrm{l}$ of the PCR product described above with $0.125 \mu \mathrm{l}$ Big Dye Mix (Applied BioSystems, Inc., Carlsbad, CA, USA), $0.215 \mu \mathrm{l}$ 5X Dilution Buffer (Applied BioSystems, Inc.), $0.25 \mu \mathrm{l}$ of a $1 \mu \mathrm{M}$ solution of the forward 'inner' primer, $0.105 \mu \mathrm{LMSO}$, $0.6 \mu$ of $5 \mathrm{M}$ betaine, plus water to bring the entire volume to $3.0 \mu$ l. Plates were then placed in a thermocycler and subjected to 30 cycles of the following conditions: $96^{\circ} \mathrm{C}$ for $10 \mathrm{~s}, 50^{\circ} \mathrm{C}$ for $15 \mathrm{~s}$, and $60^{\circ} \mathrm{C}$ for $120 \mathrm{~s}$. Sequencing reactions were analysed on a 3730XL DNA Analyser (Applied BioSystems, Inc.). TOMM40 poly-T data were available for 498 participants. 


\section{Lifestyle and health-related variables}

Body mass index (BMI, $\mathrm{kg} / \mathrm{m}^{2}$ ), smoking status (yes or no), and alcohol consumption (standard units per week) were recorded at age 79. Total serum cholesterol $(\mathrm{mmol} / \mathrm{l})$ was determined in venous blood samples at age 79 . Self-reported history of cardiovascular disease (yes or no), cerebrovascular disease (yes or no), hypertension (yes or no), and diabetes (yes or no) were recorded at age 79, and again at ages 83 and 87.

\section{Statistical analysis}

Normality of data distributions was ascertained by visual inspection of normal P-P plots. APOE genotype was defined and coded as E4+ or E4-, depending on the presence of at least one E4 allele, which is consistent with many other studies investigating the effect of APOE E4 status on cognitive functioning (Small et al., 2004; Wisdom et al., 2011). The TOMM40 allelic variants were classified into three categories, according to the length of the poly-T repeat, i.e. 'short' ( $<20$ T residues), 'long' ( $\geq 20$ T residues), or 'very long' ( $\geq 30$ T residues).

The longitudinal associations between APOE E4 status and cognitive performance were assessed by means of linear mixed models (Verbeke \& Molenberghs, 2000). This analytical method takes into account the intraindividual correlation between repeated measurements and allows the inclusion of participants with incomplete data at follow-up. Akaike's Information Criterion indicated that an unstructured covariance structure best fit the data. Separate models were fitted for $A P O E$ E4 allele status in relation to each of the three dependent cognitive variables, i.e. Verbal Fluency, Logical Memory, and Raven's Matrices. The longitudinal effect of $A P O E$ E4 allele status on cognitive functions was estimated by the two-way interaction between time (measured in years since baseline, i.e. 0,4 , and 8 years, which is acceptable because there is very little age variation among the participants within each wave) and APOE E4 allele status, which represents the rate of change in cognitive performance as a function of APOE E4 carrier status. The statistical models were adjusted for a number of covariates in three consecutive steps. First, the analyses were corrected for the demographic variables age (in days), age ${ }^{2}$ (to test for non-linear effects of age), and sex (Model 1). Age was centred around the mean to reduce the correlation between the terms for age and $\operatorname{age}^{2}$. In Model 2, the analyses were additionally adjusted for age 11 IQ to reduce the confounding effect of prior cognitive ability on age-related change in cognitive performance. Finally, $\mathrm{BMI}$, smoking status, alcohol consumption, total serum cholesterol, history of cardiovascular disease, history of cerebrovascular disease, history of hypertension, and history of diabetes were entered (Model 3), to correct for potential confounding by vascular risk factors (Haan et al., 1999; Slooter et al., 1998b). 
This procedure was repeated with MMSE score as the dependent variable, to examine the effect of $A P O E$ E4 allele status on general cognitive performance on this widely-used clinical test. Linear mixed models with APOE E2 allele status (coded as presence or absence of at least one E2 allele) as the independent variable were used to examine the effect of the APOE E2 allele on age-related cognitive change.

The relationship between the TOMM4O poly-T polymorphism and cognitive performance was analysed for the two cognitive domains showing significant associations with $A P O E$ E4 carrier status, i.e. verbal memory and abstract reasoning. First, to explore the overall effect of TOMM40 genotype on cognitive performance, summary measures for the 8-year change in Logical Memory and Raven's Matrices were calculated, by regressing test score at mean age 87 on test score at mean age 79 and saving the residuals. Univariate ANOVA and independent samples $t$ tests were used to assess whether cognitive change differed according to TOMM40 genotype.

Second, linear mixed models were performed to investigate further the crosssectional and longitudinal associations between TOMM40 genotype and cognitive performance, while correcting for demographic and health-related variables. Separate models were fitted for TOMM4O genotype in relation to Logical Memory and Raven's Matrices. The analyses were repeated in APOE E4 non-carriers, APOE E3E4 heterozygotes, and $A P O E$ E3E3 homozygotes, to differentiate between the effects of the APOE E3 and E4-linked TOMM4O variants.

Statistical differences were considered significant at $p$-values $<0.05$. All analyses were performed using SPSS 16.0 (SPSS Inc., Chicago, IL, USA).

\section{Results}

\section{Descriptives}

Table 1 shows the baseline characteristics of the participants according to APOE E4 carrier status. Allele frequencies in the sample were E2 $=0.10, \mathrm{E} 3=0.77$, and E4 = 0.14 . A Chi-square test indicated that $A P O E$ was in Hardy-Weinberg equilibrium ( $p=$ $0.300)$. At baseline, distribution of $A P O E$ genotypes was as follows: E2E2, $n=2$ (0.4\%); E2E3, $n=76$ (15.2\%); E2E4, $n=19$ (3.8\%); E3E3, $n=292$ (58.3\%); E3E4, $n=$ $107(21.4 \%) ;$ and E4E4, $n=5(1.0 \%)$. These genotype frequencies are comparable to those reported in other population-based samples of non-demented older individuals (Fillenbaum et al., 2001; Packard et al., 2007; Small et al., 1998). The covariates did not differ between APOE E4 carriers and non-carriers, except for alcohol consumption, which was lower in APOE E4 carriers, and total serum cholesterol, which was higher in APOE E4 carriers (Table 1). In addition, carriers of the APOE E4 allele performed worse on the Logical Memory test at age 87 (Table 2). 
Table 1 Baseline characteristics of the study population according to APOE E4 carrier status

\begin{tabular}{llll}
\hline & APOE E4 carriers & APOE E4 non-carriers & $\boldsymbol{p}^{\text {a }}$ \\
\hline$n$ & $131(26.1 \%)$ & $370(73.9 \%)$ & \\
Age (years) & $79.0 \pm 0.6$ & $79.1 \pm 0.6$ & 0.081 \\
Female & $82(62.6 \%)$ & $215(58.1 \%)$ & 0.408 \\
Age $11 \mathrm{IQ}^{\mathrm{b}}$ & $99.5 \pm 15.2$ & $101.3 \pm 14.2$ & 0.257 \\
$\mathrm{BMI}\left(\mathrm{kg} / \mathrm{m}^{2}\right)$ & $26.0 \pm 3.6$ & $26.4 \pm 4.3$ & 0.424 \\
Current smoker & $7(5.3 \%)$ & $26(7.0 \%)$ & 0.682 \\
Alcohol consumption & $1.0(0.0 ; 6.0)$ & $1.3(0.5 ; 7.0)$ & $0.020^{\mathrm{d}}$ \\
(standard units/week) $^{\mathrm{c}}$ & & & \\
Total serum cholesterol (mmol/I) $^{2}$ & $5.9 \pm 1.1$ & $5.6 \pm 1.1$ & 0.005 \\
Cardiovascular disease & $22(16.9 \%)$ & $60(16.4 \%)$ & 0.891 \\
Cerebrovascular disease & $9(6.9 \%)$ & $27(7.3 \%)$ & 1.000 \\
Hypertension & $57(43.5 \%)$ & $149(40.3 \%)$ & 0.606 \\
Diabetes & $3(2.3 \%)$ & $22(5.9 \%)$ & 0.108 \\
\hline Note: Values represent
\end{tabular}

Note: Values represent means \pm SD or $n(\%)$. BMI, body mass index; $A P O E$, apolipoprotein $E_{;}{ }^{a} P$-values for independent samples $t$ tests or Chi-square tests; ${ }^{b}$ Based on Moray House Test No. 12 score, corrected for age at the time of testing; ${ }^{c}$ Median value (interquartile range) is given because of skewed data distribution; ${ }^{\mathrm{d}} P$-value for non-parametric Mann-Whitney $U$ test.

Table 2 Cognitive performance at mean ages of 79 (baseline), 83, and 87 years according to APOE E4 carrier status

\begin{tabular}{|c|c|c|c|c|c|c|}
\hline \multirow[t]{2}{*}{ Cognitive test } & \multicolumn{3}{|c|}{ Completers $^{\mathrm{a}}$} & \multicolumn{3}{|c|}{ All data } \\
\hline & APOE E4 carriers & $\begin{array}{l}\text { APOE E4 non- } \\
\text { carriers }\end{array}$ & $p^{b}$ & APOE E4 carriers & $\begin{array}{l}\text { APOE E4 non- } \\
\text { carriers }\end{array}$ & $p^{b}$ \\
\hline \multicolumn{7}{|l|}{ Age 79 (baseline) } \\
\hline$n$ & 41 & 146 & & 131 & 370 & \\
\hline $\mathrm{MMSE}^{\mathrm{c}}$ & $29.0(28.0 ; 29.5)$ & $29.0(28.0 ; 30.0)$ & $0.403^{d}$ & $28.0(27.0 ; 29.0)$ & $29.0(28.0 ; 29.0)$ & $0.129^{d}$ \\
\hline Verbal Fluency & $41.8 \pm 7.9$ & $42.9 \pm 12.4$ & 0.506 & $40.2 \pm 11.7$ & $40.5 \pm 12.4$ & 0.860 \\
\hline Logical Memory & $34.5 \pm 9.0$ & $36.0 \pm 13.8$ & 0.418 & $28.9 \pm 12.4$ & $33.5 \pm 12.7$ & $<0.001$ \\
\hline Raven's Matrices & $33.1 \pm 7.4$ & $34.1 \pm 8.4$ & 0.471 & $30.6 \pm 8.1$ & $32.0 \pm 8.8$ & 0.117 \\
\hline \multicolumn{7}{|l|}{ Age 83} \\
\hline$n$ & 41 & 146 & & 67 & 217 & \\
\hline $\mathrm{MMSE}^{\mathrm{c}}$ & $29.0(28.0 ; 30.0)$ & $29.0(28.0 ; 29.8)$ & $0.651^{d}$ & $28.0(27.0 ; 30.0)$ & $29.0(28.0 ; 30.0)$ & $0.183^{d}$ \\
\hline Verbal Fluency & $40.5 \pm 9.5$ & $41.8 \pm 12.7$ & 0.494 & $39.2 \pm 12.1$ & $41.1 \pm 13.0$ & 0.298 \\
\hline Logical Memory & $33.4 \pm 10.8$ & $36.8 \pm 14.6$ & 0.109 & $30.7 \pm 13.3$ & $35.5 \pm 14.2$ & 0.015 \\
\hline Raven's Matrices & $30.8 \pm 6.7$ & $32.2 \pm 8.3$ & 0.348 & $28.1 \pm 9.2$ & $31.5 \pm 8.6$ & 0.007 \\
\hline \multicolumn{7}{|l|}{ Age 87} \\
\hline$n$ & 41 & 146 & & & & \\
\hline $\mathrm{MMSE}^{\mathrm{c}}$ & $28.0(27.0 ; 29.0)$ & $29.0(27.0 ; 29.0)$ & $0.397^{d}$ & & & \\
\hline Verbal Fluency & $39.9 \pm 9.6$ & $41.2 \pm 12.6$ & 0.466 & & & \\
\hline Logical Memory & $29.6 \pm 11.8$ & $35.8 \pm 14.4$ & 0.013 & & & \\
\hline Raven's Matrices & $26.5 \pm 8.4$ & $29.2 \pm 9.0$ & 0.087 & & & \\
\hline
\end{tabular}

Note: Values represent means \pm SD. APOE, apolipoprotein E; MMSE, Mini-Mental State Examination ; ${ }^{a}$ All participants who completed the three waves of cognitive testing at mean ages of 79, 83, and 87 years ( $n$ $=187) ;{ }^{b} P$-values for independent samples $t$ tests; ${ }^{c}$ Median value (interquartile range) is given because of skewed data distribution; ${ }^{d} P$-value for non-parametric Mann-Whitney $U$ test. 
At baseline, TOMM40 genotypes were distributed as follows: short-short, $n=90$ (18.1\%); short-long, $n=60$ (12.0\%); short-very long, $n=178$ (35.7\%); long-long, $n=$ 5 (1.0\%); long-very long, $n=65$ (13.1\%); and very long-very long, $n=100$ (20.1\%). Supplementary Table 1 shows the distribution of TOMM4O genotypes stratified by $A P O E$ genotype.

Of the 501 participants at baseline, 187 completed the third wave of cognitive testing at mean age 87 . Distribution of $A P O E$ genotypes at mean age 87 was as follows: E2E2, $n=1$ (0.5\%); E2E3, $n=27$ (14.4\%); E2E4, $n=5$ (2.7\%); E3E3, $n=118$ (63.1\%); E3E4, $n=35$ (18.7\%); and E4E4, $n=1$ (0.5\%). Dropout equalled $69 \%$ in APOE E4 carriers, and $61 \%$ in non-carriers of the E4 allele ( $p=0.115$ using a Chisquare test). Logistic regression analysis revealed that dropout was not associated with APOE E4 status ( $p=0.098$ for dropout due to any reason; $p=0.105$ for dropout because of death). However, lower cognitive scores at baseline significantly predicted dropout at follow-up ( $p<0.01$ for each of the three cognitive measures). Chisquare tests indicated that participants who were lost to follow-up did not differ from the remaining participants in terms of demographic or health-related characteristics, except for smoking, which significantly increased the likelihood of dropping out $(p=0.024)$.

\section{Associations between APOE E4 and E2 allele status and cognitive performance}

Table 3 shows the results of the linear mixed model analyses. Significant interactions between $A P O E$ E4 allele status and time were identified for Logical Memory and Raven's Matrices, but not for Verbal Fluency. Possession of the APOE E4 allele was accompanied by an additional annual decline of 0.5 points on the Logical Memory test, and 0.3 points on Raven's Matrices - corresponding to a 4.0 points (0.3 SD) greater decline in verbal memory and a 2.4 points $(0.3 \mathrm{SD})$ greater decline in abstract reasoning between 79 and 87 years.

When the analyses were repeated with MMSE score as the dependent variable, no significant longitudinal effect of APOE E4 allele status was found (estimate [95\% $\mathrm{Cl}$ ] for $A P O E \mathrm{E} 4 \times$ time in the fully adjusted model $=-0.02$ [-0.09; 0.04], $p=0.453$ ). However, APOE E4 carriers showed a significantly greater longitudinal decline in MMSE performance when participants with suspected dementia (MMSE <24) at mean ages of 83 or 87 ( $n=27)$ were included in the statistical analyses. This association was significant after correction for the demographic variables (estimate $[95 \%$ $\mathrm{Cl}]$ for $A P O E \mathrm{E} 4 \times$ time $=-0.10[-0.18 ;-0.02], p=0.015)$, but not after additional correction for age $11 \mathrm{IQ}$ and vascular risk factors (estimate $[95 \% \mathrm{Cl}]$ for APOE E4 $\times$ time $=-0.05[-0.13 ; 0.03], p=0.193)$.

Linear mixed models with APOE E2 carrier status as the independent variable did not reveal any significant longitudinal effects on cognitive performance (Supplementary Table 2). 
Table 3 Longitudinal associations between APOE E4 allele status and cognitive performance between mean ages of 79 and 87 years

\begin{tabular}{|c|c|c|c|c|c|c|}
\hline & \multicolumn{2}{|l|}{ Verbal Fluency } & \multicolumn{2}{|c|}{ Logical Memory } & \multicolumn{2}{|c|}{ Raven's Matrices } \\
\hline & Estimate $(95 \% \mathrm{Cl})$ & $p$ & Estimate $(95 \% \mathrm{Cl})$ & $p$ & Estimate $(95 \% \mathrm{CI})$ & $p$ \\
\hline \multicolumn{7}{|l|}{ Model $1^{a}$} \\
\hline$A P O E$ E4 status ${ }^{b}$ & $-0.23(-2.67 ; 2.21)$ & 0.854 & $-4.65(-7.18 ;-2.12)$ & $<0.001$ & $-1.53(-3.25 ; 0.20)$ & 0.082 \\
\hline Time & $-0.17(-0.34 ;-0.001)$ & 0.048 & $0.06(-0.15 ; 0.26)$ & 0.597 & $-0.58(-0.71 ;-0.46)$ & $<0.001$ \\
\hline APOE E4 $\times$ time & $-0.10(-0.44 ; 0.25)$ & 0.578 & $-0.54(-0.97 ;-0.10)$ & 0.015 & $-0.27(-0.53 ;-0.02)$ & 0.037 \\
\hline \multicolumn{7}{|l|}{ Model 2} \\
\hline APOE E4 status & $0.12(-2.32 ; 2.56)$ & 0.923 & $-4.40(-6.98 ;-1.82)$ & 0.001 & $-1.26(-2.88 ; 0.37)$ & 0.130 \\
\hline Time & $-0.18(-0.36 ; 0.00)$ & 0.050 & $0.05(-0.17 ; 0.26)$ & 0.683 & $-0.61(-0.73 ;-0.48)$ & $<0.001$ \\
\hline$A P O E \mathrm{E} 4 \times$ time & $-0.08(-0.44 ; 0.28)$ & 0.657 & $-0.56(-1.00 ;-0.12)$ & 0.012 & $-0.29(-0.54 ;-0.04)$ & 0.023 \\
\hline \multicolumn{7}{|l|}{ Model 3} \\
\hline APOE E4 status & $0.16(-2.32 ; 2.64)$ & 0.900 & $-3.94(-6.63 ;-1.25)$ & 0.004 & $-1.53(-3.20 ; 0.14)$ & 0.072 \\
\hline Time & $-0.16(-0.34 ; 0.02)$ & 0.090 & $0.00(-0.22 ; 0.22)$ & 0.985 & $-0.60(-0.73 ;-0.48)$ & $<0.001$ \\
\hline$A P O E$ E4 $\times$ time & $-0.07(-0.42 ; 0.29)$ & 0.707 & $-0.50(-0.93 ;-0.07)$ & 0.024 & $-0.27(-0.52 ;-0.02)$ & 0.034 \\
\hline
\end{tabular}

Note: $A P O E$, apolipoprotein $\mathrm{E}^{2}{ }^{a}$ Model 1 is corrected for age, age ${ }^{2}$, and sex; Model 2 is additionally corrected for age $11 \mathrm{IQ}$; and Model 3 is additionally corrected for body mass index, smoking status, alcohol consumption, total serum cholesterol, history of cardiovascular disease, history of cerebrovascular disease, history of hypertension, and history of diabetes; ${ }^{b}$ The estimate for APOE E4 status represents the cross-sectional association between APOE E4 status and cognitive performance at baseline. The time estimate equals the effect of time on cognitive performance in non-carriers of the APOE E4 allele. The estimate for the interaction effect between time and $A P O E$ E4 status corresponds to the additional annual change in $A P O E$ E4 carriers as compared with non-carriers.

\section{Associations between TOMM40 genotype and cognitive performance}

Supplementary Table 3 shows the cognitive change of participants who completed three waves of testing between mean ages of 79 and 87, categorised according to $A P O E$ and TOMM4O genotype. Overall, cognitive change did not vary according to TOMM40 genotype ( $p=0.062$ for Logical Memory and $p=0.269$ for Raven's Matrices). However, when carriers of at least one long poly-T repeat $(n=41)$ were compared with non-carriers, the 8-year change in Logical Memory was significantly lower in participants in possession of a long TOMM40 poly-T allele (mean \pm SD $=-$ $4.18 \pm 1.12$ as compared with $1.06 \pm 1.05, p=0.006$ ).

Linear mixed models, corrected for demographic and health-related variables, did not reveal any significant cross-sectional associations between TOMM40 genotype and Raven's Matrices (Table 4). Logical Memory showed a significant crosssectional relationship with TOMM40 genotype, with statistically significant parameter estimates for TOMM40 variants characterised by at least one long poly-T repeat (Table 4), indicating that Logical Memory performance at baseline was lower in carriers of the long allelic variant of TOMM40 as compared with non-carriers. No overall longitudinal effects of TOMM40 genotype on Logical Memory or Raven's Matrices were identified; however, the parameter estimates for the long-very long genotype were statistically significant for both cognitive domains (Table 4), implying 
that this TOMM40 variant was associated with a greater annual decline in Logical Memory and Raven's Matrices. Repeating the analyses with TOMM40 genotype as a dummy variable ( 1 = presence of at least one long poly-T allele; $0=$ no long poly- $\mathrm{T}$ allele) revealed a significant cross-sectional association with Logical Memory performance (parameter estimate $[95 \% \mathrm{Cl}]=-4.09[-6.79 ;-1.39], p=0.003$ ), and significant longitudinal associations with both Logical Memory (parameter estimate $[95 \% \mathrm{Cl}]=-0.52[-0.95 ;-0.09], p=0.019)$ and Raven's Matrices (parameter estimate $[95 \% \mathrm{Cl}]=-0.26[-0.51 ;-0.01], p=0.040)$. These results indicate that carriers of the long TOMM40 poly-T allele showed a lower verbal memory performance at baseline, and a greater annual decline on the cognitive domains of verbal memory and abstract reasoning, as compared with non-carriers.

Table 4 Longitudinal associations between TOMM40 genotype and cognitive performance between mean ages of 79 and 87 years $^{a}$

\begin{tabular}{|c|c|c|c|c|}
\hline & \multicolumn{2}{|c|}{ Logical Memory } & \multicolumn{2}{|c|}{ Raven's Matrices } \\
\hline & Estimate $(95 \% \mathrm{Cl})$ & $p$ & Estimate $(95 \% \mathrm{CI})$ & $p$ \\
\hline TOMM40 genotype (overall) ${ }^{b}$ & & 0.018 & & 0.167 \\
\hline Short-long & $-5.07(-9.42 ;-0.73)$ & 0.022 & $-0.38(-3.09 ; 2.32)$ & 0.781 \\
\hline Short-very long & $-2.24(-5.69 ; 1.21)$ & 0.204 & $0.02(-2.10 ; 2.14)$ & 0.987 \\
\hline Long-long & $-18.19(-32.49 ;-3.89)$ & 0.013 & $-7.88(-18.37 ; 2.60)$ & 0.140 \\
\hline Long-very long & $-5.06(-9.39 ; 0.74)$ & 0.022 & $-1.06(-3.72 ; 1.60)$ & 0.432 \\
\hline Very long-very long & $-0.97(-4.89 ; 2.95)$ & 0.627 & $1.78(-0.63 ; 4.19)$ & 0.148 \\
\hline Time & $-0.02(-0.42 ; 0.39)$ & 0.940 & $-0.54(-0.77 ;-0.31)$ & $<0.001$ \\
\hline TOMM40 genotype (overall) $\times$ time & & 0.168 & & 0.185 \\
\hline Short-long $\times$ time & $-0.41(-1.08 ; 0.27)$ & 0.238 & $-0.23(-0.61 ; 0.15)$ & 0.229 \\
\hline Short-very long $\times$ time & $0.01(-0.49 ; 0.52)$ & 0.960 & $-0.02(-0.30 ; 0.26)$ & 0.878 \\
\hline Long-long $\times$ time & $1.01(-1.25 ; 3.27)$ & 0.381 & $-0.99(-2.92 ; 0.94)$ & 0.313 \\
\hline Long-very long $\times$ time & $-0.69(-1.37 ;-0.01)$ & 0.047 & $-0.39(-0.77 ;-0.01)$ & 0.047 \\
\hline Very long-very long $\times$ time & $0.05(-0.56 ; 0.65)$ & 0.880 & $-0.25(-0.59 ; 0.09)$ & 0.145 \\
\hline
\end{tabular}

Note: TOMM40, translocase of outer mitochondrial membrane 40 homolog; ${ }^{a}$ Corrected for age, age ${ }^{2}$, sex, age $11 \mathrm{IQ}$, body mass index, smoking status, alcohol consumption, total serum cholesterol, history of cardiovascular disease, history of cerebrovascular disease, history of hypertension, and history of diabetes; ${ }^{b}$ The estimates for TOMM4O genotype represent the cross-sectional associations between TOMM 40 variants and cognitive performance at baseline, with the TOMM40 short-short genotype as reference category. The time estimate equals the effect of time on cognitive performance in individuals with the TOMM4O short-short genotype. The estimate for the interaction effect between time and TOMM4O genotype corresponds to the additional annual change in cognitive performance associated with TOMM4O.

When the analyses were repeated in APOE E4 non-carriers $(n=367)$, i.e. representing only the short-short, short-very long, and very long-very long TOMM4O variants, no significant results were obtained (data not shown). In addition, repeating the analyses in APOE E3E4 heterozygotes with either the short-long or long-very long TOMM4O genotype $(n=105)$ did not yield any significant results (data not shown). Repeating the analyses in participants with the APOE E3E3 genotype ( $n=$ 
290), to differentiate between the APOE E3-linked short and very long TOMM 40 allelic variants in individuals without the 'protective' $A P O E$ E2 allele or the 'risk' allele $A P O E \mathrm{E} 4$, did not reveal any significant results (data not shown).

\section{Discussion}

We found that APOE E4 allele carrier status was associated with an increased rate of cognitive decline between 79 and 87 years on the domains of verbal memory and abstract reasoning in a narrow age cohort of older community-dwelling individuals. In addition, we found that the long allelic variant of the TOMM4O poly-T polymorphism, which is linked to the APOE E4 allele, showed a similar relationship with cognitive performance over 8 years.

Not only did our findings indicate that $A P O E$ E4 carrier status may account for a significant proportion of variance associated with cognitive changes in old age, they also suggest that the influence of $A P O E$ E4 allele status on age-related cognitive decline may be restricted to specific domains of cognitive functioning, as we did not find any support for an effect of the E4 allele on verbal fluency, which assesses an aspect of executive functioning.

The present results are in agreement with some of those reported by other population-based studies, indicating that $A P O E$ E4 allele status may have a negative impact on age-related change in memory performance (Blair et al., 2005; Bretsky et al., 2003; Caselli et al., 2009; Deary et al., 2004a; Packard et al., 2007; Small et al., 1998) and abstract reasoning (Bretsky et al., 2003) in older individuals. The finding that verbal fluency was not affected by $A P O E$ E4 allele status, is in agreement with several other reports, which have put forward that the APOE E4 allele may differentially affect cognitive functioning on various domains (Blair et al., 2005; Deary et al., 2004a; Packard et al., 2007; Small et al., 1998). Indeed, the existing literature seems to suggest that the APOE E4 allele may primarily affect episodic memory, although not all studies have found significant effects (Jorm et al., 2007; Luciano et al., 2009b).

Some population-based studies have found that possession of the APOE E4 allele may be associated with decreased general cognitive functioning (Bretsky et al., 2003; Fillenbaum et al., 2001; Haan et al., 1999), but others did not find any evidence for such an association (Bunce et al., 2004; Deary et al., 2003; Small et al., 1998). The fact that the APOE E4 allele showed no association with MMSE score in our study might be due to the relative insensitivity of this test to individual variation in normal cognitive functioning, as it was originally developed to screen for symptoms of cognitive impairment (Folstein et al., 1975), and has a ceiling effect in the present sample. Not surprisingly, we did find a significant relationship between $A P O E$ E4 allele status and MMSE performance when cases of possible dementia at 
follow-up were included in our study sample, which confirms the notion that the $A P O E$ E4 allele may play a role in pathological degrees of cognitive impairment.

We have previously shown that possession of the APOE E2 allele predicted higher verbal memory performance at age 79 (Deary et al., 2004a). However, the present study did not suggest any effect of $A P O E$ E2 allele status on the rate of cognitive decline in healthy ageing individuals from 79 to 87 years, suggesting that the beneficial influence of the APOE E2 allele on cognitive functioning may be restricted to individual differences in the level of cognitive performance.

Previous research addressing the relationship between APOE and cognitive functioning has primarily focused on the effects of the 'risk' allele E4 and the 'protective' allele E2. However, recent studies have suggested that the APOE E3 allele, when connected to a very long TOMM40 poly-T repeat, is associated with an earlier onset of Alzheimer's disease, comparable to the age of onset typically observed in APOE E4 carriers (Roses et al., 2009). The present study assessed whether the APOE E3 and E4-linked TOMM4O variants might also play a role in non-pathological cognitive decline. Our results did not offer support for an interaction between APOE and TOMM4O in mediating age-related cognitive decline in the ninth decade. We found that only the long TOMM4O allelic variant, which is linked to the APOE E4 allele, was predictive of the rate of cognitive change in old age. Although these findings strengthen our conclusion that APOE E4 carrier status may increase cognitive decline in older individuals, it does not offer support for a separate effect of TOMM40 in relation to non-pathological cognitive functioning. In fact, as other TOMM40 variants were not associated with individual variation in cognitive performance, TOMM4O poly-T status might be considered a marker for APOE E4 carrier status rather than an independent risk factor for cognitive decline in the ninth decade.

APOE E4 carriers might be more susceptible to neurodegeneration than noncarriers due to poor neuronal repair and an elevated risk of atherosclerosis (Mahley \& Rall, 2000; Smith, 2002). Indeed, APOE E4 carrier status has been related to increased hippocampal atrophy (Den Heijer et al., 2002) and a greater decline in cerebral blood flow in frontal, temporal, and parietal areas (Thambisetty et al., 2010). As the frontal and parietal areas in the brain have been implicated in abstract reasoning (Melrose et al., 2007), and reduced hippocampal volumes have been associated with memory decline in the ageing population (Reitz et al., 2009; Zimmerman et al., 2008), it may not be unreasonable to assume that the lower performance on memory and reasoning tests observed in APOE E4 carriers might be accounted for by changes in brain morphology. Furthermore, the putative role of $A P O E$ E4 in neuronal damage and atherosclerosis might offer a suitable explanation for the finding that $A P O E$ E4 carrier status is associated with cognitive performance in old age, but not in childhood (Deary et al., 2002; Deary et al., 2004a) or in adults 
before age 50 (Caselli et al., 2009), as neurodegenerative processes might not take place until later in life.

The aim of our study was to investigate the relationship between APOE genotypes and non-pathological cognitive decline. As APOE E4 carriers are more prone to develop dementia than non-carriers (Corder et al., 1993), a potential limitation of population-based studies addressing the effects of the APOE E4 allele on cognitive ageing is that their results might be biased by the possible inclusion of cases of incipient dementia. However, in the present study, all participants lived independently at baseline, had no history of dementia, and obtained MMSE scores of 24 or more at baseline and at follow-up. Therefore, we consider it unlikely that the observed associations are substantially accounted for by incipient dementia.

A possible disadvantage of excluding all individuals with potential dementia at any point is that it may increase survivor bias, which is very common in longitudinal studies performed in older populations. In our study, dropout was associated with a lower level of cognitive functioning at baseline. By using a statistical approach that allows for the inclusion of participants with incomplete data at follow-up, this selection bias was, at least partly, compensated for. However, if anything, selective dropout or exclusion of cognitively impaired participants probably would have caused the observed associations to be underestimated.

Learning effects on cognitive tests may also result in conservative estimates of the longitudinal associations between APOE E4 allele status and cognitive performance, by obscuring possible age-related cognitive decline. In contrast to verbal fluency and abstract reasoning, which declined over 8 years of follow-up, Logical Memory performance did not show a significant decline between 79 and 87 years, which may be due to procedural learning. Thus, it is conceivable that the observed associations between APOE E4 allele status and verbal memory might have been underestimated.

Another potential source of bias in longitudinal studies is selective attrition. Statistical testing revealed that dropout was not related to APOE E4 carrier status in the present study. Moreover, APOE allele frequencies in our study were similar to those reported for younger populations (Blair et al., 2005; Cumming \& Robertson, 1984), which strongly argues against the possibility of selective attrition. The finding that APOE E4 status was not associated with increased dropout or increased mortality in the present study allowed us to compare our results with those obtained in studies performed in younger individuals (Blair et al., 2005; Bretsky et al., 2003) or study populations with a broader age range (Fillenbaum et al., 2001; Small et al., 1998), in which comparable genotype distributions were reported.

The strengths of our study were its longitudinal design, the administration of sensitive, domain-specific cognitive tests, the narrow range of chronological age, and the adjustment for demographic and lifestyle variables, as well as vascular risk factors. Furthermore, correcting our analyses for childhood intelligence allowed for 
the assessment of individual variation in cognitive decline in old age, whilst eliminating the confounding influence of the stable trait of general cognitive ability (Deary et al., 2004b). Moreover, our study was the first to investigate the potential influence of the TOMM4O poly-T polymorphism on the relationship between APOE allele status and age-related cognitive decline. Finally, the study included three waves of testing spanning most of the ninth decade, and genetic-cognitive examination of this important part of old age is rare.

In conclusion, by using a unique narrow age cohort of initially healthy older individuals, we were able to demonstrate that individual variation in age-related cognitive change in the rarely-studied ninth decade of the human life course was related to $A P O E$ E4 allele status. Compared with non-carriers, carriers of the APOE E4 allele showed a greater 8-year decline on the cognitive domains of verbal memory and abstract reasoning. Thus, the E4 allelic variant of the APOE gene may not only predispose to dementia, but may also have a negative impact on cognitive decline in non-demented older individuals. Future studies may further unravel the genetic and environmental determinants of non-pathological cognitive ageing, by addressing the potential mechanisms underlying the association between APOE genotypes and cognitive performance, as well as investigating the potential interactions between the $A P O E$ gene and other risk factors.

\section{Acknowledgements}

We thank the LBC1921 participants. We thank Beverly Roberts and Martha Whiteman for data collection. We thank the Scottish Council for Research in Education for allowing access to the Scottish Mental Survey 1932. The Biotechnology and Biological Sciences Research Council funded data collection for Wave 1; a Royal SocietyWolfson Research Merit Award to Ian J. Deary funded data collection for Wave 2; a grant from the Scottish Government's Health Directorates Chief Scientist Office supported data collection in Wave 3. The work was undertaken by The University of Edinburgh Centre for Cognitive Ageing and Cognitive Epidemiology, part of the cross council Lifelong Health and Wellbeing Initiative (G0700704/84698). Funding from the Biotechnology and Biological Sciences Research Council (BBSRC), Engineering and Physical Sciences Research Council (EPSRC), Economic and Social Research Council (ESRC), and Medical Research Council (MRC) is gratefully acknowledged. 


\section{References}

Blair, C. K., Folsom, A. R., Knopman, D. S., Bray, M. S., Mosley, T. H., \& Boerwinkle, E. (2005). APOE genotype and cognitive decline in a middle-aged cohort. Neurology, 64(2), 268-276.

Bretsky, P., Guralnik, J. M., Launer, L., Albert, M., \& Seeman, T. E. (2003). The role of APOE- 44 in longitudinal cognitive decline: MacArthur Studies of Successful Aging. Neurology, 60(7), 1077-1081.

Bunce, D., Fratiglioni, L., Small, B. J., Winblad, B., \& Backman, L. (2004). APOE and cognitive decline in preclinical Alzheimer disease and non-demented aging. Neurology, 63(5), 816-821.

Caselli, R. J., Dueck, A. C., Osborne, D., Sabbagh, M. N., Connor, D. J., Ahern, G. L., Baxter, L. C., Rapcsak, S. Z., Shi, J., Woodruff, B. K., Locke, D. E., Snyder, C. H., Alexander, G. E., Rademakers, R., \& Reiman, E. M. (2009). Longitudinal modeling of age-related memory decline and the APOE $\varepsilon 4$ effect. $N$ Engl J Med, 361(3), 255-263.

Corder, E. H., Saunders, A. M., Risch, N. J., Strittmatter, W. J., Schmechel, D. E., Gaskell, P. C., Jr., Rimmler, J. B., Locke, P. A., Conneally, P. M., Schmader, K. E., \& et al. (1994). Protective effect of apolipoprotein E type 2 allele for late onset Alzheimer disease. Nat Genet, 7(2), 180-184.

Corder, E. H., Saunders, A. M., Strittmatter, W. J., Schmechel, D. E., Gaskell, P. C., Small, G. W., Roses, A. D., Haines, J. L., \& Pericak-Vance, M. A. (1993). Gene dose of apolipoprotein E type 4 allele and the risk of Alzheimer's disease in late onset families. Science, 261(5123), 921-923.

Cosentino, S., Scarmeas, N., Helzner, E., Glymour, M. M., Brandt, J., Albert, M., Blacker, D., \& Stern, Y. (2008). APOE $\varepsilon 4$ allele predicts faster cognitive decline in mild Alzheimer disease. Neurology, 70(19 Pt 2), 1842-1849.

Cumming, A. M., \& Robertson, F. W. (1984). Polymorphism at the apoprotein-E locus in relation to risk of coronary disease. Clin Genet, 25(4), 310-313.

Deary, I. J., Whalley, L. J., St Clair, D., Breen, G., Leaper, S., Lemmon, H., Hayward, C., \& Starr, J. M. (2003). The influence of the $\varepsilon 4$ allele of the apolipoprotein $E$ gene on childhood $I Q$, nonverbal reasoning in old age, and lifetime cognitive change. Intelligence, 31(1), 85-92.

Deary, I. J., Whalley, L. J., \& Starr, J. M. (2009). A lifetime of Intelligence: Follow-up Studies of the Scottish Mental Surveys of 1932 and 1947. Washington, DC: American Psychological Association.

Deary, I. J., Whiteman, M. C., Pattie, A., Starr, J. M., Hayward, C., Wright, A. F., Carothers, A., \& Whalley, L. J. (2002). Cognitive change and the APOE \&4 allele. Nature, 418(6901), 932.

Deary, I. J., Whiteman, M. C., Pattie, A., Starr, J. M., Hayward, C., Wright, A. F., Visscher, P. M., Tynan, M. C., \& Whalley, L. J. (2004a). Apolipoprotein e gene variability and cognitive functions at age 79: a follow-up of the Scottish mental survey of 1932. Psychol Aging, 19(2), 367-371.

Deary, I. J., Whiteman, M. C., Starr, J. M., Whalley, L. J., \& Fox, H. C. (2004b). The impact of childhood intelligence on later life: following up the Scottish mental surveys of 1932 and 1947. J Pers Soc Psychol, 86(1), 130-147.

Den Heijer, T., Oudkerk, M., Launer, L. J., Van Duijn, C. M., Hofman, A., \& Breteler, M. M. (2002). Hippocampal, amygdalar, and global brain atrophy in different apolipoprotein E genotypes. Neurology, 59(5), 746-748.

Fillenbaum, G. G., Landerman, L. R., Blazer, D. G., Saunders, A. M., Harris, T. B., \& Launer, L. J. (2001). The relationship of APOE genotype to cognitive functioning in older African-American and Caucasian community residents. J Am Geriatr Soc, 49(9), 1148-1155.

Folstein, M. F., Folstein, S. E., \& McHugh, P. R. (1975). "Mini-mental state”. A practical method for grading the cognitive state of patients for the clinician. J Psychiatr Res, 12(3), 189-198.

Gow, A. J., Johnson, W., Pattie, A., Brett, C. E., Roberts, B., Starr, J. M., \& Deary, I. J. (2011). Stability and change in intelligence from age 11 to ages 70, 79 and 87: the Lothian Birth Cohorts of 1921 and 1936. Psychol Aging, 26(1), 232-240.

Gow, A. J., Johnson, W., Pattie, A., Whiteman, M. C., Starr, J., \& Deary, I. J. (2008). Mental ability in childhood and cognitive aging. Gerontology, 54(3), 177-186.

Haan, M. N., Shemanski, L., Jagust, W. J., Manolio, T. A., \& Kuller, L. (1999). The role of APOE $\varepsilon 4$ in modulating effects of other risk factors for cognitive decline in elderly persons. JAMA, 282(1), 40-46. 
Jorm, A. F., Mather, K. A., Butterworth, P., Anstey, K. J., Christensen, H., \& Easteal, S. (2007). APOE genotype and cognitive functioning in a large age-stratified population sample. Neuropsychology, 21(1), 1-8.

Lai, E., Riley, J., Purvis, I., \& Roses, A. (1998). A 4-Mb high-density single nucleotide polymorphism-based map around human APOE. Genomics, 54(1), 31-38.

Lezak, M. D. (1995). Neuropsychological Testing. Oxford, England: Oxford University Press.

Luciano, M., Gow, A. J., Harris, S. E., Hayward, C., Allerhand, M., Starr, J. M., Visscher, P. M., \& Deary, I. J. (2009a). Cognitive ability at age 11 and 70 years, information processing speed, and APOE variation: the Lothian Birth Cohort 1936 study. Psychol Aging, 24(1), 129-138.

Luciano, M., Gow, A. J., Taylor, M. D., Hayward, C., Harris, S. E., Campbell, H., Porteous, D. J., Starr, J. M., Visscher, P. M., \& Deary, I. J. (2009b). Apolipoprotein E is not related to memory abilities at 70 years of age. Behav Genet, 39(1), 6-14.

Lutz, M. W., Crenshaw, D. G., Saunders, A. M., \& Roses, A. D. (2010). Genetic variation at a single locus and age of onset for Alzheimer's disease. Alzheimers Dement, 6(2), 125-131.

Mahley, R. W., \& Rall, S. C., Jr. (2000). Apolipoprotein E: far more than a lipid transport protein. Annu Rev Genomics Hum Genet, 1, 507-537.

Melrose, R. J., Poulin, R. M., \& Stern, C. E. (2007). An fMRI investigation of the role of the basal ganglia in reasoning. Brain Res, 1142, 146-158.

Packard, C. J., Westendorp, R. G., Stott, D. J., Caslake, M. J., Murray, H. M., Shepherd, J., Blauw, G. J., Murphy, M. B., Bollen, E. L., Buckley, B. M., Cobbe, S. M., Ford, I., Gaw, A., Hyland, M., Jukema, J. W., Kamper, A. M., Macfarlane, P. W., Jolles, J., Perry, I. J., Sweeney, B. J., \& Twomey, C. (2007). Association between apolipoprotein E4 and cognitive decline in elderly adults. J Am Geriatr Soc, 55(11), 1777-1785.

Raven, J. C., Court, J. H., \& J., R. (1977). Manual for Raven's Progressive Matrices and Vocabulary Scales. London: H. K. Lewis.

Reitz, C., Brickman, A. M., Brown, T. R., Manly, J., DeCarli, C., Small, S. A., \& Mayeux, R. (2009). Linking hippocampal structure and function to memory performance in an aging population. Arch Neurol, 66(11), 1385-1392.

Roses, A. D., Lutz, M. W., Amrine-Madsen, H., Saunders, A. M., Crenshaw, D. G., Sundseth, S. S., Huentelman, M. J., Welsh-Bohmer, K. A., \& Reiman, E. M. (2009). A TOMM40 variable-length polymorphism predicts the age of late-onset Alzheimer's disease. Pharmacogenomics J, 10(5), 375-384.

Scottish Council for Research in Education (1933). The intelligence of Scottish Children: A national survey of an age-group. London: University of London Press.

Slooter, A. J., Cruts, M., Kalmijn, S., Hofman, A., Breteler, M. M., Van Broeckhoven, C., \& Van Duijn, C. M. (1998a). Risk estimates of dementia by apolipoprotein $E$ genotypes from a population-based incidence study: the Rotterdam Study. Arch Neurol, 55(7), 964-968.

Slooter, A. J., Van Duijn, C. M., Bots, M. L., Ott, A., Breteler, M. B., De Voecht, J., Wehnert, A., De Knijff, P., Havekes, L. M., Grobbee, D. E., Van Broeckhoven, C., \& Hofman, A. (1998b). Apolipoprotein E genotype, atherosclerosis, and cognitive decline: the Rotterdam Study. J Neural Transm Suppl, 53, 17-29.

Small, B. J., Basun, H., \& Bäckman, L. (1998). Three-year changes in cognitive performance as a function of apolipoprotein E genotype: evidence from very old adults without dementia. Psychol Aging, 13(1), 80-87.

Small, B. J., Rosnick, C. B., Fratiglioni, L., \& Bäckman, L. (2004). Apolipoprotein E and cognitive performance: a meta-analysis. Psychol Aging, 19(4), 592-600.

Smith, J. D. (2002). Apolipoproteins and aging: emerging mechanisms. Ageing Res Rev, 1(3), 345-365.

Thambisetty, M., Beason-Held, L., An, Y., Kraut, M. A., \& Resnick, S. M. (2010). APOE $\varepsilon 4$ genotype and longitudinal changes in cerebral blood flow in normal aging. Arch Neurol, 67(1), 93-98.

Verbeke, G., \& Molenberghs, G. (2000). Linear Mixed Models for Longitudinal Data. New York: Springer.

Wechsler, D. (1987). Wechsler Memory Scale-Revised. New York: Psychological Corporation.

Wenham, P. R., Price, W. H., \& Blandell, G. (1991). Apolipoprotein E genotyping by one-stage PCR. Lancet, 337(8750), 1158-1159. 


\section{CHAPTER 9}

Wisdom, N. M., Callahan, J. L., \& Hawkins, K. A. (2011). The effects of apolipoprotein E on non-impaired cognitive functioning: a meta-analysis. Neurobiol Aging, 32(1), 63-74.

Zimmerman, M. E., Pan, J. W., Hetherington, H. P., Katz, M. J., Verghese, J., Buschke, H., Derby, C. A., \& Lipton, R. B. (2008). Hippocampal neurochemistry, neuromorphometry, and verbal memory in nondemented older adults. Neurology, 70(18), 1594-1600. 
Supplementary Table 1 Distribution of TOMM4O genotypes at baseline, stratified by APOE genotype

\begin{tabular}{|c|c|c|c|c|c|c|c|}
\hline \multirow{2}{*}{$\begin{array}{l}\text { APOE } \\
\text { genotype }\end{array}$} & \multicolumn{6}{|c|}{ TOMM40 genotype } & \multirow[b]{2}{*}{ Total } \\
\hline & Short-short & Short-long & $\begin{array}{l}\text { Short-very } \\
\text { long }\end{array}$ & Long-long & $\begin{array}{l}\text { Long-very } \\
\text { long }\end{array}$ & $\begin{array}{l}\text { Very long- } \\
\text { very long }\end{array}$ & \\
\hline E2E2 & 0 & 0 & 2 & 0 & 0 & 0 & 2 \\
\hline E2E3 & 15 & 0 & 37 & 0 & 0 & 23 & 75 \\
\hline E2E4 & 0 & 2 & 0 & 0 & 17 & 0 & 19 \\
\hline E3E3 & 75 & 0 & 138 & 0 & 0 & 77 & 290 \\
\hline E3E4 & 0 & 58 & 1 & 1 & 47 & 0 & 107 \\
\hline E4E4 & 0 & 0 & 0 & 4 & 1 & 0 & 5 \\
\hline Total & 90 & 60 & 178 & 5 & 65 & 100 & 498 \\
\hline
\end{tabular}

Note: $A P O E$, apolipoprotein E; TOMM40, translocase of outer mitochondrial membrane 40 homolog.

Supplementary Table 2 Longitudinal associations between APOE E2 allele status and cognitive performance between mean ages of 79 and 87 years

\begin{tabular}{|c|c|c|c|c|c|c|}
\hline & \multicolumn{2}{|c|}{ Verbal Fluency } & \multicolumn{2}{|c|}{ Logical Memory } & \multicolumn{2}{|c|}{ Raven's Matrices } \\
\hline & Estimate $(95 \% \mathrm{Cl})$ & $p$ & Estimate $(95 \% \mathrm{Cl})$ & $p$ & Estimate $(95 \% \mathrm{Cl})$ & $p$ \\
\hline \multicolumn{7}{|l|}{ Model $1^{a}$} \\
\hline$A P O E$ E2 status $^{\mathrm{b}}$ & $0.50(-2.23 ; 3.23)$ & 0.719 & $4.69(1.86 ; 7.51)$ & 0.001 & $0.80(-1.12 ; 2.71)$ & 0.415 \\
\hline Time & $-0.24(-0.41 ;-0.08)$ & 0.004 & $-0.06(-0.27 ; 0.14)$ & 0.555 & $-0.68(-0.80 ;-0.56)$ & $<0.001$ \\
\hline APOE E2 $\times$ time & $0.30(-0.08 ; 0.67)$ & 0.119 & $0.03(-0.45 ; 0.50)$ & 0.908 & $0.21(-0.07 ; 0.49)$ & 0.137 \\
\hline \multicolumn{7}{|l|}{ Model 2} \\
\hline$A P O E$ E2 status & $0.40(-2.40 ; 3.19)$ & 0.780 & $4.75(1.81 ; 7.69)$ & 0.002 & $0.37(-1.49 ; 2.22)$ & 0.697 \\
\hline Time & $-0.24(-0.41 ;-0.06)$ & 0.007 & $-0.08(-0.30 ; 0.13)$ & 0.462 & $-0.72(-0.84 ;-0.60)$ & $<0.001$ \\
\hline APOE E2 $\times$ time & $0.22(-0.18 ; 0.62)$ & 0.274 & $-0.01(-0.51 ; 0.49)$ & 0.974 & $0.23(-0.05 ; 0.51)$ & 0.109 \\
\hline \multicolumn{7}{|l|}{ Model 3} \\
\hline APOE E2 status & $1.17(-1.66 ; 4.01)$ & 0.417 & $4.86(1.81 ; 7.91)$ & 0.002 & $1.02(-0.87 ; 2.90)$ & 0.289 \\
\hline Time & $-0.19(-0.37 ;-0.01)$ & 0.035 & $-0.09(-0.31 ; 0.12)$ & 0.397 & $-0.69(-0.82 ;-0.57)$ & $<0.001$ \\
\hline APOE E2 $\times$ time & $0.11(-0.29 ; 0.51)$ & 0.602 & $-0.08(-0.58 ; 0.42)$ & 0.758 & $0.15(-0.13 ; 0.44)$ & 0.286 \\
\hline \multicolumn{7}{|c|}{$\begin{array}{l}\text { Note: } A P O E \text {, apolipoprotein } \mathrm{E} ;{ }^{a} \text { Model } 1 \text { is corrected for age, age }{ }^{2} \text {, and sex; Model } 2 \text { is additionally } \\
\text { corrected for age } 11 \mathrm{IQ} \text {; and Model } 3 \text { is additionally corrected for body mass index, smoking status, } \\
\text { alcohol consumption, total serum cholesterol, history of cardiovascular disease, history of cerebrovascu- } \\
\text { lar disease, history of hypertension, and history of diabetes; }{ }^{b} \text { The estimate for } A P O E \text { E2 status represents } \\
\text { the cross-sectional association between } A P O E \text { E2 status and cognitive performance at baseline. The time } \\
\text { estimate equals the effect of time on cognitive performance in non-carriers of the APOE E2 allele. The } \\
\text { estimate for the interaction effect between time and } A P O E \text { E2 status corresponds to the additional } \\
\text { annual change in } A P O E \text { E2 carriers as compared with non-carriers. }\end{array}$} \\
\hline
\end{tabular}


Supplementary Table 3 Cognitive change according to APOE and TOMM40 genotype in participants who completed three waves of cognitive testing between mean ages of 79 and 87 years

\begin{tabular}{lllll}
\hline APOE genotype & TOMM40 genotype & $n$ & \multicolumn{2}{c}{ Cognitive change $^{\text {a }^{2}}$} \\
\cline { 3 - 5 } & & & Logical Memory & Raven's Matrices $^{\text {E2E2 }}$ \\
E2E3 & Short-very long & 1 & 7.52 & 1.34 \\
& Short-short & 7 & $-4.70(-1.20 ; 2.56)$ & $0.82(-5.34 ; 6.97)$ \\
& Short-very long & 12 & $6.73(-0.89 ; 14.34)$ & $3.26(-1.11 ; 7.63)$ \\
E2E4 & Very long-very long & 8 & $8.00(2.10 ; 13.90)$ & $0.76(-1.20 ; 2.71)$ \\
E3E3 & Long-very long & 5 & $-7.84(-1.46 ;-1.08)$ & $-1.20(-1.09 ; 8.53)$ \\
& Short-short & 36 & $0.07(-3.42 ; 3.56)$ & $0.34(-1.91 ; 2.58)$ \\
& Short-very long & 57 & $-0.14(-2.87 ; 2.59)$ & $0.37(-1.35 ; 2.09)$ \\
E3E4 & Very long-very long & 23 & $1.70(-2.97 ; 6.37)$ & $-1.48(-3.66 ; 0.70)$ \\
& Short-long & 21 & $-4.25(-9.70 ; 1.20)$ & $0.19(-1.88 ; 2.27)$ \\
E4E4 & Long-very long & 14 & $-3.26(-1.03 ; 3.75)$ & $-2.86(-6.98 ; 1.26)$ \\
\hline
\end{tabular}

Note: Values are means $(95 \% \mathrm{Cl}) ; A P O E$, apolipoprotein E; TOMM40, translocase of outer mitochondrial membrane 40 homolog; ${ }^{a}$ Cognitive change was defined as the residuals of regressing test score at mean age 87 on test score at mean age $79 ;{ }^{b} n=0$. 
CHAPTER 10

Concluding remarks 
The objectives of the present thesis were to investigate nutritional and genetic determinants of cognitive functioning and mood in older community-dwelling adults. We used a neuroepidemiological approach to study the relationship between the above-mentioned biological parameters and behavioural outcome measures. This chapter comments on the main findings by discussing relevant methodological aspects, clinical and practical implications, as well as by giving recommendations for further research.

\section{The role of nutritional and genetic factors in cognitive ageing and mood}

\section{Nutritional variables}

The nutritional factors studied in the present thesis, including fatty acid status and fish consumption, serum iron parameters, erythrocyte folate, and plant sterols and stanols, did not exhibit robust or straightforward relationships, if any, with cognitive performance or mood in healthy older individuals. For example, although long-chain polyunsaturated fatty acid (LCPUFA) status showed a significant inverse association with depressed mood, this association only became apparent in persons with depressive symptoms above the clinical threshold. In addition, whereas fatty acid status was not significantly related to physical or mental well-being in the general population, we did find a positive association between fish consumption and the physical dimension of quality of life. Furthermore, serum iron parameters were not associated with individual differences in the rate of cognitive decline in older community-dwelling adults, although serum iron and ferritin did reveal a negative crosssectional relationship with cognitive performance, which appeared to be modified by apolipoprotein E (APOE) E4 carrier status. Several explanations might be put forward for the heterogeneous results obtained with respect to the influence of nutritional factors on neurocognitive functioning in the older population.

First, some nutrients may play a critical role in brain functioning during the early stages of the life course, whereas their role in adulthood or old age may be less prominent. For instance, because of the involvement in neurite outgrowth, membrane biogenesis, signal transduction, and neurotransmission processes, adequate concentrations of LCPUFA are important for normal brain development in early life (Assisi et al., 2006; Innis, 2007). In addition, it is well established that folate deficiency during pregnancy increases the risk of neural tube defects (Goh \& Koren, 2008), which illustrates the critical role of folate in early neurodevelopment. However, it has become increasingly clear that individual variation in LCPUFA status or folate concentrations might not influence neurocognitive functioning in later life to such a great extent. Indeed, population-based studies investigating the relationship 
between LCPUFA or folate status on the one hand and cognitive performance or mood on the other have yielded mixed results (Appleton et al., 2008b; D'Anci \& Rosenberg, 2004). Thus, in contrast to brain development, current evidence, including the results presented in this thesis, does not consistently support the involvement of nutritional factors, such as $n-3$ fatty acids or folate, in mediating individual variability in cognitive performance or mood during adulthood.

Second, it may be suggested that significant associations between dietary factors and behavioural variables in old age might only be observed in cases of severe nutritional deficiency. Such a view implies that normal variations in the blood concentrations of nutrients, i.e. as occurring in the general population on a standard Western diet, might not show a clear relationship with cognitive performance or mood. From this perspective, association studies performed in healthy communitydwelling adults are less likely to yield statistically significant results. For example, as discussed in chapter 5, the lack of any significant associations between nontransferrin bound iron and cognitive performance may be related to the fact that this serum iron parameter shows a relatively narrow distribution in a population of healthy individuals.

Alternatively, it may also be argued that nutritional variables might only play a prominent role in pathological degrees of cognitive performance or depressive symptoms. This assumption is illustrated by the results presented in chapter 2 of this thesis, which indicated that suboptimal n-3 fatty acid concentrations accompanied depressive symptoms only within the clinical range. Further support for this notion has been provided by a recent study by Appleton et al. (2008a), who suggested that, in contrast with clinical populations, n-3 LCPUFA may not be related to depressed mood in non-clinical samples. Consequently, the associations between n3 fatty acid status and mood, as well as their biological underpinnings, might differ according to symptom severity. In this respect, however, it should be noted that suboptimal $n-3$ LCPUFA concentrations may either precede or follow depressive symptoms. Due to the cross-sectional nature of our study, we were not able to establish the direction of causality of the observed inverse relationship between fatty acid status and depressed mood.

Finally, it may be suggested that the effects of nutritional factors on cognitive functioning and mood in older individuals might exclusively become apparent in combination with other variables, such as genetic risk factors or components of an unhealthy lifestyle, implying that the independent effects of single nutrients might be negligible. For example, it has been put forward that certain genetic polymorphisms might modify individual responses to the Mediterranean diet by influencing the metabolic pathways involved (Lairon et al., 2009). In addition, in chapter 5 of the present thesis, we showed that the associations between serum iron parameters and cognitive performance were modified by donor status, sex, and APOE E4 allele carrier status. Thus, from this viewpoint, individual susceptibility to cognitive 
decline or depressive symptoms may have its origin in the interplay between different risk factors. As a consequence, instead of focusing on single nutrients, the intricate relationship between various nutrients, e.g. as part of a specific nutritional pattern, together with the effects of other environmental or genetic parameters, should be investigated in order to identify the nutritional determinants of individual differences in neurocognitive functioning. Therefore, in the present thesis, we did not only aim for assessing the main effects of different nutrients and genetic factors, but we also assessed various interactions between these variables in relation to cognitive performance and mood state.

\section{Genetic variables}

Previous studies into the genetic foundations of cognition and behaviour have indicated that heritability may account for more than $50 \%$ of the individual variation in cognitive functioning in adulthood (Deary et al., 2009b; Finkel et al., 2005), and approximately one-third of the variance associated with age-related cognitive decline (Finkel et al., 2005). Interestingly, the influence of genetic factors on cognitive phenotype has been reported to increase with age (Haworth et al., 2010; Plomin et al., 1994).

Estimations of the heritability of psychopathological diseases have pointed out that the contribution of genetic factors to major depressive disorder is about 30 to $40 \%$ (Sullivan et al., 2000). However, individual genes tend to explain only a small fraction of the heritable component of cognitive performance and mood state. Indeed, although some genetic factors may exhibit a rather pronounced relationship with neurocognitive functioning, e.g. APOE E4 carrier status shows a fairly robust association with the rate of cognitive decline in old age, accumulating evidence suggests that most genes do not account for a large amount of variance, if any, in cognition or mood (Bouchard \& McGue, 2003; Levinson, 2006). Hence, a more tenable explanation for the marked heritability of cognition and mood seems to lie in the cumulative effect of different genes or gene-environment interactions, rather than the independent influence of distinct genes.

In the present thesis, we did not find any significant associations between cognitive performance and genetically determined variability in iron homeostasis or folate metabolism, or the epigenetic mechanism of global DNA methylation. A number of reasons might account for these null findings.

One possible explanation is that phenotypic expression of a given gene or genetic polymorphism may be dependent on environmental factors, implying that the behavioural effects of a specific gene or genetic mutation may only become apparent under specific circumstances. For example, phenotypic expression of the 5,10-methylenetetrahydrofolate reductase (MTHFR) 677C $\rightarrow$ T polymorphism is more prominent in the presence of low folate concentrations (Girelli et al., 1998). How- 
ever, the studies described in chapters 6 and 7, which tested for a possible modifying effect of folate status on the putative relationship between genetic variation in folate metabolism and cognitive performance, did not reveal any significant results. Thus, it is likely that other factors might be responsible for the lack of any associations between cognitive functioning and the polymorphic variants assessed.

Another possibility is that genetic variables might only affect behaviour when part of a more complex genetic profile. In this case, a certain set of genes or the combination of different genetic polymorphisms may be considered a far better predictor of cognitive decline or depressive symptoms than any single gene or genetic mutation. This implies that there may be no detectable main effects of a specific gene, only additive effects of different genes, or higher order gene-gene interactions. Such complex effects may result from linkage between different genetic loci, but they may also derive from multiple independently acting genes. As an example, in chapters 6 and 7 of the present thesis, we assessed the putative interactions between the MTHFR $677 \mathrm{C} \rightarrow \mathrm{T}$ and $1298 \mathrm{~A} \rightarrow \mathrm{C}$ polymorphisms, as well as the possibility of effect modification by APOE E4 allele carrier status. In addition, we investigated whether the translocase of outer mitochondrial membrane 40 homolog (TOMM40) poly-T polymorphism modified the relationship between APOE genotype and age-related cognitive decline. Although no significant interaction effects were identified, other studies have provided evidence in support of the notion that multiple genetic factors might be needed for behavioural effects to become manifest (Bouchard \& McGue, 2003). However, it should be noted that it might be difficult to examine such gene-gene interactions in relation to behavioural variables, because very large samples are needed to test for the putative interaction between rare allelic variants. In any case, the genetic interactions assessed in the present thesis do not appear to predict a significant amount of variance in cognitive performance or mood.

Lastly, besides main genetic effects, gene-gene interactions, or geneenvironment interactions, part of the genetic variance associated with cognitive performance and mood may be explained by epigenetic factors. With respect to epigenetics, a distinction should be made between inherited or somatically acquired epigenetic abnormalities, which are more or less static (cf. neurodevelopmental disorders, such as Fragile X syndrome) (Tsankova et al., 2007), or short-term, dynamic regulation of gene expression through epigenetic mechanisms, which may be influenced by environmental factors, including nutrition (Levi \& Sanderson, 2004; Reichenberg et al., 2009). The latter variant has been hypothesised to play a role in individual variability in cognitive performance or mood in adulthood (Kaplan et al., 2007; Reichenberg et al., 2009). Dynamic mechanisms of epigenetic regulation may modify the phenotypic expression of a given gene, thereby potentially enhancing or reducing its behavioural effects. In addition, it has been suggested that aberrant epigenetic markers and control mechanisms, particularly within brain regions that 
are most vulnerable to the effects of ageing, such as the hippocampus, may contribute to age-related cognitive decline (Penner et al., 2010). In the present thesis, DNA methylation status was not associated with cognitive functioning in healthy older adults, which might be due to the non-specific nature of global DNA methylation in comparison with the methylation status of particular, yet unidentified, genes or gene regions that may be more closely related to cognitive performance. Clearly, further research is required to assess the putative involvement of epigenetic mechanisms in the regulation of behaviour in later life.

Summarising, in line with previous studies, the results of the present thesis suggest that the independent nutritional and genetic components of cognition and mood tend to be rather small. These findings imply that a substantial part of phenotypic variance may be accounted for by the complex interplay between both types of variables, which is addressed in the next paragraph.

\section{Gene-environment interactions}

When investigating the potential influence of biological factors on cognitive performance and mood, studies may focus on genetics, environmental factors, or both. It has been argued that the main benefit of studying genetic factors lies in the fact that the effects of genes reflect lifetime exposure, which implies that the associations between genetic factors and behaviour are not confounded by other variables. This is known as the principle of Mendelian randomisation (Tobin et al., 2004).

However, the concept of epigenetics introduces a new view on the abovementioned concept of lifetime exposure to genetic factors, as the expression of genes appears to be a dynamic rather than a static process, potentially modified by a variety of environmental factors. Interestingly, there may be critical periods in the life course, during which the individual shows increased sensitivity to the influence of such gene-environment interactions. As an example, both maternal undernutrition or overnutrition, which represent suboptimal environmental conditions during foetal development, have been suggested to influence behavioural parameters in later life, such as the risk of psychopathological disorders, by influencing epigenetic modification of gene expression (Bale et al., 2010).

As genes and environmental factors, such as nutrients, may interact or show cumulative effects in mediating cognition and behaviour, it may be difficult to disentangle their relative contributions, which advocates taking into account both categories of variables when assessing the biological basis of individual variation in cognitive functioning and mood. 


\section{Methodological considerations}

\section{Measurement of cognitive functioning and mood}

To measure cognitive performance, we used a variety of neuropsychological tests designed to assess different domains of cognitive functioning known to be affected by ageing, including memory (Visual Verbal Word Learning Task, WLT (Van der Elst et al., 2005)), executive functioning (Verbal Fluency Test (Van der Elst et al., 2006a)), abstract reasoning (Raven's Progressive Matrices (Raven et al., 1977)), and speed of information processing (Stroop Color-Word Interference Test (Stroop, 1935; Van der Elst et al., 2006d), Concept Shifting Test, CST (Van der Elst et al., 2006b), and LetterDigit Substitution Test (Van der Elst et al., 2006c)). As age-related changes in cognitive function are generally quite small in comparison with the full range of cognitive performance, studying cognitive ageing requires the use of sensitive cognitive tests in order to be able to detect individual variation in the trajectory of cognitive functioning (Morris et al., 1999). Therefore, we used neuropsychological tests with ample sensitivity to age-related variability in cognitive performance (Jolles et al., 1995).

As different cognitive domains may show different rates of decline during ageing, it is important to measure various domains of cognitive functioning when assessing age-related cognitive changes (Morris et al., 1999). In the studies using data from the Maastricht Aging Study (MAAS) (Jolles et al., 1995; Van Boxtel et al., 1998) and the Folic Acid and Carotid Intima-Media Thickness (FACIT) study (Durga et al., 2005; Durga et al., 2007), the raw test scores of the WLT, the Stroop Color-Word Interference Test, and the CST were clustered into three a-priori defined composite performance indices, representing memory, sensorimotor speed, and complex speed (Lezak et al., 2004). Reducing the number of dependent variables in this manner not only diminished the chance of a type I error, but also improved the robustness of the underlying cognitive construct (Lezak et al., 2004). The three summary indices of cognitive performance were defined on the basis of previous research, indicating that memory and processing speed - the latter of which can be subdivided into a simple and a complex type - are distinctive domains of cognitive functioning in older individuals (La Rue, 1992; Lezak et al., 2004).

Mood state was measured using two questionnaires: the Center for Epidemiologic Studies Depression Scale (CES-D) (Radloff, 1977) and the depression subscale of the Symptom Checklist 90 (SCLdep) (Arrindell \& Ettema, 1986). It should be noted that the baseline assessments of the MAAS study only included SCLdep data, thereby limiting the use of the CES-D questionnaire in longitudinal analyses. Likewise, in the dietary intervention trial described in chapter 4 , mood state was measured by means of the SCLdep questionnaire only. Although both instruments are widely-used, valid tools for detecting depressive symptoms, the CES-D question- 
naire may be considered the most appropriate instrument for assessing mood state in non-clinical populations, as it has been developed specifically for detecting depressive symptoms in the general population. In addition, compared with the SCLdep questionnaire, the CES-D puts less stress on somatic aspects of depressive symptomatology, which makes the CES-D questionnaire a better predictor of depressed mood in older adults. Thus, future studies using population-based samples might benefit from administering the CES-D questionnaire, rather than the SCLdep questionnaire, when assessing mood state in older adults.

\section{Measurement of biological factors}

We used venous blood samples to determine genetic polymorphisms, global DNA methylation status, and serum or plasma concentrations of various nutrients. Nutrient concentrations determined in serum or plasma offer a more accurate measure of nutritional status than estimations based on dietary intake, as the latter are subject to recall bias. Interestingly, by applying both types of measurement in chapter 3, we were able to demonstrate that the positive association between fish consumption and quality of life could not be attributed to the fatty acid content of fish. Only using fish consumption as a measure of fatty acid intake would have resulted in the incorrect conclusion that $n-3$ LCPUFA might have been responsible for the observed relationship. However, aside from the substantial measurement error that may be associated with estimates of dietary intake, it should be noted that daily variations in the blood concentrations of nutrients might also bias the relationship with cognition or mood to a certain extent.

The fact that nutrient concentrations as well as DNA methylation status were measured in the periphery rather than in brain tissue or cerebrospinal fluid may be regarded as a limitation of our studies. Although all cells of the human body have the same genetic code, the level of expression of a given gene may vary between cells located in the periphery and the brain (Schilling \& Rehli, 2007). In addition, as the brain may show selective uptake of nutrients from the bloodstream, and some compounds are known to cross the blood-brain barrier more easily than others, the brain concentrations of various nutrients may differ from those observed in serum or plasma. Therefore, it remains uncertain whether leukocyte DNA methylation status may accurately represent DNA methylation in neurons, and whether the blood concentrations of iron parameters and phospholipid-associated $n-3$ fatty acids may be regarded as reliable indicators of the concentrations present in the brain.

However, the problem associated with using indirect methods for estimating the concentrations of nutritional and epigenetic factors in the brain is very difficult to overcome, as only proxy measures are available in healthy human volunteers. The potential measurement error introduced by the indirect measurement of brain 
concentrations should, therefore, be considered an inevitable limitation of human studies investigating dietary and epigenetic factors in relation to neurocognitive functioning.

\section{Use of population-based studies}

The observational studies described in this thesis were performed using populationbased samples. The strengths of the three databases used, i.e. MAAS, FACIT, and the Lothian Birth Cohort 1921 (LBC1921) (Deary et al., 2009c; Deary et al., 2004), were their large sample sizes and their longitudinal design. Large study samples have the advantage of yielding sufficient statistical power to detect small associations. In addition, they allow for the correction for various possible confounders. Furthermore, a prospective design with multiple follow-up measurements enables the assessment of the level of neurocognitive functioning and the course of individual changes over time, both of which are very important aspects of studying individual variability in age-related cognitive decline or mood. Moreover, as they typically use samples that are representative of the general community, populationbased studies have a large external validity when compared with experimental study designs.

Possible disadvantages of longitudinal population-based studies include loss to follow-up and selective attrition, which may bias the results obtained. Due to the old age of the study population, the LBC1921 cohort in particular was characterised by substantial loss to follow-up. Although dropout from the study was not related to any of the independent variables assessed, except for smoking, it was significantly associated with a lower level of cognitive performance at baseline. Selective dropout of cognitively impaired individuals might lead to an underestimation of cognitive change, thereby potentially biasing the results towards zero (Van Beijsterveldt et al., 2002). By using a statistical approach that allowed for the inclusion of participants with incomplete data at follow-up, i.e. linear mixed models, we were able to compensate, at least in part, for this selection bias.

Another potential limitation of longitudinal studies investigating determinants of cognitive functioning is the repeated administration of cognitive tests, which may introduce learning effects. Such learning effects may obscure age-related cognitive decline, thereby affecting estimates of cognitive change (Rabbitt et al., 2001). Although this potential problem may be partly overcome by using different test versions at each follow-up assessment, the occurrence of procedural learning, which refers to practice effects caused by the familiarisation to test procedures, cannot be prevented entirely. For instance, although participants may not remember the exact words included in tests of verbal memory, they might remember the fact that delayed recall is tested after $25 \mathrm{~min}$. However, it is unlikely that learning effects might have influenced the present results to a great extent, as longitudinal 
variability in cognitive performance is generally well preserved, thereby permitting the detection of individual differences in the rate of age-associated cognitive change (Rabbitt et al., 2001).

Unfortunately, we were not able to perform longitudinal analyses in all of the studies described in the present thesis, as repeated measurements were lacking for some parameters, such as LCPUFA concentrations in the MAAS study. In this respect, the cross-sectional nature of the studies presented in chapters 2 and 3 limited the interpretation of the results, in that no inferences could be made about causality of the observed associations. However, although prospective studies with multiple follow-up measurements are better suited for investigating causal relationships than cross-sectional studies, only studies with an experimental design allow for drawing definite conclusions about cause and effect.

\section{Approach of the present thesis}

We selected four datasets to investigate the biological determinants of cognitive ageing. For each study performed, we used the dataset we considered most suitable for testing a specific hypothesis. From a methodological perspective, it seems worthwhile to evaluate the effectiveness of our approach, particularly as four out of eight studies have yielded statistically non-significant results.

First, we consider it unlikely that different results would have been obtained if the studies had specifically been designed to accomplish our research goals. Obviously, when performing statistical analyses or interpreting the results, we came across several limitations that were inherent to our approach of using existing datasets, such as the lack of certain variables (e.g. folate concentrations in the MAAS study or depressive symptoms in the FACIT study), or the lack of longitudinal data (e.g. fatty acid status in the MAAS study). Nevertheless, the datasets used were so detailed, and contained such a large number of variables as well as background information, that the benefits of using pre-existing datasets by far outweighed the limitations.

From the perspectives of time efficiency and cost-effectiveness, we would not have been able to create a sufficiently large dataset, consisting of cross-sectional as well as longitudinal data, and comprising all the variables necessary, to allow for achieving all of our research aims. On the contrary, using data from existing studies enabled us to examine certain aspects that would not have been feasible otherwise, such as assessing the putative interaction between long-term folic acid supplementation and iron homeostasis (chapter 5), or combining data from two communitybased samples to investigate the associations between genetic variation in folate metabolism and neurocognitive functioning (chapter 6). Being able to address such research questions contributed to investigating putative mechanisms underlying neurocognitive functioning, and examining effect modification by relevant biological 
factors. Furthermore, using the unique LBC1921 cohort allowed for investigating the effects of genetic factors on individual changes in cognitive decline in old age, while eliminating any variance in the outcome measures that was accounted for by cognitive ability in childhood (chapters 7 and 9). Moreover, because of the large sample sizes, the administration of sensitive and domain-specific cognitive tests, and the accurate measurement of biological variables, we think the datasets used provided sufficient statistical power and sensitivity to detect associations even with small effect sizes. Therefore, we consider it unlikely that the null findings obtained could be attributed to the methodological approach used in the present thesis. In contrast, the present thesis underscores the notion that, when addressing epidemiological research questions, it might be particularly worthwhile to establish in advance whether appropriate datasets may already be available.

\section{Clinical implications: translating the present findings into daily practice}

The present results offer more insight into the trajectories of cognitive ageing, and increase our understanding about the potential determinants of cognitive functioning and depressed mood. Besides their scientific relevance, the question arises whether the present findings might also have implications for clinical practice. In other words, is it possible to define risk groups for dementia or clinical depression on the basis of nutritional or genetic factors?

As our studies were conducted in population-based samples, some caution is warranted when attempting to extrapolate the present findings to a clinical setting. However, from the viewpoint that non-pathological and pathological degrees of cognitive decline, as well as subclinical and clinical manifestations of depressive symptoms, may represent the extreme ends of a continuum rather than discrete categories (Angst \& Merikangas, 2001; Brayne \& Calloway, 1988; Deary et al., 2009a; Kessler et al., 1997), it might be argued that this thesis addressed the very early, non-clinical stages of cognitive impairment and depression.

In this thesis, several nutritional and genetic factors showed statistically significant associations with cognitive performance or mood in older adults. In an attempt to evaluate their clinical relevance, we calculated the effect sizes of the observed associations between fish consumption and physical well-being, as well as the associations between cognitive performance and serum iron parameters or APOE E4 carrier status. Using Cohen's $d$, effect sizes ranged from 0.10 to 0.30 , indicating small effect sizes. This does not necessarily imply, however, that these associations do not have any clinical relevance, as even small-sized effects may be meaningful on the functional level, e.g. with respect to quality of life or the extent of cognitive change. 
We found that $A P O E$ E4 carrier status predicted cognitive deterioration in later life. Older persons carrying the E4 allele may have a heightened vulnerability to cognitive impairment, as they typically show an increased rate of cognitive decline as compared with non-carriers. Since the APOE E4 allele seems to have a negative impact on the entire spectrum of cognitive functioning, ranging from age-related cognitive decline to pathological cognitive impairment, determining APOE genotype in the older population makes a valuable contribution to identifying persons at risk of dementia.

In addition, APOE E4 carrier status may modify associations between other biological variables and neurocognitive functioning, which also illustrates the involvement of this genetic variant in determining part of the individual variability in cognitive decline. For example, chapter 5 showed that the negative relationship between serum iron parameters and cognitive speed was most pronounced in APOE E4 carriers, which seems to suggest that elevated iron concentrations might exacerbate cognitive decline in persons susceptible to cognitive impairment. Hence, monitoring iron concentrations in genetically predisposed individuals might contribute to identifying persons with an increased risk of cognitive impairment. These findings illustrate that, as individual nutritional or genetic effects on neurocognitive functioning generally tend to be quite small, it appears to be worthwhile to judge their clinical relevance from a broader perspective, by taking into account various modifying factors.

In the study presented in chapter 2 , we found that suboptimal docosahexaenoic acid (DHA, 22:6n-3) concentrations accompanied depressive symptoms only within the clinical range. Thus, measuring $n-3$ LCPUFA concentrations may be informative in classifying depression risk. These results might imply that high-risk groups may be identified, at least in part, on the basis of individual fatty acid status.

With respect to the positive association between fish consumption and the physical dimension of quality of life, on the other hand, it is rather difficult to establish clinical relevance, as it is not clear whether the observed increase in physical well-being may be attributable to vitamins and nutrients present in fish, or to a healthy lifestyle in general. As such, based on the present findings, it seems premature to recommend a high fish intake in order to improve physical well-being in community-dwelling adults. However, the nature of our observations is particularly noteworthy, as more complex mechanisms than fatty acids alone seem to account for the observed association between fish consumption and quality of life. Obviously, further research is necessary to resolve which factors might be involved in mediating this relationship.

In any case, the results presented in chapters 2 and 3 clearly illustrate the importance of taking into account null findings when evaluating the clinical implications of any association observed in a research setting. By demonstrating that quality of life was related to fish consumption, but not LCPUFA status, chapter 3 
showed that it might not always be justified to attribute the positive effects of fish intake on behavioural outcome measures to $n-3$ fatty acids. In addition, chapter 2 provided a novel understanding of the differential findings of population-based and clinical studies investigating the relationships between $n-3$ fatty acids and depressive symptoms, by showing the lack of a relationship between LCPUFA status and depressed mood in the general population. Unfortunately, non-significant results are often underreported, thereby biasing the existing literature. As an example, recent meta-analyses have shown that the considerable heterogeneity between results from studies investigating the relationship between fatty acid status and depressed mood is partly caused by publication bias, where studies reporting positive findings are more likely to be published than studies reporting null findings (Appleton et al., 2008b, 2010). In the present thesis, we have shown that statistically non-significant findings make a valuable contribution to increasing our knowledge about the nature and clinical relevance of the putative associations between nutrients or genetic factors and neurocognitive functioning.

\section{Future directions}

\section{Unravelling further the biological underpinnings of cognitive ageing}

The increasing personal, financial, and societal burdens associated with cognitive decline and poor mental well-being in older individuals urge for the identification of the underlying mechanisms and the factors responsible for individual differences in these behavioural parameters. The involvement and relative contribution of genetic and environmental factors in determining cognitive decline and mood needs to be investigated further in order to be able to discern which individuals might be at risk for cognitive impairment and depression. Early identification of high-risk groups may contribute to a prolonged preservation of cognitive and psychological functioning, particularly when modifiable risk factors are involved, such as lifestyle or dietary habits, for which effective intervention strategies are available (Haan \& Wallace, 2004).

It may be speculated that individual vulnerability to cognitive or depressive disorders might be defined on the basis of some sort of weighted score, in which various potential determinants, such as nutritional status, physical activity, genetic profile, social activities, lifetime exposure to toxic substances, vascular profile, and history of chronic illnesses or inflammatory diseases, are taken into account. Such a multivariate approach should also take into consideration that a number of factors may show considerable overlap, as certain characteristics are likely to co-occur, e.g. healthy dietary habits are often correlated with a physically active lifestyle. Also, it should be kept in mind that some of the potential determinants mentioned above 
are intermediate factors in the causal pathway leading to cognitive impairment or depression. For example, although inflammatory processes may be regarded as an independent risk factor for depression (Schiepers et al., 2005), they might also mediate the relationship between fatty acid status and depressive symptoms (Kiecolt-Glaser et al., 2007).

It should be noted, however, that estimating individual disease risk might also be subject to ethical issues, for instance related to genetic screening. In addition, whereas the opportunity to treat modifiable risk factors may significantly improve quality of life in older individuals, the identification of non-modifiable risk factors, such as genetic predisposition, might have a negative impact on mental well-being, e.g. because of the psychological burden associated with the prospect of impeding functional decline. Therefore, it is crucial to take into account both the benefits and potential drawbacks when assessing individual risk of cognitive impairment or depression on the basis of biological factors.

\section{Challenging future research - the relationship between diabetes and cognitive decline}

The multifactorial nature of causes and mechanisms underlying cognitive impairment is clearly illustrated by the relationship between diabetes and cognitive functioning. Diabetes mellitus, which is one of the most frequently occurring chronic diseases with a current prevalence of 10 to $20 \%$ in persons aged 65 years or older (Wild et al., 2004), is a rapidly growing health-care burden. Relevant to the present context, it has been shown that diabetes may increase the risk of cognitive impairment and dementia (Stewart \& Liolitsa, 1999). Although the biological foundations of this relationship remain to be elucidated, it has been suggested that vascular as well as non-vascular factors may be involved (Roriz-Filho et al., 2009; Umegaki, 2010). Interestingly, many of the neuropathological consequences of diabetes are also observed in normal cognitive ageing, and diabetes and cognitive decline might share a number of causal mechanisms (Roriz-Filho et al., 2009; Umegaki, 2010). As the risk of cognitive decline that may be attributed to diabetes continues to increase due to global population ageing, investigating the possible involvement of this chronic disease in cognitive decline may be one of the challenges for future research.

\section{Moving forward: from a reductionist view towards an integrated approach}

Because of the multifactorial character of cognitive ageing, future research may need to leave the 'candidate gene' or 'single nutrient' approach, and focus more on the cumulative effect or complex interplay of various risk factors. Given that the biological mechanisms underlying many cognitive disorders, behavioural traits, or 
normal neurocognitive variation are often unknown, thereby constraining the generation of a-priori hypotheses, future studies in this field of research might benefit from a data-driven, rather than a hypothesis-driven, approach.

One such approach is the technique of genome-wide association studies (GWAS), which involves searching the whole genome in a systematic manner to reveal the genetic basis of a certain phenotype (Kruglyak, 2008). In terms of studying the biological determinants of cognitive ageing, the data-driven nature of GWAS offers the advantage of potentially identifying novel genes and risk factors that might not have been revealed using a traditional candidate gene approach. Although one of the disadvantages of GWAS is that they require very large sample sizes (up to tens of thousands of participants) to detect small genetic effects, the systematic way in which the genome can be searched for causative or mediating factors provides a convincing rationale for applying GWAS methods. Indeed, since 2005, a large number of genetic associations for various diseases and traits have been detected using GWAS, generating new pathophysiological hypotheses (Cichon et al., 2009). Therefore, the possibility of being able to reveal the biological basis of cognitive decline or depressed mood by scanning the whole genome, strongly advocates the use of GWAS in genetic studies using large population-based samples. It seems reasonable to assume that the majority of genetic factors involved in cognitive ageing, as well as their respective biological pathways, may ultimately be uncovered by means of modern technologies, such as GWAS.

In order to unravel further the biological foundations of cognitive functioning, it may also be informative to use structural and functional brain-imaging methods, such as magnetic resonance imaging (MRI), in addition to neuropsychological tests. Although imaging techniques usually do not allow for assessing very large samples, they may offer more insight into the neural substrates of individual differences in cognitive functioning or the rate of cognitive decline, by aiming to identify the structural, molecular, or metabolic correlates of brain ageing (Raz \& Rodrigue, 2006). Furthermore, brain-imaging technology may also be useful in examining the genetic origins of cognitive functioning. For example, twin studies using imaging methods have shown that brain gray-matter volume and structure are strongly heritable (Koten et al., 2009; Posthuma et al., 2002; Thompson et al., 2001), and that genetic make-up may influence brain activation patterns related to individual differences in cognition (Koten et al., 2009).

Ideally, the above-mentioned objectives may be accomplished by conducting a prospective study assessing a wide range of potentially relevant biological variables, as well as their interactions, in relation to cognitive functioning and mood state. Such a study should be sufficiently large to enable detection of very small effects, and to allow for testing data-driven hypotheses, e.g. by using GWAS methods. In addition, the study population needs to comprise non-clinical as well as clinical degrees of cognitive impairment and depressive symptoms, for the entire range of 
cognitive performance and mood to be investigated. However, large-scale longitudinal studies, which require the systematic measurement of an extensive number of health-related variables, are expensive and time-consuming. Therefore, it might be more convenient to use other comprehensive data sources to investigate the biological determinants of cognitive ageing, such as patient registries or medical files. On the other hand, such a method might not be very appropriate from an ethical perspective. When ethical issues are properly dealt with, however, adopting such a strategy might offer new opportunities for large-scale data collection.

Alternatively, the information needed might also be collected by means of the approach applied in the present thesis, i.e. to reuse existing datasets with a large number of genetic and environmental variables, and multiple follow-up measurements. At the same time, these studies may provide replication cohorts for GWAS and other data-driven methods. Hence, such an approach might be an efficient and cost-effective alternative to developing new studies. Combined with novel molecular genetic strategies and brain-imaging techniques, this might be an appealing way of gathering relevant information and gaining more insight into the biological underpinnings of cognition and behaviour. 


\section{References}

Angst, J., \& Merikangas, K. R. (2001). Multi-dimensional criteria for the diagnosis of depression. J Affect Disord, 62(1-2), 7-15.

Appleton, K. M., Gunnell, D., Peters, T. J., Ness, A. R., Kessler, D., \& Rogers, P. J. (2008a). No clear evidence of an association between plasma concentrations of $n-3$ long-chain polyunsaturated fatty acids and depressed mood in a non-clinical population. Prostaglandins Leukot Essent Fatty Acids, 78(6), 337-342.

Appleton, K. M., Rogers, P. J., \& Ness, A. R. (2008b). Is there a role for $n-3$ long-chain polyunsaturated fatty acids in the regulation of mood and behaviour? A review of the evidence to date from epidemiological studies, clinical studies and intervention trials. Nutr Res Rev, 21(1), 13-41.

Appleton, K. M., Rogers, P. J., \& Ness, A. R. (2010). Updated systematic review and meta-analysis of the effects of n-3 long-chain polyunsaturated fatty acids on depressed mood. Am J Clin Nutr, 91(3), 757770.

Arrindell, W. A., \& Ettema, J. H. M. (1986). SCL-90. Een multidimensionele psychopathologie-indicator [SCL-90. A multidimensional indicator of psychopathology]. Lisse, The Netherlands: Swets \& Zeitlinger.

Assisi, A., Banzi, R., Buonocore, C., Capasso, F., Di Muzio, V., Michelacci, F., Renzo, D., Tafuri, G., Trotta, F., Vitocolonna, M., \& Garattini, S. (2006). Fish oil and mental health: the role of $n-3$ long-chain polyunsaturated fatty acids in cognitive development and neurological disorders. Int Clin Psychopharmacol, 21(6), 319-336.

Bale, T. L., Baram, T. Z., Brown, A. S., Goldstein, J. M., Insel, T. R., McCarthy, M. M., Nemeroff, C. B., Reyes, T. M., Simerly, R. B., Susser, E. S., \& Nestler, E. J. (2010). Early life programming and neurodevelopmental disorders. Biol Psychiatry, 68(4), 314-319.

Bouchard, T. J., Jr., \& McGue, M. (2003). Genetic and environmental influences on human psychological differences. J Neurobiol, 54(1), 4-45.

Brayne, C., \& Calloway, P. (1988). Normal ageing, impaired cognitive function, and senile dementia of the Alzheimer's type: a continuum? Lancet, 1(8597), 1265-1267.

Cichon, S., Craddock, N., Daly, M., Faraone, S. V., Gejman, P. V., Kelsoe, J., Lehner, T., Levinson, D. F., Moran, A., Sklar, P., \& Sullivan, P. F. (2009). Genomewide association studies: history, rationale, and prospects for psychiatric disorders. Am J Psychiatry, 166(5), 540-556.

D’Anci, K. E., \& Rosenberg, I. H. (2004). Folate and brain function in the elderly. Curr Opin Clin Nutr Metab Care, 7(6), 659-664.

Deary, I. J., Corley, J., Gow, A. J., Harris, S. E., Houlihan, L. M., Marioni, R. E., Penke, L., Rafnsson, S. B., \& Starr, J. M. (2009a). Age-associated cognitive decline. Br Med Bull.

Deary, I. J., Johnson, W., \& Houlihan, L. M. (2009b). Genetic foundations of human intelligence. Hum Genet, 126(1), 215-232.

Deary, I. J., Whalley, L. J., \& Starr, J. M. (2009c). A Lifetime of Intelligence: Follow-up Studies of the Scottish Mental Surveys of 1932 and 1947. Washington, DC: American Psychological Association.

Deary, I. J., Whiteman, M. C., Starr, J. M., Whalley, L. J., \& Fox, H. C. (2004). The impact of childhood intelligence on later life: following up the Scottish Mental Surveys of 1932 and 1947. J Pers Soc Psychol, 86(1), 130-147.

Durga, J., Bots, M. L., Schouten, E. G., Kok, F. J., \& Verhoef, P. (2005). Low concentrations of folate, not hyperhomocysteinemia, are associated with carotid intima-media thickness. Atherosclerosis, 179(2), 285-292.

Durga, J., Van Boxtel, M. P. J., Schouten, E. G., Kok, F. J., Jolles, J., Katan, M. B., \& Verhoef, P. (2007). Effect of 3-year folic acid supplementation on cognitive function in older adults in the FACIT trial: a randomised, double blind, controlled trial. Lancet, 369(9557), 208-216.

Finkel, D., Reynolds, C. A., McArdle, J. J., \& Pedersen, N. L. (2005). The longitudinal relationship between processing speed and cognitive ability: genetic and environmental influences. Behav Genet, 35(5), 535-549. 
Girelli, D., Friso, S., Trabetti, E., Olivieri, O., Russo, C., Pessotto, R., Faccini, G., Pignatti, P. F., Mazzucco, A., \& Corrocher, R. (1998). Methylenetetrahydrofolate reductase C677T mutation, plasma homocysteine, and folate in subjects from northern Italy with or without angiographically documented severe coronary atherosclerotic disease: evidence for an important genetic-environmental interaction. Blood, 91(11), 4158-4163.

Goh, Y. I., \& Koren, G. (2008). Folic acid in pregnancy and fetal outcomes. J Obstet Gynaecol, 28(1), 3-13.

Haan, M. N., \& Wallace, R. (2004). Can dementia be prevented? Brain aging in a population-based context. Annu Rev Public Health, 25, 1-24.

Haworth, C. M., Wright, M. J., Luciano, M., Martin, N. G., De Geus, E. J., Van Beijsterveldt, C. E., Bartels, M., Posthuma, D., Boomsma, D. I., Davis, O. S., Kovas, Y., Corley, R. P., Defries, J. C., Hewitt, J. K., Olson, R. K., Rhea, S. A., Wadsworth, S. J., lacono, W. G., McGue, M., Thompson, L. A., Hart, S. A., Petrill, S. A., Lubinski, D., \& Plomin, R. (2010). The heritability of general cognitive ability increases linearly from childhood to young adulthood. Mol Psychiatry, 15(11), 1112-1120.

Innis, S. M. (2007). Dietary (n-3) fatty acids and brain development. J Nutr, 137(4), 855-859.

Jolles, J., Houx, P. J., Van Boxtel, M. P. J., \& Ponds, R. W. H. M. (Eds.). (1995). The Maastricht Aging Study: Determinants of Cognitive Aging. Maastricht, The Netherlands: Neuropsych Publishers.

Kaplan, B. J., Crawford, S. G., Field, C. J., \& Simpson, J. S. (2007). Vitamins, minerals, and mood. Psychol Bull, 133(5), 747-760.

Kessler, R. C., Zhao, S., Blazer, D. G., \& Swartz, M. (1997). Prevalence, correlates, and course of minor depression and major depression in the National Comorbidity Survey. J Affect Disord, 45(1-2), 1930.

Kiecolt-Glaser, J. K., Belury, M. A., Porter, K., Beversdorf, D. Q., Lemeshow, S., \& Glaser, R. (2007). Depressive symptoms, omega-6:omega-3 fatty acids, and inflammation in older adults. Psychosom Med, 69(3), 217-224.

Koten, J. W., Jr., Wood, G., Hagoort, P., Goebel, R., Propping, P., Willmes, K., \& Boomsma, D. I. (2009). Genetic contribution to variation in cognitive function: an FMRI study in twins. Science, 323(5922), 1737-1740.

Kruglyak, L. (2008). The road to genome-wide association studies. Nat Rev Genet, 9(4), 314-318.

La Rue, A. (1992). Aging and Neuropsychological Assessment. New York: Plenum Press.

Lairon, D., Defoort, C., Martin, J. C., Amiot-Carlin, M. J., Gastaldi, M., \& Planells, R. (2009). Nutrigenetics: links between genetic background and response to Mediterranean-type diets. Public Health Nutr, 12(9A), 1601-1606.

Levi, R. S., \& Sanderson, I. R. (2004). Dietary regulation of gene expression. Curr Opin Gastroenterol, 20(2), 139-142.

Levinson, D. F. (2006). The genetics of depression: a review. Biol Psychiatry, 60(2), 84-92.

Lezak, M. D., Howieson, D. B., \& Loring, D. W. (2004). Neuropsychological Assessment (4th ed.). New York: Oxford University Press.

Morris, M. C., Evans, D. A., Hebert, L. E., \& Bienias, J. L. (1999). Methodological issues in the study of cognitive decline. Am J Epidemiol, 149(9), 789-793.

Penner, M. R., Roth, T. L., Barnes, C. A., \& Sweatt, J. D. (2010). An epigenetic hypothesis of aging-related cognitive dysfunction. Front Aging Neurosci, 2, 9.

Plomin, R., Pedersen, N. L., Lichtenstein, P., \& McClearn, G. E. (1994). Variability and stability in cognitive abilities are largely genetic later in life. Behav Genet, 24(3), 207-215.

Posthuma, D., De Geus, E. J., Baare, W. F., Hulshoff Pol, H. E., Kahn, R. S., \& Boomsma, D. I. (2002). The association between brain volume and intelligence is of genetic origin. Nat Neurosci, 5(2), 83-84.

Rabbitt, P., Diggle, P., Smith, D., Holland, F., \& Mc Innes, L. (2001). Identifying and separating the effects of practice and of cognitive ageing during a large longitudinal study of elderly community residents. Neuropsychologia, 39(5), 532-543.

Radloff, L. S. (1977). The CES-D scale: a self-report depression scale for research in the general population. Appl Psychol Meas, 1, 385-401. 
Raven, J. C., Court, J. H., \& J., R. (1977). Manual for Raven's Progressive Matrices and Vocabulary Scales. London: H. K. Lewis.

Raz, N., \& Rodrigue, K. M. (2006). Differential aging of the brain: patterns, cognitive correlates and modifiers. Neurosci Biobehav Rev, 30(6), 730-748.

Reichenberg, A., Mill, J., \& MacCabe, J. H. (2009). Epigenetics, genomic mutations and cognitive function. Cogn Neuropsychiatry, 14(4-5), 377-390.

Schiepers, O. J. G., Wichers, M. C., \& Maes, M. (2005). Cytokines and major depression. Prog Neuropsychopharmacol Biol Psychiatry, 29(2), 201-217.

Schilling, E., \& Rehli, M. (2007). Global, comparative analysis of tissue-specific promoter CpG methylation. Genomics, 90(3), 314-323.

Stewart, R., \& Liolitsa, D. (1999). Type 2 diabetes mellitus, cognitive impairment and dementia. Diabet Med, 16(2), 93-112.

Stroop, J. (1935). Studies of interference in serial verbal reaction. J Exp Psychol, 18, 643-662.

Sullivan, P. F., Neale, M. C., \& Kendler, K. S. (2000). Genetic epidemiology of major depression: review and meta-analysis. Am J Psychiatry, 157(10), 1552-1562.

Thompson, P. M., Cannon, T. D., Narr, K. L., Van Erp, T., Poutanen, V. P., Huttunen, M., Lönnqvist, J., Standertskjöld-Nordenstam, C. G., Kaprio, J., Khaledy, M., Dail, R., Zoumalan, C. I., \& Toga, A. W. (2001). Genetic influences on brain structure. Nat Neurosci, 4(12), 1253-1258.

Tobin, M. D., Minelli, C., Burton, P. R., \& Thompson, J. R. (2004). Commentary: development of Mendelian randomization: from hypothesis test to 'Mendelian deconfounding'. Int J Epidemiol, 33(1), 2629.

Tsankova, N., Renthal, W., Kumar, A., \& Nestler, E. J. (2007). Epigenetic regulation in psychiatric disorders. Nat Rev Neurosci, 8(5), 355-367.

Van Beijsterveldt, C. E. M., Van Boxtel, M. P. J., Bosma, H., Houx, P. J., Buntinx, F., \& Jolles, J. (2002). Predictors of attrition in a longitudinal cognitive aging study: the Maastricht Aging Study (MAAS). J Clin Epidemiol, 55(3), 216-223.

Van Boxtel, M. P. J., Buntinx, F., Houx, P. J., Metsemakers, J. F. M., Knottnerus, J. A., \& Jolles, J. (1998). The relation between morbidity and cognitive performance in a normal aging population. $J$ Gerontol A Biol Sci Med Sci, 53(2), M147-M154.

Van der Elst, W., Van Boxtel, M. P. J., Van Breukelen, G. J. P., \& Jolles, J. (2005). Rey's verbal learning test: normative data for 1855 healthy participants aged 24-81 years and the influence of age, sex, education, and mode of presentation. J Int Neuropsychol Soc, 11(3), 290-302.

Van der Elst, W., Van Boxtel, M. P. J., Van Breukelen, G. J. P., \& Jolles, J. (2006a). Normative data for the Animal, Profession and Letter $M$ Naming verbal fluency tests for Dutch speaking participants and the effects of age, education, and sex. J Int Neuropsychol Soc, 12(1), 80-90.

Van der Elst, W., Van Boxtel, M. P. J., Van Breukelen, G. J. P., \& Jolles, J. (2006b). The Concept Shifting Test: adult normative data. Psychol Assess, 18(4), 424-432.

Van der Elst, W., Van Boxtel, M. P. J., Van Breukelen, G. J. P., \& Jolles, J. (2006c). The Letter Digit Substitution Test: normative data for 1,858 healthy participants aged 24-81 from the Maastricht Aging Study (MAAS): influence of age, education, and sex. J Clin Exp Neuropsychol, 28(6), 998-1009.

Van der Elst, W., Van Boxtel, M. P. J., Van Breukelen, G. J. P., \& Jolles, J. (2006d). The Stroop Color-Word test: influence of age, sex, and education; and normative data for a large sample across the adult age range. Assessment, 13(1), 62-79.

Wild, S., Roglic, G., Green, A., Sicree, R., \& King, H. (2004). Global prevalence of diabetes: estimates for the year 2000 and projections for 2030. Diabetes Care, 27(5), 1047-1053. 



\section{Summary}

Due to an increasing life expectancy, Western societies are ageing rapidly. Consequently, the prevalence of age-associated cognitive disorders, such as dementia, will continue to rise. In addition to cognitive deterioration, ageing may also be accompanied by changes in mood state. Because of the personal, societal, and financial burdens associated with the growing number of older individuals suffering from cognitive impairment or depressive symptoms, identifying the biological determinants of cognitive ageing and mental well-being is of major importance.

The main objective of the present thesis is to identify nutritional and genetic determinants of age-related cognitive decline and depressed mood in older community-dwelling individuals. Chapter 1 outlines the rationale and aims of the different studies performed, and provides an overview of the chapters included in this thesis. In short, the first part of the present thesis (chapters 2 to 5) addresses the putative involvement of various nutrients in cognitive functioning and mental wellbeing in older adults, and the second part (chapters 6 to 9) deals with the possible role of genetic factors in cognitive ageing.

Chapter 2 examines the relationship between long-chain polyunsaturated fatty acids (LCPUFA) and depressive symptoms. Whereas plasma phospholipid LCPUFA concentrations were not associated with mood state in the general population, we did find a significant correlation between reduced $n-3$ fatty acid concentrations and increased depressed mood in persons with depressive symptoms above the clinical threshold. These results suggest that although LCPUFA status may be normal in individuals showing mild to moderate symptoms of depressed mood, $n-3$ LCPUFA concentrations might be suboptimal in persons with depressive symptoms within the clinical range. As such, our study offers a novel understanding of the apparent discrepancy between the results of studies using population-based samples and those using clinical populations while investigating the associations between LCPUFA status and depressed mood.

Chapter 3 focuses on the possible associations between LCPUFA concentrations, fish consumption, and quality of life in healthy adults. Whereas no significant associations were identified between LCPUFA status and the physical or mental dimensions of quality of life, fish consumption was found to be related to increased physical well-being in the general population. As this relationship did not appear to be mediated by the $n-3$ fatty acid content of fish, we argue that fish consumption might serve as a proxy for favourable dietary habits or a healthy lifestyle. 
In chapter 4, we investigated the effects of long-term consumption of functional foods enriched with plant sterols and stanols on neurocognitive functioning. Although these compounds are known to pass the blood-brain barrier, previous studies have not assessed whether this might affect cognitive functioning and mental well-being in humans. Our findings indicate that long-term use of plant sterols or stanols at recommended intakes of $2.5 \mathrm{~g} /$ day, which was already regarded safe from a physiological perspective, does not affect cognitive functioning or mood in hypercholesterolaemic individuals on statin treatment.

The relationship between serum iron parameters and cognitive functioning is examined in Chapter 5. Cross-sectional analyses indicated that increased serum ferritin was associated with decreased sensorimotor speed, complex speed, and information processing speed, and increased serum iron was associated with decreased sensorimotor speed. These associations were more pronounced in individuals carrying at least one APOE E4 allele, as compared with non-carriers. Cognitive performance over 3 years, however, did not show a significant relationship with any of the serum iron parameters measured, nor with haemochromatosis (HFE) $282 \mathrm{C} \rightarrow \mathrm{Y}$ genotype, which is generally associated with increased body iron concentrations. We conclude that although serum iron parameters do not appear to show a straightforward relationship with cognitive functioning or age-related cognitive decline in older community-dwelling individuals, elevated iron levels might decrease cognitive speed in older persons susceptible to cognitive impairment.

Chapter 6 deals with the possible role of genetic variation in folate metabolism in cognitive functioning and mood state. Using two independent, large populationbased samples, both cross-sectional and longitudinal analyses were performed. The results suggest that there are no associations between the MTHFR 677C $\rightarrow$ T, TS $2 \mathrm{R} \rightarrow 3 \mathrm{R}$, and SHMT1 $1420 \mathrm{C} \rightarrow \mathrm{T}$ polymorphisms, which are known to affect enzyme activity in the folate-homocysteine cycle, on the one hand and cognitive performance, age-related cognitive decline, or mood on the other in healthy individuals. Additional analyses did not support a role for erythrocyte folate concentrations or APOE E4 carrier status as putative effect modifiers.

In chapter 7, we assessed whether the folate-related MTHFR 677C $\rightarrow$ T and $1298 \mathrm{~A} \rightarrow \mathrm{C}$ polymorphisms might be involved in age-related cognitive change over 8 years of follow-up in older community-dwelling individuals. Longitudinal analyses did not reveal any associations between the two genetic variants and the rate of cognitive change between 79 and 87 years, neither in all 476 participants, nor in a subsample of individuals with erythrocyte folate levels below the median. In addition, APOE E4 carrier status did not interact with MTHFR genotype in affecting change in cognitive performance in the ninth decade of life.

The putative associations between the epigenetic mechanism of DNA methylation and cognitive functioning were examined in chapter 8 . In healthy older individuals, global DNA methylation status was not associated with the level of cogni- 
tive functioning. We argue that the observed null findings might have been related to the fact that DNA methylation status was measured in leukocytes rather than brain tissue or cerebrospinal fluid. In addition, we suggest that future studies should investigate whether short-term or gene-specific changes in DNA methylation patterns in the brain might be related to cognitive performance.

Chapter 9 addresses the relationship between APOE E4 carrier status and agerelated cognitive decline in non-demented older individuals. Using longitudinal analyses adjusted for demographic variables, vascular risk factors, and IQ at age 11 years, carriers of the APOE E4 allele showed a higher relative rate of cognitive decline for verbal memory and abstract reasoning over 8 years. Verbal fluency was not affected by $A P O E$ E4 status. Similar results were found in persons with the long allelic variant of TOMM40, which is linked to APOE E4. We conclude that possession of the APOE E4 allele may not only predispose to Alzheimer's disease, but also appears to be a risk factor for non-pathological decline in verbal memory and abstract reasoning in the ninth decade of life.

Finally, the present findings are critically discussed in chapter 10. Clinical implications of the results presented in this thesis are evaluated, along with methodological aspects and recommendations for further research. We advocate a more integrated and multidimensional approach to study the relative contribution of nutritional and environmental factors to neurocognitive functioning, in order to unravel further the biological mechanisms involved in cognitive ageing and mental well-being. 



\section{Samenvatting}

Als gevolg van de wereldwijd toegenomen levensverwachting vergrijst de Westerse samenleving in een hoog tempo. Hierdoor zal het aantal ouderen met cognitieve stoornissen, zoals dementie, in de komende decennia gestaag groeien. Naast cognitieve achteruitgang kan het ouder worden ook gepaard gaan met stemmingsveranderingen. Omdat de toename van het percentage ouderen met cognitieve beperkingen of stemmingsklachten aanzienlijke persoonlijke, maatschappelijke en financiële consequenties heeft, is het van belang te achterhalen welke biologische factoren een rol spelen bij cognitieve veroudering en mentaal welzijn.

In dit proefschrift staat de mogelijke betrokkenheid van voedingsstoffen en genetische factoren in het proces van leeftijdsgerelateerde cognitieve achteruitgang en stemmingsklachten centraal. Hoofdstuk 1 biedt een samenvatting van de rationale en onderzoeksdoelen van de diverse studies, en verschaft een overzicht van de hoofdstukken in dit proefschrift. In het eerste deel van dit proefschrift (hoofdstuk 2 tot en met 5) wordt de mogelijke betrokkenheid van verschillende voedingsstoffen in het cognitief functioneren en mentaal welzijn van ouderen beschreven. In het tweede deel (hoofdstuk 6 tot en met 9) komt de mogelijke rol van genetische factoren in cognitieve veroudering aan bod.

De relatie tussen meervoudig onverzadigde vetzuren en depressieve symptomen werd onderzocht in hoofdstuk 2. Terwijl er geen significant verband werd gevonden tussen de concentraties van meervoudig onverzadigde vetzuren in plasma fosfolipiden en stemming in de algemene populatie, waren afgenomen omega-3 vetzuurconcentraties wel gerelateerd aan toegenomen depressieve stemming in personen met klinisch relevante depressieve symptomen. Deze resultaten zouden erop kunnen wijzen dat milde vormen van depressieve stemming gepaard gaan met normale bloedwaarden van omega-3 vetzuren, terwijl de concentraties van deze vetzuren in het bloed steeds minder gunstig zijn naarmate de klinische relevantie van de depressieve symptomen toeneemt. Deze resultaten bieden een nieuw inzicht in de schijnbare tegenstrijdigheid tussen de resultaten van populatiestudies en klinische studies die de relatie onderzochten tussen vetzuurstatus en depressieve stemming.

In hoofdstuk 3 komen de associaties tussen vetzuurstatus, visconsumptie en kwaliteit van leven in gezonde volwassenen aan de orde. Er werd geen significant verband aangetoond tussen vetzuurstatus en de lichamelijke of mentale dimensie van kwaliteit van leven. Er werd echter wel een verband gevonden tussen viscon- 
sumptie en een verhoogd lichamelijk welbevinden. Aangezien deze relatie niet werd gemedieerd door de omega-3 vetzuren in vis, wordt geconcludeerd dat gezonde voedingsgewoonten als onderdeel van een gezonde leefstijl de meest waarschijnlijke verklaring vormen voor het gevonden verband tussen visconsumptie en een verhoogd lichamelijk welzijn.

Hoofdstuk 4 beschrijft de lange-termijn effecten van consumptie van voedingsstoffen die verrijkt zijn met plantensterolen en -stanolen op cognitief functioneren en stemming. Ondanks dat deze stoffen de bloed-hersenbarrière kunnen passeren, werd niet eerder onderzocht of plantensterolen en -stanolen het neurocognitief functioneren en mentaal welzijn zouden kunnen beïnvloeden. Onze bevindingen geven aan dat langdurig gebruik van plantensterolen en -stanolen in de aanbevolen dosering van $2.5 \mathrm{~g} / \mathrm{dag}$, hetgeen veilig wordt geacht vanuit fysiologisch perspectief, geen effecten heeft op het cognitief functioneren of de stemming van personen met hypercholesterolemie die worden behandeld met statines.

Het mogelijke verband tussen ijzerparameters in het bloedserum en cognitief functioneren staat centraal in hoofdstuk 5. Cross-sectionele analyses lieten zien dat een verhoogd serum ferritine geassocieerd was met een verlaagde cognitieve snelheid, zowel op het gebied van eenvoudige als meer complexe informatieverwerking. Daarnaast was een verhoogd ijzergehalte in het bloedserum geassocieerd met afgenomen cognitieve snelheid op het gebied van eenvoudige informatieverwerking. Deze verbanden waren meer uitgesproken in personen met tenminste één $A P O E$ E4 allel, vergeleken met personen zonder dit genetische kenmerk. Cognitieve prestatie over een periode van 3 jaar, daarentegen, vertoonde geen verband met de ijzerparameters in het bloedserum, of met het haemochromatosis (HFE) $282 \mathrm{C} \rightarrow \mathrm{Y}$ genotype, dat doorgaans zorgt voor verhoogde ijzerwaarden in het lichaam. We concluderen dat de onderzochte ijzerparameters geen eenduidige relatie vertonen met cognitief functioneren of leeftijdsgebonden cognitieve achteruitgang in gezonde ouderen, hoewel verhoogde ijzerwaarden zouden kunnen leiden tot verlaagde cognitieve snelheid in personen met een genetische kwetsbaarheid voor het ontwikkelen van cognitieve beperkingen.

In hoofdstuk 6 wordt de mogelijke betrokkenheid van genetische variatie in foliumzuurmetabolisme in het cognitief functioneren en depressieve stemming besproken. Gebruikmakend van twee onafhankelijke, grote steekproeven van gezonde personen werden zowel cross-sectionele als longitudinale analyses uitgevoerd. De resultaten geven aan dat de MTHFR $677 \mathrm{C} \rightarrow \mathrm{T}$, TS $2 \mathrm{R} \rightarrow 3 \mathrm{R}$ en SHMT1 $1420 C \rightarrow T$ polymorfismen, die enzymactiviteit in de foliumzuur-homocysteine cyclus beïnvloeden, niet gerelateerd zijn aan cognitieve prestatie, leeftijdsgebonden cognitieve achteruitgang of depressieve stemming. Aanvullend onderzoek bood geen ondersteuning voor mogelijke effectmodificatie door APOE E4 genotype of de concentratie van foliumzuur in rode bloedcellen. 
Hoofdstuk 7 behandelt een studie waarin werd onderzocht of de foliumzuurgerelateerde $M T H F R$ $677 C \rightarrow$ T en $1298 \mathrm{~A} \rightarrow C$ polymorfismen betrokken waren bij leeftijdsgebonden verandering in het cognitief functioneren van 476 gezonde ouderen over een periode van 8 jaar. Longitudinale analyses toonden geen verband aan tussen de twee onderzochte genetische varianten en snelheid van cognitieve verandering tussen de leeftijd van 79 en 87 jaar. Dit verband was ook afwezig in een subgroep van personen met lage foliumzuurwaarden in rode bloedcellen.

In hoofdstuk 8 wordt nagegaan of er een verband bestaat tussen het epigenetische mechanisme van DNA methylatie en cognitief functioneren in gezonde ouderen. De resultaten geven aan dat globale DNA methylatiestatus niet gerelateerd is aan cognitieve prestatie. Het feit dat DNA methylatie werd gemeten in witte bloedcellen in plaats van hersenweefsel of hersenvocht zou een verklaring kunnen bieden voor deze niet-significante resultaten. Daarnaast stellen we voor dat toekomstige studies zouden moeten onderzoeken of korte termijn- of genspecifieke veranderingen in DNA methylatiepatronen in het brein wel geassocieerd zijn met cognitief functioneren.

De relatie tussen APOE E4 genotype en leeftijdsgerelateerde cognitieve achteruitgang komt aan bod in hoofdstuk 9. Longitudinale analyses, gecorrigeerd voor demografische variabelen, vasculaire risicofactoren en IQ op 11-jarige leeftijd, lieten een versnelde cognitieve achteruitgang zien op het gebied van verbaal geheugen en abstract redeneren over een periode van 8 jaar in niet-demente personen met het $A P O E$ E4 allel. Het APOE E4 genotype had geen invloed op de verbale fluency. Vergelijkbare resultaten werden gevonden in personen met de lange variant van het TOMM40 genotype, dat verbonden is met APOE E4. We concluderen dat het APOE E4 allel niet alleen een verhoogd risico geeft op de ziekte van Alzheimer, maar ook een risicofactor lijkt te zijn voor niet-pathologische cognitieve achteruitgang op het gebied van verbaal geheugen en abstract redeneren in het negende decennium van het leven.

Tot slot worden de bevindingen van dit proefschrift kritisch besproken in hoofdstuk 10. De klinische implicaties van de resultaten die beschreven staan in dit proefschrift worden geëvalueerd. Daarnaast worden methodologische aspecten besproken en aanbevelingen voor toekomstig onderzoek gepresenteerd. We moedigen een geïntegreerde en multidimensionele benadering aan in het onderzoek naar de relatieve rol van voedingsstoffen en omgevingsfactoren in het neurocognitief functioneren, om verder bij te dragen aan het achterhalen van de biologische mechanismen die ten grondslag liggen aan cognitieve veroudering en mentaal welzijn. 



\section{APPENDIX}

\section{Author reply to comment on Chapter 5}




\title{
Response to Baggott and Tamura: "Serum iron parameters and plasma total homocysteine concentrations"
}

\author{
Olga J. G. Schiepers and Jane Durga \\ J Gerontol A Biol Sci Med Sci (2011), 66A(6): 657-658
}

In their comment on our article, Baggott and Tamura (2011) suggest that plasma total homocysteine concentrations may serve as a marker for excess body iron stores. They refer to a study conducted in five healthy volunteers, in which nonprotein bound iron was found to catalyse the conversion of thioethers, such as methionine and S-adenosylmethionine, into homocysteine (Baggott \& Tamura, 2007). The authors hypothesise that the association between iron stores and homocysteine concentrations may underlie the apparent lack of any significant effects of B-vitamin supplementation on occlusive vascular disease.

In our recently published paper, we reported that increased concentrations of serum iron and ferritin were associated, cross-sectionally, with decreased cognitive performance in the Folic Acid and Carotid Intima-Media Thickness (FACIT) population (Schiepers et al., 2010). Plasma total homocysteine did not confound the observed associations, as results were similar regardless if homocysteine concentrations were included in the analyses.

We evaluated the relationship between serum iron parameters, HFE $282 \mathrm{C} \rightarrow \mathrm{Y}$ genotype, and plasma total homocysteine in our study sample. We found that carriers of the HFE $282 \mathrm{C} \rightarrow \mathrm{Y}$ mutation did not differ significantly from non-carriers in terms of homocysteine concentrations ( $t=-0.677, p=0.499)$. In addition, the concentrations of serum iron, total iron binding capacity, transferrin saturation, and non-transferrin bound iron were not significantly correlated with homocysteine concentrations at baseline $(r=-0.064, p=0.068 ; r=0.005, p=0.885 ; r=-0.066, p=$ 0.060 ; and $r=-0.042, p=0.236$, respectively). However, serum ferritin, which is an indicator of body iron stores, showed a significant positive correlation with plasma total homocysteine at baseline (Spearman's rank correlation coefficient $=0.125, p$ $<0.001)$.

At first glance, our data on serum ferritin seem to support the hypothesis that plasma total homocysteine concentrations may serve as a marker for body iron stores, as put forward by Baggott and Tamura. Also, in line with the authors' hypothesis, we did not observe any effect of 3-year folic acid supplementation on the risk of cardiovascular disease, as measured by carotid intima-media thickness, in the FACIT study, despite a significant reduction in plasma total homocysteine (Durga et al., 2007). 
However, in a previous study performed in the FACIT population, we showed that serum iron parameters, including ferritin and non-transferrin bound iron, were not related to carotid intima-media thickness (Engberink et al., 2008). These findings do not offer support for the authors' hypothesis that excess free iron or iron stores might increase the risk of cardiovascular disease.

Furthermore, although we did not demonstrate any effect of 3-year supplementation with folic acid on cardiovascular disease risk, we did find a significant improvement in cognitive performance concomitant with the observed decrease in homocysteine concentrations (Durga et al., 2007). In contrast, serum ferritin, which showed a negative relationship with cognition, significantly increased over 3 years of follow-up (mean change $[95 \% \mathrm{Cl}]=16.6 \mu \mathrm{g} / \mathrm{l}[6.7 ; 26.4], p=0.001$ ) (Schiepers et al., 2010). These divergent findings suggest that the relationship between iron parameters and cognitive performance on the one hand and the relationship between folate-homocysteine metabolism and cognition on the other may be mediated by different mechanisms. In addition, our findings contradict the notion that excess iron stores may catalyse or promote the formation of homocysteine in vivo. If plasma total homocysteine were to represent the amount of body iron stores, changes in homocysteine concentrations over time would be expected to parallel, at least in part, the changes in serum ferritin.

A final remark should be made with regard to the range of plasma total homocysteine concentrations in the FACIT trial. As participants with plasma total homocysteine concentrations $<13 \mu \mathrm{mol} / \mathrm{I}$ or $>26 \mu \mathrm{mol} / /$ were excluded from the study, it cannot be ruled out that the correlations between serum iron parameters and homocysteine observed in this study may differ to a certain extent from those obtained in other populations.

In conclusion, our findings regarding the associations between serum iron parameters, plasma total homocysteine, and risk of cardiovascular disease in a large population of older adults do not appear to support the notion that excess iron stores may, at least partly, be responsible for the increased risk of cardiovascular disease often attributed to homocysteine.

\section{References}

Baggott, J. E. \& Tamura, T. (2007). Iron-dependent formation of homocysteine from methionine and other thioethers. Eur J Clin Nutr, 61(12), 1359-1363.

Baggott, J. E., \& Tamura, T. (2011). Serum iron parameters and plasma total homocysteine concentrations. J Gerontol A Biol Sci Med Sci, 66(6), 656.

Durga, J., Van Boxtel, M. P. J., Schouten, E. G., Kok, F. J., Jolles, J., Katan, M. B. \& Verhoef, P. (2007). Effect of 3-year folic acid supplementation on cognitive function in older adults in the FACIT trial: a randomised, double blind, controlled trial. Lancet, 369(9557), 208-216.

Engberink, M. F., Geleijnse, J. M., Durga, J., Swinkels, D. W., De Kort, W. L. A. M., Schouten, E. G. \& Verhoef, P. (2008). Blood donation, body iron status and carotid intima-media thickness. Atherosclerosis, 196(2), 856-862. 
Schiepers, O. J. G., Van Boxtel, M. P. J., De Groot, R. H. M., Jolles, J., De Kort, W. L. A. M., Swinkels, D. W., Kok, F. J., Verhoef, P. \& Durga, J. (2010). Serum iron parameters, HFE C282Y genotype, and cognitive performance in older adults: results from the FACIT study. I Gerontol A Biol Sci Med Sci, 65(12), 1312-1321. 


\section{Dankwoord}

Het is zover, na vier jaar is 'het boekje' af! Graag wil ik een woord van dank richten aan iedereen die een bijdrage heeft geleverd aan de totstandkoming van dit proefschrift.

Allereerst wil ik mijn promotieteam, Jelle Jolles, Martin van Boxtel en Renate de Groot, bedanken voor de kans om als promovendus aan de slag te kunnen gaan. Dank voor jullie vertrouwen en de vrijheid die jullie me boden om het project op mijn eigen manier in te vullen.

Beste Jelle, jij hebt me alle ruimte gegeven om mijn eigen richting te bepalen. Veel dank voor het vertrouwen!

Beste Martin, bedankt voor jouw kritische blik, je grote betrokkenheid en je ondersteuning bij het vinden van de juiste invalshoeken. Ons overleg was altijd productief! Ik hoop in de toekomst nog veel met je te mogen samenwerken.

Beste Renate, jij motiveerde me om scherp te formuleren en de essentie van de afzonderlijke studies nauwlettend in de gaten te houden. Bedankt voor jouw inzet en het grote vertrouwen dat je in mij stelde. Je hebt mij altijd gesteund in de keuzes die ik maakte, dit waardeer ik zeer!

Many thanks to my supervisor at the Centre for Cognitive Ageing and Cognitive Epidemiology, Prof. Ian Deary. Dear lan, it was an honour and a great pleasure to work with you. Thank you for granting me the opportunity to collaborate with such an excellent team, and for allowing me to use a unique dataset for studying the genetic correlates of cognitive ageing. The expertise of the CCACE team is truly amazing. Alan, Alison, Anna, Beverly, Caroline, Catherine, Dave, Gail, Jack, Janie, Lars, Lorna, Michelle, Mike, Paul, Ross, and Sarah, thanks for a wonderful time at the Centre!

Jogchum Plat, Ronald Mensink en Ariënne de Jong, bedankt dat ik de data van de LTS studie mocht gebruiken! Het was prettig met jullie samen te werken. Dieter Lütjohann, thank you for your co-authorship and the pleasant discussions we had about cholesterol metabolism in the brain. 
Jane Durga, Petra Verhoef, Frans Kok, Dorine Swinkels en Wim de Kort, dank jullie voor de plezierige en zeer vruchtbare samenwerking in het kader van de FACIT studie. Het was geweldig met deze omvangrijke dataset te mogen werken! Beste Jane, via de telefoon hebben we vele leuke gesprekken gehad en interessante discussies gevoerd. Jouw gedetailleerde commentaar op de conceptversies van mijn artikelen was onmisbaar en zette altijd aan tot verder denken over het hoe en waarom van de betreffende studie. Bedankt dat ik van jouw expertise gebruik mocht maken!

Alle deelnemers van de cohort- en interventiestudies waarvan ik de data heb mogen gebruiken, dank voor jullie inzet en tijd.

Collega's en oud-collega's bij NP, bedankt voor de gezelligheid en fijne gesprekken. Elsa Misdom, dank voor de organisatorische hulp en het napluizen van het manuscript!

Mijn (oud-)kamergenoten Aukje Aben, Esther Hoogenhout, Danny Lanckohr, Esther Keulers en Wim van der Elst, dank jullie wel voor de fijne tijd op het werk. Esther $\mathrm{H}_{\text {., }}$ dank je voor jouw betrokkenheid en de vele leuke gesprekken over de wetenschap en alles daarbuiten! Wim van der Elst, bedankt voor de serieuze en minder serieuze discussies over tijdschriften en reviewer-commentaren, Darwin en Linnaeus, en de kwaliteit van automatenkoffie. Esther K., ook al zijn we maar kort kamergenootjes geweest, het klikte meteen tussen ons. Heel erg bedankt dat jij mijn paranimf wil zijn.

Lieve vrienden, in het bijzonder Kim Gagliardi, Stijn de Bekker en Katherine Farnon, dank jullie wel voor jullie interesse en steun. Kim, onze vriendschap gaat inmiddels al heel wat jaren terug. Wat hebben wij samen al veel meegemaakt en wat is het fijn dat we nog steeds zulke goede vriendinnen zijn! Dank je voor jouw medeleven en steun, de lange telefoongesprekken en leuke dagjes Mestreech en Den Haag. Het is altijd als vanouds gezellig! Stijn en Kate, we wonen dan wel niet bij elkaar om de hoek, maar als we elkaar zien, is altijd weer even gezellig en vertrouwd. Bedankt voor jullie gastvrijheid, warmte en optimisme!

Mijn dierbare familie en schoonfamilie, pap en mam, Chris en Dorien, Aniek, Francis en Ger, Liesbeth en Ralph, Jan-Willem, Els, Annemarie, Jörgen, Ruth en Lennard, heel erg bedankt voor jullie interesse en betrokkenheid. Lieve Chris, wat fijn dat jij mijn paranimf bent! Ik ben trots op de sterke band die wij als broer en zus hebben. Lieve Aniek, dank je wel voor het ontwerpen van de kaft! Ondanks de verschillende karakters, voelen we elkaar perfect aan. Ik ben blij met zo'n lieve zus als jij. Lieve pap en mam, jullie staan altijd voor ons klaar. Ik kan altijd bij jullie terecht voor hulp, 
goede raad of gewoon een luisterend oor. Ik prijs me gelukkig met zulke ouders. Bedankt voor alles!

Lieve Remco, jouw promotie was een van de eerste mijlpalen in ons leven samen. $\mathrm{Nu}$ zes jaar later ook mijn proefschrift klaar is, zijn we inmiddels al een jaar getrouwd, wonen we alweer in ons derde huis én hebben we een prachtige zoon gekregen. Ik geniet elke dag van ons samenzijn. Jij bent er altijd voor me, dank je wel voor je liefde, steun en onbegrensd vertrouwen. Bedankt ook voor jouw nuchtere blik, die zeker tijdens mijn promotietraject enorm relativerend werkte. Zes jaar geleden stonden we aan het begin van onze toekomst samen. Nu staan we aan het begin van een prachtig leven als gezin, dat hopelijk nog heel lang mag duren.

Thijmen, lieve jongen, wat is het geweldig dat we jou in ons leven mochten verwelkomen. Jouw stralende lach doet al het andere vergeten, ik ben ontzettend dankbaar voor het grote geluk dat jij ons brengt! 



\section{Curriculum vitae}

Olga Schiepers werd geboren op 11 maart 1979 te Maastricht. Van 1991 tot 1997 doorliep zij het Gymnasium- $\beta$ aan het Trichter College in Maastricht. Hierna begon zij haar studie Medische Biologie aan de Vrije Universiteit Amsterdam. Zij koos voor de specialisatie neurobiologie, met onderzoeksstages in de psychofarmacologie en neuropathologie. Haar literatuurscriptie schreef zij bij de vakgroep Psychiatrie en Neuropsychologie van de Universiteit Maastricht. Een jaar voor het behalen van haar doctoraaldiploma in 2003 startte zij met de opleiding Gezondheidswetenschappen aan de Universiteit Maastricht. Zij volgde de richting Geestelijke Gezondheidkunde, waarin zij in 2005 'cum laude' afstudeerde. Vervolgens was zij werkzaam als wetenschappelijk onderzoeker bij de Universiteit Leiden en het Erasmus Medisch Centrum Rotterdam, alwaar zij participeerde in onderzoek naar de ontwikkeling van jonge kinderen. In 2007 startte zij haar promotieonderzoek bij de vakgroep Psychiatrie en Neuropsychologie van de Universiteit Maastricht. De resultaten van dit onderzoek staan beschreven in dit proefschrift. Als onderdeel van haar promotietraject bracht zij in 2010 drie maanden door als 'visiting researcher' aan het Centre for Cognitive Ageing and Cognitive Epidemiology, University of Edinburgh (GrootBrittannië). Momenteel is zij als postdoc onderzoeker verbonden aan de vakgroep Psychiatrie en Neuropsychologie en het Alzheimer Centrum Limburg. 



\section{Publications}

Schiepers, O. J. G., Van Boxtel, M. P. J., De Groot, R. H. M., Jolles, J., Kok, F. J., Verhoef, P., \& Durga, J. (2011). DNA methylation and cognitive functioning in healthy older adults. Br J Nutr, Epub ahead of print.

Schiepers, O. J. G., Van Boxtel, M. P. J., De Groot, R. H. M., Jolles, J., Bekers, O., Kok, F. J., Verhoef, P., \& Durga, J. (2011). Genetic variation in folate metabolism is not associated with cognitive functioning or mood in healthy adults. Prog Neuropsychopharmacol Biol Psychiatry, 35, 1682-1688.

Schiepers, O. J. G., \& Durga, J. (2011). Response to Baggott and Tamura: Serum iron parameters and plasma total homocysteine concentrations. J Gerontol A Biol Sci Med Sci, 66A(6), 657-658.

Schiepers, O. J. G., Harris, S. E., Gow, A. J., Pattie, A., Brett, C. E., Starr, J. M., \& Deary, I. J. (2011). APOE E4 status predicts age-related cognitive decline in the ninth decade: longitudinal follow-up of the Lothian Birth Cohort 1921. Mol Psychiatry, Epub ahead of print.

Schiepers, O. J. G., Van Boxtel, M. P. J., Harris, S. E., Gow, A. J., Pattie, A., Brett, C. E., De Groot, R. H. M., Jolles, J., Starr, J. M., \& Deary, I. J. (2011). MTHFR polymorphisms and cognitive ageing in the ninth decade: the Lothian Birth Cohort 1921. Genes Brain Behav, 10, 354-364.

Schiepers, O. J. G., Van Boxtel, M. P. J., De Groot, R. H. M., Jolles, J., De Kort, W. L. A. M., Swinkels, D. W., Kok, F. J., Verhoef, P., \& Durga, J. (2010). Serum iron parameters, HFE C282Y genotype, and cognitive performance in older adults: results from the FACIT study. J Gerontol A Biol Sci Med Sci, 65(12), 1312-1321.

Schiepers, O. J. G., De Groot, R. H. M., Jolles, J., \& Van Boxtel, M. P. J. (2010). Fish consumption, not fatty acid status, is related to quality of life in a healthy population. Prostaglandins Leukot Essent Fatty Acids, 83(1): 31-35. 
Schiepers, O. J. G., De Groot, R. H. M., Van Boxtel, M. P. J., Jolles, J., De Jong, A., Lütjohann, D., Plat, J., \& Mensink, R. P. (2009). Consuming functional foods enriched with plant sterol or stanol esters for 85 weeks does not affect neurocognitive functioning or mood in statin-treated hypercholesterolemic individuals. J Nutr, 139(7), 1368-1373.

De Groot, R. H. M., Van Boxtel, M. P. J., Schiepers O. J. G., Hornstra, G., \& Jolles, J. (2009). Age dependence of plasma phospholipid fatty acid levels: potential role of linoleic acid in the age-associated increase in EPA and DHA concentrations. $\mathrm{Br} J$ Nutr, 102, 1058-1064.

Schiepers, O. J. G., De Groot, R. H. M., Jolles, J., \& Van Boxtel, M. P. J. (2009). Plasma phospholipid fatty acid status and depressive symptoms: association only present in the clinical range. J Affect Disord, 118(1-3): 209-214.

Vanderschuren, L. J. M. J., Trezza, V., Griffioen-Roose, S., Schiepers, O. J. G., Van Leeuwen, N., De Vries, T. J., \& Schoffelmeer, A. N. M. (2008). Methylphenidate disrupts social play behavior in adolescent rats. Neuropsychopharmacology, 33, 2946-2956.

Homberg, J. R., Schiepers, O. J. G., Schoffelmeer, A. N. M., Cuppen, E., \& Vanderschuren, L. J. M. J. (2007). Acute and constitutive increases in central serotonin levels reduce social play behaviour in peri-adolescent rats. Psychopharmacology (Berl), 195, 175-182.

Schiepers, O. J. G., Wichers, M. C., \& Maes, M. (2005). Cytokines and major depression. Prog Neuropsychopharmacol Biol Psychiatry, 29, 201-217.

\section{Submitted}

Van de Rest, O., Van Hooijdonk, L. W. A., Doets, E., Schiepers, O. J. G., Eilander, A., De Groot, C. P. G. M. (under review). B-vitamins and $n-3$ fatty acids for brain development and function: review and evaluation of the current literature. 